Tesis doctoral

\title{
Geología y metalogénesis del distrito polimetálico Purísima-Rumicruz, departamento de Cochinoca, Provincia de Jujuy.
}

Licenciado Luciano López

Dirección: Dr. Horacio Echeveste Co-Dirección: Dr. Isidoro B. Schalamuk

Facultad de Ciencias Naturales y Museo.

Universidad Nacional de La Plata. 
A la laia. 


\section{ÍNDICE}

Agradecimientos

vi

Resumen

$\mathbf{x}$

Abstract

xiv

1. CAPÍTULO 1. INTRODUCCIÓN Y ANTECEDENTES. 1

1.1. Introducción. $\quad 2$

1.2. Marco Geológico Regional. $\quad 4$

1.2.1.Proterozoico superior-Eopaleozoico.

1.2.2. Cretácico-Eoceno.

1.2.3.Eoceno-Neógeno.

1.3. Marco minero del Noroeste Argentino. 13

1.4. Área de estudio. $\quad 14$

2. CAPÍTULO II. MATERIALES Y MÉTODOS. 16

$\begin{array}{ll}\text { 2.1. Introducción. } & 17\end{array}$

2.2. Tareas de campo 17

2.2.1.Cartografía base para la confección del mapa geológico.

2.2.2. Mapeo geológico - mineralizaciones.

2.2.3.Muestreo geológico-minero.

2.2.4.Perfiles sedimentológicos.

2.2.5.Perfiles geoeléctricos.

2.3. Tareas de gabinete y laboratorio.

2.3.1. Análisis petrográfico y mineralógico de la mena, ganga y roca de caja.

2.3.2. Geoquímica

2.3.3. Microsonda electrónica

2.3.4.Estudios de inclusiones fluidas.

2.3.5.Isótopos inestables

2.3.6. Isótopos estables.

3. CAPÍTULO III. ANÁLISIS SEDIMENTOLÓGICO Y ESTRATIGRÁFICO DE LA FORMACIÓN ACOITE EN EL SECTOR SUR DEL CERRO COLORADO DE COBRE.

3.1. Análisis sedimentológico de los depósitos de la Formación Acoite.

3.1.1. Introducción.

3.1.2. Antecedentes.

3.1.3. Análisis de la litofacies.

3.1.3.1.Asociaciones de Facies A. 
3.1.3.2.Asociaciones de Facies B.

3.1.3.3.Asociaciones de Facies $C$.

3.1.3.4.Asociaciones de Facies D.

3.2.Análisis petrológico de la Formación Acoite. 39

3.3.Modelo depositacional. $\quad 42$

3.3.1. Sistemas y procesos depositacionales en plataformas abiertas silicoclásticas.

3.3.2.Procesos y depósitos de las sedimentitas de la Formación Acoite.

3.4.Implicancias regionales.

3.5.Geoquímica.

4.CAPÍTULO IV. DEPÓSITO POLIMETÁLICO PURÍSIMA-RUMICRUZ: YACENCIA Y MINERALOGÍA.

4.1.Antecedentes y reseña histórica del distrito. 56

4.2.Descripción general de las vetas $\quad \mathbf{5 8}$

4.2.1.1. Vetas con sulfuros.

4.2.1.2. Vetas de cuarzo.

4.3.Caracterización de la yacencia y mineralogía de las vetas.

60

4.3.1.Sector Purísima-Rumicruz.

4.3.1.1.Veta Purísima.

4.3.1.1.1.Sulfuros.

4.3.1.1.2.Arseniuros y sulfoarseniuros.

4.3.1.1.3.Óxidos.

4.3.1.2. Veta Rumicruz.

4.3.1.2.1. Sulfuros.

4.3.1.2.2. Sulfoarseniuros

4.3.1.2.3. Minerales secundarios de la zona de oxidación.

4.3.1.3. Veta Liliana.

4.3.1.3.1.Sulfuros/sulfoarseniuros

4.3.2. Sector el Brechón

4.3.2.1.Veta El Brechón.

4.3.2.1.1.Sulfuros/sulfoarseniuros/óxidos.

4.3.3.Sector La Nueva .

4.3.3.1.Veta La Nueva.

4.3.4.Área Jesuitas (Sector III)

4.3.4.1.Sulfuros/sulfoarseniuros/óxidos.

5.1.Paragénesis del distrito Purísima-Rumicruz.

5.2.Áreas Anexas.

5.2.1. El Marciano

5.2.2.San Agustín 
5.3.Consideraciones mineralógicas y genéticas.

5. CAPÍTULO V. GEOQUÍMICA Y QUÍMICA MINERAL. 92

5.1.Geoquímica de superficie.

5.1.1.Geoquímica de las vetas con sulfuros.

5.1.2. Geoquímica de las vetas de cuarzo.

5.1.3.Consideraciones de la geoquímica de superficie.

5.2.Química mineral.

99

5.2.1. Uraninita.

5.2.2. Calcosina, galena, bornita, millerita.

5.2.3. Niquelina.

5.2.4. Grupo tetrahedrita-tennantita.

5.2.5.Gersdorfita.

5.3.Consideraciones finales.

107

6. CAPÍTULO VI. GEOLOGÍA ESTRUCTURAL 111

6.1.Introducción 112

6.1.1.Ciclo Pampeano

6.1.2. Ciclo Famatiniano.

6.1.3.Ciclo Patagonídico. Etapa extensional de intraplaca (CretácicoPaleoceno).

6.1.4.Ciclo Ándico. Etapa compresiva (Paleoceno-Holoceno).

6.2.Geología estructural del sector sur del Cerro Colorado de Cobre.

6.2.1.Deformación dúctil.

6.2.2. Deformación frágil.

6.2.2.1.Lineamientos.

6.2.2.2.Fallas.

6.3.Controles estructurales de las vetas del distrito Purísima-Rumicruz.

6.4.Discusión de los resultados.

7. CAPÍtUlO VII. ESTUdIO GEOELÉCTRICO DEL DEPÓSITO PURÍSIMARUMICRUZ.

7.1.Introducción 131

7.1.1.Potencial inducido y resistividad en el distrito Purísima-Rumicruz. $\quad 133$

7.1.2.Purísima-Rumicruz.

7.1.3.El Brechón.

7.1.4.La Nueva.

7.2.Modelado tridimensional.

7.3.Discusión e interpretación.

8. CAPÍTULO VIII. CARACTERIZACIÓN DE LOS FLUIDOS HIDROTERMALES. 147 
8.1.Inclusiones fluidas.

8.1.1.Introducción.

8.1.2. Petrografía de las inclusiones.

8.1.2.1.Calcita.

8.1.2.2. Cuarzo.

8.1.3.Análisis microtermométrico.

8.1.4.Discusión.

8.2.Isótopos estables.

155

8.2.1.Introducción.

8.2.2. Isótopos de azufre.

8.2.3. Isótopos de oxígeno.

8.2.4. Isótopos de carbono.

8.2.5.Discusión.

8.2.5.1.Isótopos de azufre.

8.2.5.2.Isótopos de oxígeno.

8.2.5.3.Isótopos de carbono.

8.3.Isótopos radiogénicos.

8.3.1.Pb-Pb.

8.3.1.1.Resultados

8.3.1.2.Interpretación.

8.4.Consideraciones genéticas de los fluidos hidrotermales.

168

9. CAPITULO IX. MODELO METALOGENÉTICO. 170

9.1. Origen, transporte y precipitación de los metales y fluidos hidrotermales.

9.1.1. Origen.

9.1.2. Transporte.

9.1.3.Precipitación.

9.2.Edad de la mineralización. $\quad 177$

9.3.Modelo Metalogenético 178

9.4.Purísima Rumicruz, ¿un Five elements Deposit? 182

9.4.1.Introducción.

9.4.2. Yacencia.

9.4.3. Mineralogía.

9.4.4. Fluido hidrotermal.

9.4.4.1.Temperatura y salinidad.

9.4.4.2. Isótopos estables.

9.4.5. Modelo genético.

10. CAPÍTULO X. CONCLUSIONES.

10.1. Conclusiones. 


\section{AGRADECIMIENTOS}

A pesar de caer en el lugar común, quienes hemos transcurrido por el camino de realizar una tesis doctoral (o quienes nos han padecido), sabemos que es imprescindible la compañía de las diversas personas que, desde distintos lugares, nos han brindado sus aportes a lo largo de estos años. Realizar un agradecimiento detallado de cada uno de los que me asistieron sería extenso y correría el riego de olvidar a alguien importante. Puntualizaré aquí aquellas personas e instituciones que han sido imprescindibles para realizar este trabajo, pero no quiero dejar de hacer inclusivo mi agradecimiento a todos los que estuvieron a mi lado en este viaje.

\section{$* * *$}

Quiero expresar mi agradecimiento a mi director Horacio Echeveste y a mi codirector Abel Schalamuk. Ambos me acompañaron desde el primer momento, planificando lo que sería el tema de esta tesis y, luego, durante estos años, generando aportes, discusiones, acompañándome al campo y compartiendo generosamente su experiencia.

Los aportes de jurados han sido fundamentales para mejorar esta tesis. Sus lecturas críticas, aportes y sugerencias me permitieron clarificar y volver a reflexionar sobre algunos de los conceptos aquí expresados. Asimismo sus correcciones me ayudaron a pulir la redacción y edición. Muchas gracias Raúl Fernandez, Graciela Mas y Nora Rubinstein.

Quisiera extender mi más sincero y profundo agradecimiento a mis compañeros de campañas, Laura Lamarca, Matías Galina, Nicolas Scivetti y Agustín Argüello. El compromiso y su constante predisposición posibilitaron a que este trabajo sea lo que es.

Asimismo, me siento agradecido con todos los compañeros y docentes de las materias y cursos que realicé durante mi doctorado junto con todos los colegas que me acompañaron a los diversos congresos, jornadas o encuentros, que me brindaron sus comentarios y que amenizaron mis estadías. Una mención especial merece Milka de Brodtkorb, quien compartió sus amplísimos conocimientos calcográficos y brindó generosamente una serie de pulidos que fueron utilizados durante este trabajo. 
Un gran número de las labores analíticas fueron realizadas en laboratorios externos. Agradezco a los responsables de los Institutos que permitieron llevarlos a cabo.

A Javier Ríos, de cuya legendaria generosidad fui testigo y que me posibilitó realizar los estudios de inclusiones fluidas y microsonda electrónica. Sumo al agradecimiento a todo el equipo del CDTN, quienes me hicieron sentir como en casa en dos oportunidades.

A Colombo Tassinari, colegas y técnicos del Laboratorio de Pesquisas Geocronológicas de la Universidad de São Paulo que me posibilitaron realizar las labores relativas a los isótopos radiogénicos que componen esta tesis.

A Sergio Matheos, Daniel Poiré, Sebastián Richiano, Augusto Varela y Pablo García, que me permitieron y asistieron para la realización de los estudios de rayos $X$ en el Centro de Investigaciones Geológicas. En el CIG permanentemente me abrieron las puertas para innumerables discusiones, evacuar y generar dudas y realizar aportes. Muchas gracias nuevamente a Augusto y Sebastián, que sumados a Ernesto Swartz y Gonzalo Veiga, con inmensa paciencia me estimularon en el entendimiento y me contagiaron su entusiasmo por la sedimentología.

A Remigio Ruiz y Ricardo Etcheverry, quienes desinteresadamente y con suma responsabilidad realizaron las mediciones correspondientes a los isótopos estables en el Laboratorio de Isótopos Estables de la Universidad de Salamanca. Asimismo expreso mi agradecimiento a Clemente Recio, que me permitió realizar los estudios allí.

A Mabel Lanfranchini por su asistencia con los análisis químicos de la microsonda electrónica, a Miguel del Blanco por su ayuda en microscopía óptica; a Raúl de Barrio por las determinaciones mineralógicas y por su apoyo con bibliografía siempre pertinente y a Mario Tessone por el procesamiento de la información geoeléctrica. A Marquitos y Nicky por darme una mano con la separación de los minerales y a Euge Cobo con la elaboración de los gráficos 3D de la geoeléctrica.

A Diego Guido, quien me ha brindado innumerables oportunidades para mi desarrollo profesional y que ha estado pendiente sobre el desarrollo de esta tesis desde el principio.

Quiero agradecer a los que aportaron comentarios, críticas y opiniones en diferentes capítulos o trabajos relacionados con esta tesis. Muchas gracias Gerardo 
Páez, Sebastián Jovic, Diego Guido, Mario Tessonne, Leandro D’Elía, Andrés Bilmes, Ricardo Etcheverri, Marta Alperín y Esteban Cardellach. ¡Muchas gracias por su tiempo y esfuerzos!

A todos mis compañeros de trabajo en el INREMI con los cuales compartí viajes, charlas y mates. En particular quiero destacar la altísima predisposición y compromiso de Marcela y Marijo con las finanzas, trámites y tareas administrativas.

Al INREMI, que me brindo el espacio físico para desarrollar las tareas que involucraron esta tesis. Además quiero agradecerle por el apoyo logístico, financiero y humano durante todos estos años.

Al CONICET, institución que me otorgó las becas doctorales que permitieron llevar adelante este trabajo.

A la empresa Bolland Minera S.A. que financió parte de las tareas de campo y brindó su permiso para poder realizar este trabajo. Particularmente, quiero expresar mi agradecimiento al Sr. R. lacovone y Sr. E. Franco por su asistencia y predisposición.

A la SEG, que me otorgó en dos ocasiones sucesivas la beca Hugh E. McKinstry que constituyó un aporte fundamental para completar las tareas de campo y para financiar las estadías en los laboratorios externos.

A la Universidad Nacional de La Plata y particularmente a la Facultad de Ciencias Naturales y Museo, instituciones a la que cada día me siento más orgulloso de pertenecer.

A la comunidad Rumicruz por permitirme realizar este estudio en sus tierras y por su amable hospitalidad.

$* * *$

A todos mis amigos, los marplatenses, porteños y platenses, que me han aportado muchísima energía, todos de alguna u otra manera están aquí presente.

Finalmente, quiero agradecer enormemente a mi familia: Norma y Carlos que sin su entrega, guía, dedicación, generosidad y amor esto hubiese sido imposible. Se suman a ellos Vilma, Aldo, Nico y Mauro, que estuvieron presentes desde siempre. Completa, mi nueva familia "adoptada" quienes constantemente me han brindado y brindan su apoyo. 
Por último, y especialmente, a mi compañera, Sol, que me asistió en innumerables oportunidades para el desarrollo de este trabajo, desde la separación de minerales para análisis hasta la lectura crítica del manuscrito, sugiriendo aportes que ayudaron en la mejor transmisión de los conceptos aquí expresados. Además, fue un invaluable sostén en los momentos de desazón y un estímulo constante en todos los aspectos imaginables.

¡Gracias a todos y todas! 
El Noroeste Argentino contiene una extensa historia de explotación minera de elementos metalíferos. La provincia de Jujuy exhibe en la actualidad dos explotaciones a gran escala, Mina Aguilar y Mina Pirquitas. Además existen numerosos depósitos de tipo vetiforme, que han sido explotados artesanalmente a pequeña escala. Sobre estos últimos han sido efectuados estudios fundamentalmente de carácter mineralógicos, sin embargo en numerosos de estos todavía persisten interrogantes respecto a su génesis. Los estudios llevados a cabo en estos pequeños depósitos permitieron determinar que algunos presentan una asociación mineral inusual con la presencia de sulfuros, sulfoarseniuros de Ni y Co y pechblenda. El depósito polimetálico Purísima Rumicruz constituye uno de estos pequeños yacimientos y fue explotado con irregular intensidad desde la década del ' 40 hasta los años 70's. La explotación del yacimiento se llevó a cabo mediante 450 m de galerías, 40 m de piques y 30 m de chiflones.

El presente trabajo tuvo como objetivo comprender cuales fueron las características de los fluidos hidrotermales y los controles litológicos y estructurales que permitieron la concentración mineral y sobre esta base proponer un modelo metalogenético para el depósito polimetálico.

Para llevar a cabo este trabajo inicialmente se efectuó una recopilación bibliográfica de los antecedentes geológicos y mineros de la región. Para la confección del mapa base se procesaron fotos aéreas e imágenes satelitales y se añadió la información de los mapas geológicos publicados. Se realizaron tareas de mapeo geológico-estructural de detalle y muestro geoquímico de las estructuras mineralizadas y de las escombreras de la explotación y la información fue compilada en un sistema de información geográfico (SIG). Se efectuó un relevamiento geofísico donde se analizaron las respuestas geoeléctricas de resistividad y cargabilidad de las estructuras mineralizadas y de la roca de caja. Se efectuaron estudios mineralógicos y geoquímicos de la mineralización y la roca encajante. La caracterización de los fluidos hidrotermales que generaron el depósito se realizó mediante el análisis de inclusiones fluidas y de isótopos estables de C, O y S. El análisis de los isótopos radiogénicos de $\mathrm{Pb}$, permitió efectuar determinaciones geocronológicas y aportó datos para evaluar la fuente de los metales.

El área de estudio se ubica en el sector sur del Cerro Colorado de Cobre, ubicado en el límite de las provincias geológicas de la Puna y la Cordillera Oriental. Las vetas se concentran en una superficie de $3,5 \mathrm{Km}^{2}$. Las rocas aflorantes corresponden a la 
Formación Acoite de edad Tremadociana (Ordovícico inferior), que en el sector norte del área de estudio son puestas en contacto con depósitos de edad Cretácica del Grupo Salta por medio de una falla regional denominada Falla Tabladitas.

Los sedimentos correspondientes a la Formación Acoite se relacionan con la máxima inundación de la cuenca eopaleozoica del Noroeste Argentino. Para el análisis estratigráfico de la Formación Acoite fueron definidas cuatro asociaciones de facies sedimentarias. A partir de estas se identificaron dos procesos con características distintivas: procesos donde predomina la decantación de material pelítico, y procesos de flujos tractivos, turbulentos, principalmente unidireccionales y erosivos que depositan material de granulometría arena fina a muy fina en niveles decimétricos que se intercalan entre los niveles de pelita. El ambiente de depositación de esta secuencia corresponde a una plataforma abierta, clástica dominada por tormentas. Estas pueden propiciar o favorecer la generación de corrientes de turbidez encontradas en el registro. Las interpretaciones se ajustan a las presentadas por otros autores en la región, principalmente hacia este de la zona de estudio. Las pelitas correspondientes a la Formación Acoite se depositaron en condiciones anóxicas y presentan una elevada concentración de elementos como $\mathrm{Ag}, \mathrm{Ba}, \mathrm{Cu}, \mathrm{Ni}, \mathrm{Pb}, \mathrm{S}, \mathrm{Sb}, \mathrm{U}$ y $\mathrm{Zn}$. Estas concentraciones son frecuentes en pelitas depositadas hacia el final de los cortejos transgresivos.

Las rocas de la Formación Acoite en el sector sur del Cerro Colorado de Cobre se encuentran deformadas dúctilmente, conformando pliegues apretados con ejes con dirección predominante hacia el SSO y buzantes con inclinaciones de aproximadamente $20^{\circ} \mathrm{S}$. Durante el Jurásico medio-Cretácico inferior comenzó en el Noroeste Argentino (NOA), un proceso de rifting continental, que estructuró hemigrabenes que controlaron la depositación del Grupo Salta, principalmente durante la etapa de sinrift. El desarrollo de este rift estuvo controlado principalmente por fallas de dirección meridiana, que en área están representadas por la falla Tabladitas, de dirección NO-SE.

La mayor frecuencia de las fallas relevadas fue en dirección $\mathrm{N} 120^{\circ}$ y una dirección secundaria con azimut $90^{\circ}$. Las vetas del depósito polimetálico Purísima-Rumicruz ponderadas por su longitud presentan una orientación principal con azimut $120^{\circ}$ y dos direcciones subordinadas con orientaciones $\mathrm{N} 90^{\circ}$ y N105. Estos datos sugieren que las vetas del distrito Purísima-Rumicruz fueron alojadas durante la formación o la reactivación de planos de falla. Estas interpretaciones son acordes con las texturas de brechamiento mecánico registradas en las vetas. 
El relevamiento geoeléctrico fue realizado mediante perfiles en tres áreas que abarcan la mayor parte de las vetas del distrito, denominadas La Nueva, El Brechón y Purísima-Rumicruz. Estos perfiles fueron integrados y se obtuvo una zoneografía en planta de las anomalías de cargabilidad y resistividad a una profundidad a $57 \mathrm{~m}$ debajo de la superficie. En el distrito se reconocieron zonas de baja resistividad interpretadas como el resultado de un aumento en la porosidad producto del fallamiento. Fueron consignados elevados valores en cargabilidad, sin embargo las interpretaciones que surgen de estos datos deben realizarse con precaución debido a los altos valores de fondo en la roca de caja producto de la presencia de pirita diagenética diseminada en ella. La correlación negativa de la resistividad con los valores en cargabilidad, la continuidad lateral y en profundidad de las anomalías y la vinculación espacial con las vetas registradas en superficie son elementos diagnósticos para las interpretaciones geoeléctricas en el distrito.

Las vetas que conforman el depósito Purísima-Rumicruz fueron diferenciadas de acuerdo a su composición, de esta forma se discriminaron las vetas de sulfuro dominante, de baritina dominante y vetas de cuarzo. Fue sobre las primeras donde se concentraron los estudios mineralógicos, geoquímicos e isotópicos. Las estructuras mineralizadas están conformadas por vetas, vetillas y stockwork, las potencias son centimétricas y las corridas cortas. Las vetas presentan textura brechosa con clastos de roca de caja cementada por sucesivos pulsos de relleno hidrotermal. Los análisis geoquímicos indicaron la presencia de altos tenores de $\mathrm{Ag}, \mathrm{As}, \mathrm{Co}, \mathrm{Cu}, \mathrm{Ni}, \mathrm{Pb}, \mathrm{Sb}$ y $\mathrm{Zn}$.

El depósito Purísima Rumicruz exhibe una paragénesis que comprende cinco etapas de precipitación. La primera está compuesta por galena, pirita, calcopirita, tetrahedrita-tennantita rica en Zn y calcosina. La segunda etapa concentra los arseniuros y sulfoarseniuros de níquel y cobalto, formando niquelina, gersdorfita, en sus variedades ordenada y desordenada, gersdorfita cobaltífera, ullmanita y completa esta etapa la presencia de pechblenda botroidal. En la tercera, la calcosina es el mineral más abundante seguido de calcopirita, tetrahedrita-tennantita, bornita, digenita y millerita. La cuarta etapa corresponde al enriquecimiento secundario, representado con covelina y una quinta removiliza los elementos previamente depositados conteniendo malaquita y azurita. La ganga del depósito está representada principalmente por carbonatos, fundamentalmente calcita, aunque ha sido reconocida ankerita, dolomita y siderita, la baritina es frecuente en la totalidad de las vetas y en algunas es el mineral preponderante, por otro lado, el cuarzo es escaso y está solo presente en la primera etapa de precipitación mineral. 
Los estudios realizados bajo microsonda electrónica permitieron la determinación mineralógica de las especies de reducido tamaño, así como comprender las variedades y distribución de los elementos constituyentes de las especies minerales halladas en el distrito. Además permitió la utilización de un geotermómetro que es dependiente de la composición química de la gersdorffita consignando que la temperatura de formación de este mineral fue menor a $300^{\circ} \mathrm{C}$.

Las inclusiones fluidas estudiadas se alojaron en cuarzo y calcita, no siendo posible efectuar mediciones en los minerales de mena ya que resultaron opacos bajo luz normal e infrarroja. Han sido obtenidas temperaturas de homogeneización entre los 110 y $350{ }^{\circ} \mathrm{C}$. Los sólidos disueltos en esta solución presentan una salinidad aproximada entre 5 a $12 \%$ peso de $\mathrm{NaCl}$ eq. para el cuarzo y salinidades mayores para los carbonatos con una moda de $22 \%$ peso de $\mathrm{NaCl}$ eq., sin embargo las mediciones sobre estos últimos presentaron problemas de cierre al realizar los ensayos. Se han realizado mediciones de las relaciones isotópicas en C, O y S y a partir de las determinaciones en los minerales ha sido posible calcular la composición isotópica de los fluidos hidrotermales que formaron la mineralización. Las determinaciones sobre estos isótopos indicaron una fuente sedimentaria/metamórfica/magmática para los fluidos, mientras que los metales posiblemente fueron lixiviados de las pelitas de la Formación Acoite. Los datos obtenidos de los isótopos de $\mathrm{Pb}-\mathrm{Pb}$ indican como fuente niveles corticales altos. Estos estudios permitieron obtener una edad modelo $\mathrm{Pb}-\mathrm{Pb}$ en sulfuros y establecer la geocronología de la mineralización correspondiente con $235 \mathrm{Ma}$. Considerando que los datos presentan una moderada dispersión y que los datos estructurales son coherentes con los esfuerzos distensivos del rifting continental del NOA, se propone una edad Jurásico superior-Cretácica inferior para la mineralización.

Sobre la base estos datos se propone un modelo metalogenético. Durante los primeros estadios del sinrift desarrollado en Jurásico medio-Cretácico, se generó una anomalía térmica producto del adelgazamiento cortical o intrusiones profundas. Aguas connatas de la Formación Acoite o de unidades infrayacentes fueron calentadas, movilizadas y lixiviaron elementos metálicos concentrados en las pelitas anóxicas de la Formación Acoite. Estos fluidos hidrotermales fueron canalizados y ascendieron a través de fallas durante sucesivas reactivaciones. La precipitación de los metales ocurrió por cambios en el Eh y pH del fluido, sin embargo no se descartan procesos de ebullición por descompresión o mezcla con aguas meteóricas. Purísima Rumicruz reúne características mineralógicas, geoquímicas, isotópicas, de yacencia y genéticas que permitieron clasificarlo como un Five Element Deposit. 


\section{ABSTRACT}

The Northwestern part of Argentina has an extensive mining history, particularly for metalliferous minerals. Two large scale mines are active at the present time in Jujuy province, Mina Aguilar and Mina Pirquitas. Also, several veind eposits have been mined in a small handcrafted scale. In the latter ones, some mineralogical studies have been performed; however the genesis of these deposits remained uncertain. The study of these deposits has allowed the identification of unusual mineral assemblages of sulfides, Ni-Co sulfoarsenides and pitchblende. The polymetallic Purísima-Rumicruz deposit belongs to these small ores types, and was mined irregularly since the 40's to the 70's. Mining was carried out by $450 \mathrm{~m}$ of galleries, $40 \mathrm{~m}$ of shafts, and $30 \mathrm{~m}$ of inclined shafts.

The focus of this work was to understand the genesis and evolution of the hydrothermal system; and the lithological and structural controls on the ore deposit formation, and to propose a metallogenetic model for this polymetallic deposit.

An extensive bibliography search was carried out in order to understand the geologic and metallogenetic background of the study area. In order to produce a base map, aerial photographs and satellite images were used, along with previously published geological maps. During field works, a detailed geological-structural mapping was carried out, along with surface geochemical sampling of veins and dumps piles. All this information was compiled into a geographic information system (GIS) database. Geophysical survey included geoelectric resistivity and chargeability determinations for veins and host rocks. Detailed mineralogical and geochemical studies of the mineralization and the host rocks were performed. In order to understand the origin of the hydrothermal fluids a fluid inclusions studies and stable isotope of $\mathrm{C}, \mathrm{O}$ and $\mathrm{S}$ analysis were carried out. Lead isotope studies allowed to constrain a geocronological framework for the mineralization and provided data to suggest metal sources.

The study area is located in the southern portion of the Cerro Colorado de Cobre, close to the boundary between the Puna and Cordillera Oriental geological provinces. The veins crop out in a $3,5 \mathrm{~km}^{2}$ area, were the Tremadocian (Early Ordovician), Acoite Formation is in tectonic contact with the Cretaceous sedimentary sequence of the Salta Group. This regional fault is named Tabladitas Fault, and acted as a main tectonic feature for the area.

The Acoite Formation sediments are related to the maximum flooding of the Eopaleozoic basin of the Northwestern Argentina. Four sedimentary facies 
associations have been established. Two distinctive processes were identified from the analysis of the sedimentary facies: a) a decantation process for the fine-grained sediments, and b) tractive, turbulent, mainly unidirectional, erosive flows process, for fine sandy to very fine sandy decimetric beds interbedded within the shales. This sequence corresponds to an open, clastic storm dominated shelf. These interpretations are consistent with other studies in the area, performed mostly toward the east of the study area. The shales of the Acoite Formation have been deposited in an anoxic setting where $\mathrm{Ag}, \mathrm{Ba}, \mathrm{Cu}, \mathrm{Ni}, \mathrm{Pb}, \mathrm{S}, \mathrm{Sb} \mathrm{U}, \mathrm{Zn}$ have been concentrated. This metal concentration in shales is frecuent in the last stages of transgressive system tracts.

Toward the south of the Cerro Colorado de Cobre, the Acoite Formation is ductilly deformed, with the development of tight folds with SSW axis trends dipping $20^{\circ} \mathrm{S}$. An extensive continental rifting occurred in the Northwestern part of Argentina from the Middle Jurassic to the Lower Cretaceous, with the development of several halfgrabens that controlled the deposition of the Salta Group deposits, particularly during the sinrift stage. The main tectonic features controlling the rifting show north-south trends, and within the study area this faults are represented by the NW-SE trending Tabladitas fault.

The main fault trend is $\mathrm{N} 120^{\circ}$ with a secondary trend of an azimuth of $90^{\circ}$. The Purísima-Rumicruz veins show a main trend of azimut $120^{\circ}$ and two subordinated trends of azimut 90 and 105. These data suggest that the Purísima-Rumicruz veins were formed during the formation or late reactivation of the fault planes. This interpretation is also consistent with mechanical brecciation textures recognized in most of the veins.

A geoelectrical survey was performed in three areas using IP/resistivity lines covering most of the outcropping veins of the district. The results of the survey were integrated and a resistivity and chargeability anomaly map was obtained for a level at $57 \mathrm{~m}$ below the surface. Low resistivity anomalies have been recognized in the district and were interpreted as the result of a rise in the porosity due to faulting. High chargeability values were recorded; however the interpretations that emerge from these data should be considered with caution due to high background values in the country rock due to the presence of diagenetic disseminated pyrite. The negative correlation of resistivity with chargeability values, the lateral and depth continuity of the anomalies, and the spatial relationship with surface veins are diagnostic elements for geoelectrical interpretations in the district. 
The mineralized structures are veins, veinlets and stockworks of centimetric widths and short continuity along strike. Most of the veins have breccia textures with country rock clasts cemented by a hydrothermal filling in successive pulses. Geochemical analysis indicated high anomalies in $\mathrm{Ag}, \mathrm{As}, \mathrm{Co}, \mathrm{Cu}, \mathrm{Ni}, \mathrm{Pb}, \mathrm{Sb}$ and $\mathrm{Zn}$.

The Purísima-Rumicruz deposit exhibits a paragenesis with five stages of mineral deposition. The first one is characterized by galena, pyrite, chalcopyrite, Zn-rich tetrahedrite-tennantite and chalcocite. The second stage includes niccolite, gersdorffite (ordered and disordered varieties), Co-rich gersdorffite, ullmanite and pitchblende. In the third stage, the most abundant mineral is chalcocite, with minor chalcopyrite, tetrahedrite-tennantite, bornite, millerite and digenite. The fourth stage corresponds to secondary enrichment processes minerals and the fifth remobilizes most of the previously deposited elements. The most abundant gange minerals is calcite, although ankerite, dolomite and siderite are also recognized, barite is also common and occasionally is the predominant gange mineral; quartz is scarce and is only present in the first stage of the paragenetic sequence.

Electron microprobe studies allowed mineralogical determinations of small sized minerals, the identification of different mineral varieties, and the analysis of the distribution of metals within the different minerals species. Also, electron microprobe analysis were used for geothermometer determinations using the chemical composition of the gersdorffite, obtaining a temperature of precipitation lower than $300^{\circ} \mathrm{C}$ for this mineral.

Fluid inclusions studies were carried out in quartz and calcite; it was not possible to perform any measurements in ore minerals because all of them were opaque under normal and infrared light. Homogenization temperatures between 110 and $350^{\circ} \mathrm{C}$ have been obtained for the mineralizing fluids, with salinities ranging from 5 to $12 \mathrm{wt} \% \mathrm{NaCl}$ eq. for quartz; and higher salinities for carbonates (mode of $22 \mathrm{wt} \% \mathrm{NaCl}$ eq.), however salinity determinations in calcite presented closure problems during the analysis.

Carbon, oxygen and sulfur isotopes studies carried out in ore and gangue minerals, and allow to establish the isotopic composition of the hydrothermal fluids. Results of stable isotopes determinations indicate a sedimentary/metamorphic/magmatic source for the fluids, while metals were probably leached from the Acoite Formation shales.

Data obtained from $\mathrm{Pb}-\mathrm{Pb}$ radiogenic isotopes indicate a high crustal level source for the fluids. These studies also allowed to obtain a $\mathrm{Pb}-\mathrm{Pb}$ model age for the sulfides, and to constrain the age of the mineralization to $\sim 235 \mathrm{Ma}$. Considering the moderate 
dispersion of the data, this age must should be with caution; however, the strong similarities observed in the structural data from veins and faults with the strain orientations determined for the Salta Group rift structures, allow to suggest a Jurassic to Cretaceous age for the mineralization.

Based on field observations and laboratory determinations, a metallogenetic model is proposed for the deposit. During Middle Jurassic to Cretaceous times the early stages of a rift system was developed in the Northwestern part of Argentina, and consequently a thermal anomaly was generated due to crustal thinning or deep intrusions. Connate waters of the Acoite Formation or deeper units, were heated, metals from the anoxic shales of the Acoite Formation. These hydrothermal fluids were ultimately channeled and ascended, through fault planes during successive reactivation events. The precipitation of the metals occurred probably due to Eh and $\mathrm{pH}$ changes in the fluids, however boiling caused by decompression or mixing with meteoric waters cannot be discarded as triggering processes acting during mineral deposition.

Finally, the Purísima Rumicruz deposit has a mineralogy, a geochemical signature, isotopic compositions, and genetic characteristics that allow us to classify it as a Five Element type Deposit. 


\section{CAPÍTULO I}

INTRODUCCIÓNY ANTECEDENTES 


\section{INTRODUCCIÓN}

El objetivo principal de este trabajo está orientado a lograr un mayor conocimiento acerca de los procesos metalogénicos que condujeron a la generación de una mineralización con una paragénesis polimetálica poco común, como es la mineralización del distrito minero Purísima-Rumicruz. La misma reúne elementos compatibles propios de depósitos de segregación magmática como $\mathrm{Ni}$ y $\mathrm{Co}$, con otros incompatibles como $\mathrm{U}$ ó típicamente hidrotermales como $\mathrm{As}, \mathrm{Cu}$ o $\mathrm{Pb}$. Esta asociación polimetálica es poco frecuente a nivel regional y mundial. A partir de la realización del programa de trabajo propuesto oportunamente, se pretendió, ampliar el conocimiento del distrito Purísima-Rumicruz estableciendo un modelo genético que permita explicar las relaciones de la mineralización con su entorno geotectónico y que se constituya en una herramienta para ser utilizada en la región en programas de prospección y exploración de depósitos de características similares.

La tesis está organizada por temáticas, que reflejan el orden de las tareas realizadas. Se describen los resultados obtenidos principalmente en las tareas de campo abordado, luego los datos analíticos de laboratorio y finalmente las interpretaciones globales y las conclusiones del trabajo. Se ha procurado brindar consideraciones finales o comentarios que sinteticen las interpretaciones en cada uno de los capítulos con el fin de generar una cierta independencia, sin desmedro de la fluidez y coherencia entre ellos.

De esta forma, los resultados de la investigación se organizaron en diez capítulos y un apartado de la bibliografía citada. En el presente capítulo introductorio se exponen los objetivos, se detalla sucintamente el marco geológico regional abordando las principales características geológicas y mineras, y finalmente se hace referencia al área de estudio, detallando las características climáticas y demográficas.

El capítulo II versa sobre las distintas técnicas y metodologías utilizadas para la recolección y análisis de los datos, distinguiéndose los procedimientos utilizados durante las tareas de campo y de laboratorio.

En el capítulo III se aborda el estudio de la sedimentología desde la perspectiva del análisis de facies, para realizar inferencias del ambiente de depositación de los sedimentos que constituyen la roca encajante del depósito Purísima-Rumicruz. En este sentido se describe también la petrografía de las litologías principales y la 
geoquímica de las pelitas, información que servirá de insumo para las interpretaciones genéticas del depósito polimetálico.

La yacencia y la mineralogía de las vetas que conforman el depósito PurísimaRumicruz se describen en el capítulo IV. Se exponen las características de cada una de las vetas que componen el distrito, se describen los afloramientos de campo, las relaciones texturales y estructurales observadas en muestras de mano, con lupa binocular y microscopio y se mencionan las distintas especies minerales reconocidas. Se propone un esquema paragenético elaborando una línea temporal con los diferentes eventos de precipitación que se sucedieron durante la formación del depósito.

En el capítulo $\mathrm{V}$ se concentran los aspectos químicos de la mineralización, definidos mediante análisis geoquímicos de muestras de superficie y determinaciones bajo microsonda electrónica de diferentes especies minerales. El depósito presenta una mineralogía rica y compleja, sin embargo una dificultad para su estudio y determinación fue el pequeño tamaño de las especies encontradas. Es por ello que la química mineral arrojó luz, no solo sobre la identificación de las especies minerales, sino también sobre su composición, permitiendo realizar interpretaciones sobre la evolución de los fluidos hidrotermales y proponer consideraciones termométricas.

En el capítulo VI se analiza la geología estructural desde dos enfoques, una primera instancia examina los eventos deformacionales que afectaron a las rocas del área de estudio, con énfasis en las encajantes del depósito. Seguidamente se exponen los resultados de los posibles controles estructurales que afectaron a la mineralización. En los capítulos III y VI, se analizan los posibles controles litológicos que pudieron haber ejercido influencias en la generación, transporte y precipitación de los fluidos hidrotermales y, a su vez, los controles estructurales como controladores de la yacencia y posterior deformación de la mineralización.

En el capítulo VII se detallan los resultados e interpretaciones que surgieron del relevamiento geofísico mediante la técnica geoeléctrica dipolo-dipolo. Se analizan las particularidades acerca del comportamiento de las litologías que conforman la roca hospedante y de las anomalías en el subsuelo que pueden indicar la continuación de estructuras superficiales o estructuras ciegas. La evaluación de la información relevada permitió conocer la geometría y extensiones de las vetas que conforman el depósito. 
El capítulo VIII se focaliza sobre la naturaleza de los fluidos hidrotermales que condujeron a la generación del depósito mineral. Allí se describen los resultados de los análisis realizados con técnicas de laboratorio como las inclusiones fluidas, que aportaron información sobre la temperatura y salinidad de los fluidos. También se exponen en este apartado los aportes de los estudios de isótopos livianos (C, O, y S), que brindaron información concerniente a la fuente de las soluciones hidrotermales y los metales. Finalmente se describen los resultados e interpretaciones de los isótopos de $\mathrm{Pb}$, que han contribuido a ratificar el origen de los metales y a establecer una edad modelo para el depósito.

En el capítulo IX se plantea la modelización del depósito, considerando la evolución del mismo, abarcando el origen, transporte y precipitación de las especies minerales que lo conforman. Seguidamente se establece una comparación entre los datos obtenidos en el presente trabajo con ejemplos mundiales de depósitos que poseen características similares,

Finalmente en el capítulo $X$ se exponen las principales conclusiones surgidas de la presente investigación. Posteriormente se presenta el listado bibliográfico sobre el que se sostiene esta contribución.

\section{MARCO GEOLÓGICO REGIONAL}

Para comprender la geología del Noroeste Argentino (NOA) es preciso estudiar los eventos que acontecieron en las provincias geológicas que lo componen, Puna, Cordillera Oriental, Sierras Subandinas y Sierra de Santa Bárbara (Fig. 1-1). Esto se debe a que el límite de las provincias geológicas del NOA fue definido por la estructuración andina, pero en tiempos anteriores, estos límites se tornan difusos o inexistentes.

\section{Proterozoico superior - Eopaleozoico}

Las rocas más antiguas que afloran en el NOA corresponden a la Formación Puncoviscana, definida por Turner (1960), y representada por una espesa y heterogénea sucesión sedimentaria y volcánica, altamente deformada y con un metamorfismo regional de bajo a medio grado (Aceñolaza y Aceñolaza, 2005). Los principales afloramientos se ubican en la Cordillera Oriental. Esta unidad tiene características heterogéneas, respecto a la naturaleza de su ambiente de sedimentación, grado metamórfico y estilo de deformación (Mon y Hongn, 1987, 1988, 
Moya, 1998; Becchio et al., 1999; Hongn y Mon, 1999, Hongn et al., 2008; Omarini et al., 2008; Hong et al., 2010), razón por la cual su nomenclatura ha sido frecuentemente cuestionada (Aceñolaza y Aceñolaza, 2005). Sin embargo continúa siendo de utilidad práctica asignar a las unidades que infrayacen a la discordancia Tilcárica dentro de la Formación Puncoviscana sensu lato (Omarini et al., 2008).

La edad de esta unidad ha sido objeto de una profusa discusión que continúa actualmente. La asignación cronológica se basa principalmente en registros fosilíferos, dataciones en circones detríticos que acotan sus límites temporales y las relaciones de esta unidad con los cuerpos magmáticos que la intruyen. En forma amplia puede definirse una edad Neoproterozoica-Cámbrica para este basamento, siendo el límite superior neto y discordante con el Grupo Mesón de edad cámbrica media a superior. Este límite, de marcada trascendencia regional, fue denominado discordancia Tilcárica (Turner y Méndez, 1975) y marca el fin de la orogenia pampeana y el comienzo de la Famatiniana (Aceñolaza y Toselli, 1973).

Durante el Ciclo Pampeano se registra un magmatismo que se expresa con facies volcánicas y plutónicas. Las primeras son basaltos alcalinos con firmas geoquímicas que permiten asignaciones variadas, como Ocean Island Basalt (OIB), e intraplaca, mientras que las rocas plutónicas son granitos-monzogranitos de naturaleza calcoalcalina. El mayor representante de este plutonismo se encuentra en la "Granodiorita La Quesera" (Keidel, 1943), siendo la sección sur del plutón definida como Santa Rosa de Tastil (Kilmurray e Igarzábal 1971). La edad más antigua es $536 \pm 7 \mathrm{Ma}$. obtenida mediante U-Pb sobre circones (Bachman et al., 1987). Eeste valor fue ratificado por dataciones aplicando el método de laser ablation, (Matteini et al., 2008). Asimismo se registraron edades más jóvenes dentro del batolito. Hongn et al. (2001) registró edades $\mathrm{U} / \mathrm{Pb}$ sobre circones de $517 \pm 2$, en el sector occidental, con evidencias de intrusión en las sedimentitas cámbricas del Grupo Mesón, aunque esta relación es controversial (Aceñolaza et al., 2003; Astini, 2005). El granito Chañi presenta una edad de $511 \mathrm{Ma}$. U/Pb SHRIMP obtenida sobre circones (Zappettini et al., 2008).

La discordancia Tilcárica separa la Formación Puncoviscana de la sedimentación del Grupo Mesón. La unidad inferior muestra una fuerte deformación en condiciones de bajo grado metamórfico.

En cuanto al marco geotectónico en que se desarrolló la sedimentación del Grupo Mesón y magmatismo asociado, podría estar relacionado a un aulacógeno con rumbo 
sudoeste (Suárez-Soruco 2000), o alternativamente, se propone la existencia de un microcontinente que impactó con Gondwana produciendo la deformación de la sedimentación (Ramos, 1986; Rapela et al., 2007).

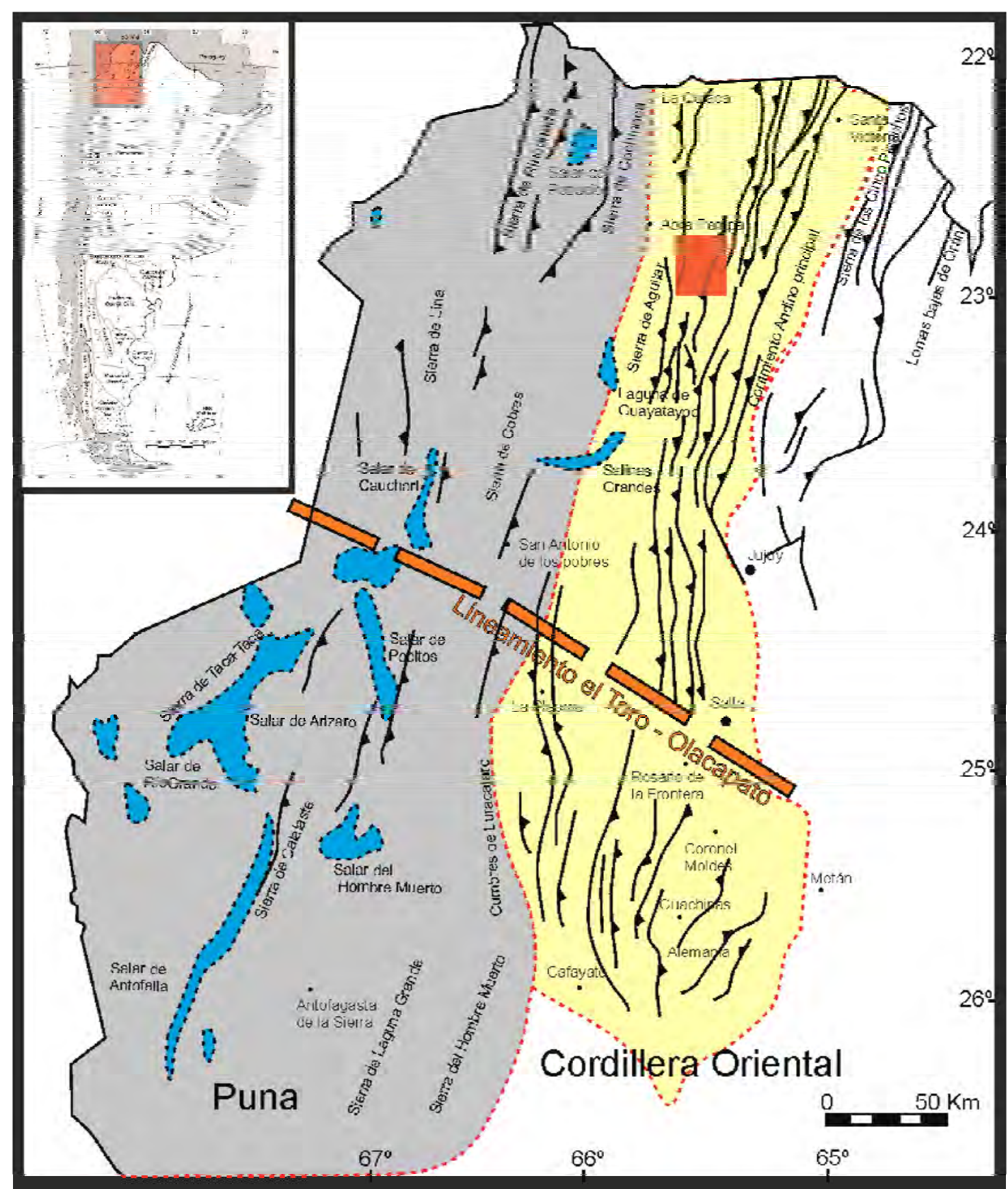

Fig. 1-1. Mapa de las provincias geológicas de Puna y Cordillera Oriental destacando las principales características estructurales. Ubicación del área de estudio en recuadro rojo. Modificado de Ramos (1999).

Sobreyace a la fase Tilcárica las sedimentitas correspondientes al Grupo Mesón el cual está conformado por las Formaciones Lizoite, Campanario y Chahualmayoc (Turner, 1960). Se interpreta a esta sedimentación como una secuencia transgresivaregresiva en un ambiente de plataforma/estuario dominado por mareas (Sánchez y Salfity, 1990, 1999; Moya 1998) en sistemas macromareales (Mángano y Buatois 
2000 , 2004). Se determinó una alta madurez composicional, sin embargo ha sido definida una polimodalidad en las granulometrías de los clastos. Esto podría sugerir que el transporte fue escaso y que la alta madurez composicional estaría dada por una intensa meteorización química bajo un clima tropical (Astini et al., 2005), que es congruente con datos paleogeográficos (Spagnuolo et al., 2005).

Moya (1998), incluye dos episodios transgresivos-regresivos en el Grupo Mesón, el primero comprende una secuencia progradante integrada por la Formación Lizoite y Campanario, mientras que el segundo está integrado por la Formación Chahualmayoc cuyo techo es truncado por la discordancia Iruya.

La edad de la sedimentación del Grupo Mesón quedaría limitada por la edad mínima de sedimentación de la Formación Puncoviscana, que aunque discutida, puede asignarse a $525 \mathrm{Ma}$ y el inicio de la sedimentación del Grupo Santa Victoria en 490Ma (Astini, 2008). Estos $35 \mathrm{Ma}$, deberían también incluir los hiatos de las discontinuidades que separan a las unidades Tilcárica e Irúyica respectivamente (Astini, 2008).

El Grupo Santa Victoria fue definido por Turner (1960) en la Quebrada de Santa Victoria. Los afloramientos de estas rocas tienen su mayor representación en la Cordillera Oriental y Puna. Si bien las unidades correspondientes al Ordovícico inferior reciben múltiples denominaciones, se adoptarán aquí las definidas por Turner (1964), quien separó al Grupo en las Formaciones Santa Rosita (Tremadociano) y Acoite (Arenigiano-Llanvirniano). Este Grupo reúne secuencias con una gran variación en los ambientes de depositación en sentido O-E, con unidades volcaniclásticas y complejos turbidíticos en la faja occidental, unidades clásticas de plataforma en la faja central y unidades deltaicas y estuarinas en la faja oriental, límite de la Cordillera Oriental con las Sierras Subandinas (Astini, 2003).

La discordancia Tumbaya asignada al Tremadociano basal a Tramadociano Superior-Arenigiano basal (Moya, 2008), separa a la Formación Santa Rosita de la Formación Acoite. La fase Tumbaya se desarrolló en el Ordovícico inferior a medio; esta discordancia involucra un hiato desde el Tremadociano inferior hasta el Arenigiano basal. Se propuso el empleo de seis Miembros para la Formación Santa Rosita (Buatois y Mángano, 2003; Buatois et al., 2006; Such et al., 2007), definidos en el margen oriental de la Quebrada de Humahuaca. Los mismos involucran dos ambientes distintos de sedimentación, uno fluvio-estuarino correspondiente al Miembro Tilcara y Pico de Halcón, con dominio macromareal, y los Miembros Casa Colorada, 
Alfarcito, Rupasca y Humacha corresponden a ambientes marinos abiertos (Buatois y Mángano, 2003; Buatois et al., 2006).

La Formación Acoite corresponde a la máxima inundación de la cuenca durante el Floiano basal (Moya, 2008), correspondiente al Ordovícico inferior. Las condiciones de sedimentación, ambiente depositacional y marco tectónico de la Formación Acoite será ampliado en el Capítulo III.

El magmatismo Ordovícico desarrollado en la región corresponde a la Faja Eruptiva de la Puna Oriental definida por Méndez et al. (1973) (Fig. 1-2), y está representado por fases efusivas y en forma subordinada fases plutónicas. Los cuerpos plutónicos se localizan en una faja estrecha, al sur de los $23^{\circ}$ de latitud sur y afloran principalmente en la Sierra de Cobres y en los cerros Quepente-Churcal (Zappettini, 2008). El volcanismo se inició a fines del Cámbrico e inicio del Tremadociano con características bimodales, representado por dacitas y basaltos subalcalinos. El registro más antiguo esta dado en las dacitas del Cerro Niño con una edad U/Pb en circones de $495 \pm 4 \mathrm{Ma}$. (Hauser et al., 2008). En las sierras de Cochinoca-Escaya el volcanismo es efusivo compuesto por lavas básicas espilíticas domos y criptodomos dacíticos sinsedimentarios con presencia de hialoclastitas (Coira et al., 1999, 2004, 2009a, 2009b; Coira, 2008), y estaría acotado al Arenigiano-Llanvirniano.

Se interpreta a la Faja Eruptiva de la Puna Oriental como un magmatismo de retroarco producto de una subducción oblicua con fusión cortical, bajo un régimen con un componente de rumbo transpresivo (Hongn y Mon, 1999) o transtensivo (Coira et al., 1999). Hacia finales del Arenigiano aumentaría el carácter contraccional y esto determinaría el fin del volcanismo y se desarrollarían cuencas de antepaís (Bahlburg, 1993; Bahlburg y Hervé, 1997; Astini, 2003).

La fase Oclóyica define la culminación de la sedimentación del Ordovícico inferior y genera una discordancia con los depósitos glacifluviales de la Formación Lipeón de edad Ashilliano-Silúrica. Sin embargo la naturaleza y edad de esta deformación es cuestionada por Moya (1999; 2008). Esta discusión será ampliada en el Capítulo VI.

El horizonte Hirnantiano es una secuencia de facies glacimarinas a glacifluviales, donde se reconocen tres asociaciones de facies. La primera constituida por diamictitas fangosas, con grandes clastos, la segunda representada por diamictitas finamente estratificadas y pelitas con dropstones, finalmente la tercera constituye depósitos arenosos con lentes conglomerádicas, correspondientes a un origen fluvial-eólico. Los depósitos glacigénicos podrían vincularse con un episodio regresivo, mientras que los 
fluviales serían depósitos de facies distales glaciales. Posteriormente ocurrió una transgresión que originó los depósitos de la Formación Lipeón.

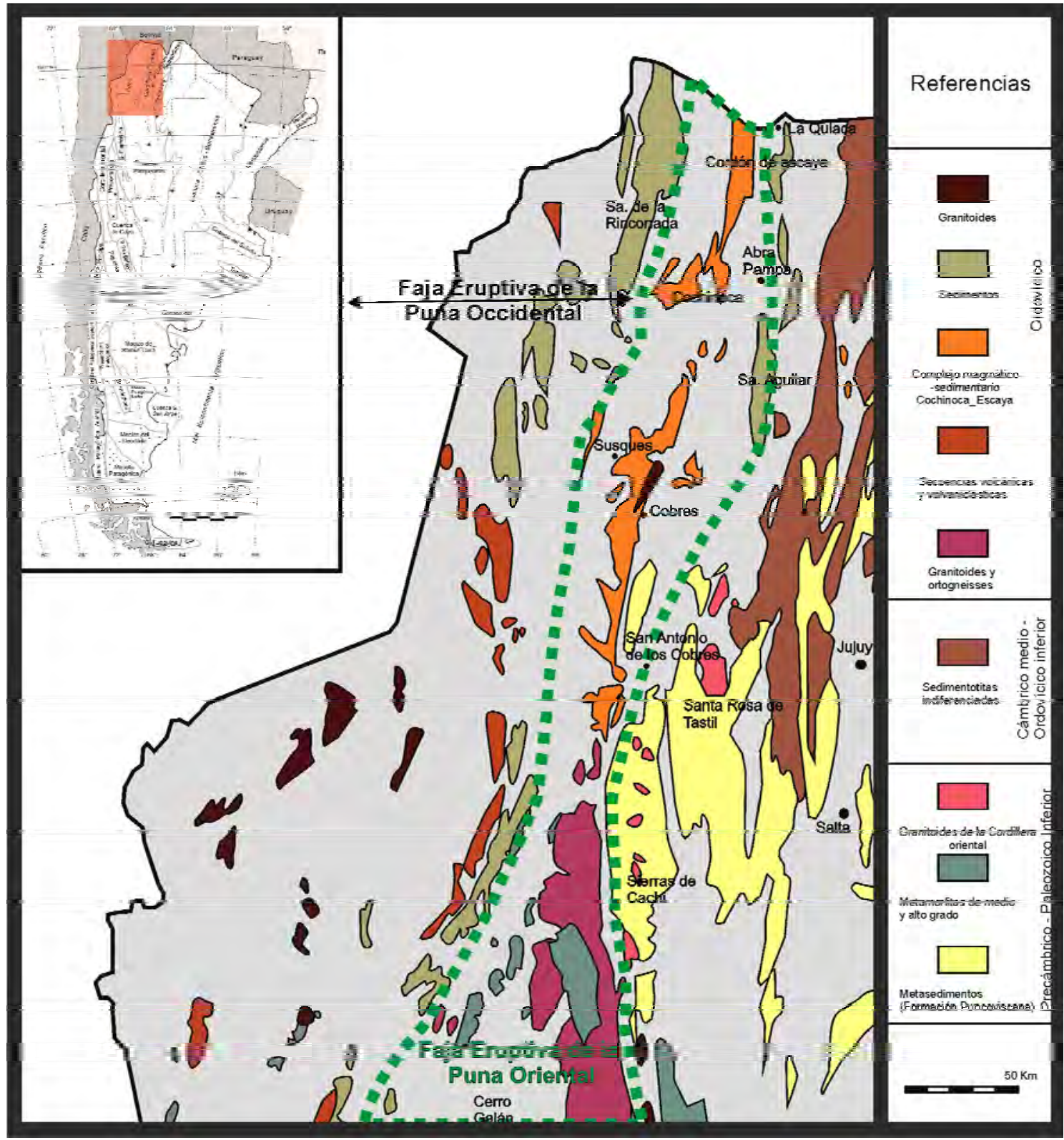

Fig. 1-2. Mapa de los afloramientos correspondientes al Proterozoico superior - Eopaleozoico de Puna y Cordillera Oriental. Se distinguen las facies magmáticas correspondientes a la Faja Eruptiva de la Puna Oriental y Occidental. Modificado de Coira et al. (2009a).

Un importante hiatus separa a las unidades Eopaleozoicos con los depósitos correspondientes a los del Grupo Salta del Mesozoico Superior-Terciario. Depósitos sedimentarios de edad Devónica a Permo-Triásica afloran en las Sierras Subandinas (Rubiolo, 2003). 
Desde el Cretácico al Eoceno se instala en el norte de Argentina, Bolivia y Perú un sistema de cuencas interconectadas interpretadas como cuencas de rift de antepaís abortados (Gallinski y Viramonte, 1988) y se relaciona con la apertura del Océano Atlántico Sur y la subducción de la Placa de Nazca por debajo de la placa Sudamericana (Viramonte et al., 1999). Se desarrolla así una sedimentación y un magmatismo con variaciones locales en las diferentes subcuencas. El área de estudio queda comprendida en la subcuenca de Tres Cruces.

Los depósitos sedimentarios del Grupo Salta son principalmente clásticos continentales, aunque también se registran niveles carbonáticos y de ambiente marino. El Grupo se subdivide en el Subgrupo Pirgua (Reyes y Salfity, 1972) que incluye las Formaciones La Yesera, Las Curtiembres y Los Blanquitos; Subgrupo Balbuena que involucra las Formaciones Lecho, Yacoraite y Olmedo; y el Subgrupo Santa Bárbara que reúne a las Formaciones Mealla, Maíz Gordo y Lumbrera.

El Subgrupo Pirgua representa el relleno de sinrift, caracterizado por una facies fluvial, donde se interpretaron abanicos aluviales, flujos densos no encauzados, planicies fangosas y facies eólicas (Boll y Hernández, 1985). La edad de este Subgrupo se extiende desde el Cretácico inferior al Cretácico superior (Rubiolo, 1999). Localmente se intercalan hacia la base coladas basálticas y flujos piroclásticos.

El Subgrupo Balbuena incluye a la Formación Lecho (Turner, 1959), de naturaleza similar al subgrupo anterior, con facies fluviales y eólicas a las que se les suma una facies carbonática continental. Son comunes las bioturbaciones y la formación de cuerpos lacustres pandos, posiblemente relacionados a un ascenso del nivel del mar, que posteriormente habría sido causal de la inundación de la cuenca y la depositación de la Formación Yacoraite (Boll y Hernández, 1985). La edad de la Formación Lecho es Campaniana. La Formación Yacoraite (Turner, 1959), está compuesta por areniscas y calizas depositada en un cuerpo muy amplio, pando y con inundaciones marinas frecuentes y episodios de desecación. La edad es Maastrichtiana. Los afloramientos de la Formación Olmedo son restringidos al sector más profundo de la cuenca, correspondiente a un medio lagunar de baja energía, sin influencia marina (Boll y Hernández, 1985).

El Subgrupo Santa Bárbara representa la secuencia de postrift que comienza con facies pelíticas-psamíticas carbonáticas interpretadas como pertenecientes a un 
ambiente fluvial y facies finas correspondientes a depósitos de llanuras de fango pertenecientes a la Formación Mealla de edad Paleocena superior a Eocena inferior (Pascual et al., 1978). La Formación Maíz Gordo (Paleocena superior-Eocena inferior, Pascual et al., 1978) se caracteriza por un predominio de facies finas interpretadas como producto de inundación de la cuenca e instalación de sistemas lacustres. Finalmente la Formación Lumbrera se encuentra compuesta por facies finas intercaladas con areniscas o conglomerados depositadas en un ambiente fluvial y de barreal (Boll y Hernández, 1985), de edad Eocena (Fernández et al., 1973).

El magmatismo extrusivo Cretácico está representado por coladas básicas intercaladas con la sedimentación del Grupo Salta y cuerpos intrusivos alcalinos a subalcalinos. Se reconocen tres etapas magmáticas (Gallinski y Viramonte, 1988). La primera, caracterizada por cuerpos intrusivos alcalinos, comienza en el Jurásico medio y se extiende hasta el Cretácico inferior ( 160-115 Ma.) (Zappettini, 2008; Hauser et al., 2008) y se vincula al magmatismo de pre-rifting (Viramonte et. al, 1999) representado por los plutones de Rangel, Hornillos, Abra Laite, Aguilar, Tusaquillas y Fundición. La segunda etapa (80-75 Ma.) incluye al basalto Las Conchas y se interpreta como magmatismo de sinrift. La última etapa (65-60 Ma.) está integrada por cuerpos subvolcánicos de composición lamprofírica y basanítica, intercalados entre los Subgrupos de Balbuena y Santa Bárbara asociados a la etapa de postrift.

Los cuerpos intrusivos desarrollados durante el rifting generados en las primeras etapas del rift están constituidos por granitos anorogénicos peraluminosos de retroarco y granitos alcalinos en un régimen extensional vinculado a la apertura del Océano Atlántico, (Viramonte et al., 1999; Rubiolo, 1999; Cristiani et al., 1999; Menegatti, 2001, Zappettini, 2008). Estos cuerpos se ubican mayormente en posiciones marginales y solo los granitos Abra Laite y Aguilar se encuentran hacia el interior del rift (Monaldi et al., 2008) (Fig. 1-3).

\section{Eoceno-Neógeno}

Los depósitos paleógenos de la subcuenca de Tres Cruces se dividen en dos Formaciones, denominadas Casa Grande y Río Grande, separadas por una discordancia erosiva o de leve angularidad (Rubiolo, 2003). La Formación Casa Grande es definida por Fernández et al. (1973), y consiste en una secuencia clástica depositada a partir de abanicos aluviales distales con baja pendiente (Boll y Hernández, 1985), de edad Eocena (Pascual y Odreman Rivas, 1973). La Formación 
Río Grande (Pascual et al., 1978), está formada por sedimentos clásticos de origen fluvial y edad Oligocena (Rubiolo, 2003).

El Neógeno esta caracterizado por la sucesión de sedimentación clástica de la Formación Pisungo (Rubiolo, 2003), correspondiente al Mioceno inferior, sobre esta Formación yacen en discordancia unidades clásticas y piroclásticas de las Formaciones Cara Cara (Rubiolo, 2003), Doncellas y Alto Laguna, estas unidades pueden ser correlacionables y por tanto coetáneas (Rubiolo, 2003). Las variaciones faciales y ambientales, así como la abundancia y distribución de las unidades piroclásticas presentan un íntimo control tectónico que refleja la evolución de la estructuración Andina.

Durante el plio-pleistoceno se reconocen depósitos aluviales y coluviales, fluvioglaciares, de playa, planicies aluviales, planicies de inundación y se configuran campos de dunas intermontanas (Rubiolo, 2003).

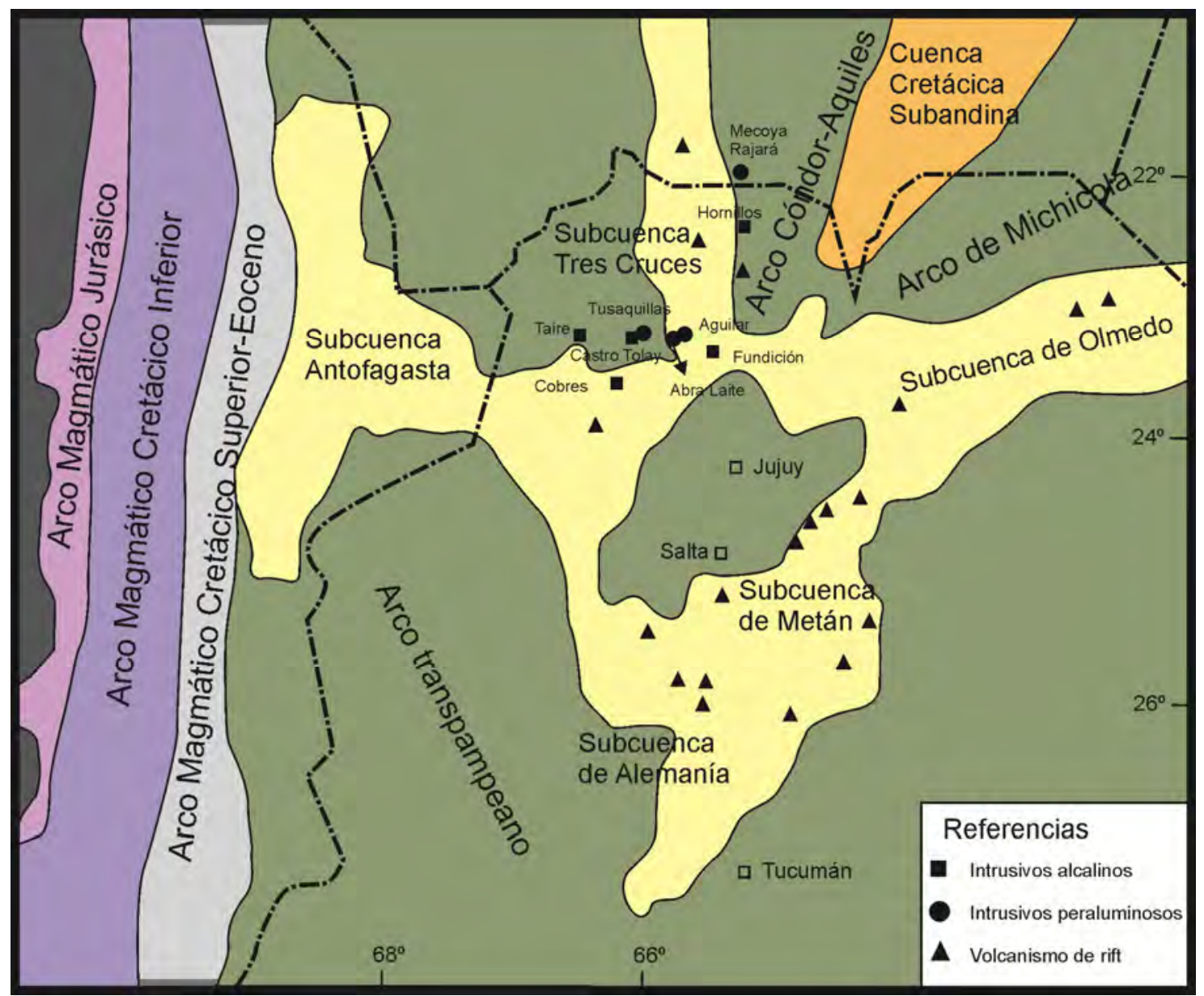

Fig. 1-3. Mapa de ubicación de los cuerpos magmáticos Cretácicos del NOA correspondientes con la etapa de rifting continental. Modificado de Zappettini et al. (2008). 
Las provincias que conforman el Noroeste Argentino contienen una larga y profusa historia minera. Los primeros registros de minería se remontan a las explotaciones realizadas por los Jesuitas, sin embargo estos yacimientos, principalmente los auríferos, posiblemente hayan sido explotados por Incas o incluso por comunidades previas. Algunas evidencias de la explotación Inca son los Maray (molinos) y las Huayras (hornos de fundición) (Aceñolaza y Alonso, 2008).

Las explotaciones de minerales metálicos se produjeron a partir de yacimientos hidrotermales y yacimientos de tipo placer. Las minas más importantes considerando el volumen explotado y la historia minera de la región son la Mina Aguilar y Pirquitas, ambas activas en la actualidad. La primera corresponde a un depósito a $45 \mathrm{Km}$ al sur del área de estudio. La explotación a gran escala comenzó en la década del '30 produciendo un concentrado de plomo-zinc. El depósito se interpreta como un SEDEX de edad Ordovícica, singenético con la Formación Acoite, donde existió removilización por metamorfismo durante la intrusión del granito Aguilar durante el Cretácico (Gemmel et al., 1992, Sureda, 1999). Pirquitas es un yacimiento ubicado a $135 \mathrm{Km}$ al oeste de la localidad de Abra Pampa, explotado principalmente por plata y estaño. La yacencia del depósito es vetiforme y diseminado, genéticamente vinculado a un cuerpo ígneo en profundidad de edad Terciaria (Chayle, 1999). Este depósito se interpreta como la prolongación más austral de la faja estanífera argentífera boliviana (Turneaure, 1971).

Son de relevancia los depósitos auríferos localizados en la Sierra de Rinconada encajados en rocas equivalentes a la Formación Acoite, con un marcado control estructural y genéticamente vinculados a la deformación y metamorfismo acaecido durante el Ordovícico tardío-Silúrico temprano (Rodríguez et al., 2001; Rodríguez, 2008). Asimismo, se destacan los sistemas vetiformes de la Puna asociados al magmatismo neógeno. Aquí se encuentran vetas polimetálicas vinculadas genéticamente a pequeños domos, mayoritariamente dacíticos, clasificadas como vetas epitermales de sulfuración intermedia (Caffe y Coira, 2008), y también vetas polimetálicas asociadas a calderas y volcanes compuestos interpretadas como sistemas epitermales de alta sulfuración (Ramírez y Díaz, 2008).

Finalmente, numerosas mineralizaciones vetiformes polimetálicas (plomo, zinc y baritina), emplazadas en estratos Ordovícicos (Rubiolo, 2003) han sido explotadas a pequeña escala a lo largo de la historia minera del NOA, actualmente estos depósitos 
se encuentran inactivos (Rubiolo, 2003). Se destacan el distrito Pumahuasi ubicado a $50 \mathrm{Km}$ al Norte del distrito Purísima-Rumicruz y los ubicados en la Sierra de Santa Victoria.

\section{ÁREA DE ESTUDIO}

El área de trabajo se encuentra ubicada próximo a la transición entre las provincias geológicas de Puna y Cordillera Oriental, en el sector nororiental de la Provincia de Jujuy. Las coordenadas limitantes (Gauss Krüger, Campo Inchauspe, Faja 3), son: N 7.473.300 a $N$ 7.481.100 y E 3.544.850 a E 3.551.200, mientras que los mismos límites expresados en coordenadas geográficas son $22^{\circ} 47^{\prime} 10^{\prime \prime}$ a $22^{\circ} 51^{\prime} 20^{\prime \prime}$ de latitud Sur y $65^{\circ} 33^{\prime} 50^{\prime \prime}$ a $65^{\circ} 30^{\prime}$ de longitud Oeste, abarcando una superficie total de $50 \mathrm{Km}^{2}$. (Fig. 1-4). La topografía se compone de colinas suaves y redondeadas limitadas por cárcavas y quebradas con pendientes pronunciadas. Las alturas varían entre los 3.400 a 4.100 msnm.

El distrito minero Purísima Rumicruz se ubica al Este de la Ruta Nacional No 9 a la altura de la localidad de Abra Pampa. La vía de acceso al distrito es un camino vecinal que une las localidades de Abra Pampa y Tres Cruces. A $25 \mathrm{Km}$ de Abra Pampa por este camino se desprende una antigua huella minera que brinda acceso al campamento de la mina Purísima. En la actualidad este camino está derrumbado y no es posible transitar el mismo con vehículo. La superficie del área de estudio pertenece íntegramente a la comunidad originaria Rumicruz.

El poblado más importante del área es la localidad de Abra Pampa con una población de 9425 habitantes (Censo Nacional, 2001), ubicada a 3484 msnm. Son numerosos los pequeños puestos unifamiliares distribuidos en la región. La actividad rural es la ganadería y en Abra Pampa es importante el desarrollo comercial.

De acuerdo a los datos de la Estación meteorológica ubicada en Abra Pampa durante el período $1990-2000$, se calculó una temperatura media de $8,7^{\circ} \mathrm{C}$, con una temperatura máxima media de $18,5^{\circ} \mathrm{C}$ y una temperatura mínima media de $-2,4^{\circ} \mathrm{C}$. La temperatura máxima y mínima absoluta para el período medido fue de 27 y $-22^{\circ} \mathrm{C}$ respectivamente. En cuanto a las precipitaciones el valor medio anual es de 387,6 $\mathrm{mm}$, mientras que la humedad relativa para el período de medición fue del 49\%. Las precipitaciones se concentran en el período estival siendo enero el mes más lluvioso. 


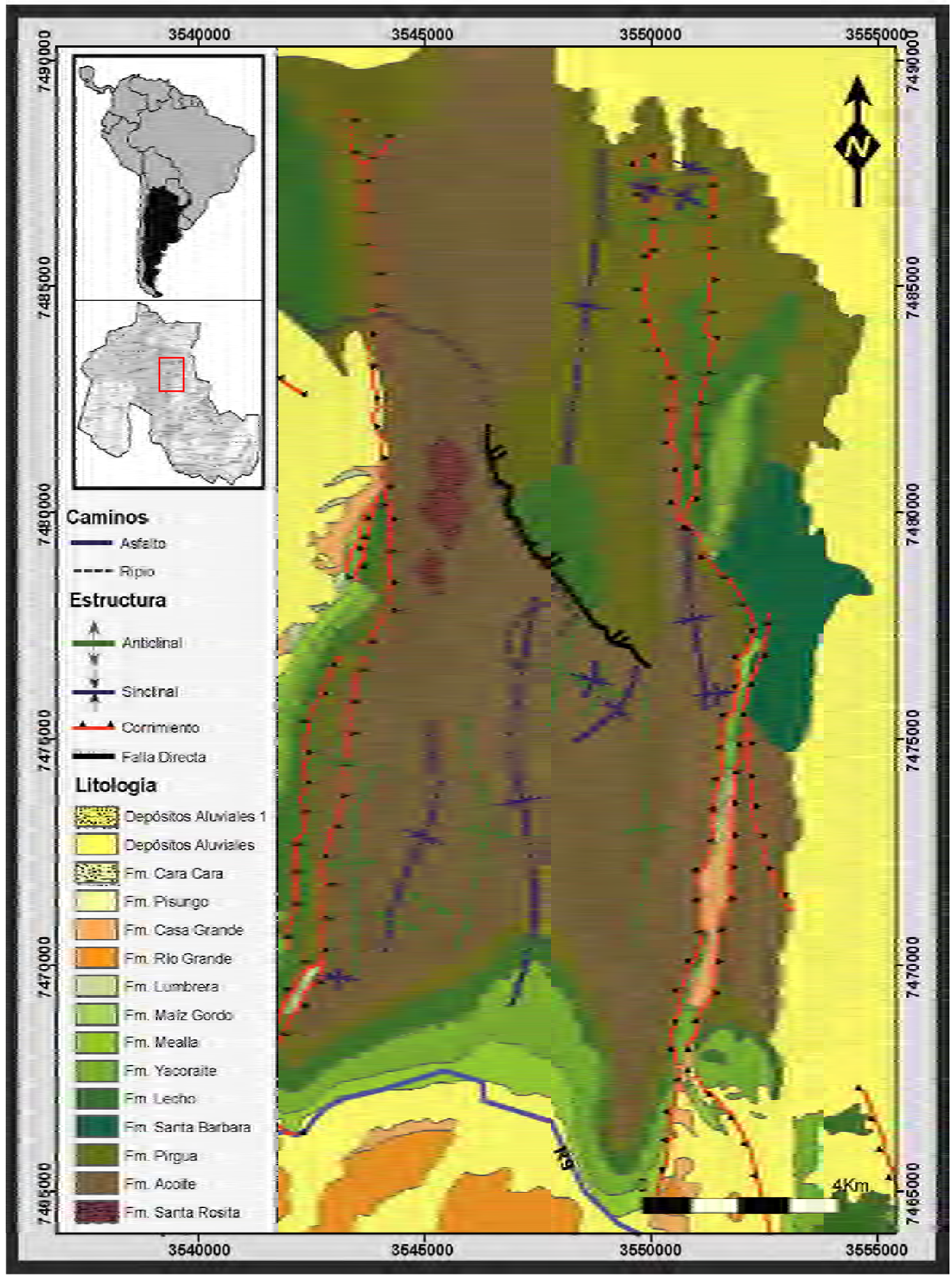

Fig. 1-4. Mapa geológico a escala 1:100.000 del área de estudio. 


\section{CAPÍTULO II}

MATERIALES Y MÉTODOS 


\section{INTRODUCCIÓN}

Para la realización de este trabajo, de acuerdo el plan propuesto, se estableció un conjunto de tareas dividido en tres grandes etapas que se realizaron en forma correlativa. La primera reúne la recopilación de antecedentes, confección de una cartografía base, reconocimiento y mapeo en campo y exploración geofísica, produciendo como resultado final un sistema de información geográfica que reunió los datos recolectados y generados durante esta etapa. La segunda concentró los estudios de gabinete con las descripciones de las muestras recolectadas a diferentes escalas y trabajo de laboratorio, mientras que en la tercera se focalizó en la integración e interpretación de los datos obtenidos para la elaboración de un modelo geológico - metalogenético del área de estudio.

\section{TAREAS DE CAMPO}

Las tareas de campo fueron realizadas entre diciembre de 2006 y abril de 2010, distribuidas en cinco campañas, totalizando 92 días de campo. Las primeras se centraron en la confección del mapa geológico, la recolección de muestras litológicas y de mineralización y en el relevamiento de datos estructurales. Una campaña fue íntegramente destinada al desarrollo de la obtención de datos geoeléctricos, mientras que la última se reservó para levantar perfiles sedimentológicos de la roca encajante de la mineralización.

\section{Cartografía base para la confección del mapa geológico.}

La confección de la carta base fue realizada en un sistema de información geográfica y se combinó diversos mapas geológicos, los cuales fueron digitalizados (en caso de presentarse en formato papel) y georeferenciados. Los mapas sobre los que se sintetizó la geología local fueron las hojas geológicas del área al 200.000 (Coira, 1979) y al 250.000 (Rubiolo, 2003). A esta información se le añadió dos corridas paralelas de fotografías aéreas a escala aproximada 1:60.000 provistas por el SEGEMAR, cubriendo el área de trabajo, las cuales fueron digitalizadas a 600dpi, ortorrectificadas y georeferenciadas y con este resultado se generó un mosaico mediante el software Earth Mapper 6.0. Se amplió esta base de datos digital con imágenes satelitales; Landsat 7 ETM+, Aster y Quikbird se utilizaron de forma combinada, ya que cada una, con sus diferentes resoluciones espaciales y espectrales 
aportó información determinante para el desarrollo del mapeo en el campo. Sucesivas fusiones entre esta información raster fue obtenida mediante la transparencia entre dos ó más imágenes (Fig. 2-1).
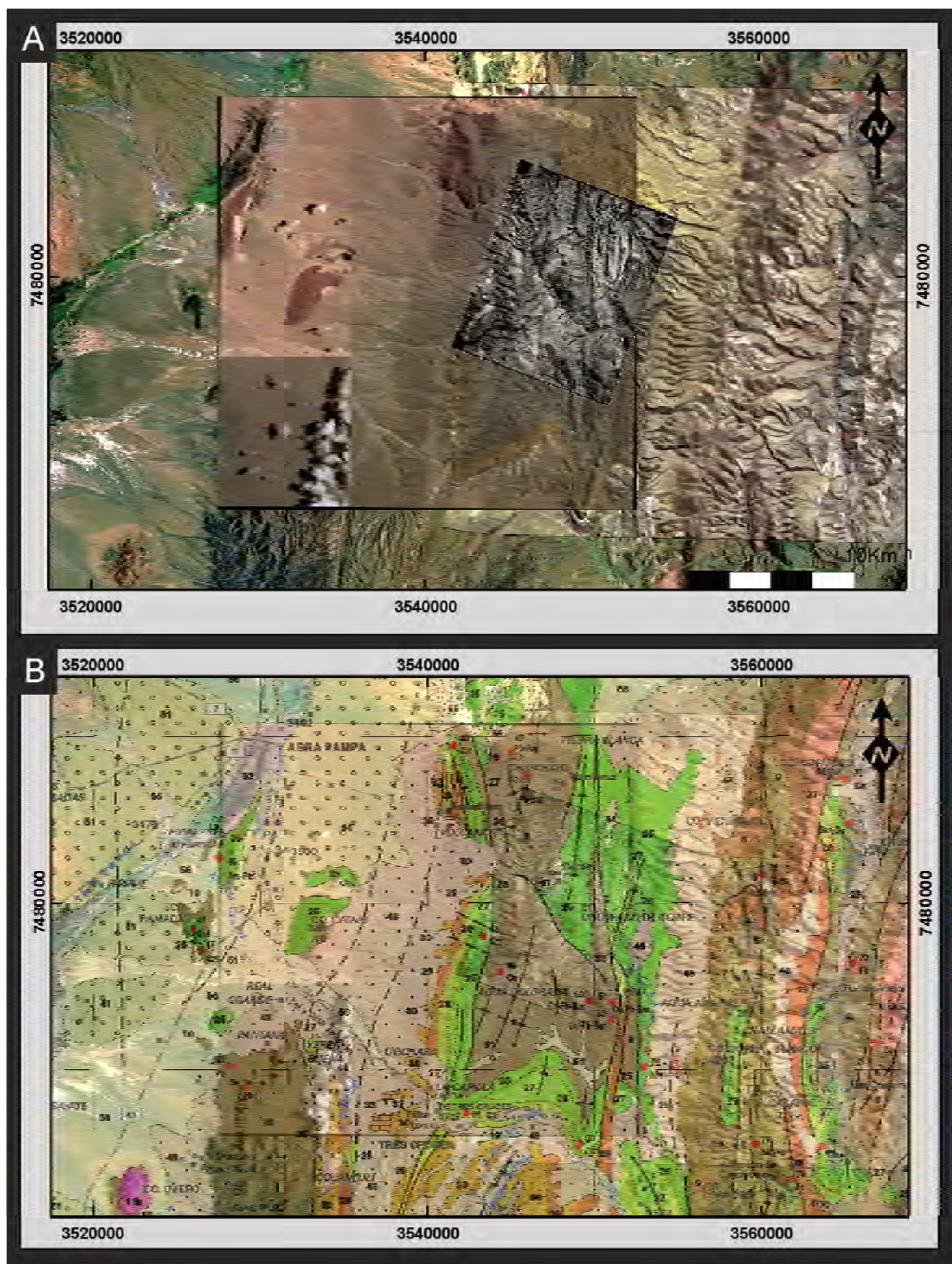

Fig. 2-1. A. superposición de las imágenes utilizadas para este estudio, desde el fondo hacia arriba, Landsat 7TM, Aster, Quikbird, Fotografía aérea. B. Idem A, con superposición de la carta geológica al 250.00 (Rubiolo, 2003). 
Para las tareas de campo se contó en el terreno con una impresión en tamaño A0 de la imagen Aster georreferenciada y con una grilla de coordenadas, que se utilizó para encuadrar las observaciones en un marco regional y para las tareas de detalle se contó con un mosaico de impresiones en tamaño A4, sobre los que se volcaron los puntos relevados en el campo. Para la ubicación y posicionamiento de los puntos se utilizaron GPS Garmin e-trex y Garmin Leyend.

La totalidad de la información representada en este estudio fue representada en coordenadas Gauss-Krügger (GK) Faja 3 con DATUM Campo Inchauspe, debido a que mayoritariamente la información previa se encontraba representada bajo este sistema de referencia.

\section{Mapeo geológico - mineralizaciones}

Sobre la base de las imágenes obtenidas previamente se elaboró una cartografía geológica a escala 1:20.000 y se seleccionaron tres sectores de interés (Bola Blanca, Purísima-Rumicruz, San Agustín), que fueron mapeados a escala 1:2.500 (Fig. 2-2). Cada punto volcado en el mapa base tuvo su correlato con sus coordenadas, altura y observaciones geológicas en una libreta de campo. Los relevamientos de datos estructurales fueron realizados con Brújula tipo Brunton para determinar el rumbo del buzamiento y la inclinación de las capas, y graficados en estereogramas mediante el software GEOrient 9.2. Para el mapeo de las mineralizaciones se discriminaron las estructuras de acuerdo al tipo (veta, vetilla, stockwork), textura y composición (sulfuros, cuarzo, baritina). El resultado de las labores cartográficas fue la elaboración de un mapa geológico regional a escala 1:100.000, un mapa del área de trabajo a escala 1:20.000 y tres mapas de detalle a escala 1:2.500. Finalmente toda la información fue condensada en un Sistema de Información Geográfico (SIG) mediante el software ArcMap 9.0, 9.1 y 9.2.

\section{Muestreo geológico-minero}

En el muestreo litológico se consideró la representación de los distintos tipos de rocas y la alteración hidrotermal en las proximidades de las vetas. Las muestras fueron tomadas con piqueta o maza. En algunos casos resultó significativo preservar las direcciones de los elementos estructurales de las muestras por lo tanto se procedió a la toma de muestras orientadas. 
El muestreo de la mineralización se tomó, cuando fue posible, sobre la veta. Las muestras fueron extraídas como "chips" con piqueta. Sin embargo, debido al grado de explotación de las vetas, las deterioradas condiciones de acceso y en el interior de las galerías, gran parte de las muestras para los estudios geoquímicos, mineralógicos e isotópicos fueron extraídos de las escombreras ubicadas en las entradas de las labores. Algunas de las muestras calcográficas analizadas de la veta Purísima fueron generosamente otorgadas por la Dra. Milka de Brodtkorb.

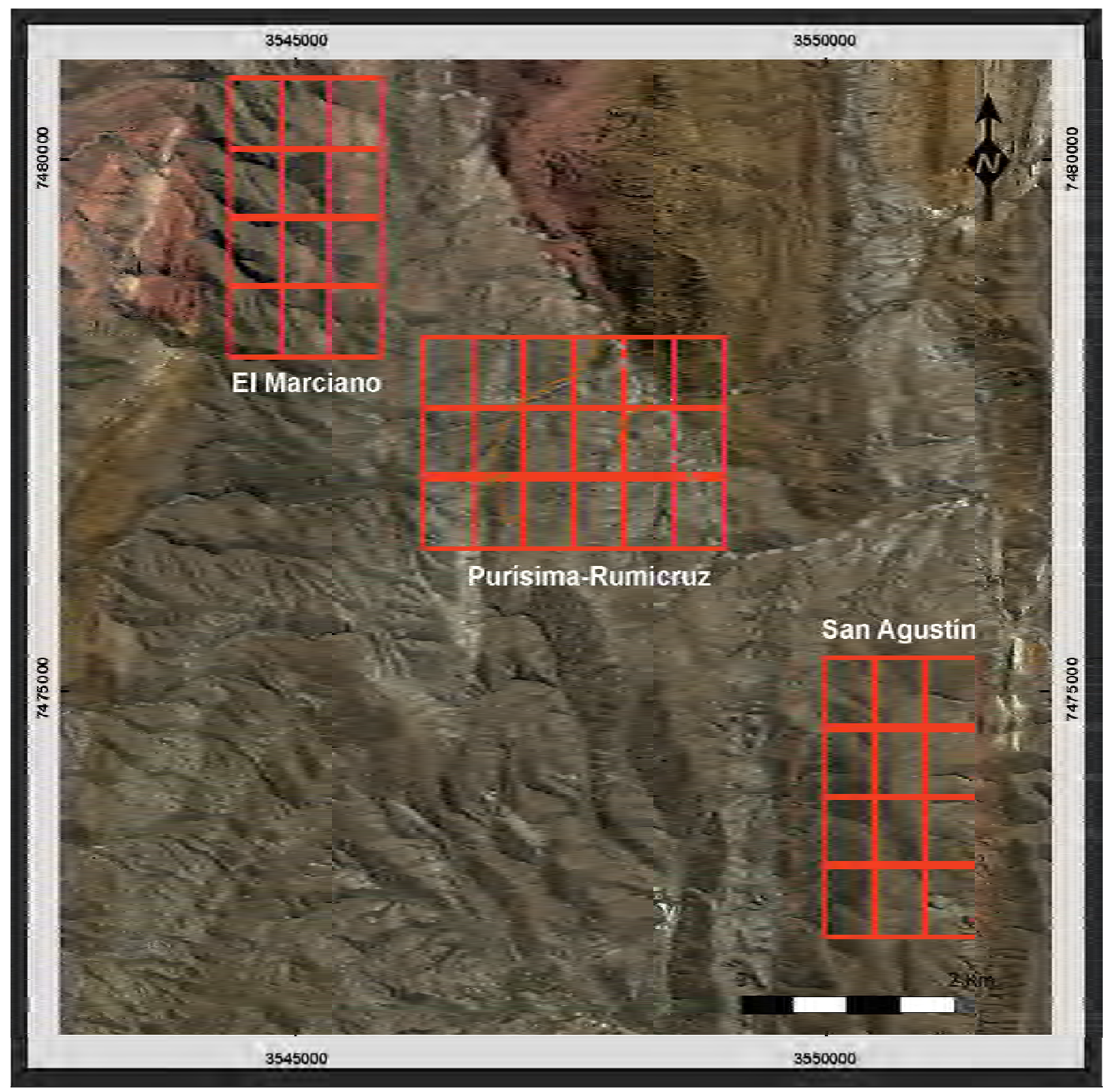

Fig. 2-2. Grilla para impresión en hojas A4 a escala 1:2.500 utilizadas para el mapeo de detalle geológico y de mineralizaciones.

\section{Perfiles sedimentológicos}

La ubicación de los perfiles sedimentológicos surgió del reconocimiento de los mejores tramos en cuanto a la calidad de exposición de los afloramientos. Se puso en 
consideración además, factores como la facilidad de acceso, bajo grado de deformación y continuidad vertical del perfil. Se levantó un total de $600 \mathrm{~m}$ distribuidos en 5 columnas sedimentológicas a escala 1:200 y los niveles de detalles fueron relevados a escala 1:20. Las mediciones fueron efectuadas mediante cinta métrica de 3 y $5 \mathrm{~m}$ y con el báculo de Jacob. La posición inicial y final de los perfiles fue acotada mediante puntos GPS. Durante estos levantamientos se consideraron los parámetros texturales, de estructuras sedimentológicas primarias y secundarias, contenido fosilífero, morfología de los cuerpos y superficies limitantes.

\section{Relevamiento geoeléctrico}

El diseño y ubicación de los perfiles donde se levantaron los datos geofísicos se realizó sobre el plano geológico-minero del sector Purísima-Rumicruz. Para la orientación de los perfiles geoeléctricos se priorizó que su dirección fuera perpendicular a la orientación promedio de las vetas reconocidas de cada sector (Fig. 2-3). La longitud de las líneas fue variable, mayoritariamente con un largo de 500m y una equidistancia de 200m para el sector Purísima-Rumicruz y El Brechón y 150m para el sector La Nueva, comprendiendo de esta forma un total de $7300 \mathrm{~m}$ lineales de datos geoeléctricos.

Los puntos de inicio y fin de cada perfil se determinaron mediante GPS (Garmin eTrex y Garmin eTrex Legend). Para la identificación de las líneas en el campo se colocaron jalones alineados de principio a fin. La topografía de cada uno de los perfiles se levantó con un clinómetro de mano (nivel de Abney), tomando mediciones sucesivas cada $25 \mathrm{~m}$. El levantamiento de las propiedades eléctricas del terreno se ejecutó según un arreglo multielectródico lineal para registrar datos en la modalidad dipolo-dipolo.

El instrumento utilizado fue un receptor IPR-12 Time Domain IP/Resistivity Receiver y la energización se realizó con una fuente IPC-9/200W, ambos construidos por la empresa Scintrex. La fuente genera una señal de corriente continua conmutada en ciclos de duración seleccionable. Esta característica permite evitar las compensaciones de potencial espontáneo, ya que se efectúan en forma estadística.

La resistividad aparente fue calculada según la expresión:

$$
\rho_{a p}=K \frac{\Delta V}{I}
$$


donde $\mathrm{K}$ es la constante geométrica del dispositivo utilizado. Los valores se expresan en ohm/m.

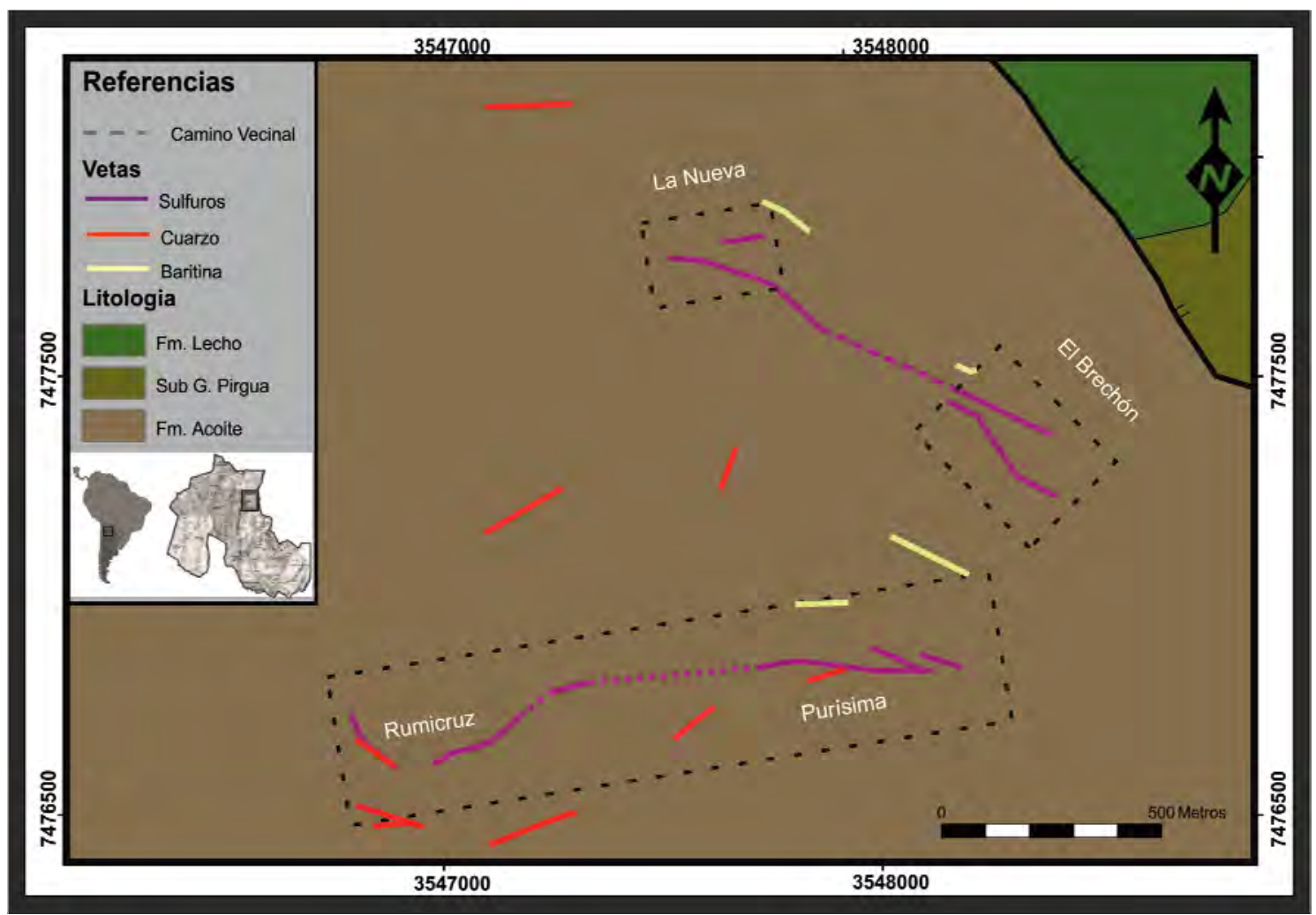

Figura 2-3. Mapa de ubicación de las áreas relevadas mediante métodos geoeléctricos. Vetas del distrito discriminadas de acuerdo a su composición dominante.

La cargabilidad aparente es calculada según la expresión:

$$
M=\frac{V_{s} * 1000}{V_{p}} \text { donde } V_{s}=\frac{\int_{t_{1}}^{t_{2}} V_{s} d t}{t_{r}}
$$

Donde:

$\mathrm{t}_{1}=$ tiempo de inicio de la ventana de medición

$\mathrm{t}_{2}=$ tiempo de fin de la ventana de medición

$\mathrm{t}_{\mathrm{r}}=$ intervalo de medición $\left(\mathrm{t}_{2}-\mathrm{t}_{1}\right)$

$V_{p}=$ tensión durante la emisión

$\mathrm{V}_{\mathrm{s}}=$ tensión medida durante el período de integración.

Los valores quedan expresados en $\mathrm{mV} / \mathrm{V}$. 
Existen diversos métodos de relevamiento geoeléctrico que dependen principalmente de la configuración espacial de los electrodos. En el relevamiento realizado en este trabajo se utilizó el método dipolo-dipolo con un espaciado "a" entre electrodos de 25m (Fig. 2-4), y para cada estación se realizaron medidas para valores de $n=1$ hasta $n=8$, siendo $n$ los distintos niveles, en profundidad, de asignación de datos. Los ciclos de duración utilizados fueron de 2 segundos.

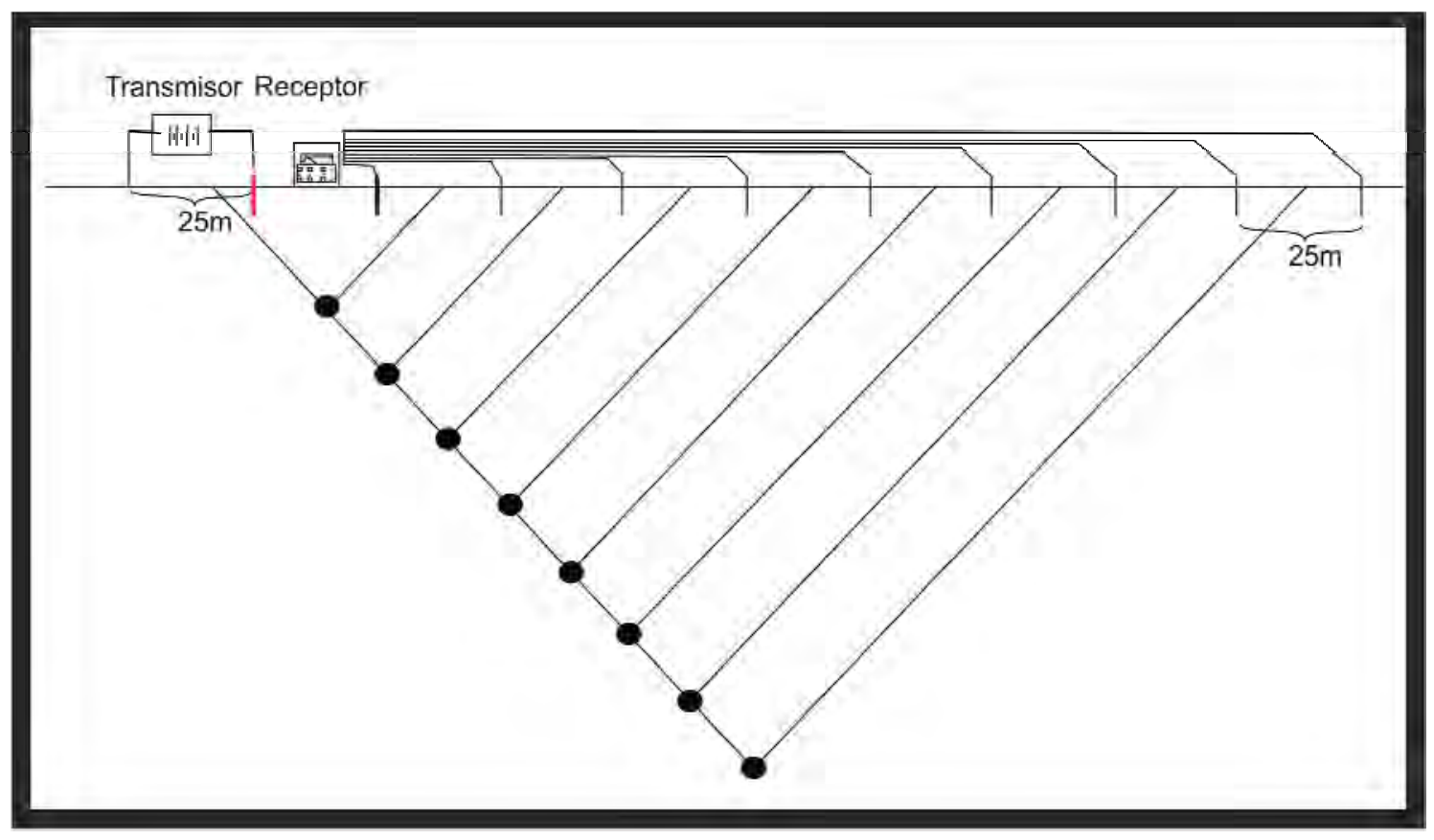

Figura 2-4. Configuración electrónica según el arreglo dipolo-dipolo.

Los datos de cargabilidad y resistividad aparentes se procesaron utilizando el software Res2dInv. La inversión de los datos fue a partir del método convencional Gauss-Newton (Loke y Dahlin 2002) El resultado del proceso es un modelo de cargabilidad y de resistividad verdadera. El error se expresa como RMS (error medio cuadrático), y se obtuvo un ajuste con un valor menor al10\%.

Los modelos obtenidos de cargabilidad y resistividad verdadera de cada sección fueron graficados en cada perfil. También se elaboraron dos plantas a $57 \mathrm{~m}$ por debajo de la superficie para cada zona, generando mapas de isocargabilidad y de isoresistividad.

Los perfiles geoeléctricos obtenidos fueron georeferenciados con el software Google Sketch Up 6.0, posteriormente se interpretaron y editaron las anomalías en 3D y se confeccionó un modelado tridimensional de las anomalías de IP superiores a $50 \mathrm{Mv} / \mathrm{v}$. 


\section{Análisis petrográfico y mineralógico de la mena, ganga y roca de caja}

La caracterización petrográfica y calcográfica fue realizada en el Laboratorio de Petrografía del Instituto de Recursos Minerales (INREMI). Se estudiaron 40 cortes petrográficos y similar cantidad de pulidos calcográficos. Fueron estudiadas seis muestras de la fracción pelítica de la roca de caja bajo análisis de difracción de rayos $X$, con muestra normal, glicolada y calcinada, para efectuar determinaciones mineralógicas de este tipo litológico. Estos estudios fueron realizados en el Centro de Investigaciones Geológicas, CONICET-UNLP. Asimismo, se llevaron a cabo una decena de análisis de difracción de rayos $X$ en muestras de alteración de la mineralización, en el Laboratorio de rayos $X$ del Museo de Ciencias Naturales-FCNyMUNLP.

\section{Geoquímica}

Se realizaron 39 análisis geoquímicos provenientes de muestras de mineralización, de los mismos 19 fueron ejecutados en los laboratorios de ALS CHEMEX, bajo la rutina ICP ME-41 donde la digestión de la muestra es bajo agua regia nítrica y analizados bajo ICP (Induced Coupled Plasma) - AES (Atomic Emission Spectroscopy), el oro fue analizado bajo la rutina Au-AA23 con ensayo de fusión a fuego y AAS (Atomic Absorption Spectroscopy). Los 20 restantes fueron analizados en el laboratorio Alex Stewart, bajo la rutina ICP-MA-39, con la disolución multiácidos y analizado bajo ICP. La roca de caja fue analizada mediante tres muestras en los laboratorios de Alex Stewart, con la misma rutina que la mineralización. Asimismo, tres muestras de este material fue analizado mediante un analizador portátil de fluorescencia de rayos $\mathrm{X}$ modelos Niton $X L 2^{\circledR}$.

\section{Microsonda electrónica}

Los estudios de microsonda electrónica han sido realizados en Laboratorio de Microsonda, Departamento de Química, Universidad Federal de Minas Gerais (UFMGCDTN). La determinación química puntual de granos minerales se realizó con el 
equipo JEOL JA, modelo 8900RL WD/ED. Las condiciones operacionales utilizadas fueron $15 \mathrm{Kv}$ (voltaje) y 50nA (corriente) con un tiempo de 40 s por cada uno de los elementos analizados. Las condiciones analíticas las siguientes: Ag (La, PETJ); As

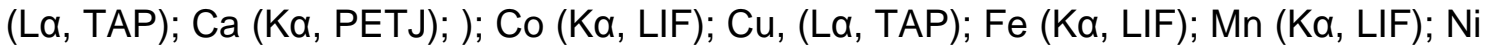
(La, TAP); Pb (Ma, PETJ); S (Ka, PETJ); Sb (La, PETJ); Zn, (Ka, LIF).

\section{Estudios de inclusiones fluidas}

Los estudios de inclusiones fluidas se llevaron a cabo en el Laboratorio de Inclusiones Fluidas y Metalogénesis (LIFM) del Centro de Desenvolvimento da Tecnología Nuclear (CDTN-UFMG), Belo Horizonte, Brasil. Para la caracterización microscópica y microtermometría de las inclusiones fluidas, se utilizó una platina de calentamiento/enfriamiento USGS adaptado a un microscopio Leica DMR-XP y una platina de calentamiento/enfriamiento ChaixMeca $-180 / 600^{\circ} \mathrm{C}$ montada sobre un microscopio Leitz, modelo Ortholux. Para la captura de imágenes se contó con una cámara de alta resolución Sony ExwaveHad blanco y negro con muy alta sensibilidad en infrarrojo cercano, con un máximo de 1,2 $\mu \mathrm{m}$. En los estudios microtermométricos, las temperaturas de descongelamiento $\left(T_{f}\right)$ fueron medidas en primer lugar, luego la temperatura del eutéctico $\left(T_{e}\right)$, la temperatura final del derretimiento del hielo $\left(T_{\text {mice }}\right)$ y finalmente la temperatura de homogenización $\left(T_{h}\right)$. Los calentamientos a partir del congelamiento total de la fase sólida fueron realizados a una velocidad de $5^{\circ} \mathrm{C} / \mathrm{min}$. La primer temperatura de fusión de sólidos $\left(T_{e}\right)$ obtenida después del congelamiento, corresponde al punto eutéctico del medio sal-agua, La salinidad fue obtenida a partir de los valores de $\mathrm{T}_{\text {mice }}$, los valores fueron calculados con el programa FlinCor según las ecuaciones de Brown (1989) y mediante las ecuaciones de Bodnar (1993) y Bodnar \& Vityk (1994).

\section{Isótopos inestables}

Los análisis isotópicos de $\mathrm{Pb}$ fueron realizados en el Centro de Pesquisas Geocronológicas del Instituto de Geociências de la Universidad de San Pablo, Brasil. Los procedimientos para el tratamiento de las muestras incluyeron el lavado con $\mathrm{HCl}+\mathrm{HNO}_{3}$ y la disolución con $\mathrm{HCl}$ en una bomba tipo Parr. El Pb fue separado utilizando $\mathrm{HCl}$ y $\mathrm{HBr}$ en una columna AG1-X8 (200-400\#). Los procedimientos adoptados para la purificación del $\mathrm{Pb}$ fueron aquellos descriptos por Babinski et al. (1999). Las relaciones isotópicas de $\mathrm{Pb}$ fueron corregidos a los valores del estándar 
NSB981 de 1,0024 para ${ }^{206} \mathrm{~Pb} /{ }^{204} \mathrm{~Pb}, 1,0038$ para ${ }^{207} \mathrm{~Pb} /{ }^{204} \mathrm{~Pb}$, y 1,0051 para ${ }^{208} \mathrm{~Pb} /{ }^{204} \mathrm{~Pb}$. Los errores analíticos de las relaciones isotópicas fueron 0,005 a 0,013\%, 0,005 a 0,015\% y 0,007 a 0,017\%, los análisis isotópicos de Pb fueron realizados en un espectrómetro de masas multicolector VG 354 Micromass. Los datos de isótopos inestables fueron analizados y graficados con el macro Isoplot 4.0 y software Excel 2007.

\section{Isótopos estables}

Los análisis de isótopos estables de oxígeno $\left({ }^{18} \mathrm{O} /{ }^{16} \mathrm{O}\right)$ y de azufre $\left(\delta^{34} \mathrm{~S}\right)$ han sido realizados en el Laboratorio de Isótopos Estables de la Universidad de Salamanca, España. La extracción del oxígeno y carga de la muestra se efectuaron siguiendo los principios de Clayton y Mayeda (1963), y Friedman y Gleason (1973). Para las determinaciones analíticas fue utilizado un espectrómetro de masas Micromass SIRAII Los resultados que se obtuvieron se dan en la notación delta habitual referidos a SMOW. El valor obtenido para el estándar NBS-28 en el laboratorio citado es $\delta^{18} \mathrm{O}$ SMOW $=+9,6 \%$.

La determinación de las relaciones isotópicas $13 \mathrm{C} / 12 \mathrm{C}$ en carbonatos se lleva a cabo por medios espectométricos sobre $\mathrm{CO} 2$ en espectómetros de doble entrada (tipo SIRA II). Dado que es un espectómetro de fuente gaseosa, se hace reaccionar a las muestras con H3PO4 y se recoge $\mathrm{CO} 2$, proceso llevado a cabo en una línea de alto vacio. Es necesario eliminar los posibles componentes no carbonatados que pudiera tener la muestra colocándolas en el plasma asher EMITEC K1050X, durante 30 minutos. Las muestras fueron preparadas moliéndolas hasta lograr un polvo homogéneo. Bajo condiciones de vacío, se las hizo reaccionar con H3P04, durante 24 hs a $25^{\circ} \mathrm{C}$ de temperatura. El CO2 obtenido fue posteriormente separado y purificado en una línea de vacío estándar, acondicionada con una serie de trampas refrigeradas a diferentes temperaturas. La generación y abundancia del CO2 puro se mide en el sensor Baratrón por medios manométricos, recogiéndose en una probeta para su análisis isotópico por espectrometría de masas. Los resultados se refieren en PDB.

La técnica empleada para el azufre es similar a la descripta por Robinson y Kusakabe (1975). Se utilizaron entre 5 y $10 \mathrm{mg}$ de sulfuro por muestra. Las relaciones ${ }^{34} \mathrm{~S} /{ }^{32} \mathrm{~S}$ fueron determinadas en un espectrómetro de masas Micromass SIRA-II. La precisión obtenida es mayor a $\pm 0,27 \%$, basada en análisis repetidos de estándares internos e internacionales (incluyendo la extracción), así como en el análisis por 
duplicado de algunas de las muestras. Los resultados se dan referidos a CDT. El valor obtenido para el estándar NBS-123 en el laboratorio citado es $\delta^{34} \mathrm{~S} C D T=17,0 \%$. 


\section{CAPÍTULO III}

ANÁLISIS SEDIMENTOLÓGICO Y ESTRATIGRÁFICO DE LA FORMACIÓN ACOITE EN EL SECTOR SUR DEL CERRO COLORADO DE COBRE 


\section{ANÁLISIS SEDIMENTOLÓGICO DE LOS DEPÓSITOS DE LA}

\section{FORMACION ACOITE}

\section{Introducción}

Las vetas que conforman el distrito polimetálico Purísima-Rumicruz se encuentran alojadas en las rocas sedimentarias de la Formación Acoite. Las rocas de caja de los yacimientos hidrotermales, lejos de tomar un rol pasivo pueden estar relacionadas directa o indirectamente con la metalogénesis del depósito. En este sentido, pueden estar vinculadas como fuente de los metales y/o de los fluidos hidrotermales, también puede propiciar o aumentar anomalías térmicas que coadyuven al establecimiento de la migración de estos fluidos (i.e. rocas volcánicas sincrónicas con los depósitos minerales). Además, las condiciones de porosidad y permeabilidad de la roca de caja operan sobre el modo en que se transportan estas soluciones por la corteza. Finalmente, la roca de caja interactúa activamente con los fluidos hidrotermales, produciendo cambios físico-químicos en el fluido que pueden propiciar la desestabilización del trasporte de los metales y producir la precipitación de los mismos en concentraciones económicas.

De esta forma, la comprensión de los aspectos petrofísicos, mineralógicos, ambientales y geoquímicos de las rocas de la Formación Acoite, permitió robustecer las interpretaciones metalogenéticas del yacimiento estudiado. Esta Formación aloja además un gran número de depósitos en el NOA y su estudio permite dimensionar su importancia como metalotecto.

\section{Antecedentes.}

Los depósitos del Ordovícico temprano en la cuenca del Noroeste Argentino (NOA), se encuentran principalmente en las provincias geológicas de Puna, Cordillera Oriental y Sierras Subandinas. La Formación Acoite definida por Harrington y Leanza (1957) fue incorporada por Turner (1960) junto con la Formación Santa Rosita al Grupo Santa Victoria.

Turner (1960) define la sección tipo en la Quebrada del Río Santa Victoria donde el espesor máximo registrado es de 2240m (Rubiolo, 2003). Corresponde a la sedimentación ocurrida durante la supersecuencia Acoite (Astini 2003), y se interpreta 
como los depósitos de la mayor transgresión en la cuenca durante el Floiano basal (Arenigiano) (Moya 2008). El ciclo culmina con la finalización del vulcanismo en la Puna (Moya 2008), o con un límite de secuencia y una superficie de exposición subaérea sobre el que se depositan sedimentos fluviales de la Aloformación Sepulturas, interpretados como pertenecientes al cortejo de mar bajo (Astini, 2003).

En la Cordillera Oriental se configuró una plataforma, caracterizada por depósitos de tormentas, mientras que en la región de la Puna la sedimentación está representada por turbiditas con aporte volcaniclástico, vinculada al desarrollo de un arco volcánico en el margen oeste de Gondwana (Coira et al., 2009a; Coira et al., 2009b). Los límites de estas provincias corresponden a rasgos morfoestructurales producidos durante la orogenia andina, por lo tanto estos límites no son válidos durante el paleozoico (Astini, 2003). La transición de un ambiente marino somero en la Cordillera Oriental a un ambiente profundo en la Puna ha sido interpretada como una rampa con bajo gradiente (Bahlburg, 1990) (Fig. 3-1).

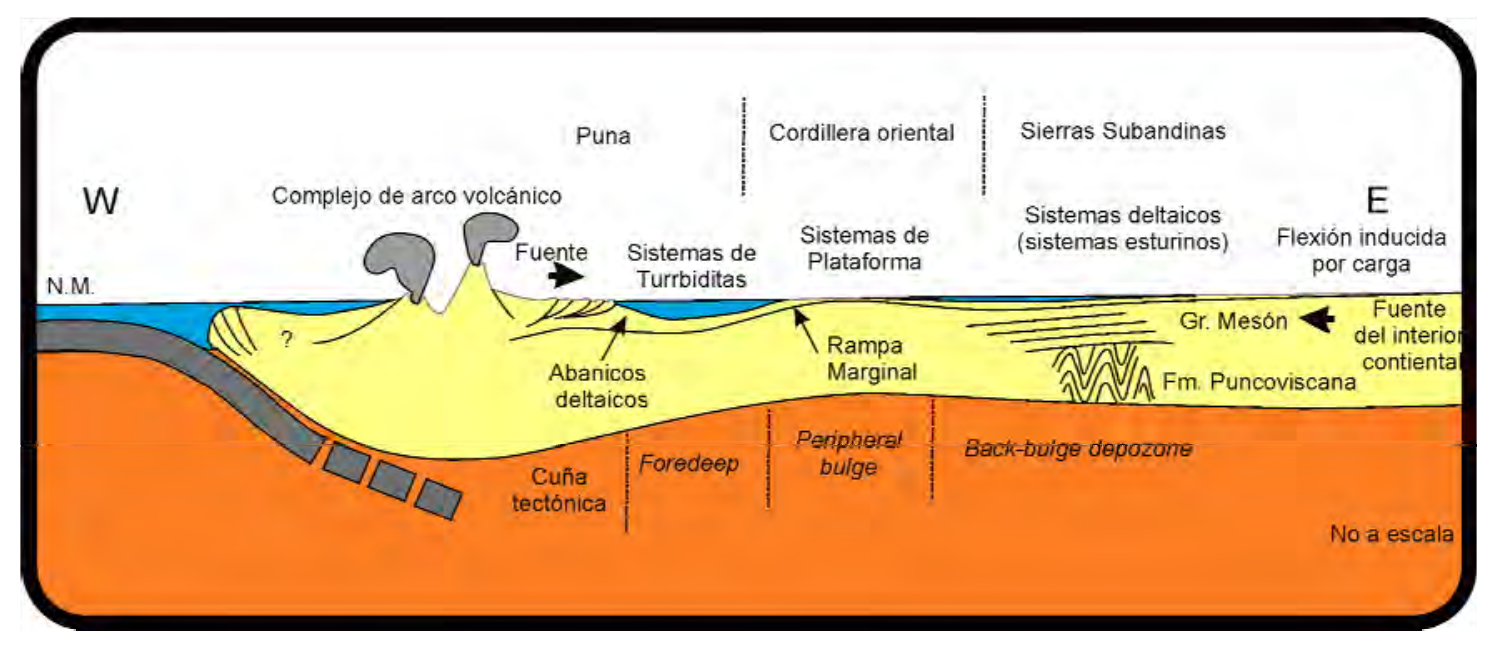

Fig. 3-1. Perfil esquemático en dirección W-E exhibiendo el contexto tectónico y de cuencas desarrolladas durante el Ordovícico. Modificado de Astini (2003).

Al sur del área de estudio, en el sector de Los Colorados, Astini y Waisfeld (1993) y Astini et al. (2004), interpretaron los depósitos de la Formación Acoite y aloforrmación Sepulturas como una plataforma que se someriza y culmina con una progradación deltaica (Fig. 3-2). La plataforma habría estado influenciada por procesos de tormenta y mareales, estos últimos fundamentalmente vinculados a un delta de tipo destructivo dominado por procesos de tormentas con desarrollo de lóbulos y barras de desembocadura. Astini et al. (2004), reconocieron asociaciones de prodelta, frente deltaico y shoreface (Formación Acoite) y asociaciones de canales interdistributarios 
representado por los depósitos de la aloformación Sepulturas. En la región de Azul Pampa la Formación Acoite se vinculó a la sedimentación en una plataforma marina con bajo gradiente afectada por olas de buen tiempo y olas de tormentas, y con depósitos subordinados de upper-offshore (Such et al., 2007).

Los depósitos correlacionables con la Formación Acoite en Cordillera Oriental, hacia el norte de la zona de estudio, se interpretan como depósitos tipo turbiditas e incluidos en la zona de transición de la región de la Puna (Astini, 2003).

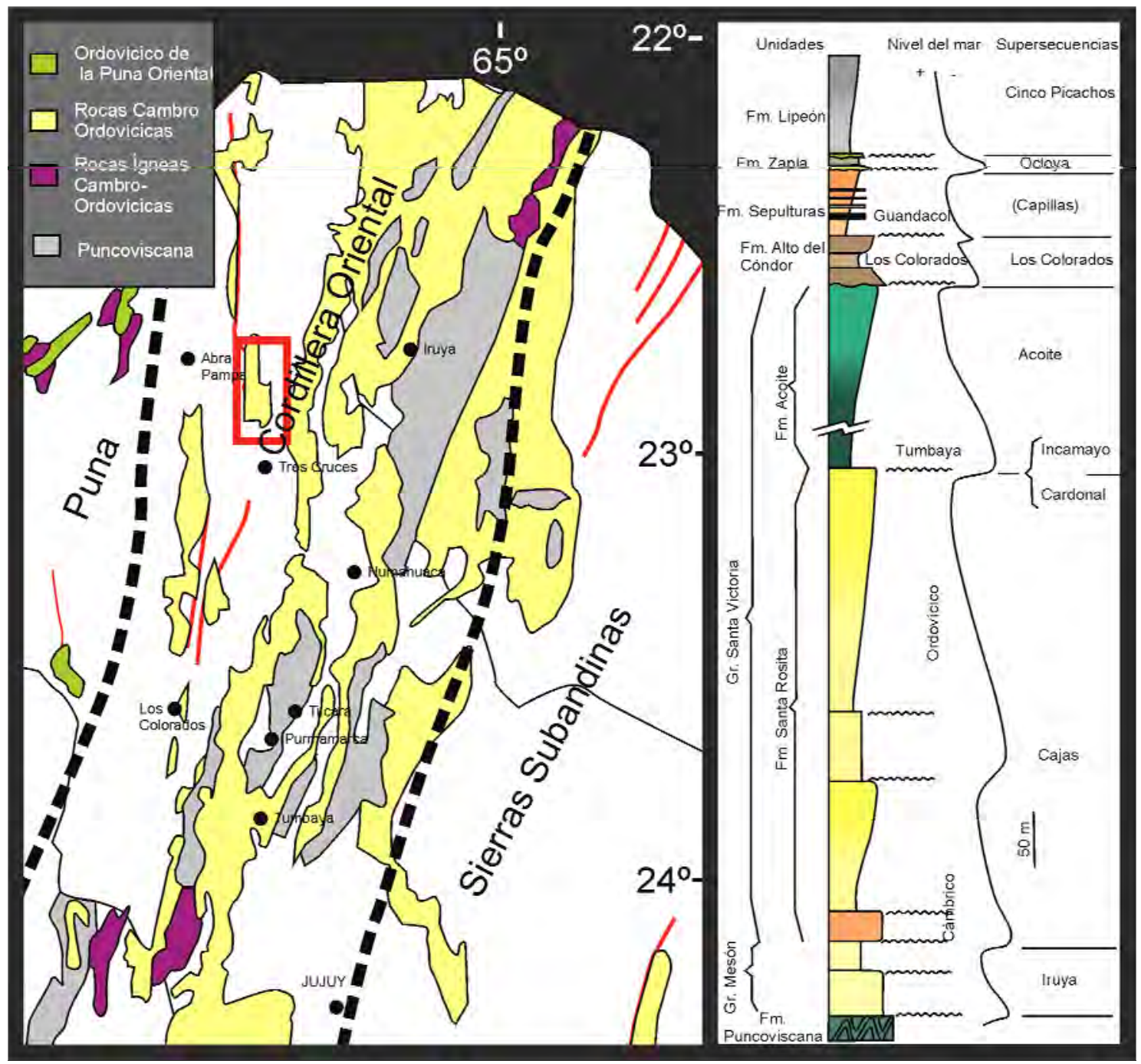

Fig. 3-2. A. Mapa de afloramiento de las unidades correspondientes al paleozoico inferior del NOA. Modificado de Astini, 2008. B. Perfil general de la sedimentación eopaleozoica y secuencias depositacionales. Modificado de Astini, 2003

\section{Análisis de las litofacies}

El modelo de facies como es comprendido hoy en día, involucra una síntesis de la información de los ambientes depositacionales actuales y antiguos en un esfuerzo por 
entender la naturaleza, escala, heterogeneidad y controles físicos de los procesos intervinientes en cada ambiente sedimentario (Walker, 2006).

A continuación se presentará la descripción e interpretación de las litofacies de la Formación Acoite en el sector sur del Cerro Colorado de Cobre (Fig. 3-3). Hasta el presente los estudios de detalle de esta unidad son escasos y los modelos sedimentarios propuestos presentan escasa continuidad lateral. Particularmente el área de estudio es tomada en cuenta en los análisis regionales y en trabajos a escala de cuenca, pero hasta el momento, no se han producido allí trabajos sedimentológicos de detalle.

El estudio estratigráfico y sedimentológico se realizó a partir del levantamiento de más de 600 metros de columnas estratigráficas de detalle, realizadas a escala 1:200 y 1:20 cuando fue necesario. Los parámetros utilizados para la descripción de las facies fueron la litología, las estructuras sedimentarias, las geometrías de los cuerpos y la naturaleza de las superficies limitantes entre ellos.

El análisis de facies permitió distinguir cuatro asociaciones de facies definidas por características texturales, composicionales, estructuras sedimentarias, geometría del depósito y superficies limitantes. Cada una de las asociaciones de facies definidas presenta las interpretaciones dinámicas del flujo que produjo su depositación.

\section{Asociación de Facies A:}

Esta asociación de facies domina en el tramo inferior de la secuencia aflorante en la zona de trabajo. Está compuesta por arcilitas de color gris oscuro a negro, presentan laminación paralela y un fuerte clivaje de plano axial que genera estructuras en lápiz. Son ocasionalmente masivas y es frecuente la presencia de concreciones subesféricas hasta 1 metro de diámetro (Fig. 3-4B y 3-4C) conformadas por material pelítico, que frecuentemente pueden contener cristales de pirita de hasta $0,5 \mathrm{~cm}$ en su interior. La geometría de estos cuerpos es tabular.

Se interpreta que el proceso dominante fue la decantación/floculación en un ambiente de muy baja energía. Esta facies contiene registro de graptofauna. La presencia de pirita framboidal, generada en condiciones anaeróbicas (Butler et al., 2000), con valores de Eh menores que 0 indica un ambiente depositacional reductor. La génesis de las concreciones está vinculada a procesos diagenéticos.

\section{Asociación de Facies B}


Esta asociación de facies se intercala como niveles decimétricos entre la asociación de facies A y está compuesta por couplets heterolíticos compuesto por láminas limolíticas de color gris oscuro a verde oscuro y pelitas negras de entre 1 y $3 \mathrm{~mm}$ de espesor con laminación paralela (Fig. 3-5).

Se interpreta a estas facies como resultado de decantación en un ambiente de muy baja a baja energía. La alternancia registrada en la granulométrica podría vincularse con eventuales contribuciones de material más grueso desde el área de aporte.

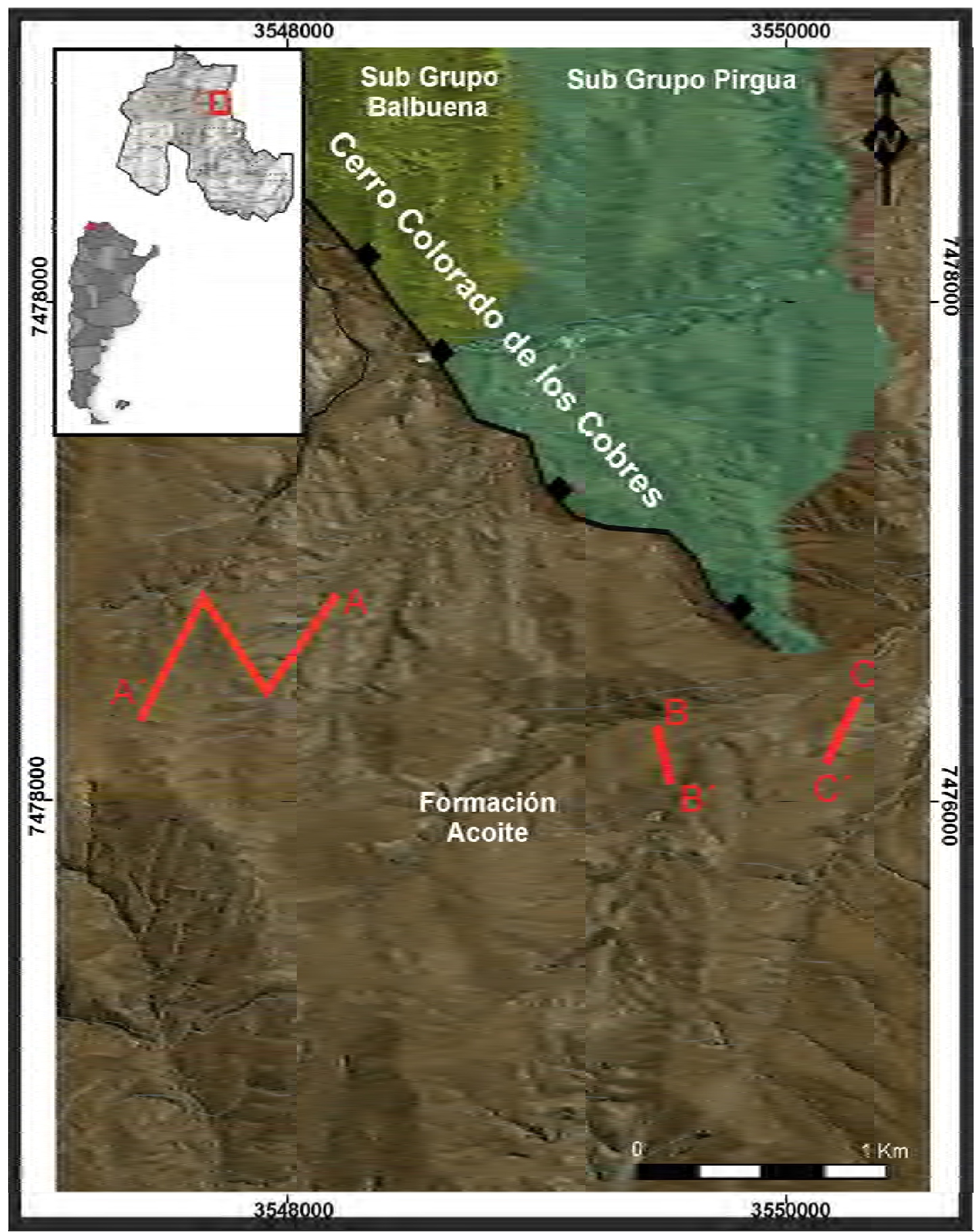

Fig. 3-3. Mapa del distrito Purísima Rumicruz indicando con línea de color rojo la traza del perfil levantado. 


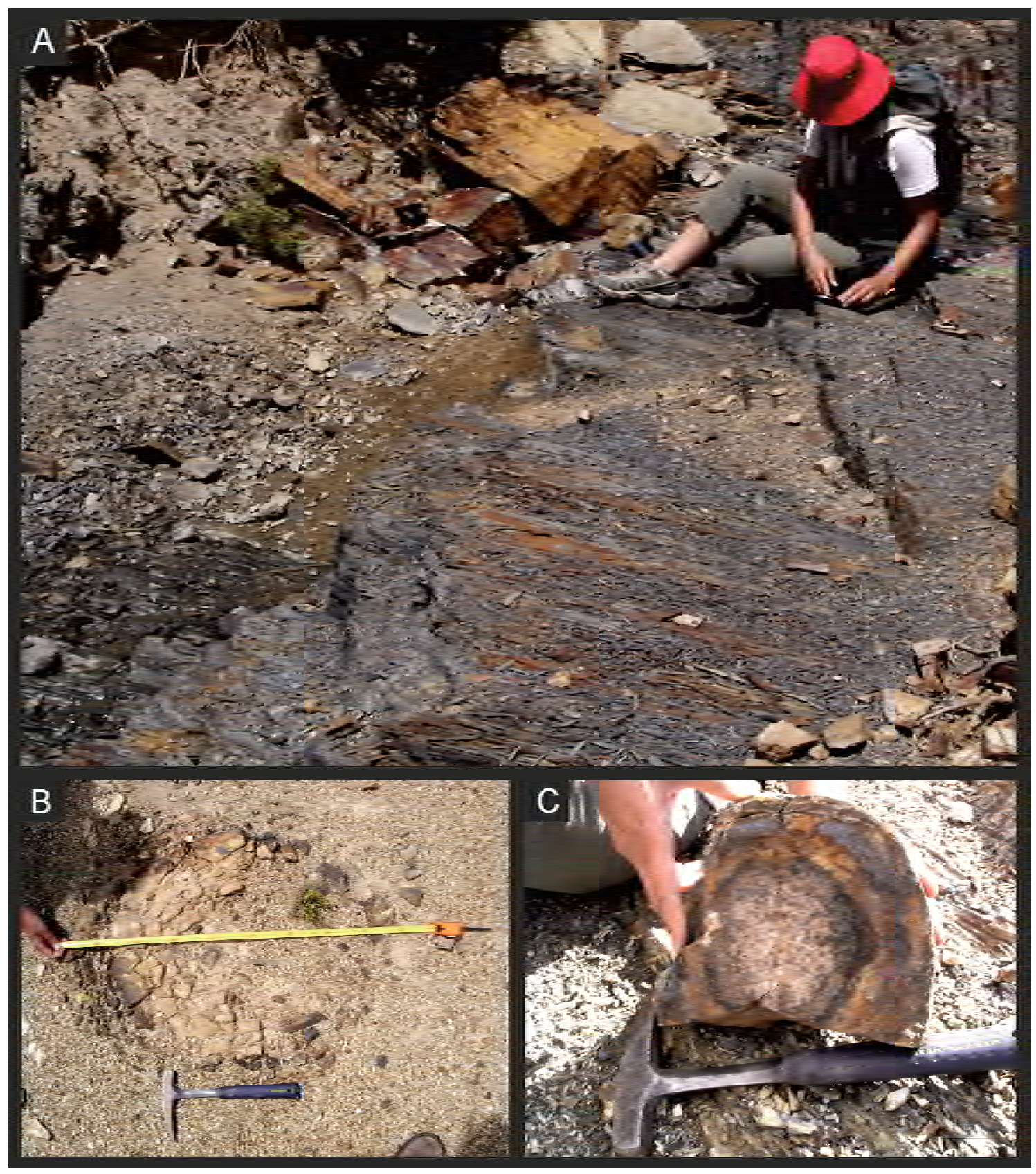

Fig. 3-4. Asociación de facies A. Foto superior, pelitas negras con fina laminación y con fuerte clivaje de plano axial que genera estructuras en lápiz. B y C: Concreciones de hasta $1 \mathrm{~m}$ de diámetro desarrolladas en la Formación Acoite.

\section{Asociación de Facies C}

Está caracterizada por limolitas con laminación paralela de color gris oscuro, donde se intercalan niveles de 1 a $5 \mathrm{~cm}$ de espesor de areniscas muy finas a finas con laminación paralela o entrecruzada de pequeña escala, conformando una estratificación mixta de tipo ondulosa a lenticular (Fig. 3-6).

Esta asociación de facies se interpreta como producto de procesos de decantación a tracción de facies finas en capa plana de bajo régimen representados por la fracción 
de granulometría limo. Las areniscas se interpretan como resultado de eventos de flujos tractivos en capa plana de alto régimen de flujo a migración de ondulas 2D.

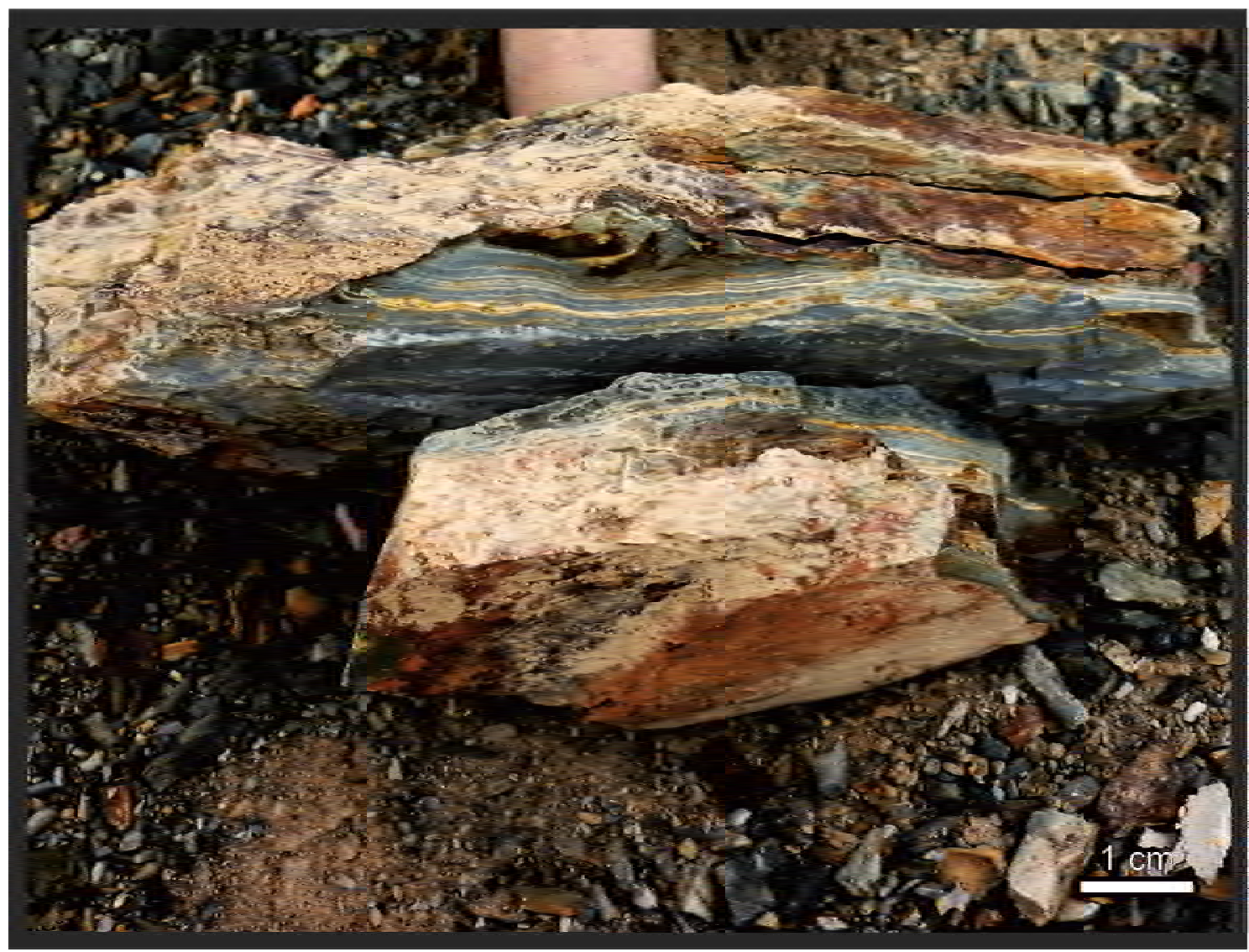

Fig. 3-5. Facies de pelitas laminadas, couplets de limolitas y arcilitas milimétricas.

\section{Asociación de Facies D}

Yacen como cuerpos tabulares por encima de la asociación de facies B ó C. Está caracterizada por capas tabulares de arenas muy finas a finas de hasta $50 \mathrm{~cm}$ de espesor. La base de los estratos es neta y plana con marcas subestratales erosivas tanto de objetos como surcos y canaletas (Fig. 3-7). Internamente las areniscas presentan laminación paralela plana a levemente ondulada, en general gradan transicionalmente a una facies de areniscas muy finas a finas caracterizadas internamente por laminación entrecruzada con escalonamiento subcrítico (Fig. 3-8A), ocasionalmente fueron reconocidas estructuras monticulares de alto ángulo y con longitudes de onda que raramente superaban 0,5 $\mathrm{m}$ y amplitudes de aproximadamente $5 \mathrm{~cm}$. El techo presenta óndulas asimétricas 3D de crestas continuas y sinuosas (Fig. 3-8B), interpretadas como microhummockys.

Se interpreta a estas facies como una secuencia con un flujo de velocidad decreciente producto de flujos unidireccionales o combinados (oscilatorios y 
unidireccionales) con dominio de flujos unidireccionales (Duke et al., 1991; Dumas et al., 2005; Dumas y Arnott, 2006).

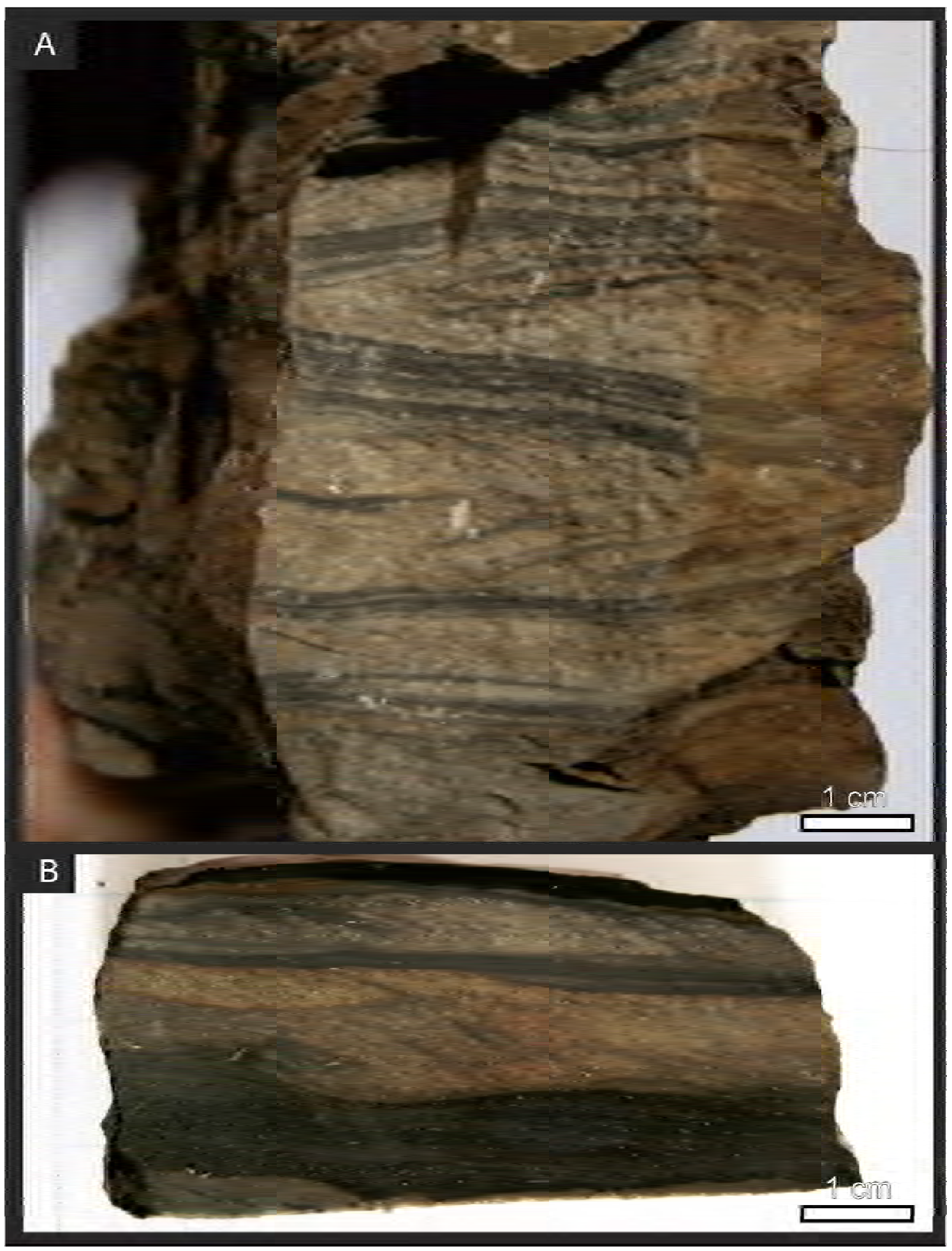

Fig. 3-6. Facies heterolíticas. A. Tipo flaser. B. Heterolítica ondulosa 


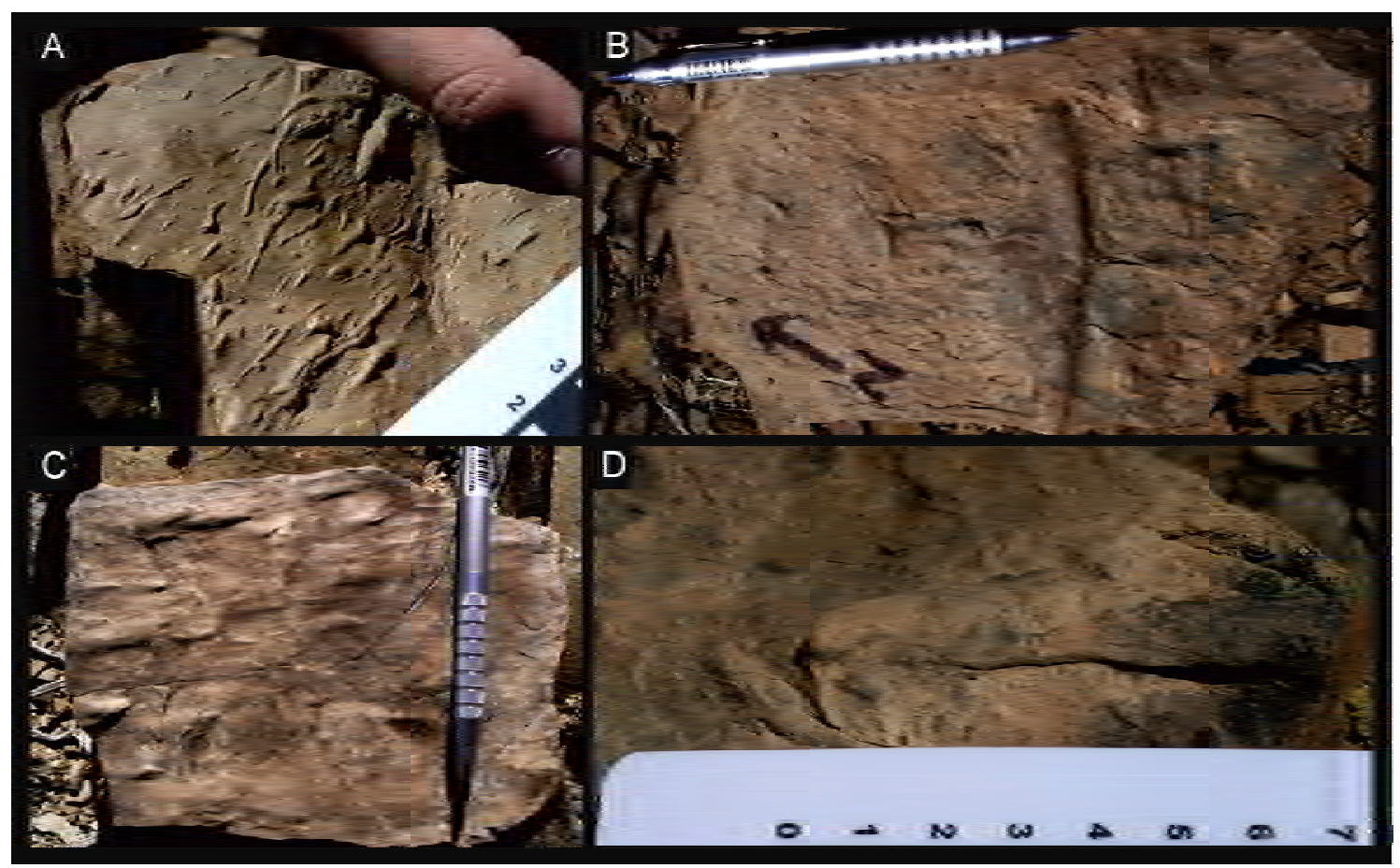

Fig. 3-7. Marcas subestratales de las capas de areniscas de la Formación Acoite. A. Marcas de punzamiento y roce, B. Calco de canaleta, C. Calco de de surco y D. Calco de canaleta. Regla en centímetros.

Los estudios experimentales demuestran que los campos de estabilidad de las formas de lecho en flujos combinados están influenciados tanto por la granulometría como por el período de oscilación de los flujos oscilatorios (Dumas et al., 2005; Dumas y Arnott, 2006) (Fig. 3-9). El campo correspondiente a la forma de lecho de la capa plana presenta una amplificación cuando se reduce el tamaño granulométrico. Las condiciones favorables para la formación de estructuras de tipo hummocky se producen cuando el periodo de oscilación de los flujos oscilatorios es mayor; este período es función de la longitud de onda de las olas, por lo tanto las estructuras tipo hummocky son proclives a desarrollarse en condiciones de olas de gran tamaño. 


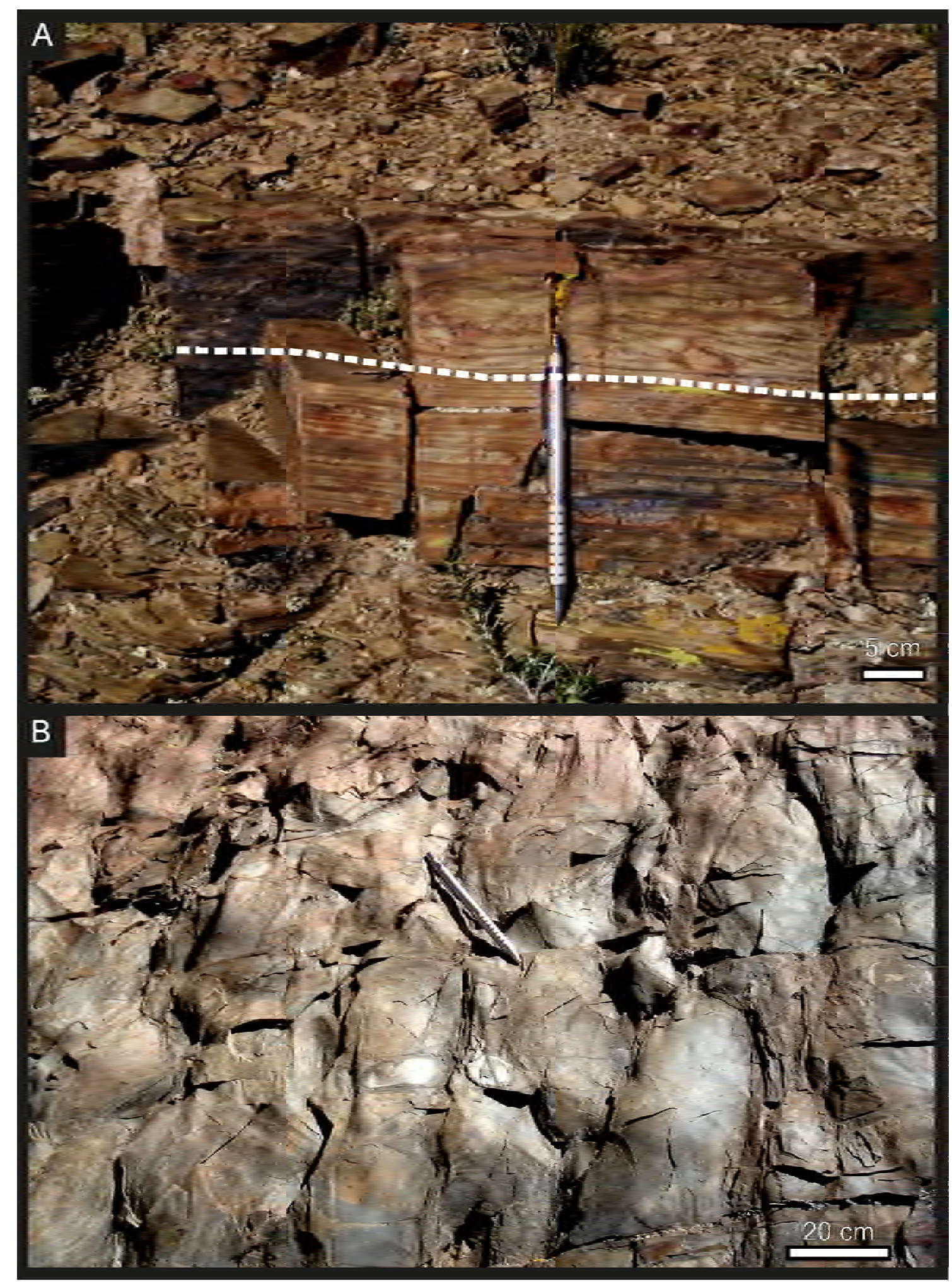

Fig. 3-8. A. Asociación de facies D. B. Techo de asociación de facies D con óndulas asimétricas de crestas sinuosas continuas (tipo 3D) 


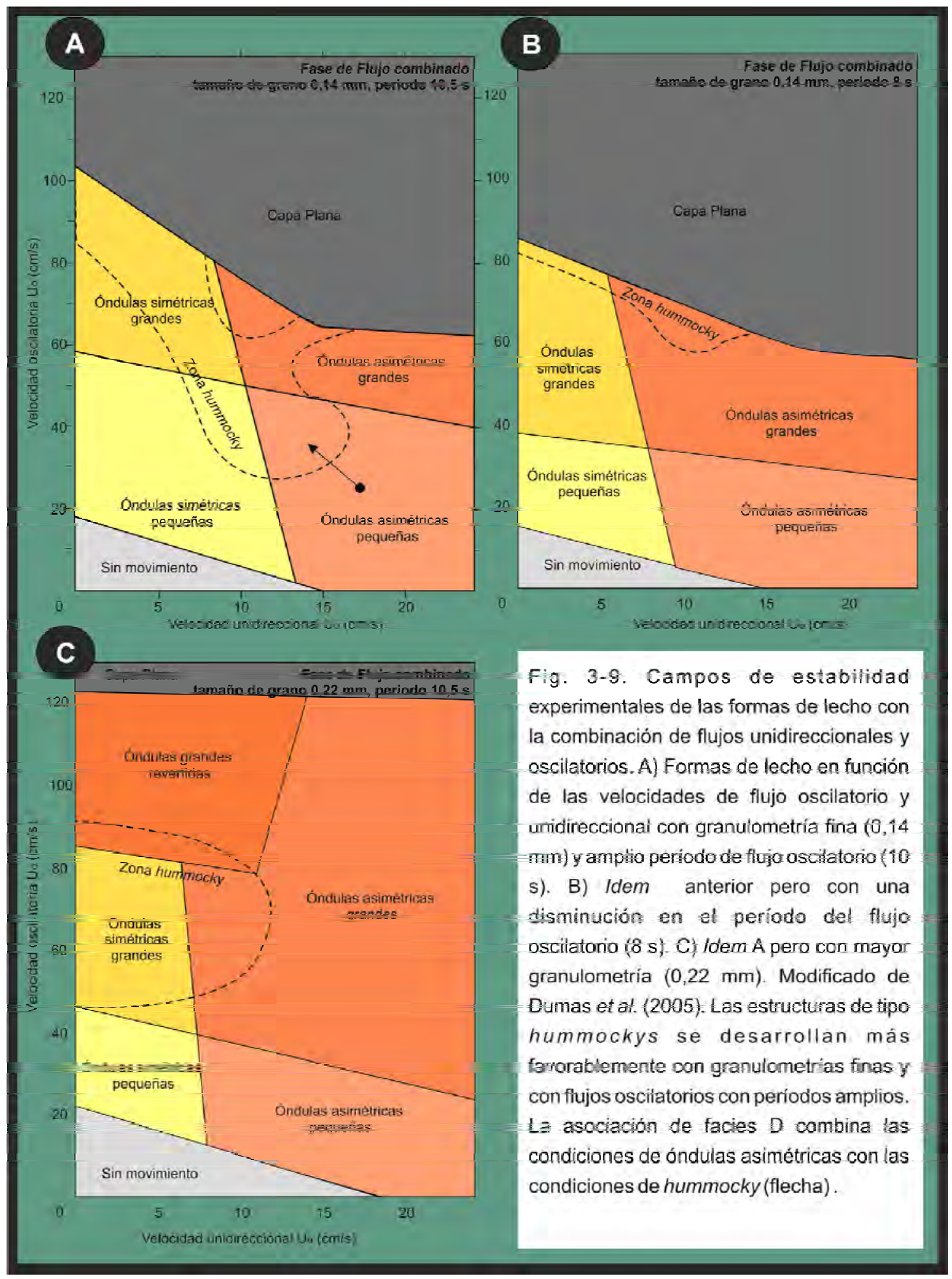

\section{ANÁLISIS PETROLÓGICO DE LA FORMACIÓN ACOITE.}

Se describirán independientemente las litologías de fracción pelítica y psamíticas. Las muestras de pelitas corresponden a las asociaciones $A$ y $B$, mientras que las psamitas corresponden a la D. 
Las psamitas son clasto sostén, composicionalmente están conformadas por una gran abundancia de cuarzo, con menores proporciones de plagioclasa, muscovita y biotita, acompañan pequeñas cantidades de anfíbol, clorita, circón y feldespato alcalino (Fig. 3-10).

El análisis de seis muestras de pelitas mediante difractograma de rayos $\mathrm{X}$, permitió la identificación de las especies minerales dominantes. Así, se identificó cuarzo y plagioclasa, acompañados por illita, caolinita y clorita. La illita, como puede observarse en la figura $3-11 B$, presenta un pico extendido y agudo lo que indica un alto grado de cristalinidad. Otros componentes que pudieron identificarse en el difractograma de la figura 3-11B fueron pirita y siderita. Adicionalmente se reconoció calcita en otros difractogramas analizados.

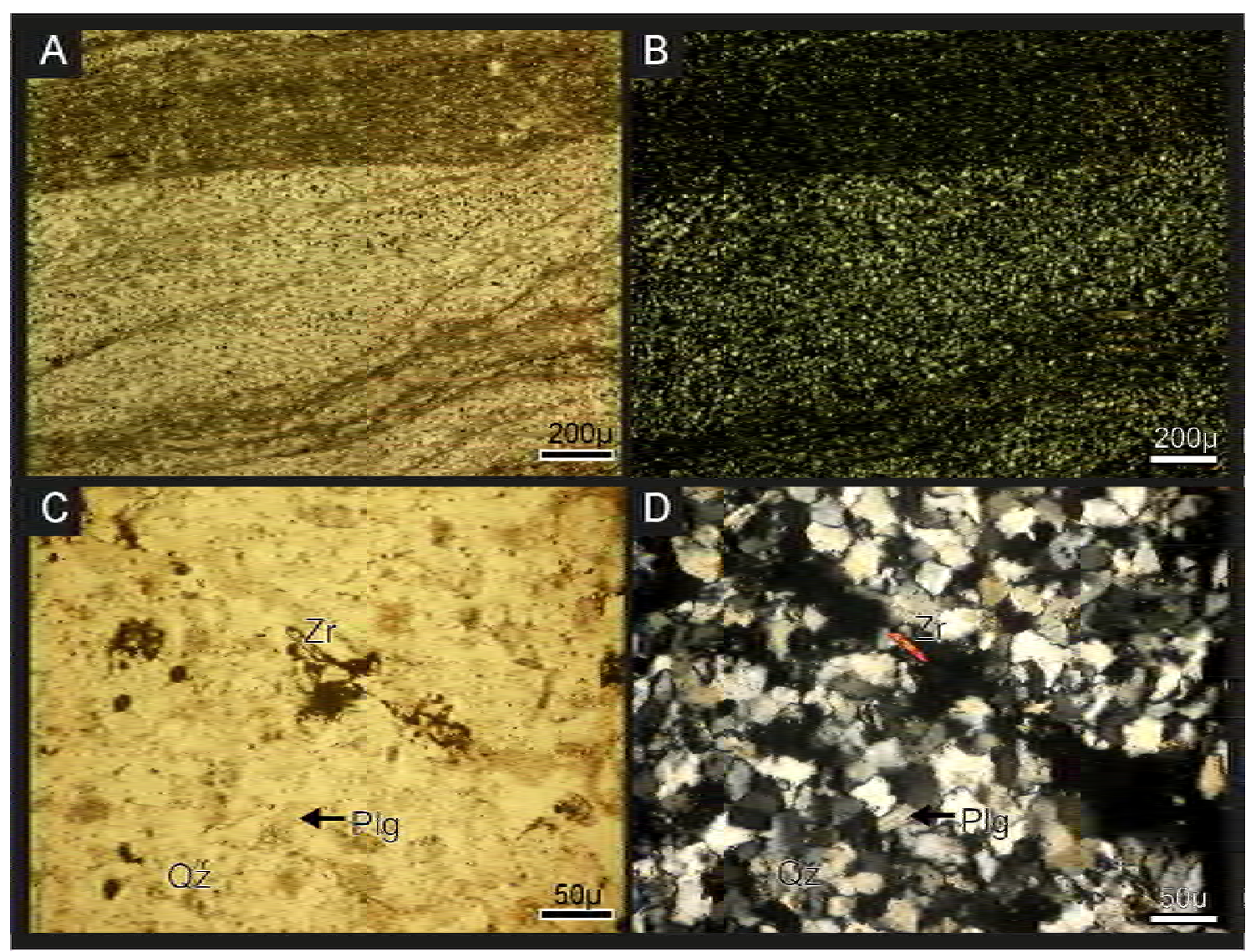

Fig. 3-10. Fotomicrografía de cortes delgados en las facies psamíticas de la Formación Acoite. A. y B. facies heterolíticas psamo-pelíticas con polarizador y analizador, respectivamente. C y D Asociación de facies D, gran preponderancia de granos de cuarzo, escaso feldespato alcalino, plagioclasa y circón. 


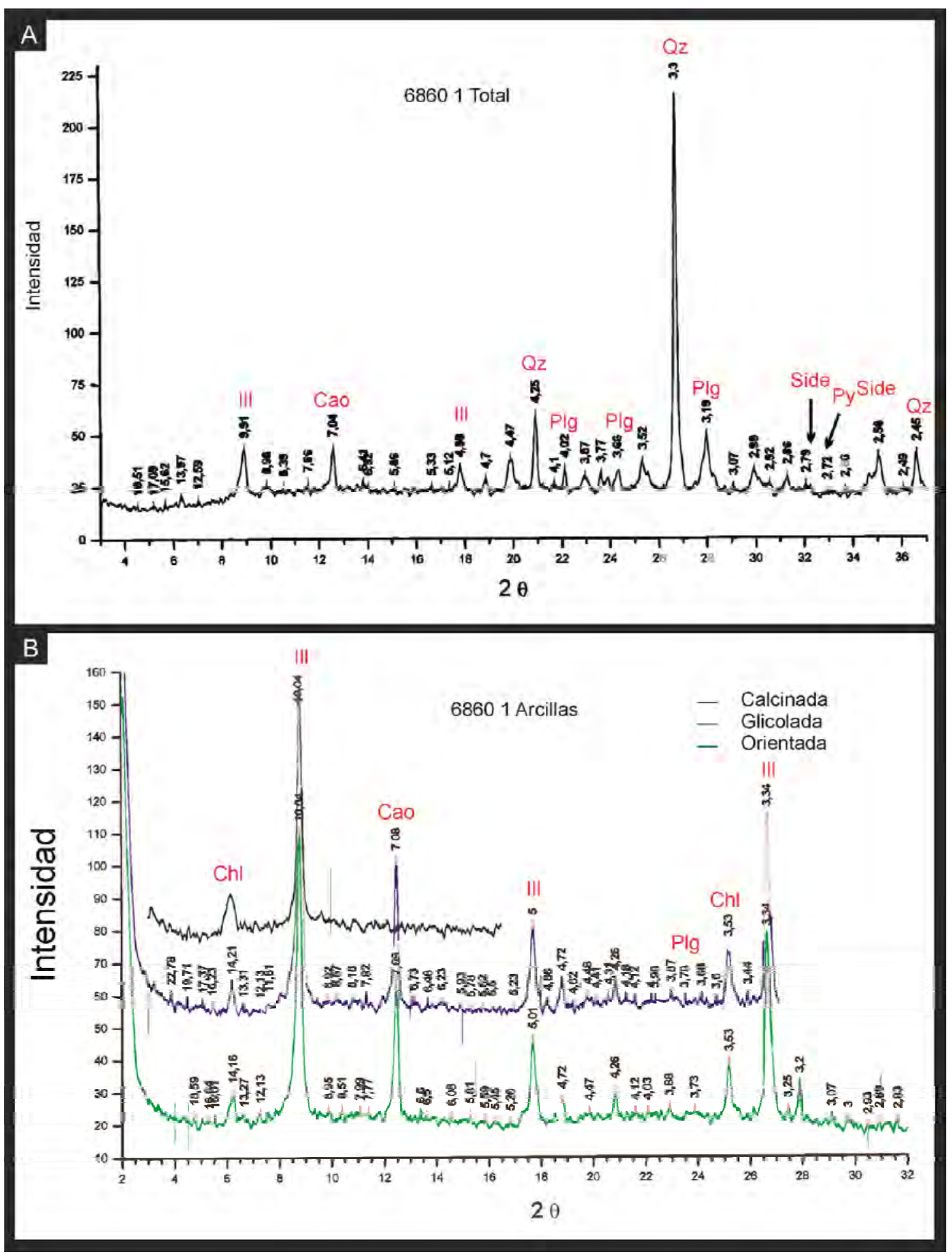

Fig. 3-11. A. Difractograma de roca total en una muestra de pelitas de la Formación Acoite. B. Difractograma de la fracción arcilla orientada (verde), glicolada (azul), y calcinada (negro). 
Sistemas y procesos depositacionales en plataformas abiertas silicoclásticas

Para interpretar las asociaciones de facies reconocidas de la Formación Acoite es necesario realizar una breve introducción a los procesos que se desarrollan en una plataforma marina con sedimentación clástica.

Las masas de agua marina pueden dividirse en dos grandes grupos, los océanos abiertos (pelágicos), que cubren la litósfera oceánica y los mares epicontinentales, sobre la corteza continental (Immenhauser, 2009), donde se desarrolla la plataforma. Esta última se extiende desde el shoreface hasta el talud continental.

De acuerdo al origen de los sedimentos de la plataforma pueden diferenciarse los materiales que se formaban in-situ o sedimentos autóctonos de los que ingresaban a la cuenca mediante transporte. Estos últimos son conocidos como alóctonos y evidencian los procesos de transporte y depositación en el offshore (Suter, 2006).

Los procesos que transportan y depositan la fracción media y gruesa en la plataforma han encendido un debate que se desarrolló en las últimas décadas y se extiende hasta la actualidad, fundamentalmente debido a la divergencia entre los estudios del registro sedimentario y los estudios actualistas. En la actualidad existen dos líneas de interpretación respecto a los niveles psamíticos en la plataforma, una propone que estos depósitos son turbiditas desarrolladas sobre la plataforma (Walker, 1984) (Fig. 3-12) mientras que otra línea propone que son depósitos generados por tormentas (tempestitas) en sus facies distales o debido a tormentas excepcionales (Aigner y Reinek, 1982; Immenhauser, 2009) (Fig. 3-13).

El mayor aporte clástico hacia la plataforma marina proviene de los sistemas continentales fluviales. De acuerdo al tipo de flujo que se genera en la interacción de estos ambientes pueden distinguirse dos tipos, los flujos hipopicnales y los flujos hiperpicnales, con características distintivas en el transporte de los sedimentos.

Los flujos hipopicnales son corrientes que flotan en el agua debido a su menor densidad en relación al agua de mar y pueden extenderse en la plataforma. Las partículas desarrollan plumas en la superficie y posteriormente decantan como granos individuales aunque son comunes los procesos de floculación en la fracción arcilla. 
Estas plumas muchas veces son influenciadas por la fuerza de Coriolis (Nittrouer \& Wright, 1994). Esta fuerza es generada por la rotación de la Tierra e imprimen una modificación en la dirección del flujo en el sentido horario en el Hemisferio Norte y en sentido antihorario en el Hemisferio Sur. Cuando esto ocurre, las corrientes pueden disponerse de forma oblicua o incluso paralela a la línea de costa y son conocidas como corrientes geostróficas (Suter, 2006).

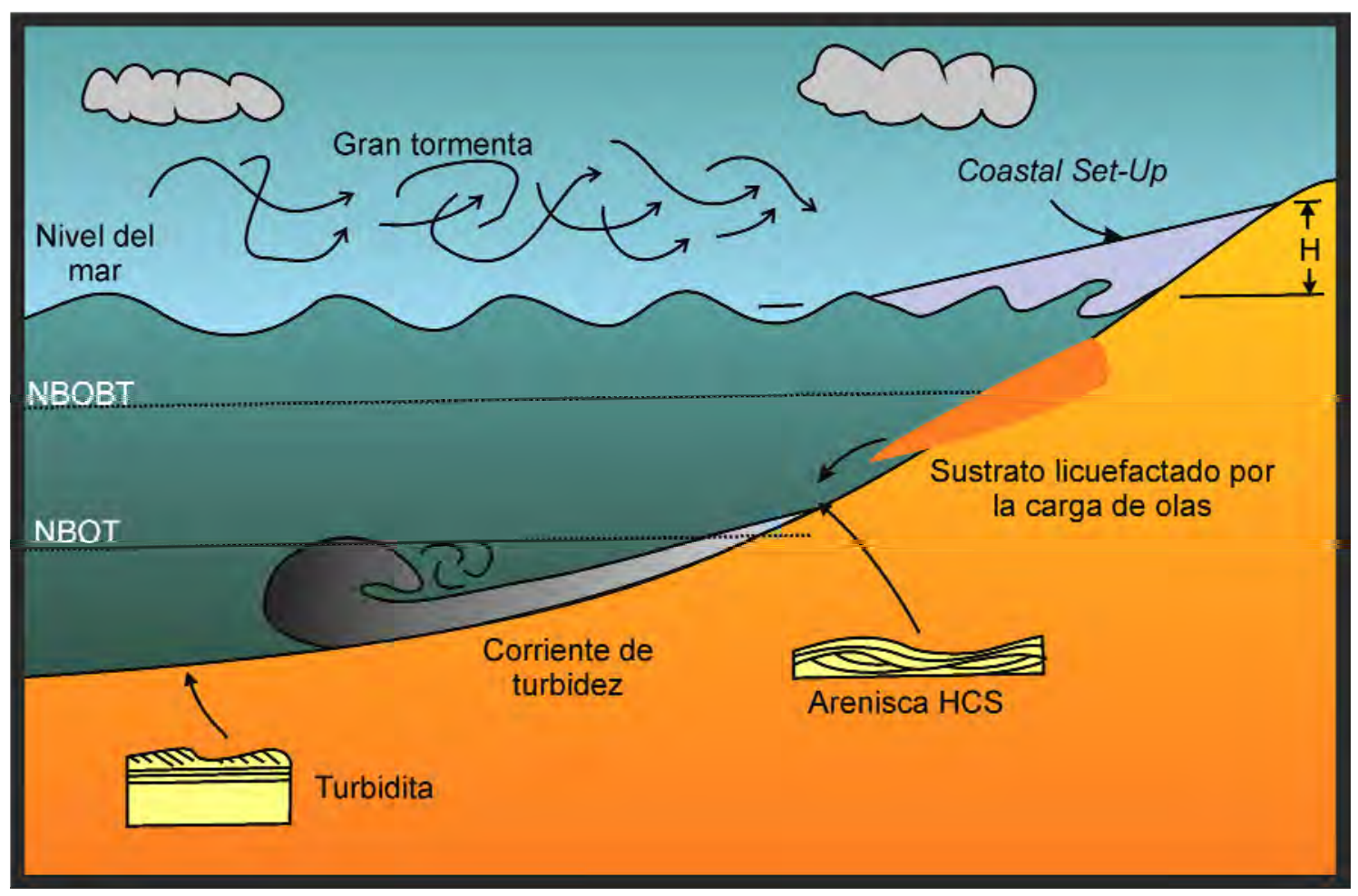

Fig. 3-12. Generación y depositación de turbiditas en la plataforma. Modificado de Walker (1984). NBOBT, Nivel de base de olas de buen tiempo; NBOT, Nivel de base de olas de tormenta; HCS: Hummocky cross stratification

Los flujos hiperpicnales son corrientes más densas que el agua de mar y el transporte de sedimento es tractivo sobre el sustrato. Esta mayor densidad puede ser producto de diversos factores (como temperatura o salinidad), usualmente se invoca para su formación a una alta concentración de sedimentos en la desembocadura de los ríos. Para que estos flujos puedan autosustentarse como flujo turbulento, es indispensable una pendiente mínima, que no es frecuente en las plataformas. Sin embargo, la turbulencia generada por las olas y las corrientes pueden disparar flujos gravitacionales en pendientes más tendidas que las necesarias en modelos teóricos (Myrow et al., 2002; Bentley y Nittrouer, 2003).

Asimismo estos flujos hiperpicnales también son afectados por la fuerza de Coriolis (Duke, 1990). Los estudios actualistas proponen que estas corrientes se desplazarían 
en dirección oblicua hasta perpendicular a la línea de costa (Suter, 2006), sin embargo los estudios en el registro sedimentario son consistentes con corrientes perpendiculares a la paleolínea de costa (Leckie y Krystinik 1989).

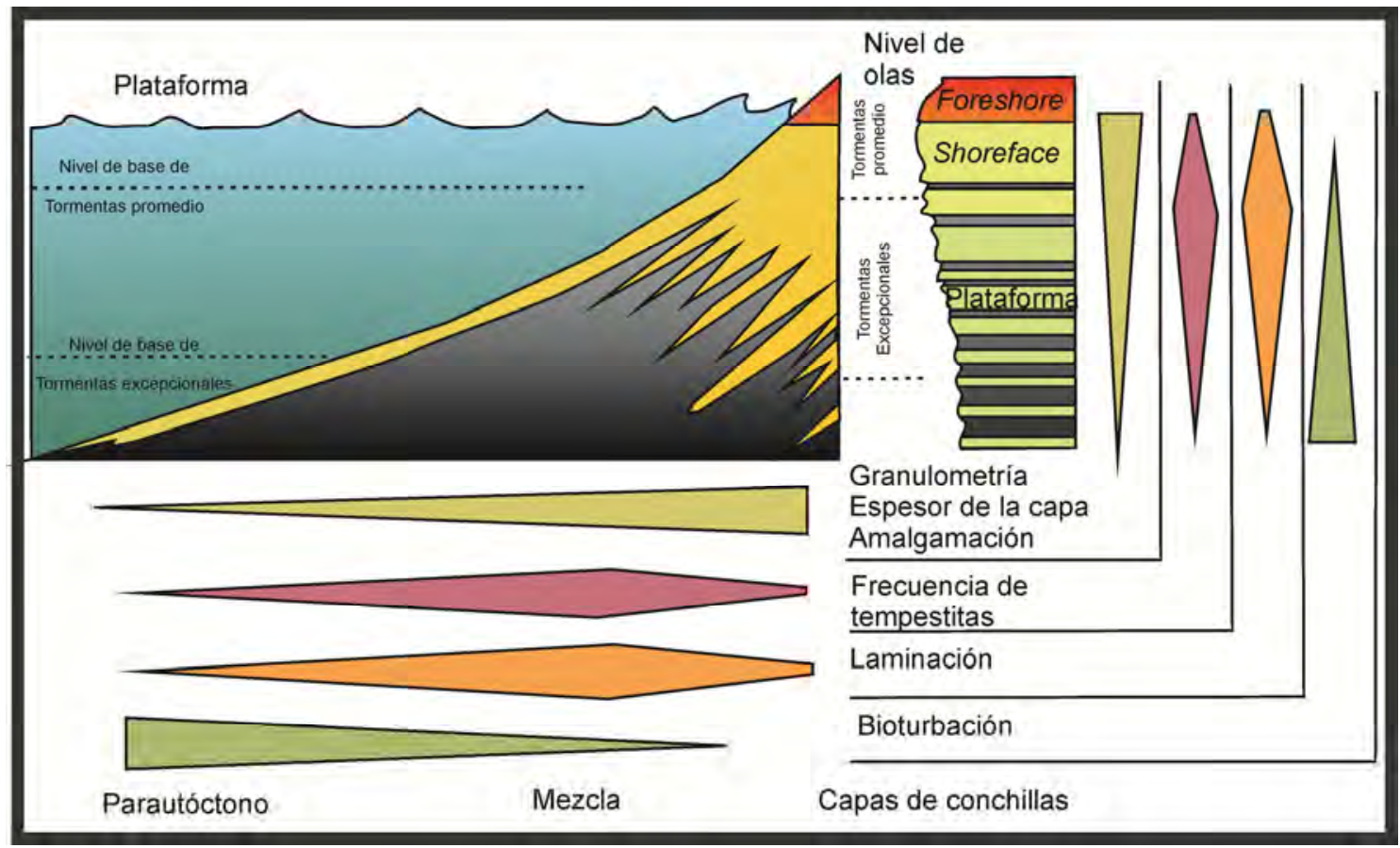

Fig. 3-13. Arreglo de facies en sentido vertical y lateral de depósitos de tempestitas. Modificado de Aigner y Reineck (1982).

Ante la complejidad de los procesos, que incluso pueden estar participando en una misma tormenta, con variable intensidad, Myrow y Southard (1996), propone un espectro de posibilidades a partir de un diagrama triangular, que en sus vértices están representados los siguientes procesos:

- Corrientes geostróficas.

- Oleaje oscilatorio.

- Flujos inducidos por densidad.

Los flujos inducidos por densidad serían las turbiditas de plataforma descriptas anteriormente. Si bien se acepta la dificultad de generar flujos turbulentos autosustentados en pendientes muy bajas, los autores indican la posibilidad de plataformas con pendientes mayores a las promedio o asociados a grandes deltas. Myrow y Southard (1996), destacan que una misma tormenta puede evolucionar dentro del diagrama, de acuerdo a la intensificación o decaimiento de los procesos actuantes (Fig. 3-14). 
Turbulencia autogenerada

por gravedad

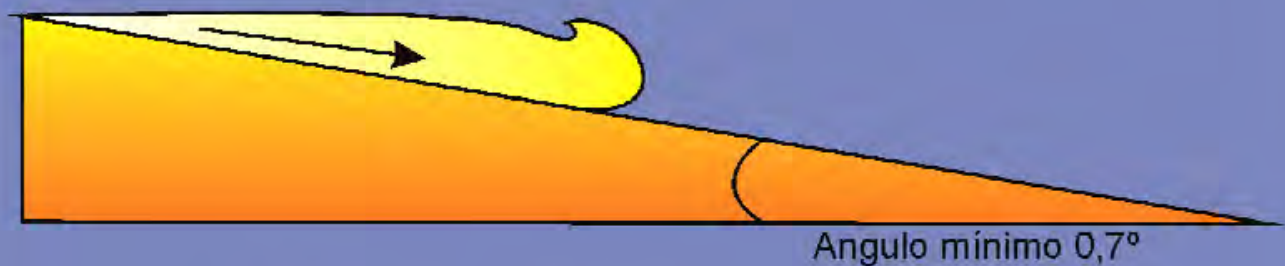

A.Flujo de gravedad autosuspendido

Turbulencia generada

por gravedad-oleaje

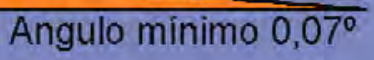

B. Flujo de gravedad reakado por olasicorrientes

Fig. 3-14. Pendientes necesarias para la sustentación de flujos donde la turbulencia es propiciada por la gravedad y flujos donde la turbulencia es incrementada por la acción de oleajes. Modificado de Suter (2006).

\section{Procesos y depósitos de las sedimentitas de la Formación Acoite}

Como se ha mencionado anteriormente, en los perfiles sedimentológicos de detalle levantados fueron interpretados dos procesos dominantes, aquellos vinculados a la decantación de material de granulometría pelítica, interrumpido por episódicos eventos de flujos tractivos, turbulentos, erosivos que depositan material de granulometría arena fina a muy fina (Fig. 3-15). El análisis detallado de las formas de lecho encontradas en los niveles arenosos (Fig. 3-16) sugiere que han sido depositados bajo flujos unidireccionales u oscilatorios dominados por flujos unidireccionales. Se reconocen solo excepcionalmente óndulas simétricas o microhummockys que podrían vincularse a condiciones hidrodinámicas de flujos dominados por corrientes oscilatorias (Dumas y Arnott, 2006). 
En el diagrama de Myrow y Southard (1996) (Fig. 3-17), las asociaciones de facies de las capas arenosas correspondientes a la asociación $D$, podrían ubicarse en una primera instancia en el campo de los flujos de densidad inducidos. Estos flujos serían perpendiculares a la paleolínea de costa (Leckie y Krystinik, 1989) y la fuerza de los mismos estaría dada por un gradiente de presión producto del alzamiento momentáneo del nivel del mar (coastal set-up), que generan las corrientes de relajación, sumado a la fuerza de exceso de peso, producto del peso del sedimento y el agua, vinculado a la pendiente del lecho (fuerza de exceso de peso) (Myrow y Southard, 1996). Estos flujos son erosivos, de alta velocidad unidireccional generando formas de lecho de capa plana de alto régimen de flujo.

En una segunda etapa, la velocidad del flujo unidireccional decrece y aumenta relativamente la influencia del flujo oscilatorio producto de oleaje de tormenta correspondiente en el diagrama al campo de las turbiditas con modificaciones de oleaje transitorio. Las evidencias del aumento de la injerencia de los flujos oscilatorios estaría dada por las estructuras monticulares, posiblemente microhummockys, y por la morfología de los techos de las capas de los niveles arenosos que registran la migración de óndulas levemente asimétricas tridimensionales con crestas redondeadas.

Estos eventos tractivos pueden quedar amalgamados en el registro sedimentario, bien debido a una alta frecuencia episódica, o bien debido a una alta tasa de erosión del material que se deposita entre estos eventos. (Fig. 3-18).

Según lo anteriormente expuesto, se propone un modelo de depositación reuniendo procesos que evolucionan en el tiempo (Fig. 3-19). El evento de tormenta comienza con corrientes unidireccionales que interactúan con un sustrato pelítico, que puede generar surcos o marcas de objetos (1); las corrientes, dominantemente unidireccionales, transportan clastos de arena muy fina a fina desde la costa por suspensión y como carga de lecho, hasta la plataforma (2); la arena se deposita rápidamente cuando las corrientes disminuyen su velocidad y la forma de lecho que generan es capa plana bajo flujos unidireccionales (3); el sistema agrada con óndulas pequeñas de escala centimétrica, su lento crecimiento y migración pueden producir una estratificación entrecruzada (4); parte de la arena es retrabajada posteriormente por olas de tormentas y las olas swell, y se forman estructuras tipo microhummocky bajo un flujo combinado (5). Finalmente, concluido el evento, el proceso dominante será la decantación de material fino que cubre a la secuencia previa (6). 


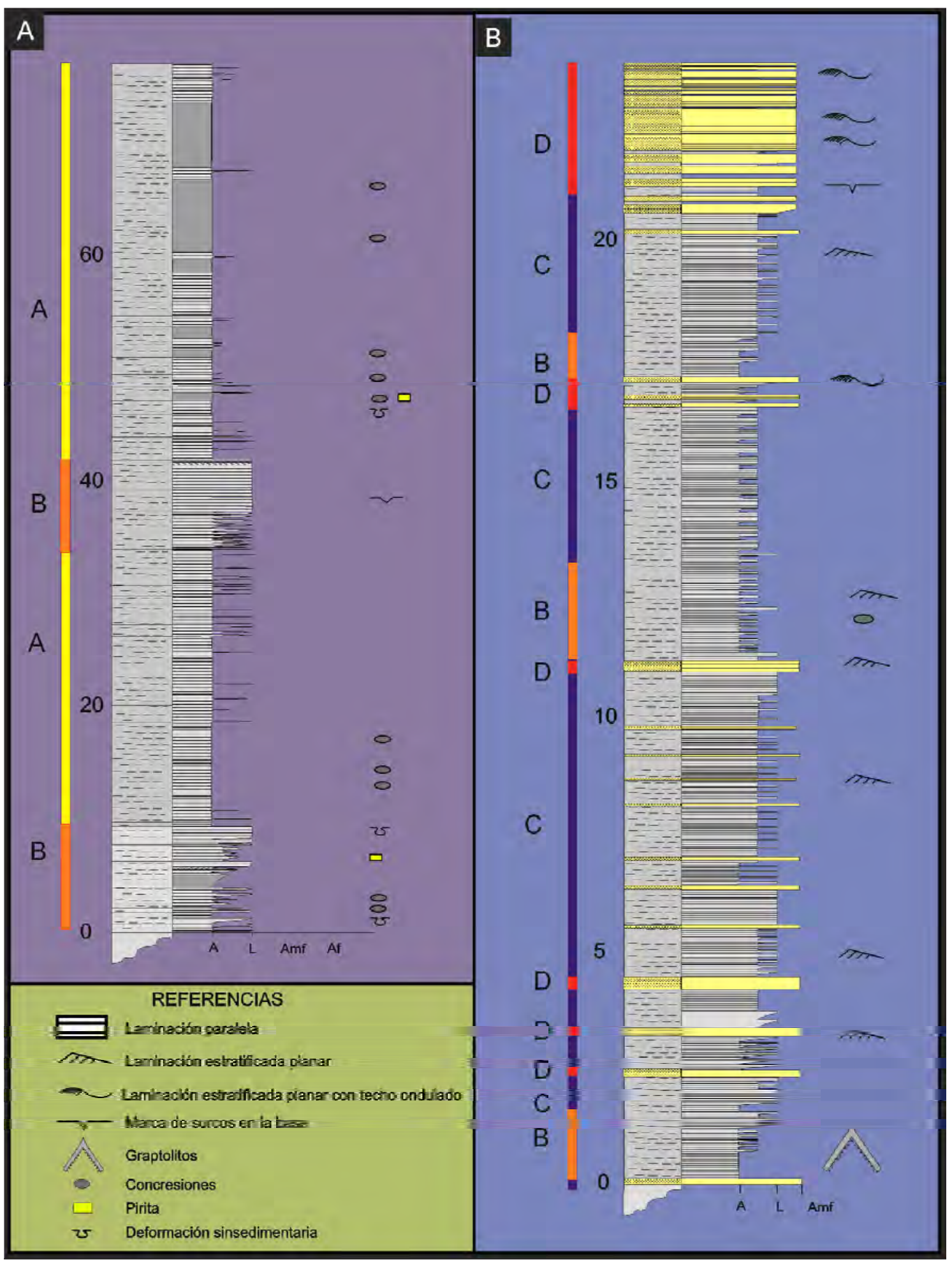

Fig. 3-15. A. Columnas sedimentológicas de detalle de la Formación Acoite en el sector sur del Cerro Colorado de Cobre. A. Sección inferior, predominio de las asociaciones de facies A y B. B. Sección media a superior, predominio de las asociaciones de facies $C$ y $D$. 


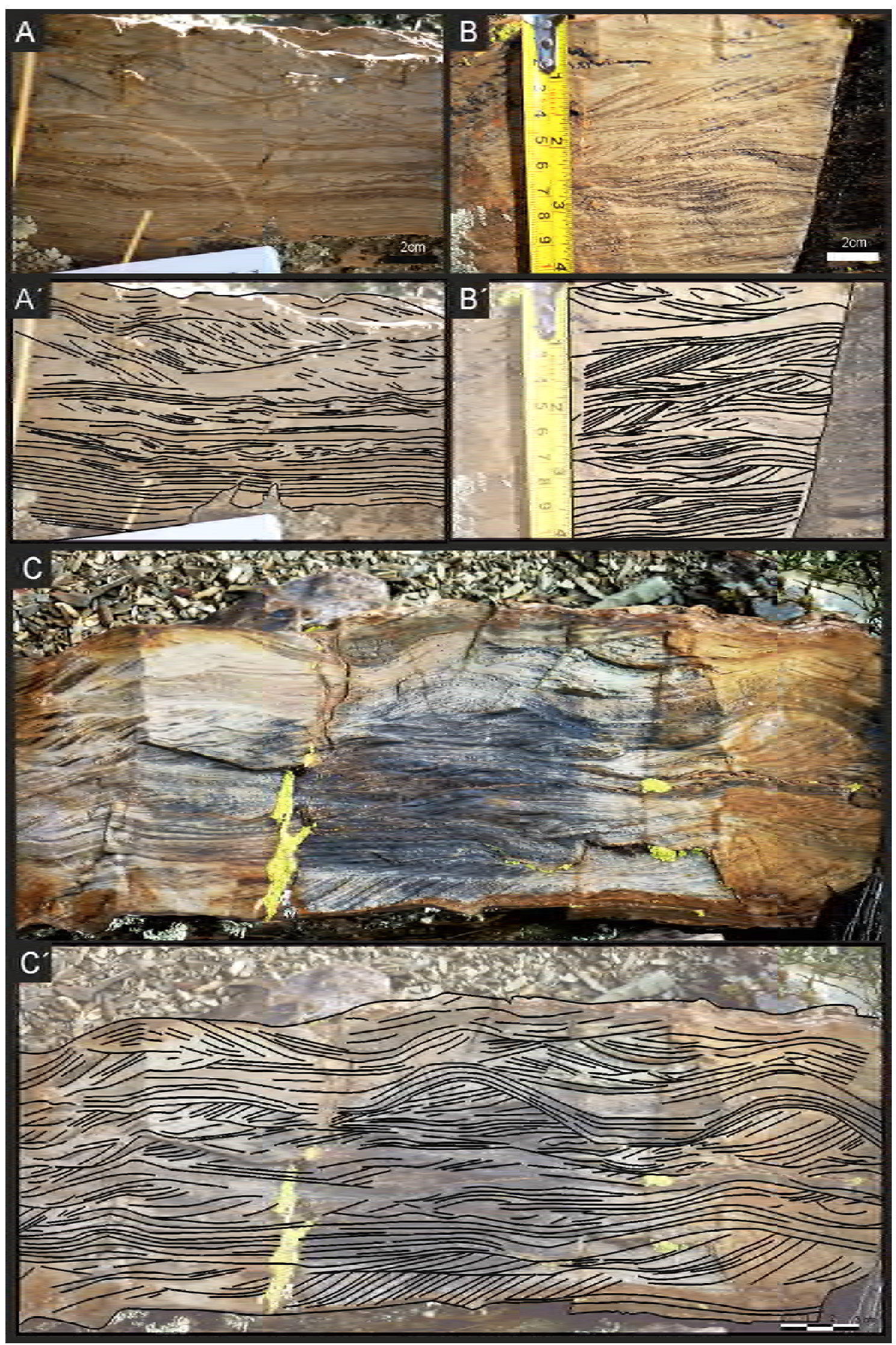

Fig. 3-16. Estructuras sedimentarias tractivas desarrolladas en las capas de areniscas de la asociación de facies $D$. A, $A^{\prime}$ y $B, B^{\prime}$. Exhiben un predominio de estructuras tractivas unidireccionales. $C$ y $C^{\prime}$. Estructuras uni y bidireccionales. 


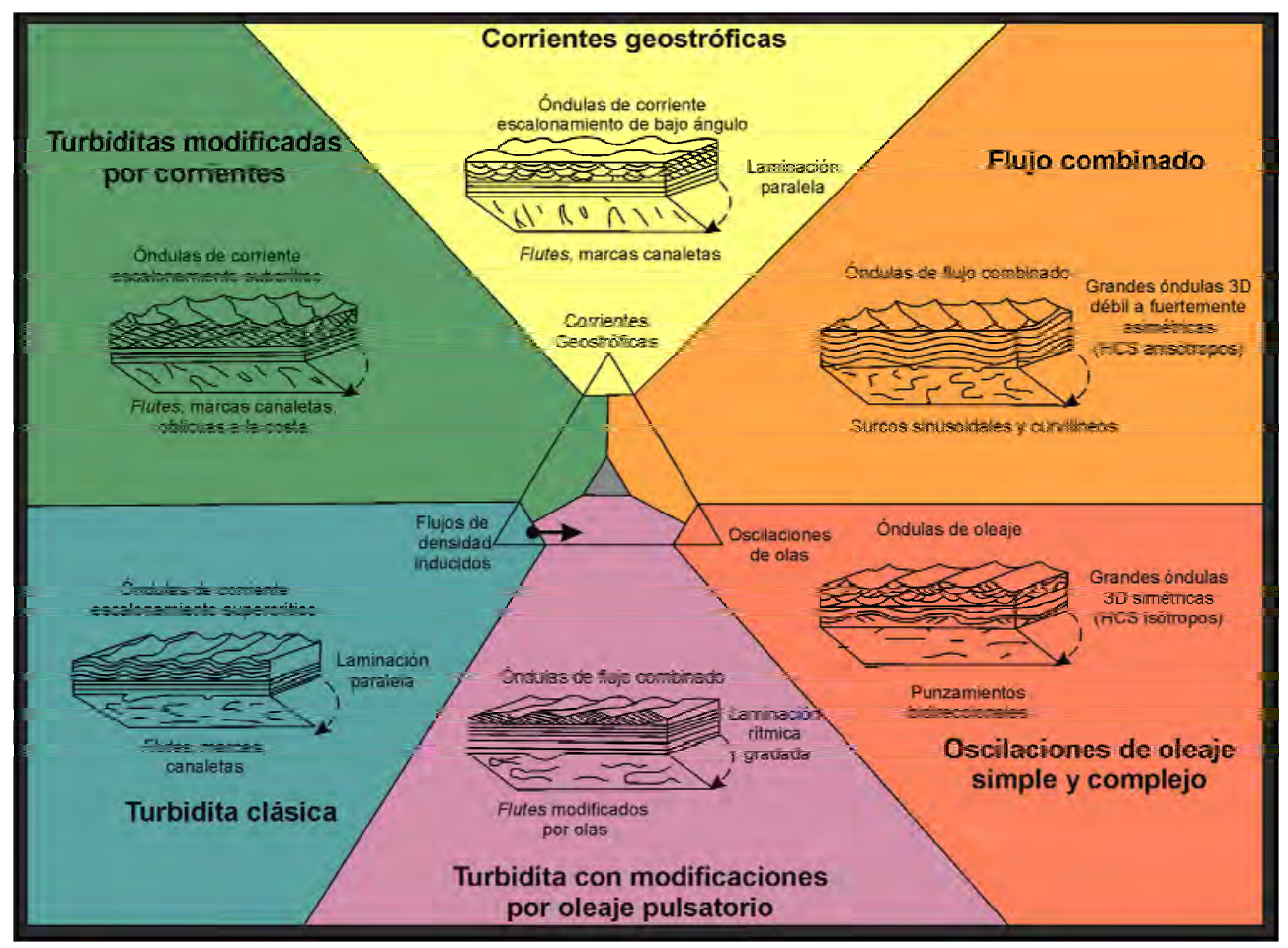

Fig. 3-17. Diagrama de los procesos y estructuras sedimentarias relacionadas a los diferentes agentes que actúan en una plataforma silicoclástica abierta. Modificado de Myrow y Southard (1996).

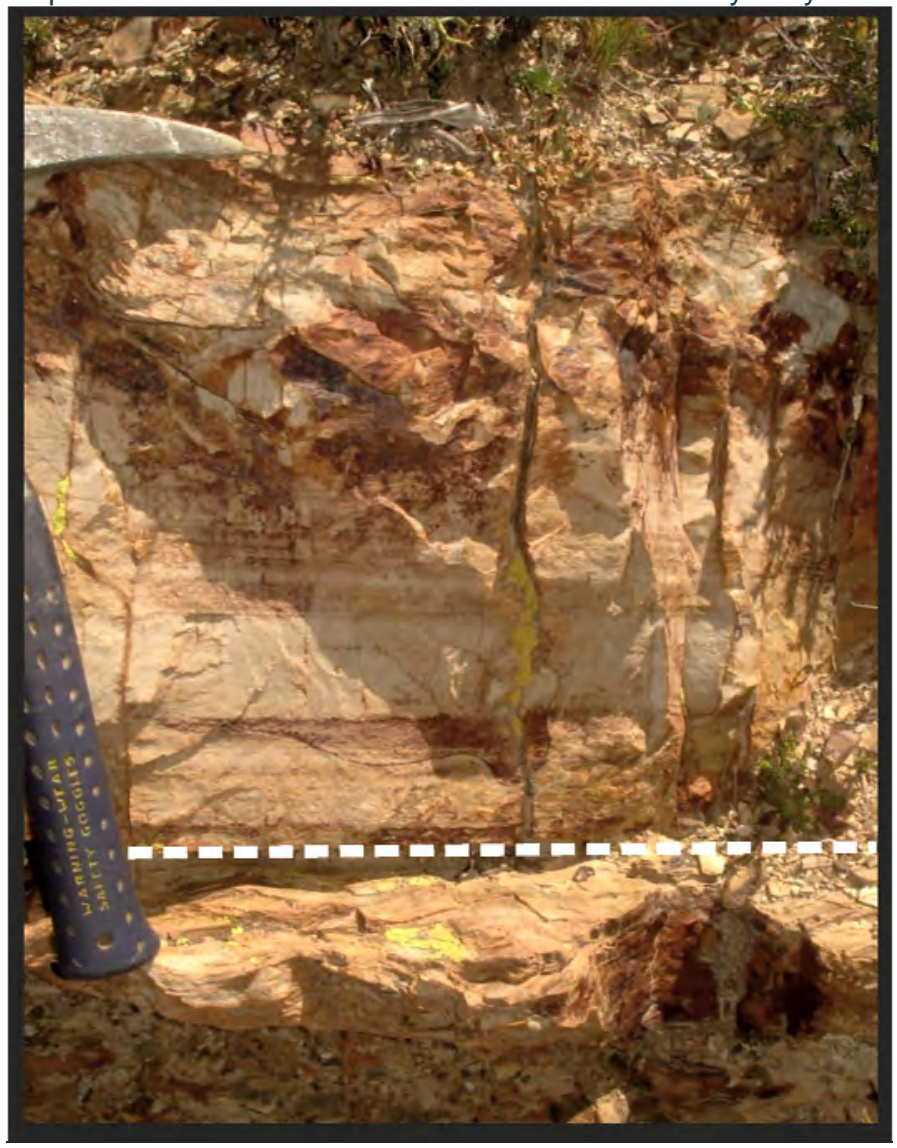

Fig. 3-18. Asociación de facies D donde se evidencia la amalgamación entre capas da areniscas finas, nótese que el techo del estrato inferior a la línea punteada es monticular, con óndulas 3D; sobre éste se deposita un estrato de areniscas con laminación en capa plana de alto régimen de flujo que hacia el techo desarrolla las estructuras monticular con óndulas de crestas en 3D. 


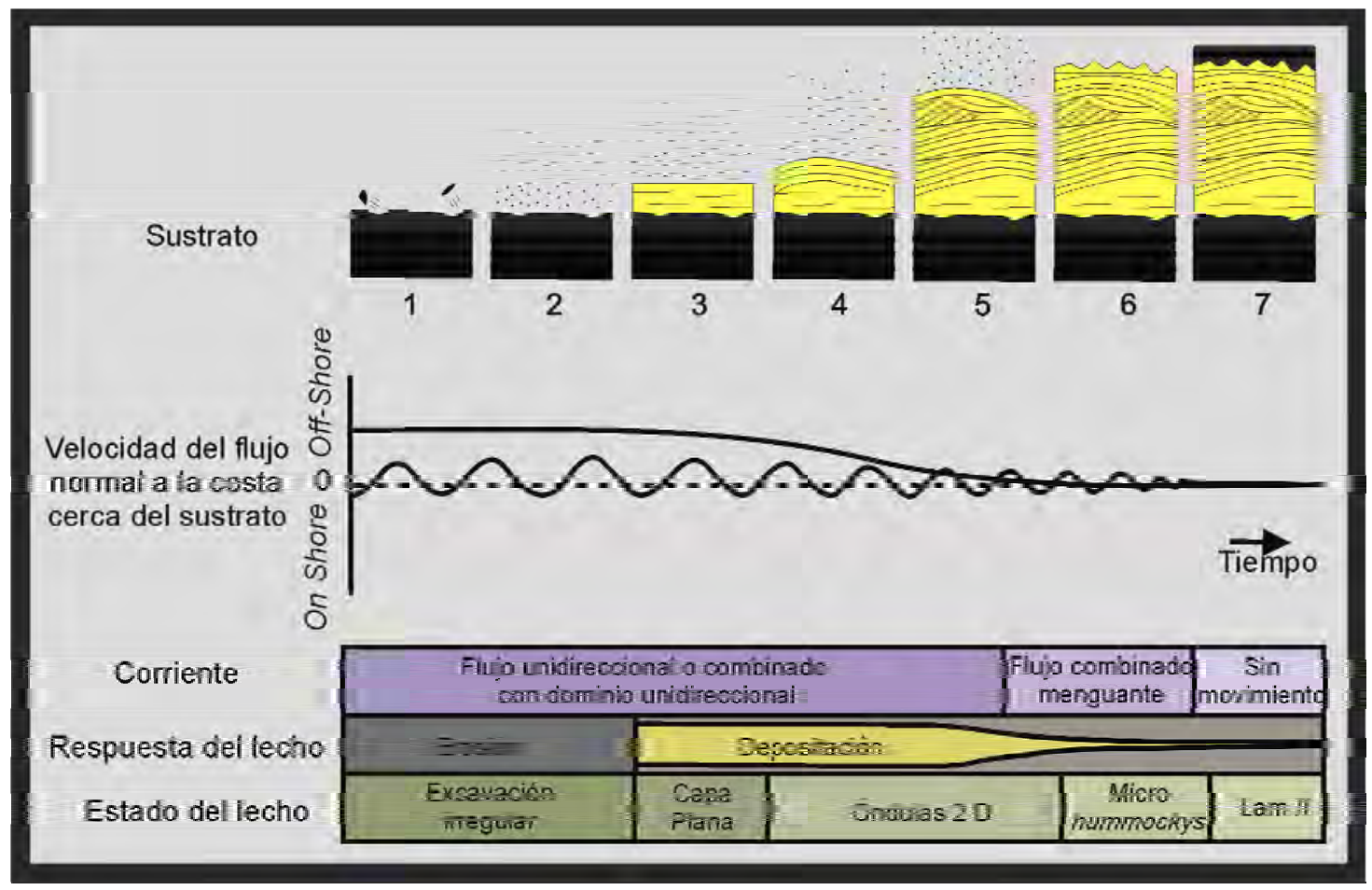

Fig. 3-19. Modelo de una secuencia depositacional y evolución temporal de una capa de la asociación de facies D. Modificado de Duke et al. (1991).

Astini y Waisfeld (1993) y Astini et al. (2004), proponen la presencia de importantes sistemas deltaicos ubicados hacia el Este de la cuenca, en el sector de Sierras Subandinas. A su vez, la evolución temporal de la secuencia de la Formación Acoite es interpretada por los autores como una progradación luego de un importante límite de secuencia con la inundación de la cuenca Ordovícica y la depositación de la supersecuencia Acoite. Esta progradación culminaría con la instalación sistemas deltaicos sobre la plataforma.

Los disparadores de las corrientes de turbidez dentro de la plataforma pueden deberse a la licuefacción de sedimentos, sumado a desmoronamientos (slumps), altas pendientes en las plataformas, terremotos, alta tasa de aporte de sedimentos (Walker, 1984), y a la turbulencia generada o incrementada por las tormentas (Myrow y Southard, 1996).

Todos estos factores pudieron potencialmente haber sido los generadores de los eventos de corrientes de turbidez registrados en esta investigación. Teniendo en cuenta la presencia de deltas como sistemas de aporte hacia esta plataforma, las corrientes pudieron dispararse por inestabilidades en el frente deltaico. Posiblemente las olas de tormenta hayan sido el principal agente generador de estas inestabilidades, aunque no se descartan inundaciones, que aumentarían la tasa de aporte de 
sedimentos, o bien a sismos, debido a que esta plataforma se encontraba en un contexto tectónicamente inestable.

\section{IMPLICANCIAS REGIONALES}

De acuerdo al modelo propuesto por Astini (2003) (Fig. 3-20) existe una variedad de ambientes tectónicos desarrollados en el margen occidental de Gondwana durante el Ordovícico. Este escenario se corresponde con distintas interpretaciones sustentadas en estilos e intensidad de la deformación, evidencias geoquímicas y de química isotópica de las rocas ígneas pertenecientes a la Faja Magmática de la Puna Oriental, y a la interpretación de procesos y ambientes sedimentarios así como también al análisis de áreas fuente de los materiales.

El volcanismo Ordovícico desarrollado en la Faja Eruptiva de la Puna Oriental, corresponde geoquímicamente a basaltos de retroarco (Coira et al., 2005). Coira et al. (2009a, 2009b), interpretan durante el Cámbrico-Tremadociano la instalación de un arco magmático en el sector occidental, mientras que en el oriental se desarrolla un magmatismo de retroarco durante el Tremadociano-Arenigiano Medio.

Bajo una óptica del sistema tectono-sedimentario, la sedimentación Ordovícica desarrollada en la Puna Occidental ha sido producto de sistemas turbidíticos con una proveniencia desde el Oeste y con abundante aporte de materiales volcaniclásticos. Los complejos deltaicos/estuarinos de las fajas central y oriental se desarrollaron en una plataforma abierta donde el área de proveniencia se ubica en región oriental.

El esquema general propuesto para el Cambro-Ordovícico, consistiría en un antepaís de retroarco que ha sufrido variaciones en el ángulo de subducción de la placa protopacífica. En el Cámbrico medio esta placa habría empinado su subducción, desarrollando un magmatismo de retroarco y la generación de un ambiente extensional (Bahlburg, 1990, 1991, Bahlburg y Furlong, 1996; Astini, 2003, 2008), que habría posibilitado el espacio de acomodación a los sedimentos de la Formación Acoite. Estos sedimentos se habrían depositado en un ambiente de antepaís, el cambio de régimen de extensional a compresivo es producto de un cambio progresivo hacia una subducción "plana" de la placa protopacífica (Astini, 2008).

Los resultados expuestos en el presente apartado confirman la existencia de una plataforma abierta silicoclástica desarrollada en el Ordovícico inferior en los afloramientos ubicados al sur del Cerro Colorado de Cobre en el sector occidental de la Cordillera Oriental. Esta plataforma se continúa hasta al menos las Sierras 
Subandinas donde se identificaron las facies proximales de sistemas deltaicoestuarino que funcionaron como fuente de aporte para los sedimentos depositados sobre el área que hoy ocupa la Cordillera Oriental.

Una cuestión de importancia en estudios futuros será establecer cuál es la naturaleza de la transición entre los depósitos de la plataforma desarrollada sobre la Cordillera Oriental y Sierras Subandinas, así como también la secuencia sedimentaria del complejo turbidítico de la Puna, lo que permitirá ajustar los modelos geotectónicos propuestos.

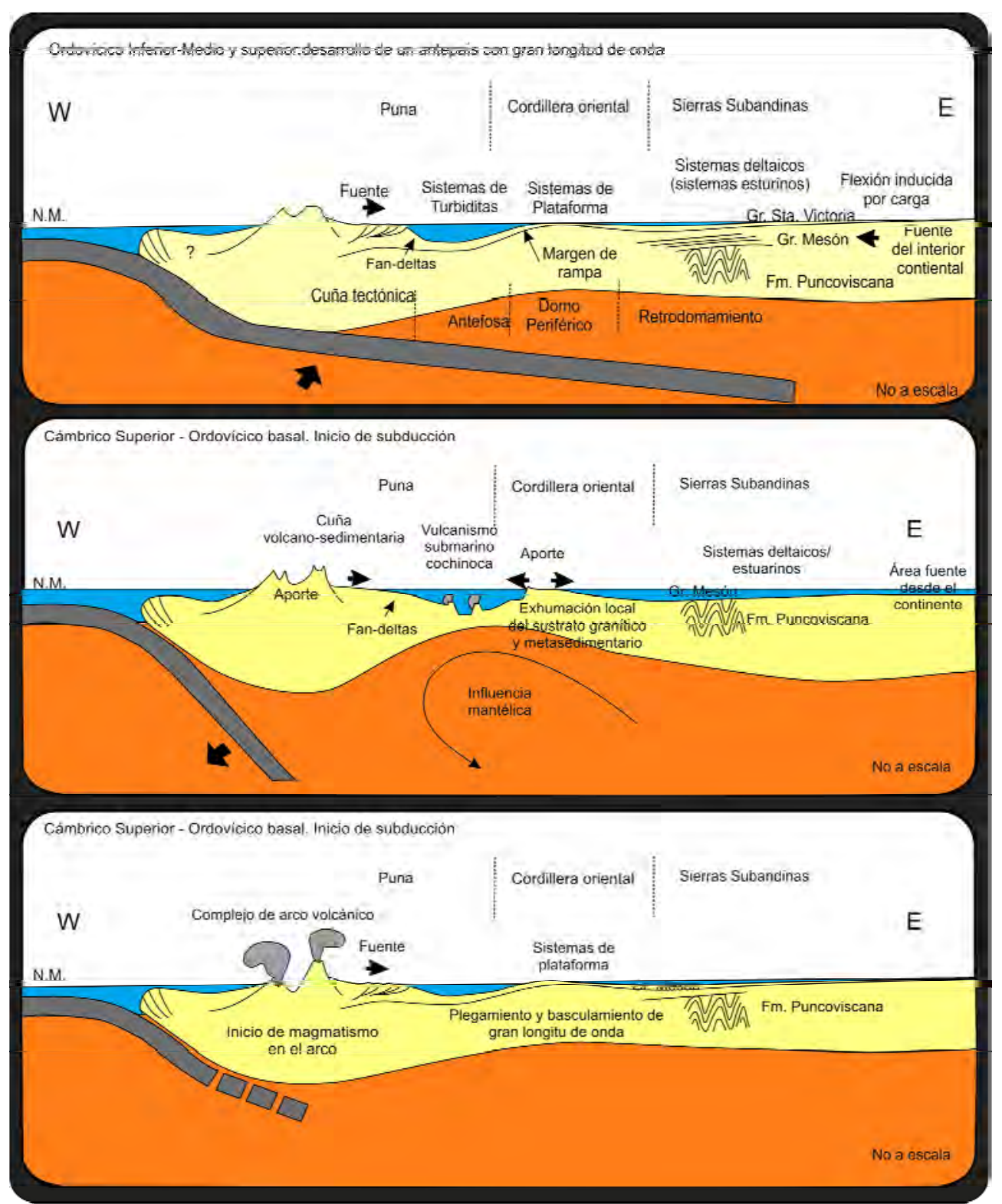

Fig. 3-20. Interpretación geotectónica de la evolución del margen occidental de Gondwana desde el Cámbrico superior hasta el Ordovícico superior. Modificado de Astini (2008). 
Para la caracterización geoquímica de las pelitas de la Formación Acoite como portadoras de elementos metálicos, se han realizado 3 análisis geoquímicos ICP-MA39 y 3 análisis por Niton ${ }^{\circledR}$ (FRx) (Tabla 3-1).

\begin{tabular}{|c|c|c|c|c|c|c|c|c|c|c|c|c|}
\hline $\begin{array}{c}\text { Muestra } \\
\mathrm{N}^{\circ}\end{array}$ & $\begin{array}{l}\mathrm{Ag} \\
\mathrm{ppm}\end{array}$ & $\begin{array}{c}\mathrm{Ba} \\
\mathrm{ppm}\end{array}$ & $\begin{array}{c}\text { Co } \\
\text { ppm }\end{array}$ & $\begin{array}{c}\mathrm{Cr} \\
\mathrm{ppm}\end{array}$ & $\begin{array}{c}\mathrm{Cu} \\
\mathrm{ppm}\end{array}$ & $\begin{array}{c}\mathrm{Ni} \\
\mathrm{ppm} \\
\end{array}$ & $\begin{array}{c}\mathrm{Pb} \\
\mathrm{ppm}\end{array}$ & $\begin{array}{l}\mathrm{S} \\
\% \\
\end{array}$ & $\begin{array}{c}\mathrm{Sb} \\
\mathrm{ppm}\end{array}$ & $\begin{array}{c}\mathrm{U} \\
\mathrm{ppm} \\
\end{array}$ & $\begin{array}{c}\mathrm{V} \\
\mathrm{ppm}\end{array}$ & $\begin{array}{l}\mathrm{Zn} \\
\mathrm{ppm}\end{array}$ \\
\hline Nivel 15 & $<0,5$ & $>2000$ & 2,96 & 92 & 49,09 & 38 & 15 & 0,08 & $<5$ & - & 173,59 & 83 \\
\hline Nivel 53 & $<0,5$ & 1628 & 4,06 & 49 & 29,33 & 46 & 16 & 0,04 & $<5$ & - & 68,94 & 113 \\
\hline Nivel $15 b$ & $<0,5$ & $>2000$ & 2,06 & 93 & 53,78 & 36 & 19 & 0,09 & $<5$ & - & 178,75 & 83 \\
\hline 6839 & $\underset{<}{4,81}$ & 881 & $\begin{array}{c}< \\
\text { LDD } \\
<\end{array}$ & $\begin{array}{l}< \\
\text { LDD } \\
<\end{array}$ & 34,17 & 117 & 31 & 0,04 & 52,25 & $\begin{array}{c}< \\
\text { LDD }\end{array}$ & 62,55 & 76 \\
\hline $6839-2$ & LDD & 1690 & LDD & LDD & 32,35 & $\begin{array}{c}79 \\
<\end{array}$ & 52 & 0,04 & 59,09 & 5,64 & 52,44 & 50 \\
\hline Caja & 5,6 & 826 & 61,42 & 14,2 & 22,58 & LDD & 12 & 0,72 & 29,55 & 7,25 & 119 & 65 \\
\hline Promedio & 2,2 & 1504 & 17,6 & 61,9 & 36,9 & 52,6 & 24,3 & 0,2 & 23,3 & 4,2 & 109,2 & 78 \\
\hline
\end{tabular}

Tabla 3-1. Resultados de análisis geoquímicos sobre elementos comúnmente concentrados en pelitas negras. En color verde se resaltan las muestras analizadas con ICP-MA-39 y en violeta los análisis de Niton ${ }^{\circledR}$. LDD: Límite de detección.

Sobre la base de estos análisis se determinaron elevados valores en $\mathrm{Ag}, \mathrm{Ba}, \mathrm{Cu}$, $\mathrm{Ni}, \mathrm{Sb}$ y U comparados con la corteza continental superior (Upper Continental Crust; UCC) (Tabla 3-2). Se registraron valores cercanos a al UCC en Pb, V y Zn. El Co registró valores bajos y solo en una muestra superó el UCC con una relación de 3,61

\begin{tabular}{|cccccccccccc|}
\hline Muestra & $\mathrm{Ag}$ & $\mathrm{Ba}$ & $\mathrm{Co}$ & $\mathrm{Cr}$ & $\mathrm{Cu}$ & $\mathrm{Ni}$ & $\mathrm{Pb}$ & $\mathrm{Sb}$ & $\mathrm{U}$ & $\mathrm{V}$ & $\mathrm{Zn}$ \\
\hline Nivel 15 & - & 3,64 & 0,17 & 1,08 & 1,96 & 0,85 & 0,90 & - & - & 1,62 & 1,16 \\
Nivel 53 & - & 2,96 & 0,24 & 0,58 & 1,17 & 1,06 & 0,96 & - & - & 0,64 & 1,59 \\
Nivel 15b & - & 3,64 & 0,12 & 1,09 & 2,15 & 0,82 & 1,14 & - & - & 1,67 & 1,17 \\
6839 & 96,2 & 1,60 & - & & 1,37 & 2,66 & 1,81 & 2613 & - & 0,58 & 1,07 \\
$6839-2$ & - & 3,07 & - & & 1,29 & 1,79 & 3,08 & 2955 & 2,01 & 0,49 & 0,71 \\
Caja & 112 & 1,50 & 3,61 & 0,17 & 0,90 & & 0,70 & 1478 & 2,59 & 1,11 & 0,91 \\
\hline
\end{tabular}

Tabla 3-2. Valores de elementos seleccionados para las 6 muestras de pelitas normalizados con respecto a la composición promedio de la Corteza Continental Superior (Taylor y McLennan, 1985). En celeste se resaltan los valores mayores a 1.

Estos valores son similares a los valores promedios de pelitas negras que han sido fuente de metales en depósitos como Rammelsberg, Tharsis y Draa Sfar (Sáez et al., 2011). Resulta llamativo en los resultados presentados el bajo contenido de Co registrado en las pelitas en comparación con estos depósitos, donde su valores medios varían entre 15 y 18 ppm. La fijación del Co en el sedimento es influenciada en forma importante por la materia orgánica (Machado et al., 2005) y por el estado de oxidación ambiental. La relación Ni/Co en condiciones oxidantes es inferior a 5 y en ambientes anóxicos esta relación es mayor a 7 (Rimmer, 2004). En las muestras 
analizadas esta relación es superior a 11 en todos los casos donde ha podido efectuarse estas determinaciones, indicando un ambiente anóxico.

Las litologías correspondientes a los ambientes euxínicos/anóxicos se caracterizan por ser texturalmente de grano fino, de color oscuro, donde la estructura principal es una fina laminación, pobres en fauna, con un alto contenido de materia orgánica (hasta $20 \%$ de carbono orgánico), alto contenido de azufre y enriquecido de ciertos elementos como Mo, U, V, Cr, Fe, Mn, Ni, Co, Cu, Zn, $\mathrm{Pb}$ y Cd. La presencia de estos elemento se debe a que algunas bacterias utilizan estos metales para funciones metabólicas (Ohmoto y Goldhaber, 1997), y al propio comportamiento geoquímico de estos elementos (Sáez et al., 2011).

Los índices de $\mathrm{V} / \mathrm{Cr}$ y $\mathrm{V} /(\mathrm{V}+\mathrm{Ni})$ son útiles para inferir la oxigenación del medio de depositación. Esto es debido a los comportamientos dispares del V, Ni y Cr durante los procesos redox en ambientes marinos con sedimentación detrítica fina (Hoffman et al., 1998). De esta forma altas relaciones $\mathrm{V} / \mathrm{Cr}$ y valores de $\mathrm{V} /(\mathrm{V}+\mathrm{Ni})$ entre 0,5 y 0,9 son característicos de ambientes anóxicos, mientras que valores mayores indican condiciones euxínicas. En ambos ambientes las condiciones de Eh son reductoras $(E h<0)$, mientras que en los ambientes anóxicos el cuerpo de agua se encuentra estratificado en los euxínicos ocurre una circulación restringida. Fueron seleccionadas las muestras analizadas mediante ICP-MA-39 debido a que las analizadas con Niton poseían valores de cromo y níquel por debajo del límite de detección. De esta forma las tres muestras consideradas se encuentran en el campo correspondiente a ambientes anóxicos (Fig. 3-21).

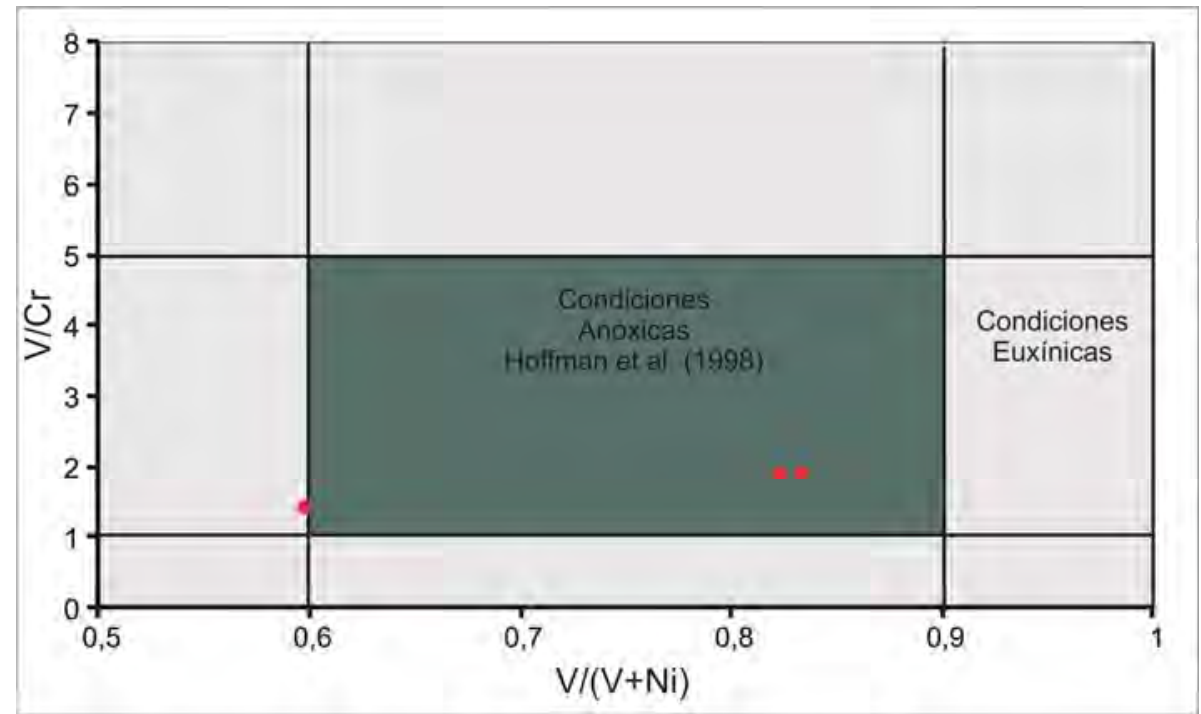

Fig. 3-21. Diagrama V/Cr vs V/(V+Ni) en muestras de pelitas del distrito Purísima-Rumicruz. Las muestras se ubican en el campo de las condiciones anóxicas (Hoffman et al., 1998). Modificado de Sáez et al., 2011). 


\section{CAPÍTULO IV}

\section{DEPÓSITO POLIMETÁLICO PURÍSIMA-RUMICRUZ: YACENCIA Y MINERALOGÍA}


El distrito minero Purísima-Rumicruz se encuentra ubicado en el sector sur del Cerro Colorado de Cobre, $25 \mathrm{Km}$ al sudeste de la localidad Jujeña de Abra Pampa, departamento de Cochinoca, Provincia de Jujuy. Se accede al distrito mediante un camino de ripio vecinal que une las localidades de Abra Pampa con Tres Cruces. Desde este camino se desprende una huella minera, actualmente inutilizable, con la que se accede hasta el antiguo campamento y a la mayoría de las labores de explotación de la mina.

El área donde se concentraron las explotaciones cubre 3,5 $\mathrm{Km}^{2}$ (Fig. 5-1), empero se han registrado tareas de exploración/explotación por fuera de estos límites, como el área Marciano y San Agustín (Fig. 5-1). El sistema de vetas alcanza unos 3.500m de estructuras aflorantes. Las vetas identificadas presentan corridas cortas, muchas veces cubiertas, por lo que solo es posible identificarlas gracias a las labores de destape y explotación registradas en la mina. La totalidad de las vetas reconocidas se encuentran alojadas en la secuencia psamopelítica de la Formación Acoite.

El yacimiento fue explotado en pequeña escala desde la década del cuarenta hasta 1971, en este lapso, la producción exhibió un carácter variable en cuanto al volumen explotado. Es en ese año que entra en vigencia el Plan Cordillerano Norte y el sector es declarado Área de Reserva No 7 (Lurgo Mayón, 1999). A mediados de los años ochenta comienza un incipiente pero creciente plan de exploración que continúa hasta la fecha. Actualmente la concesión minera le pertenece a la empresa Bolland Minera S.A.

La baritina ocupó el principal volumen del material explotado en el distrito, seguido por cobre y plomo. En el año 1968 el Banco Industrial de la República Argentina calculó reservas probables de 2.250 t con una ley de cobre de 5,5\%. Ramallo (1975), estima un ley media de cobre de $4 \%$ y entre 1 y $7 \%$ de plomo. La ley del níquel estaría comprendida entre 0,01 y $0,3 \%$ y se registraron valores de plata de hasta $270 \mathrm{ppm}$.

La explotación del yacimiento se llevó a cabo mediante $450 \mathrm{~m}$ de galerías, $40 \mathrm{~m}$ de piques y $30 \mathrm{~m}$ de chiflones. Chomnales et al. (1960), mencionan el estado de las labores de la veta Purísima: "La labor no se encuentra en buen estado de conservación; el agua inunda el piso y las paredes y los techos de la galería se hallan, en parte, derrumbados". Las galerías en la actualidad se encuentran en su mayor parte inaccesibles. 


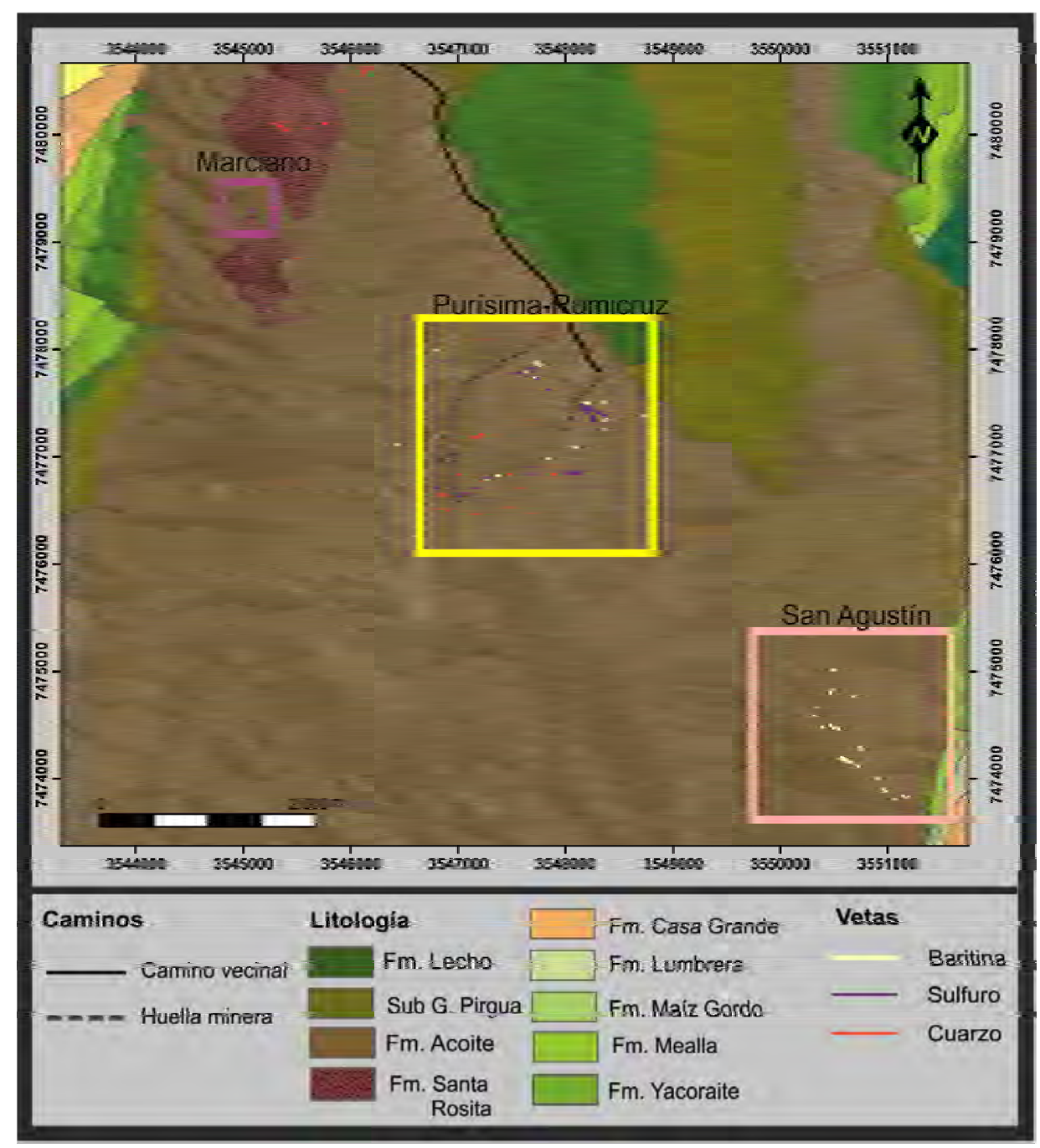

Fig. 5-1. Mapa geológico minero de las áreas Purísima-Rumicruz, Marciano y San Agustín.

La mineralogía fue inicialmente estudiada por Angelelli (1950) que denominó la mineralización por primera vez como "veta de cobre" y una década más tarde Chomnales et al., (1960), describen la presencia de galena, esfalerita, pirita, calcopirita, calcosina, bornita, malaquita y mencionan el hallazgo de minerales de níquel: niquelina y su producto de alteración, annabergita, en ganga de cuarzo, baritina y calcita. Los estudios mineralógicos detallados del distrito Purísima-Rumicruz fueron realizados a principio de la década del setenta y añaden a los minerales descriptos anteriormente la presencia de pechblenda, rammelsbergita, gersdorffita, tetraedrita, "chispas" de oro y covelina secundaria e indica la ausencia de esfalerita (Brodtkorb, 1972).

Brodtkorb (1973), propone una paragénesis similar para los yacimientos PurísimaRumicruz, La Niquelina (Salta) y La Esperanza (Salta) clasificándolos como mesotermales y posiblemente vinculadas a un mismo ciclo magmático. Por su parte 
Lurgo Mayón (1999), propone que estos yacimientos corresponderían a depósitos polimetálicos de tipo Five Element Deposits con $\mathrm{U}, \mathrm{Ni}, \mathrm{Co}, \mathrm{As}, \mathrm{Ag} \pm \mathrm{Bi}, \mathrm{Cu}, \mathrm{Pb}, \mathrm{Zn}, \mathrm{y}$ subraya la ausencia de cuerpos ígneos vinculados a las mineralizaciones. El mismo autor sugiere que la génesis de estos depósitos estaría relacionada a un rifting intracratónico en el trasarco, durante el Cretácico Superior - Eoceno.

\section{DESCRIPCIÓN GENERAL DE LAS VETAS}

En el área de estudio se han diferenciado dos tipos de vetas de acuerdo a su mineralogía dominante: vetas con sulfuros, que pueden estar parcialmente reemplazados por óxidos en superficie, y vetas de cuarzo (Fig. 5-2).

Asimismo, sobre la base de su disposición espacial se determinaron cuatro zonas en el distrito: "Purísima-Rumicruz", "El Brechón", "La Nueva” y "Jesuitas" (Fig. 5-2). Purísima-Rumicruz reúne a las vetas Purísima, Rumicruz, Sector I, Sector II y Liliana, mientras que el sector El Brechón, incluye a la veta homónima y estructuras paralelas, en el sector La Nueva confluyen las vetas La Nueva y vetas y vetillas menores asociadas. Finalmente el sector Jesuitas comprende un pique y una pequeña escombrera.

\section{Vetas con sulfuros}

En las vetas con sulfuro se distinguen las vetas de sulfuro dominante que presentan textura brechosa donde el material de relleno es principalmente sulfuros, calcita y baritina. Por otro lado las vetas de baritina dominante comprenden aquellas vetas y vetillas constituidas principalmente por baritina, donde los sulfuros reconocidos son exclusivamente producto de enriquecimiento secundario.

Los afloramientos de las vetas presentan bajo contraste topográfico lo que dificulta su reconocimiento en superficie. Dentro de este grupo se han incluido vetas, vetillas y stockworks con potencias variables, aunque raramente superan $0,5 \mathrm{~m}$. En planta se determinaron corridas cortas, de pocas decenas de metros y discontinuas. Una excepción es la veta "El Brechón" con hasta $4 \mathrm{~m}$ de potencia y una longitud mayor a $200 \mathrm{~m}$ bien expuesta gracias a labores de explotación superficial y destapes.

Las vetas en planta presentan geometrías rectas a levemente curvas. Los contactos con la roca de caja suelen suelen ser netos, aunque ocasionalmente suele existir vetillas asociadas a la estructura principal que disminuye en densidad dentro de la 
roca de caja. Estas estructuras presentan inclinaciones altas, usualmente mayores a $70^{\circ}$.

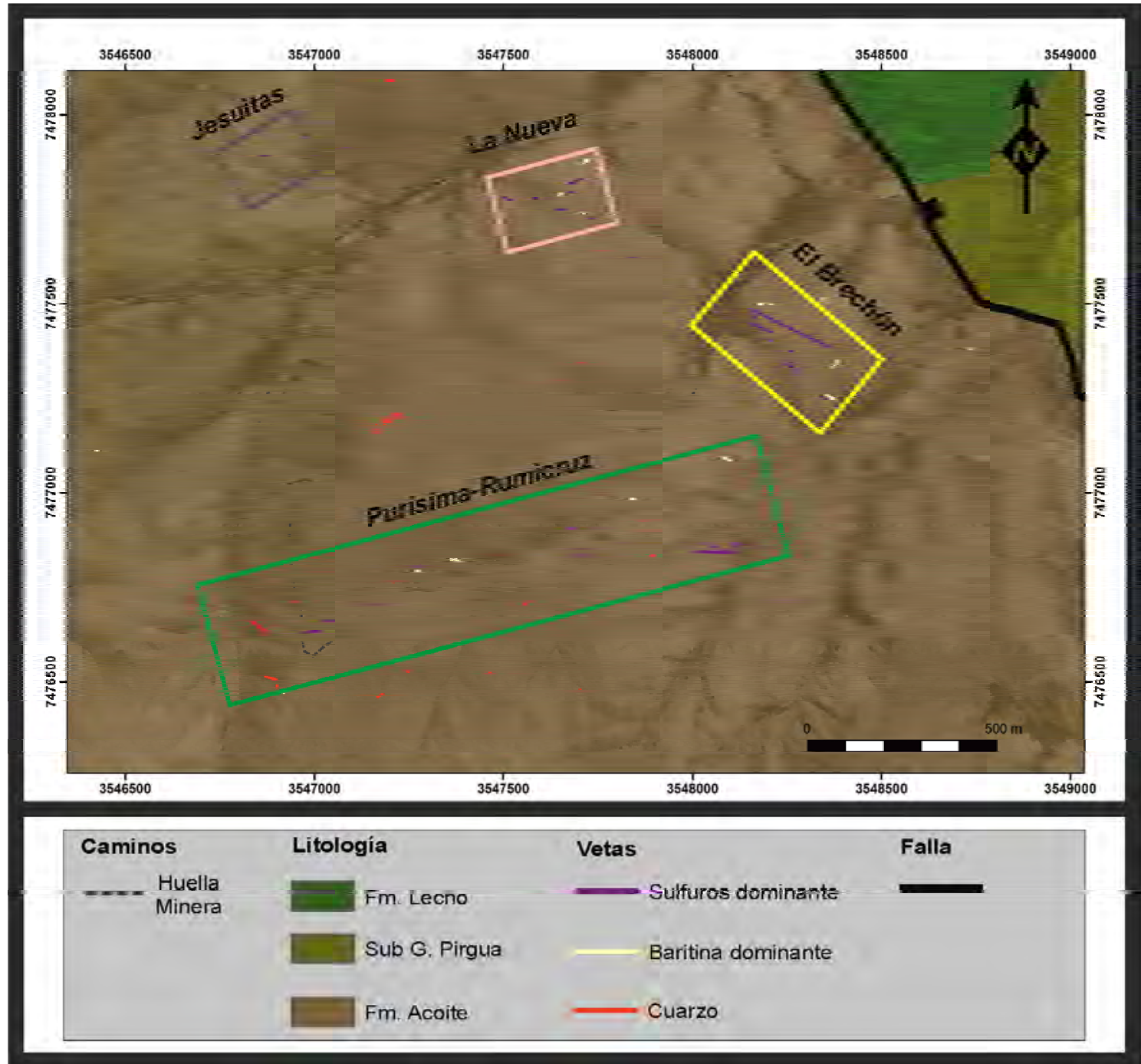

Fig. 5-2. Mapa de distribución de las vetas del distrito minero Purísima-Rumicruz

La textura preponderante en las vetas es brechosa, multiepisódica, donde sucesivos pulsos hidrotermales afectaron el mismo sistema de fracturas generando numerosos episodios de brechamiento. Los fragmentos más frecuente son de roca de caja con geometría angulosa a subangulosa, de pocos milímetros hasta decenas de centímetros de diámetro. Estos clastos están cementados por minerales hidrotermales, principalmente sulfuros, cuarzo y carbonatos que pueden sufrir a la vez sucesivos eventos de brechamiento - cementación. 


\section{Vetas de Cuarzo}

Están compuestas por cuarzo de color blanco, con cristales gruesos o con hábito masivo, aunque localmente pueden exhibir texturas brechosas y vetillas con relleno de óxidos e hidróxidos de hierro. Estas vetas presentan una distribución de sus orientaciones más dispersa que las vetas sulfuro dominante. En planta presentan longitudes de varias decenas de metros y espesores de hasta $3 \mathrm{~m}$ aunque la potencia promedio suele ser de $0,5 \mathrm{~m}$.

\section{CARACTERIZACIÓN DE LA YACENCIA Y MINERALOGÍA DE LAS}

\section{VETAS}

A continuación se describirá la yacencia y mineralogía de las vetas de sulfuros de cada uno de los sectores mencionados, caracterizando las dimensiones, composición, mineralogía y orientación de las vetas que los conforman, y las labores mineras desarrolladas para la explotación de las mismas.

Para efectuar las determinaciones mineralógicas, se examinaron distintas muestras bajo lupa binocular, petrografía de cortes delgados, calcografía de secciones pulidas, difracción de rayos $\mathrm{X}$ y análisis de microsonda electrónica sobre minerales transparentes y opacos.

\section{Sector Purísima Rumicruz}

El sector Purísima-Rumicruz es una faja elongada en sentido este-oeste de unos $1,5 \mathrm{Km}$ de largo y 0,5 Km de ancho (Fig. 5-3). Se reúnen en él a un conjunto de vetas de sulfuros y cuarzo. Las estructuras mineralizadas principales, en cuanto a su dimensión, concentración de la mineralización y extensión de las labores mineras, son las vetas Purísima, Rumicruz y Liliana.

\section{Veta Purísima}

La veta Purísima es la más importante del distrito en cuanto al desarrollo y longitud de las labores mineras realizadas. En planta no es posible establecer su continuidad debido a que se encuentra cubierta con depósitos de acarreo cuaternario. En uno de los socavones de acceso se determinó que la veta posee azimut $110^{\circ} \mathrm{e}$ inclinación de $80^{\circ} \mathrm{N}$ (Fig. 5-4) y una potencia de 1,6 m. La veta está emplazada en una faja de cizalla con planos subparalelos en los cuales se concentra un vetilleo intenso 
de baritina, óxidos de hierro, malaquita y escasa calcosina. La textura principal de la veta es brechosa con clastos de caja de la Formación Acoite donde el relleno principal es de sulfuros y sulfoarseniuros, calcita, baritina y escaso óxidos e hidróxidos de hierro.

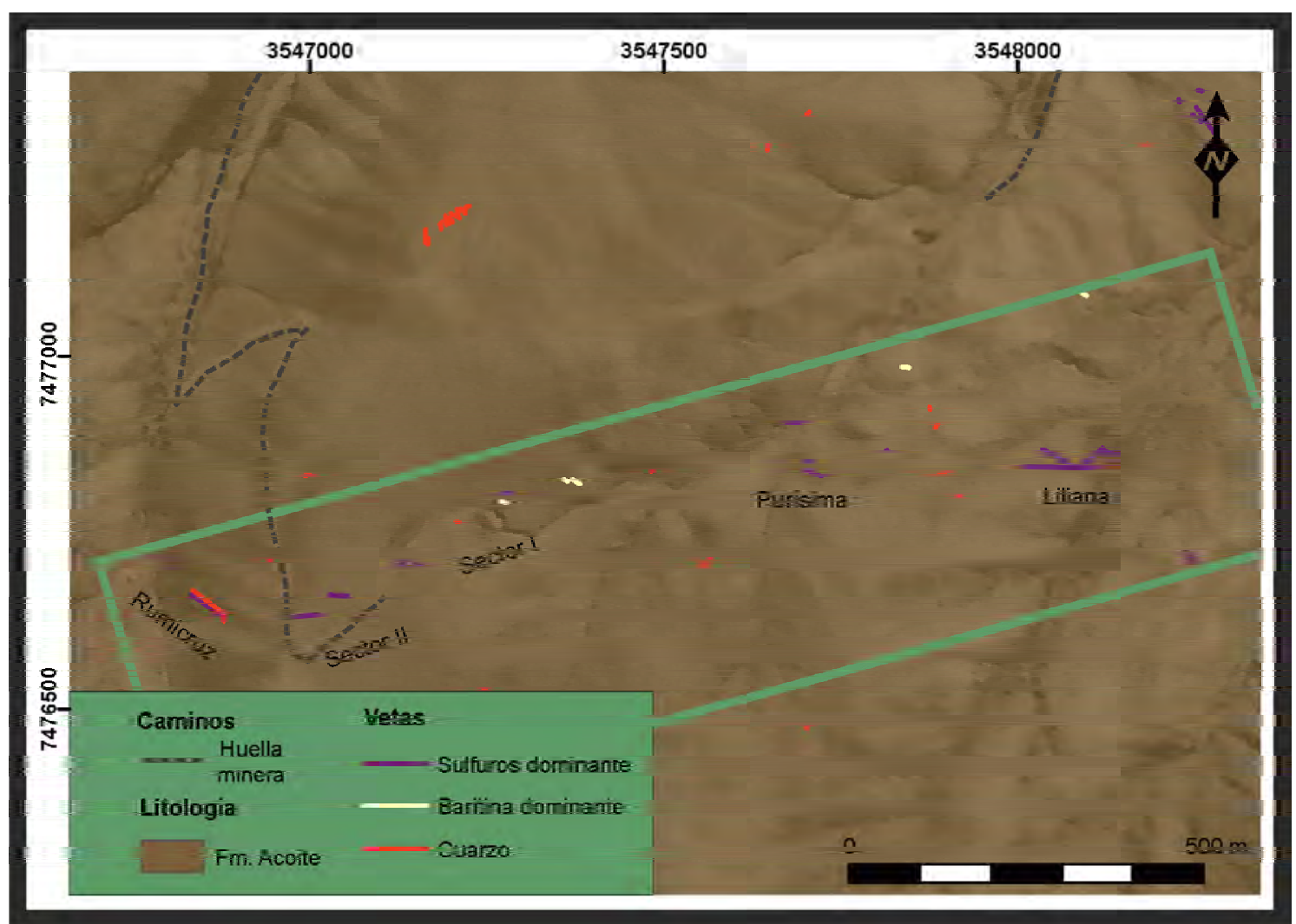

Fig. 5-3. Mapa geológico-minero del Sector Purísima-Rumicruz en recuadro.

La textura de la brecha es multi-episódica, constituida por clastos pelíticos y psamíticas de la Formación Acoite y clastos de productos hidrotermales precipitados. La sucesión de pulsos se inician con un carbonato gris (I), con cristales finos de hábito euhedral y agregados de sulfuros. Estos conforman clastos sub-redondeados a subangulosos, brechados por un segundo pulso de carbonato (II), de color blanco, principal relleno de la veta. Muy ocasionalmente los sulfuros logran conformar vetillas continuas. Cuando el carbonato II cristaliza en las oquedades puede formar pequeñas geodas con cristales escalenoédricos. Posteriormente precipita baritina de color rosa de hábito tabular radiado con escaso carbonato. Continúa la precipitación de óxidos de hierro y siderita, que se disponen en forma de bandas gruesas. Finalmente toda esta secuencia es cortada por finas vetillas de calcita, malaquita y azurita (Fig. 5-5, 5-6).

Los carbonatos constituyen el principal relleno de la veta reconocidos mediante microsonda electrónica han sido calcita, dolomita, ankerita y siderita. Esta distinción no ha sido posible de establecer claramente mediante petrografía, ni tampoco en estudios 
con cátodoluminiscencia. Debido a esto, se utiliza genéricamente el término carbonatos para referirse a cualquiera de estas especies minerales. Dentro de una asociación de sulfuros se reconoció un cristal euhedral de apatita, posiblemente de origen hidrotermal.

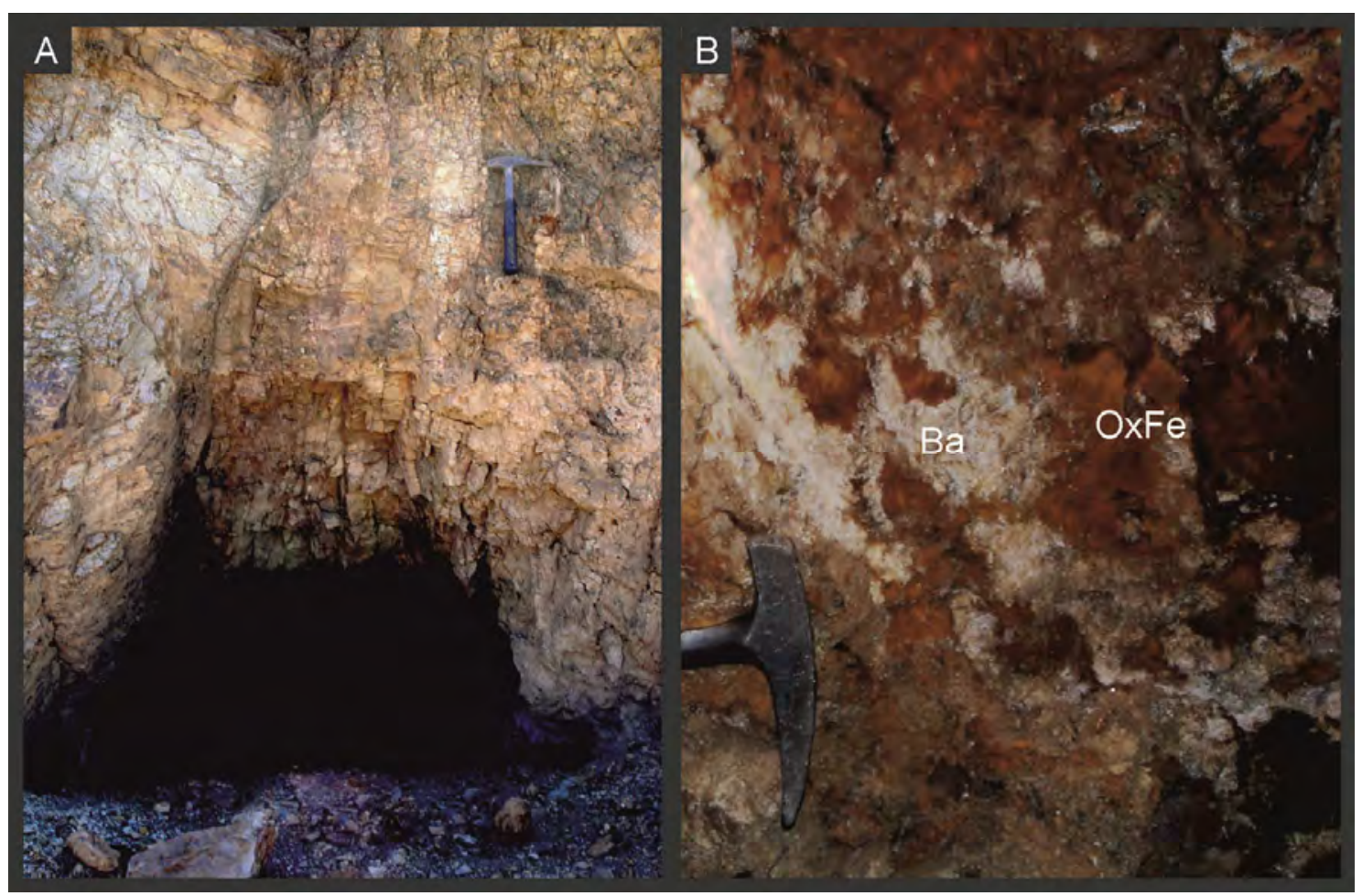

Fig. 5-4. A) Entrada labor de la veta Purísima. En el techo se identifica la zona de cizalla con inclinación subvertical. B) Foto de interior mina. Entre los planos de cizalla se determinaron zonas de apertura y precipitación de baritina y óxidos e hidróxidos de hierro.

Los minerales opacos identificados en la veta Purísima fueron los siguientes: calcosina $\left(\mathrm{Cu}_{2} \mathrm{~S}\right)$, digenita $\left(\mathrm{Cu}_{9} \mathrm{~S}_{5}\right)$, bornita, $\left(\mathrm{Cu}_{5} \mathrm{FeS}_{4}\right)$, calcopirita $\left(\mathrm{CuFeS}_{2}\right)$, tetraedrita-tennantita $\left[(\mathrm{Cu}, \mathrm{Fe}, \mathrm{Zn})_{12}(\mathrm{SbAs})_{4} \mathrm{~S}_{13}\right]$, galena (PbS), covelina (CuS), niquelina (NiAs), gersdorffita (NiAsS), millierita (NiS) y pechblenda $\left(\mathrm{UO}_{2}\right)$.

\section{Sulfuros}

El mineral más abundante es la calcosina primaria (Fig. 5-7A), de hábito lamelar a masivo, se encuentra comúnmente intercrecida con digenita y en ocasiones conforma prismas alargados con intensa corrosión hacia los bordes de los cristales (Fig. 5-7B). Son comunes las texturas de intercrecimiento mirmequítico con bornita (Fig. 5-7C). También son frecuentes los intercrecimientos de pequeños cristales de gersdorffita (Fig. 5-7D) en los bordes de los cristales de calcosina y tetrahedrita-tennantita. Localmente, asociados a gersdorffita, se ha reconocido pequeños cristales de niquelina. 


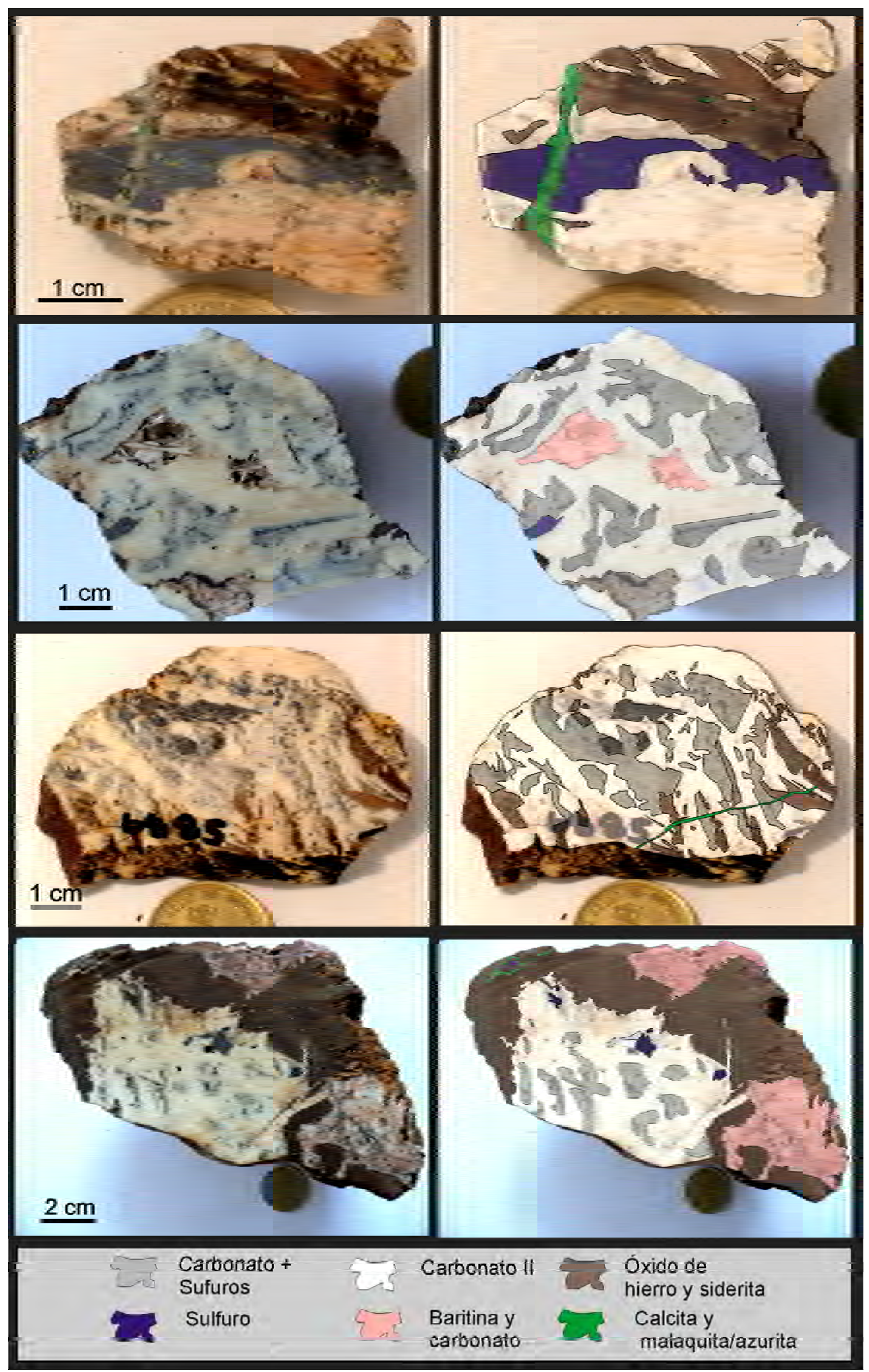

Fig. 5-5. Mineralogía y relaciones de corte en muestras de mano correspondiente a la veta Purísima. El primer pulso precipita un carbonato gris con sulfuros conformando clastos o vetillas de sulfuros, luego 


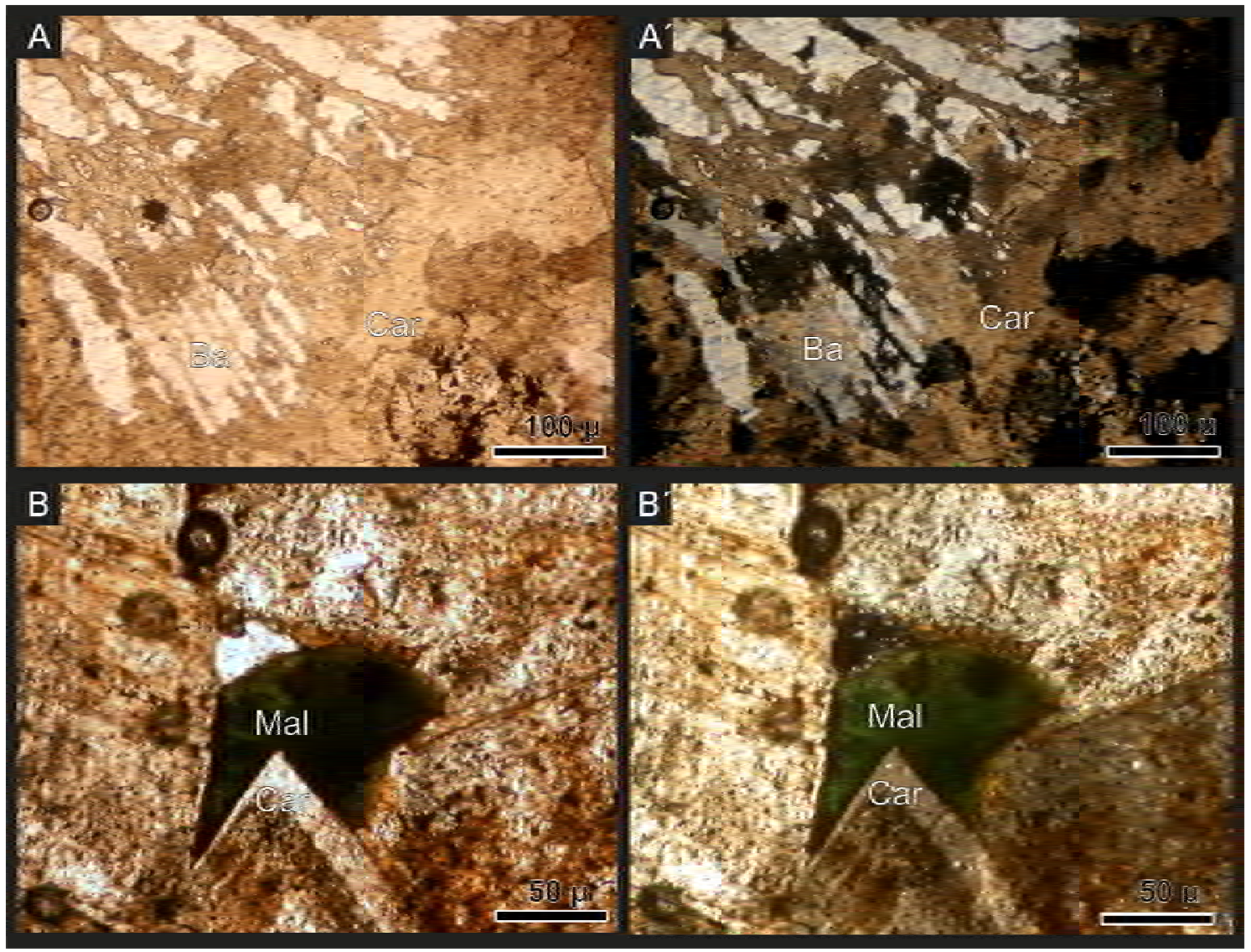

Fig. 5-6. Microfotografía de minerales transparentes de la veta Purísima. A) Baritina (Ba) intercrecida con carbonato (Car) perteneciente al segundo pulso. A'. Igual a la anterior, con analizador. B) Geoda con carbonato (calcita) del segundo pulso, escalenoédrica, rellena con malaquita (Mal) fibrosa radiada. B. Igual a la anterior, con analizador.

La bornita de hábito masivo contiene frecuentes texturas en llama con calcopirita. Ocasionalmente se encuentra rodeando a gersdorffita en pequeños cristales aislados. La galena es muy escasa y se encuentra formando cristales aislados ipidiomorfos, hasta centimétricos, con bordes sinuosos, corroídos, asociada con bornita, tetraedrita y calcopirita. Esta última se encuentra, además de la textura en llamas, como pequeños individuos aislados con bordes redondeados. La covelina se encuentra comúnmente rodeando a los minerales de cobre y de ganga creciendo a partir de fracturas en calcosina (Fig. 5-7A y 5-7D), con textura fibrosa radiada.

\section{Arseniuros y sulfoarseniuros}

La niquelina se presenta en agregados de cristales alotriomorfos con tamaño de grano variable (Fig. 5-8A, 5-8B, 5-8C), algunos casos presenta zonación (Fig. 5-8F). También se observa en pequeños individuos rodeados de gersdorffita, particularmente 
cuando está incluida en cristales de calcosina, tetrahedrita-tennantita y en menor medida en bornita.

La gersdorffita es el sulfoarseniuro más frecuente, se presenta en cristales con buen clivaje en dos direcciones conformando microvetillas en tetrahedrita-tennantita. También se lo observa, como se mencionó anteriormente, como pequeños cristales aislados desarrollados en tetrahedrita-tennantita, calcosina y bornita. Asimismo se reconocen finas bandas 0 anillos rodeando cristales de tetrahedrita-tennantitacalcosina y un hábito similar alrededor de niquelina. También se encuentra rellenando las fracturas radiales de los agregados botroidales de pechblenda (Fig. 5-8B, 5-8C, 5$8 \mathrm{E})$.

La millerita es muy escasa, fue reconocida solo un pequeño cristal en contacto con pechblenda y rodeado de gersdorffita.

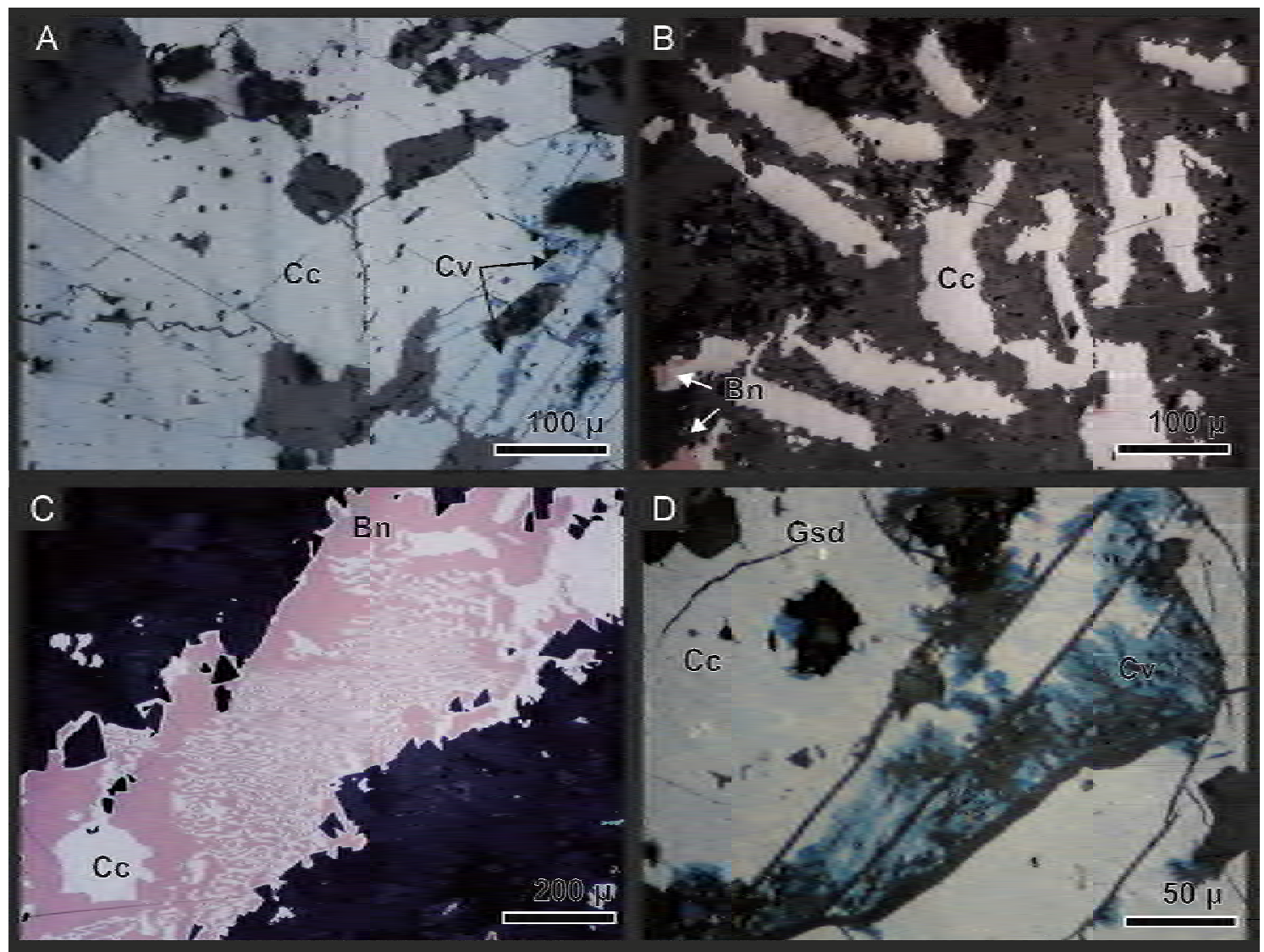

Fig. 5-7. Fotomicrografía de la asociación de sulfuros de la veta Purísima. A. Calcosina lamelar (Cc) parcialmente reemplazada por covelina (Cv) a partir de fracturas y en los bordes de los cristales. B. Calcosina esquelética con bordes corroídos asociada en algunos casos con bornita (Bn). C. Desmezcla mirmequítica entre bornita y calcosina. D. Cristales fibrosos de covelina vinculados a fracturas sobre calcosina lamelar con desmezcla de gersdorffita. En todos los casos las fotografías se tomaron sin analizador. 
La veta Purísima es la única en la que se reconoció pechblenda. Se identificó exclusivamente bajo microscopía, en forma de cintas discontinuas con múltiples repliegues, de hábito botroidal que internamente exhiben bandas de crecimiento, rodea y es rodeada por niquelina (Fig. 5-8A, 5-8B, 5-8C y 5-8E). Las bandas presentan grietas y fracturas radiales que son rellenas por gersdorffita que localmente imprimen una textura brechosa (Fig. 5-8B). Los óxidos e hidróxidos de hierro secundarios, posiblemente como producto de alteración de los sulfuros, son muy frecuentes y se presentan como vetillas o rellenando oquedades centimétricas. La malaquita y azurita forman cristales pequeños con textura fibrosa y se presentan asociadas con calcita fina conformando finas vetillas milimétricas.
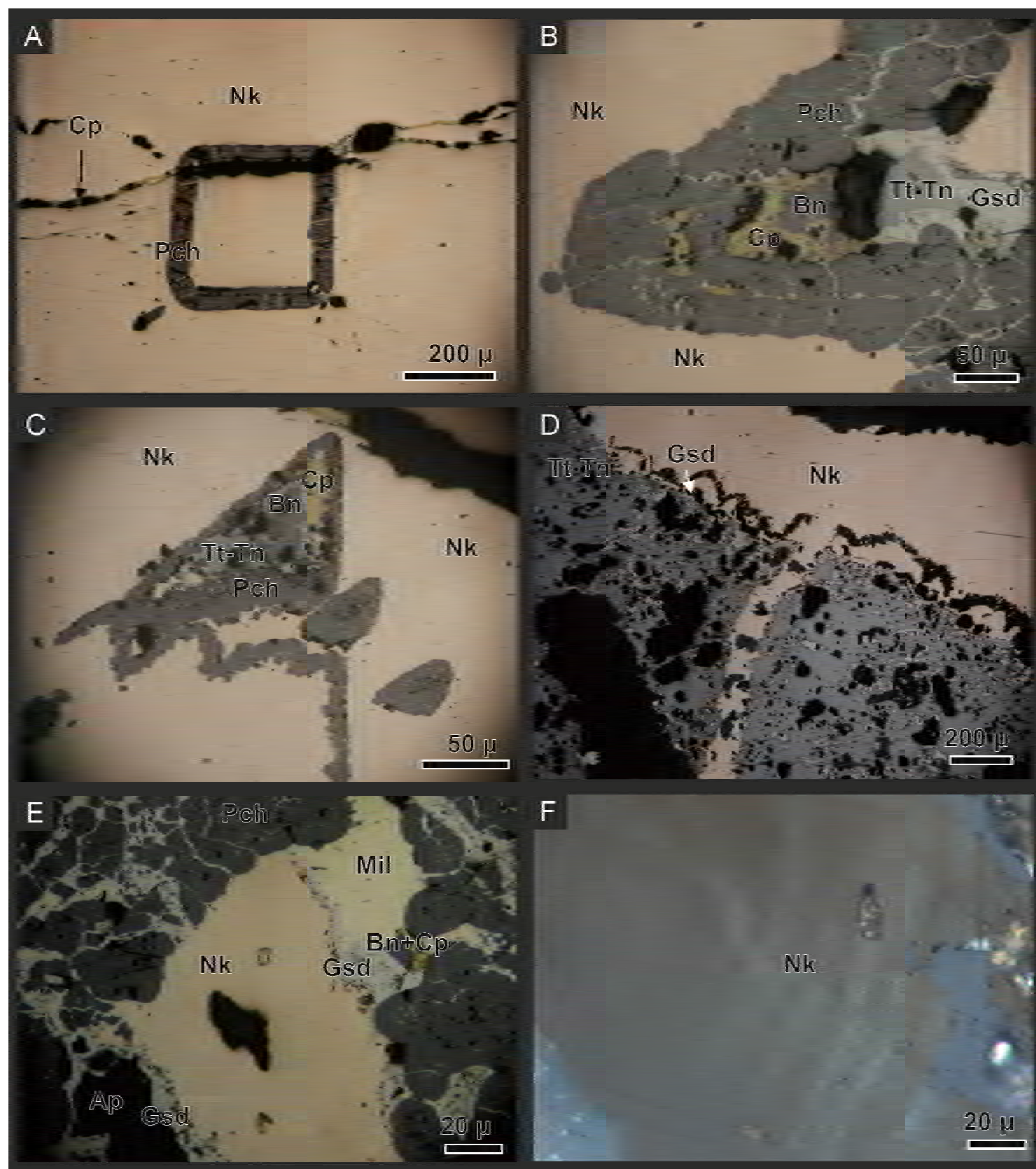

F

Fig. 5-8. A. Anillo de pechblenda (Pch) de hábito botroidal en niquelina (Nk), las grietas en la pechblenda 
son rellenas con gersdorffita (Gsd). Atraviesa una vetilla de calcopirita. B Detalle donde se observa calcopirita bornita (Bn) tetrahedrita-tennantita ( $\mathrm{Tt}-\mathrm{Tn})$ y gersdorffita rodeados de pechblenda y niquelina. C. Cristales de calcopirita, bornita y tetrahedrita-tennantita rodeados de pechblenda con fracturas rellenas de gersdorffita rodeados de niquelina. D. Microvetilla de niquelina cortando tetrahedrita-tennantita con microinclusiones de gersdorffita. E. Millierita (Mill) rodeada por gersdorffita, niquelina y pechblenda. F. Cristal zonado de niquelina. Con excepción de F, todas las fotomicrografías sin analizador.

\section{$\underline{\text { Veta Rumicruz }}$}

La veta Rumicruz tiene un azimut de $127^{\circ}$ e inclina $46^{\circ}$ NE. Su longitud en planta es de aproximadamente $50 \mathrm{~m}$, con una potencia de 0,8 m (Fig. 5-9). Consiste en una brecha con clastos de caja y fragmentos de veta cementados con nuevos pulsos de actividad hidrotermal. Predomina el cemento de óxidos de hierro, carbonatos, baritina y fragmentos de sulfuros con grandes cristales de galena de hasta $1 \mathrm{~cm}$. En contacto con la pared sur de esta veta se aloja una veta de cuarzo subparalela, que hacia el norte se flexiona hacia el este, con 0,6 m de espesor en promedio. Está formada por cristales de cuarzo finos atravesado por finas vetillas de óxido de hierro.

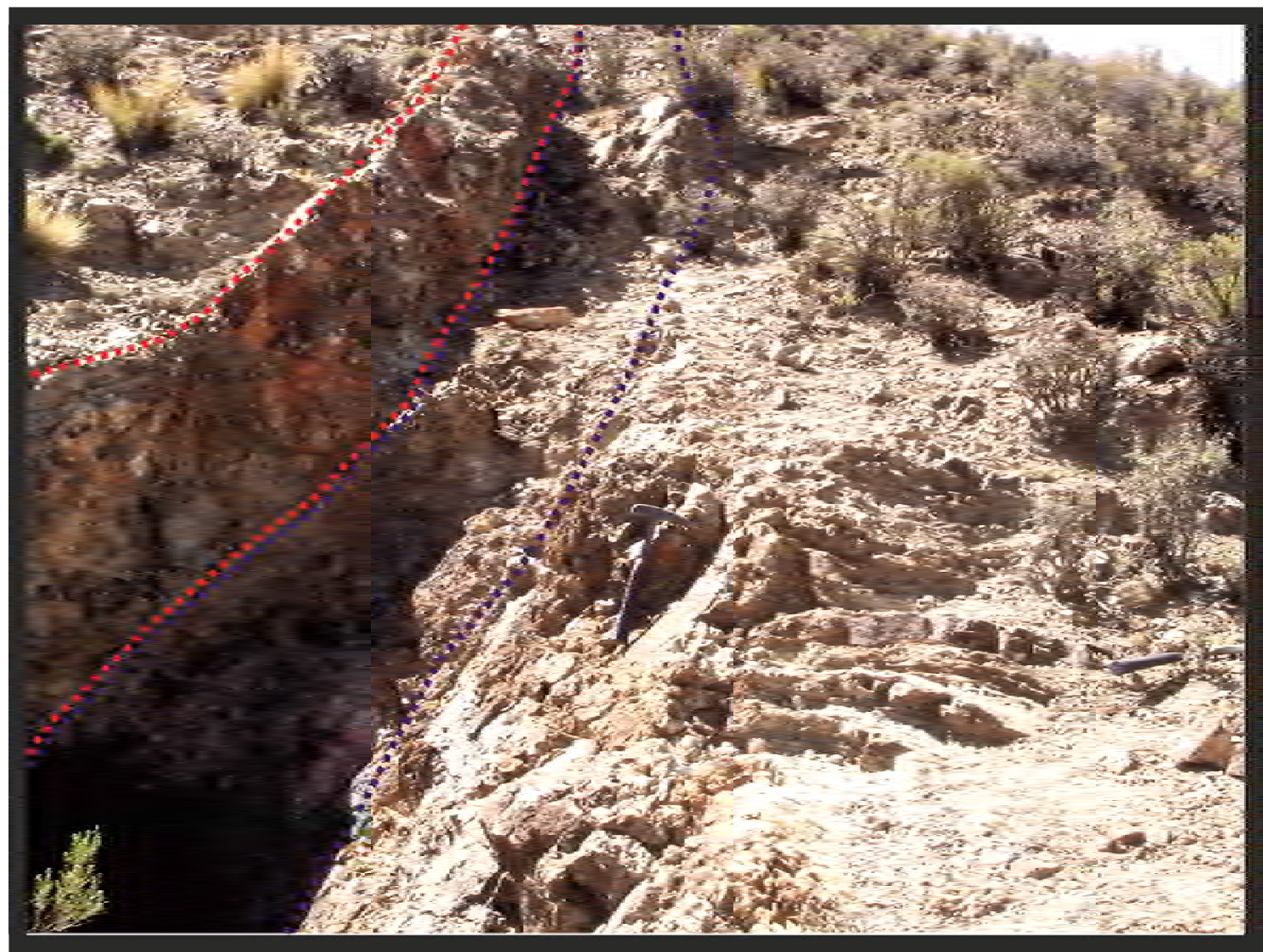

Fig. 5-9. Veta Rumicruz. En rojo veta de cuarzo con vetilleo de oxido de hierro. En azul veta con sulfuros de $0,8 \mathrm{~m}$ de potencia.

Esta veta con estructura brechosa contiene clastos de la roca de caja, con un primer relleno de carbonato parcialmente reemplazado por cuarzo transparente a blanco, una segunda generación de cuarzo y sulfuros, principalmente galena, con cristales panidiomorfos individuales o agrupándose en vetillas delgadas. 
Posteriormente precipitó un segundo carbonato, luego baritina rosa y óxidos e hidróxidos de hierro y siderita que conforma agregados con hábito masivo, botroidal y en roseta (Fig. 5-10).

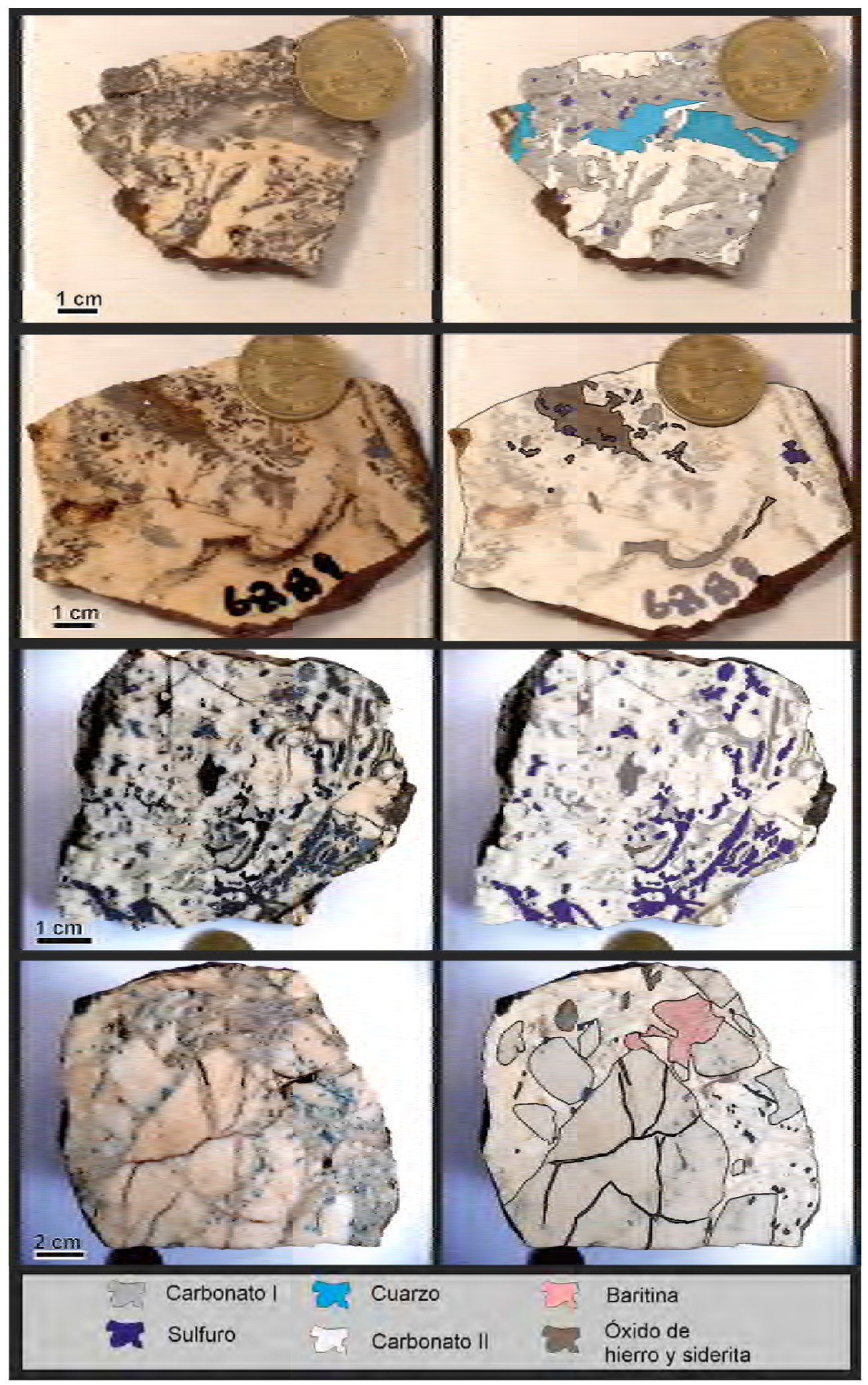


Fig. 5-10. Mineralogía y relaciones de corte en muestras de mano correspondiente a la veta Rumicruz. El primer pulso es de carbonato I y sulfuros, luego precipita cuarzo, reemplazando parcialmente al carbonato I, continúa un segundo pulso de carbonato II, luego baritina rosa, seguido de óxidos de hierro y siderita.

El cuarzo se presenta con dos texturas, (1) como cristales hipidiomorfos hexagonales, conformando individuos gruesos, de hasta $1 \mathrm{~cm}$ y con bandas de inclusiones fluidas (Fig. 5-11A), posiblemente primarias. Hacia los bordes de los cristales pueden reconocerse pequeñas inclusiones relícticas de carbonato. Además se reconocieron (2) agregados de cristales finos con texturas de reemplazo sobre carbonato (Fig. 5-11B).

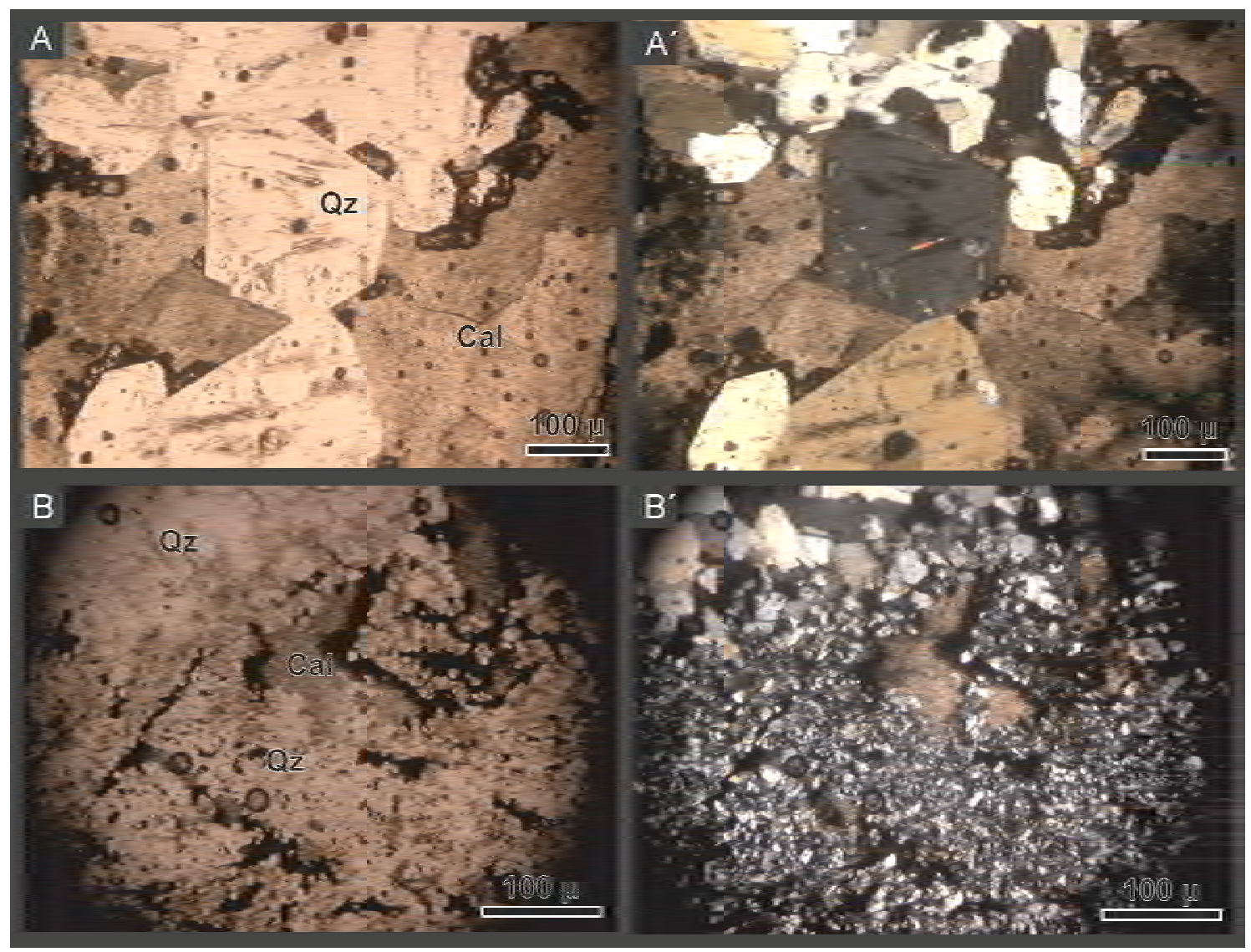

Fig. 5-11. A. Cristales de cuarzo (Qz) grueso ipidiomorfos con bandas de crecimiento evidenciadas por inclusiones fluidas (IF), rodeados de calcita (Cal). A'. Igual que la anterior, con analizador. B. Textura de reemplazo de carbonato por cuarzo microcristalino. B'. Igual a la anterior, con analizador.

En la veta Rumicruz se determinaron los siguientes minerales opacos: galena, calcopirita, tetraedrita, bornita calcosina, covelina y sulfosales de arsénico-antimonio con Ni, Co y Fe.

\section{$\underline{\text { Sulfuros }}$}

Los más abundantes son la galena y la calcopirita, seguidos por tetrahedritatennantita, escasa calcosina (Fig. 5-12A), bornita y covelina. La galena se encuentra 
conformando cristales cúbicos ipidiomorfos, de hasta $0,7 \mathrm{~cm}$, los bordes de los cristales frecuentemente son sinuosos con evidencias de corrosión (Fig. 5-12B). La galena puede estar rodeada de un bandeado de calcopirita, ullmanita y falhore (Fig. 512C). La calcopirita se encuentra dentro de la galena, conformando individuos con bordes redondeados. También se presenta intercrecida en cristales gruesos de bornita con textura lamelar (Fig. 5-12D y 5-12E), o en vetillas o bandas cortando o rodeando galena. La tetrahedrita-tennantita se aprecia intercrecido con la galena y asociado a calcopirita (Fig. 5-12C), los cristales pueden ser hasta milimétricos y en imágenes de electrones retrodispersados se puede determinar una fina zonación (Fig. 5-12F). La covelina reemplaza a calcosina y bornita a partir de fracturas (Fig. 5-12A, D y E).

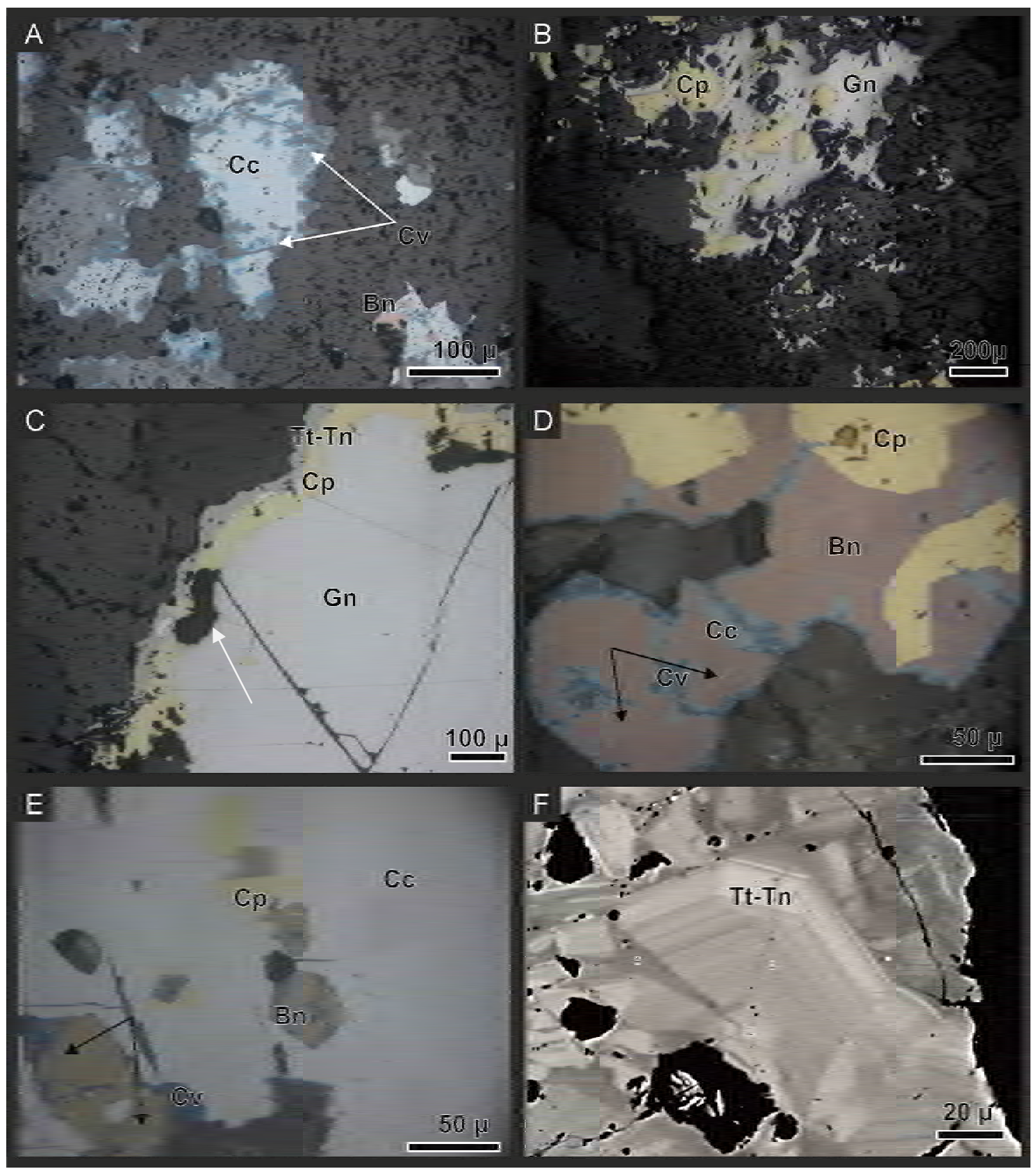

Fig. 5-12. A Cristales de calcosina con bordes corroídos (Cc) con covelina (Cv) creciendo a partir de 
fracturas y desde los bordes de los granos. B. Cristales de galena (Gn) incluyendo calcopirita con bordes redondeados. C. Bandeado coloforme compuesto por calcopirita (Cp), ullmanita (flecha blanca) y tetrahedrita-tennantita (Tt-Tn) creciendo sobre un cristal de galena (Gn). D. Bornita y calcopirita como cristales gruesos, textura lamelar de calcopirita en bornita (Bn) (flechas negras), covelina (Cv) reemplazando a bornita a partir de fracturas. E. Cristales de calcopirita y bornita con desmezcla de calcopirita dentro de calcosina. F. Imagen de electrones retrodispersados de un cristal fracturado de tetrahedrita-tennantita donde se puede apreciar una marcada zonación. Todas las fotos de microscopio calcográfico sin analizador.

\section{$\underline{\text { Sulfoarseniuros }}$}

Se reconocieron pequeños cristales de ullmanita asociados con galena, calcopirita y tetrahedrita-tennantita (Fig. 5-13A) y también fueron identificadas diversas variedades de gersdorffita, donde la variedad cobaltífera conforma pequeños cristales, ocasionalmente como parches dentro de individuos mayores de gersdorffita (Fig. 513B).

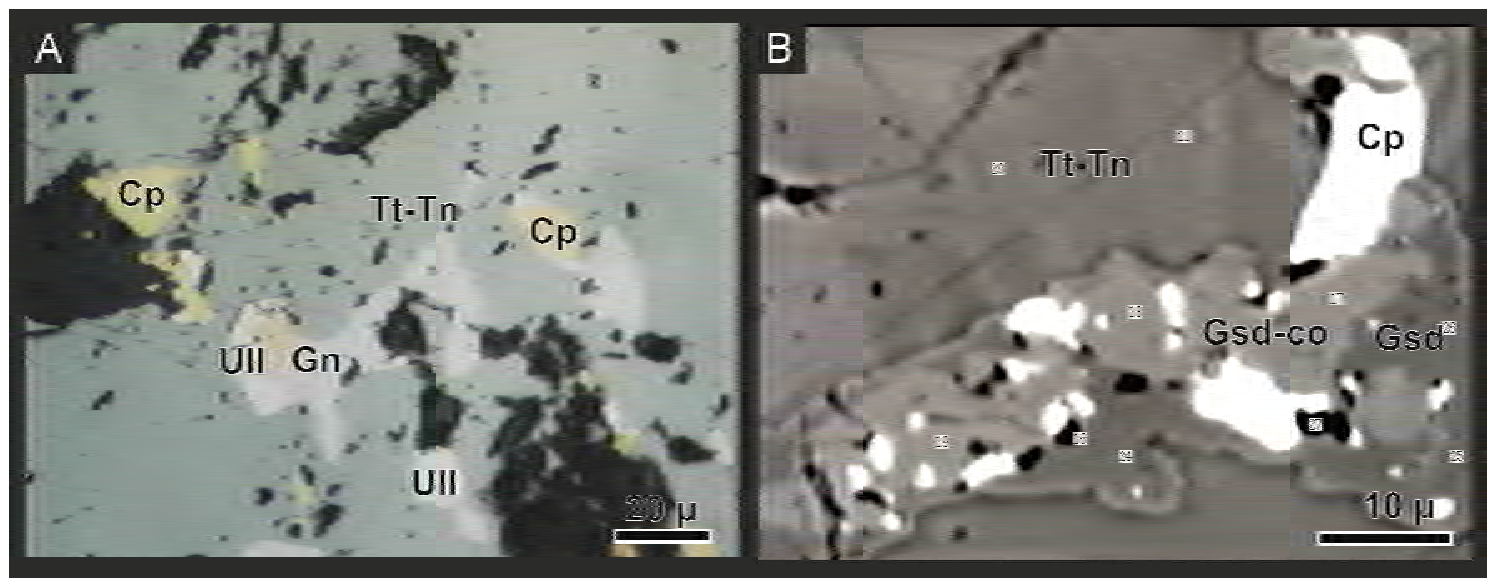

Fig. 5-13. A. Tetrahedrita-tennantita (Tt-Tn) pequeños cristales de calcopirita (Cp), ullmanita (UII) y galena (Gn), foto sin analizador. B. Imagen de electrones retrodispersados donde se pueden observar una cristal de gersdorffita (Gsd) con inclusiones de fases de gersdorffita cobaltífera (Gsd-Co), asociado a calcopirita, rodeados de tetrahedrita-tennantita (Tt-Tn) zonado.

\section{Minerales secundarios de la zona de oxidación}

La oxidación esta representada por óxidos e hidróxidos de hierro. Los carbonatos de cobre, al igual que en la veta Purísima se presentan dentro de vetillas, reemplazando sulfuros o rellenando oquedades.

\section{Veta Liliana}

Liliana es un conjunto de vetas con rumbos este-oeste y noroeste-sudeste, de textura brechosa con clastos de roca de caja y abundante relleno de baritina, óxidos de hierro, escasa calcosina y malaquita (Fig. 5-14). Las labores mineras de explotación de esta veta, una de las pocas a las que se pudo acceder, constan de un nivel con dos galerías horizontales sobre vetas (Fig. 5-15). 


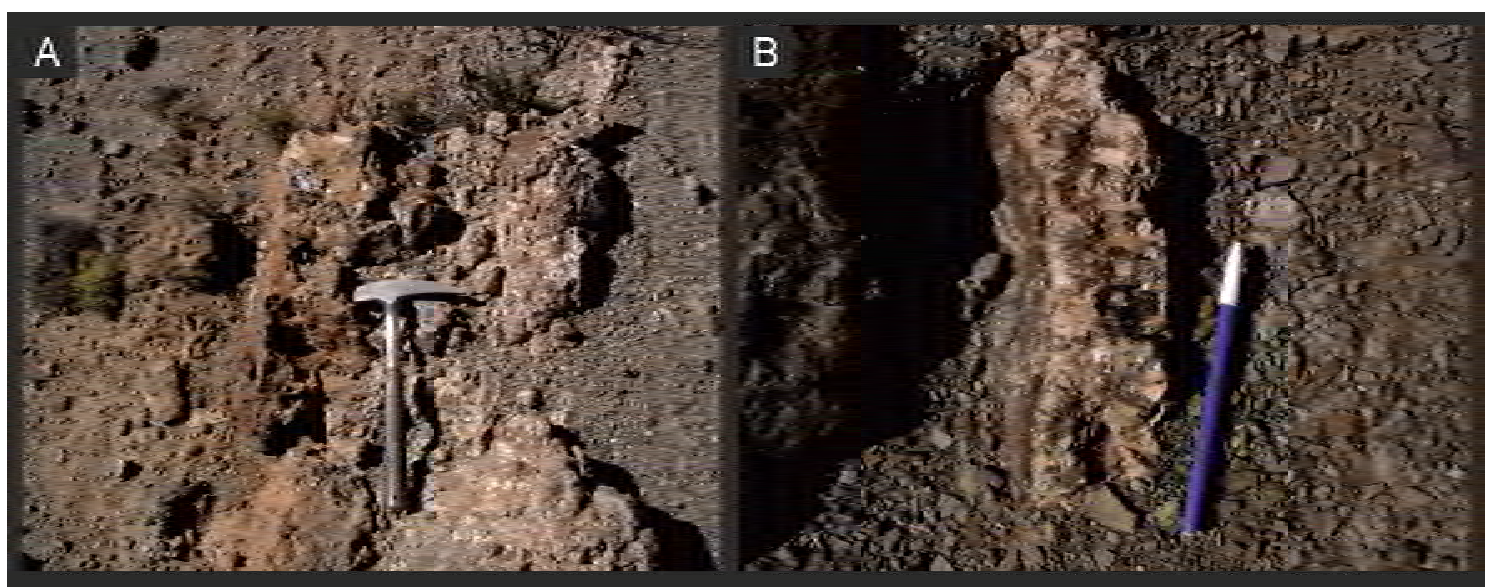

Fig. 5-14. Vetas del sistema Liliana. Los afloramientos presentan escaso contraste topográfico y son discontinuos. B Vetilla de baritina y óxidos de hierro.

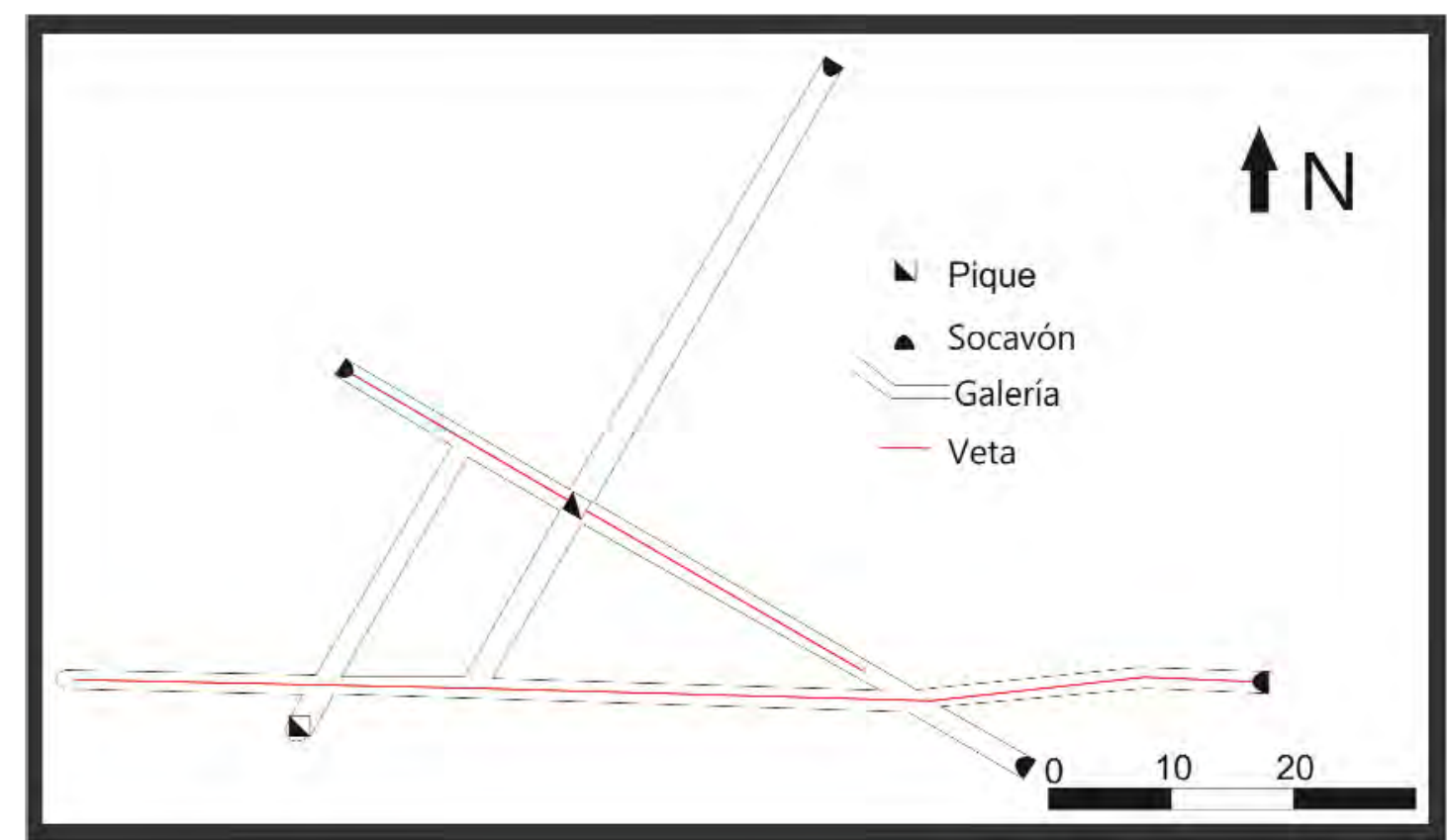

Fig. 5-15. Diseño en planta de labores de explotacion del conjunto de vetas Liliana. La explotación se realizó a partir de dos galerías horizontales desarrolladas sobre una veta con orientacion E-O y otra veta NW-SE.

La veta Liliana, al igual que las anteriores presenta una estructura brechosa (Fig. 516), con fragmentos de roca de caja angulosos. Se determinó un primer relleno de escaso cuarzo rodeando clastos de roca de caja (Fig. 5-17A), luego carbonato (I) con pequeños cristales de sulfuros. Posteriormente precipita otro carbonato, posiblemente dolomita, y toda la secuencia es brechada y cementada luego por un posterior pulso de carbonato (II). Este último es el más abundante en la veta y microscópicamente se determino la presencia de más de una especie de carbonato (Fig. 5-17B). Corta como vetillas al primer carbonato y a la dolomita y también conforma geodas. Posteriormente precipita baritina de color rosa, con hábito tabular y prismático. Finalmente esta secuencia es atravesada por vetillas de óxido de hierro y siderita (Fig. 5-16; Fig. 5-17). 


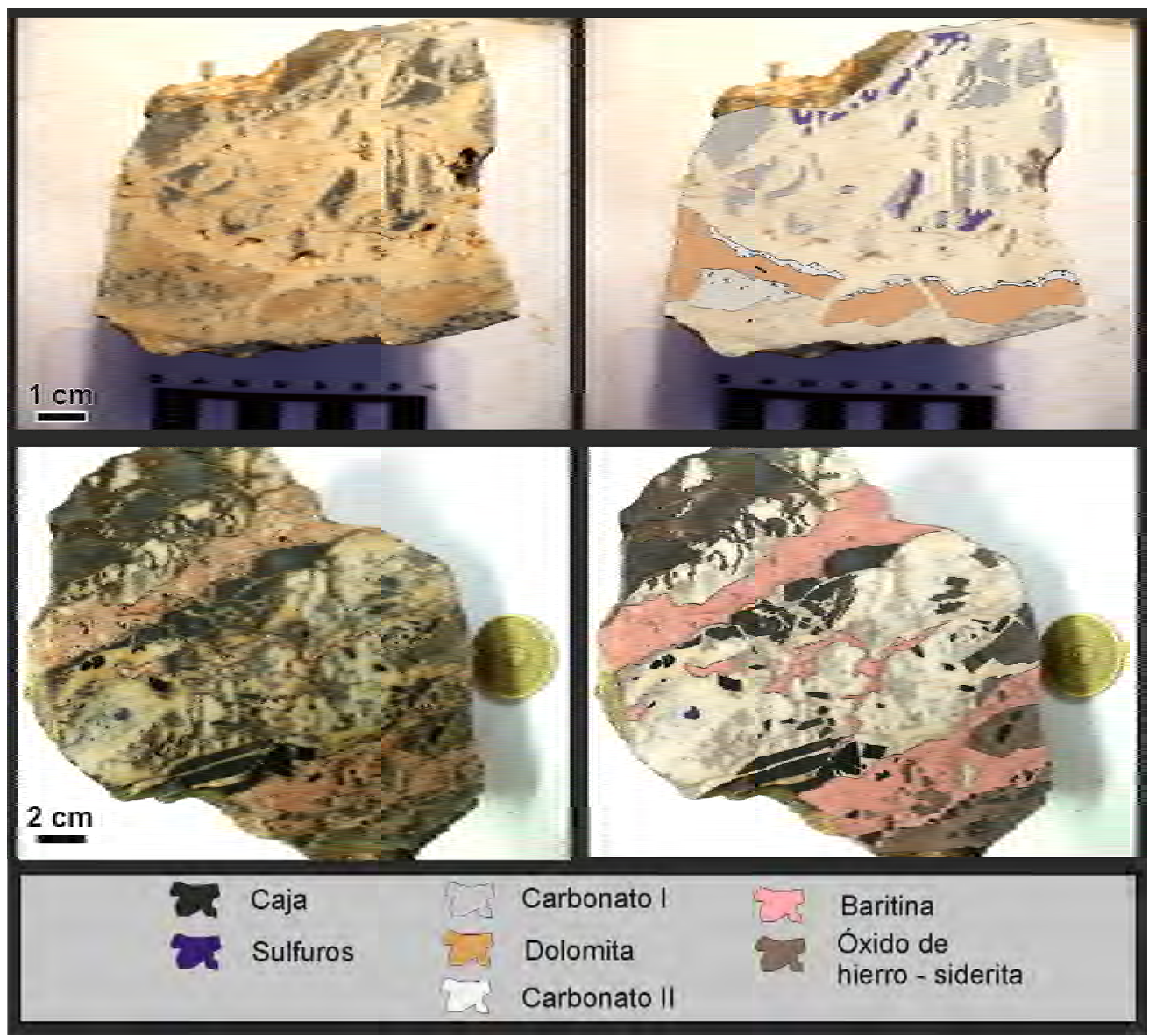

Fig. 5-16. Mineralogía y relaciones de corte de la veta Liliana. Comienza a precipitar cuarzo, luego un carbonato asociado a sulfuros, seguido por posible dolomita, luego otro carbonato que brecha a la secuencia previa, continúa la precipitación de baritina y finalmente vetillas de óxidos de hierro y siderita.

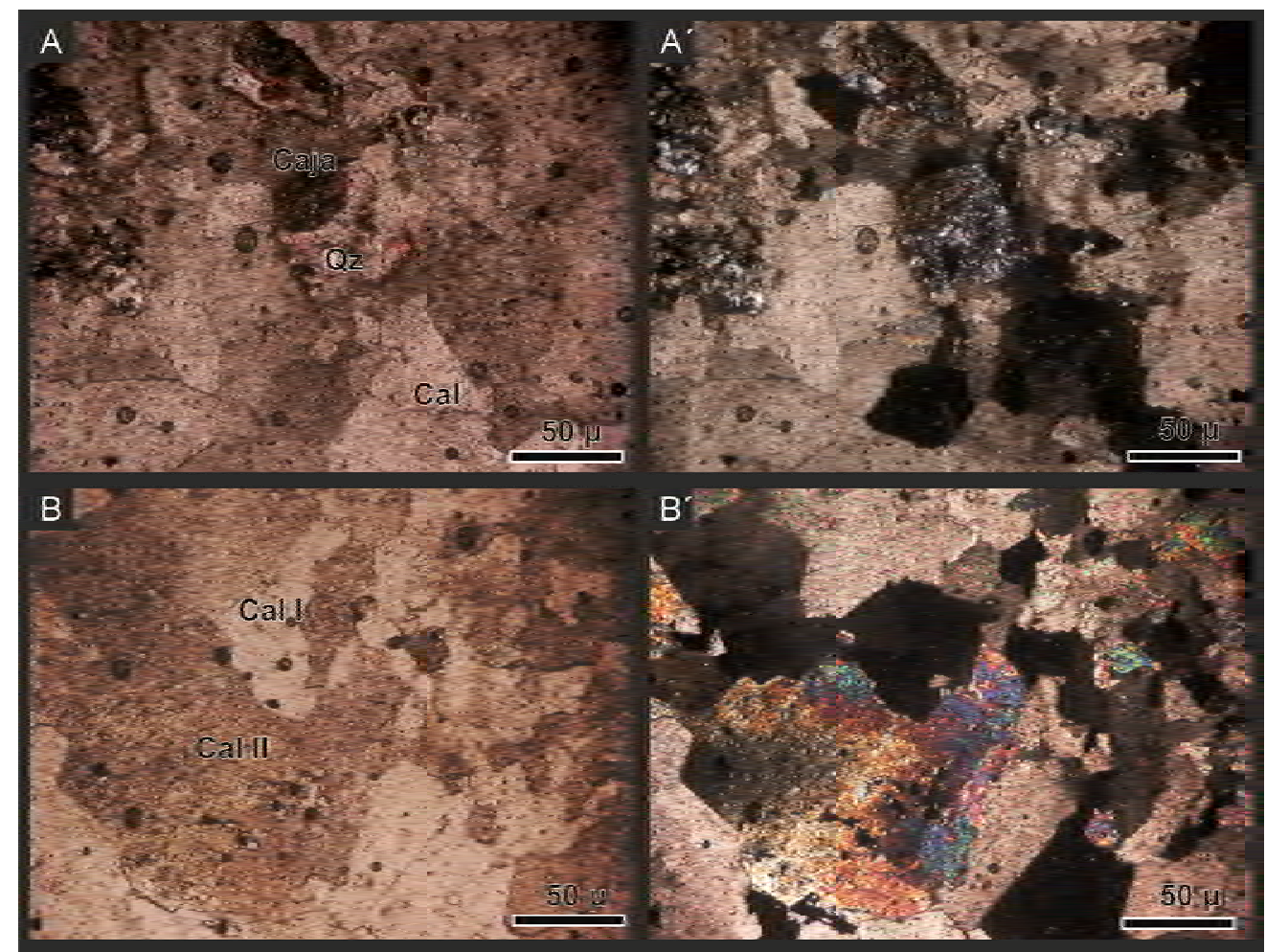

Fig. 5-17. A. Clasto de pelita rodeado por cuarzo fino, a su vez rodeado de carbonato, sin analizador y con analizador. B. Dos tipos de carbonato sin analizador y con analizador. 
El mineral más abundante es la calcosina, ocasionalmente con bordes corroídos, asociada con bornita (Fig. 5-18A, 5-18B, 5-18C). Se identificó tetrahedrita-tennantita con inclusiones de gersdorffita, calcosina azul anisótropa, que correspondiente a la variedad calcosina lamelar (sensu Ramdhor, 1980) (Fig. 5-18D), covelina con inclusiones de gersdorffita y bornita y raramente pequeños cristales de pirita.

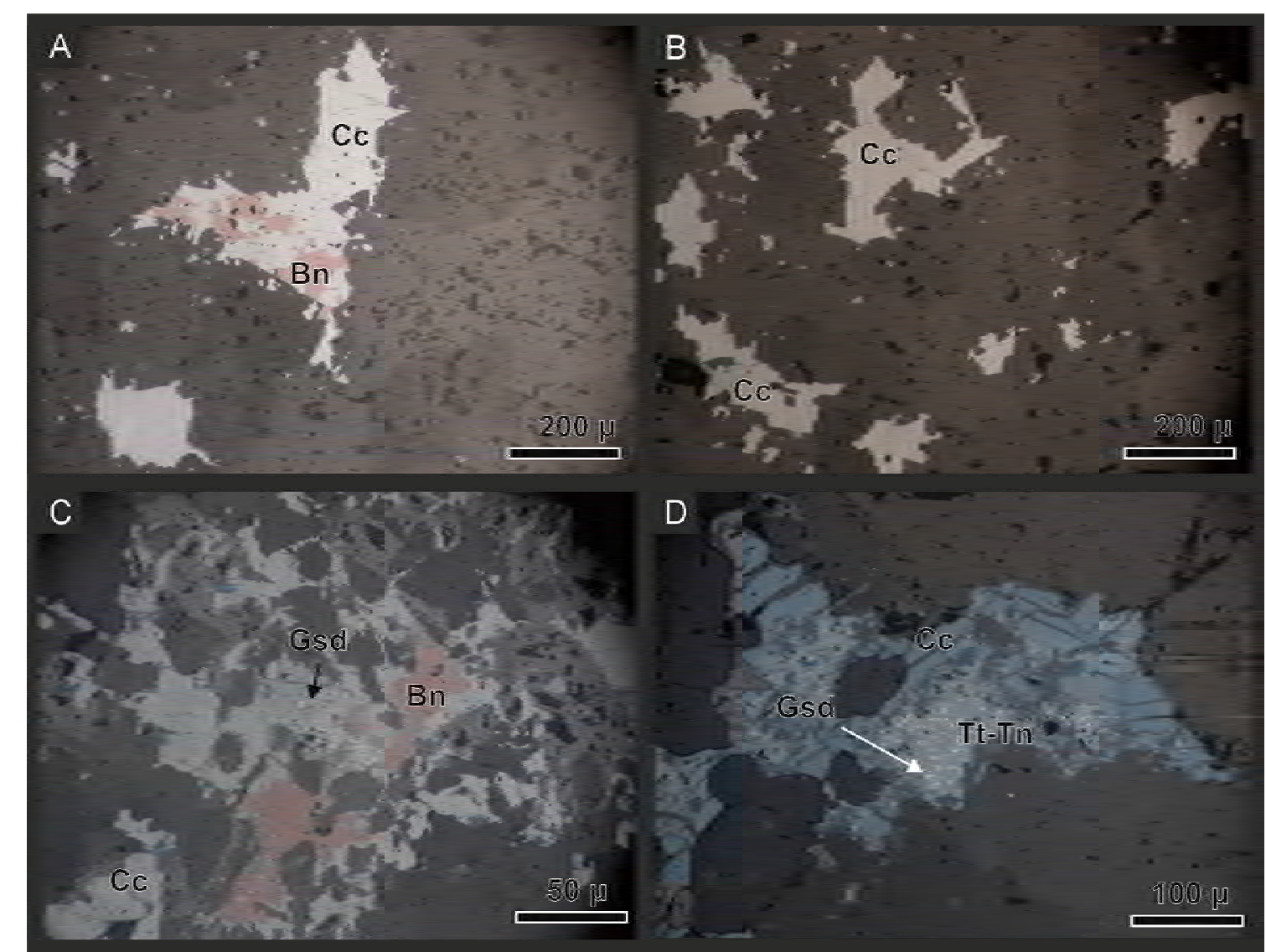

Fig. 5-18. A. Cristales de calcosina (Cc) y bornita (Bn) en calcita. B Cristales esqueléticos de calcosina con bordes corroídos. C. Asociación de calcosina, bornita y gersdorffita (Gsd). D. Calcosina lamelar, tetrahedrita-tennantita ( $\mathrm{Tt}-\mathrm{Tn}$ ) con inclusiones de gersdorffita. En todos los casos las fotografías se tomaron sin analizador. Sector El Brechón

Este sector ocupa un área rectangular de $300 \mathrm{~m}$ de largo por $250 \mathrm{~m}$ de ancho y contiene a los afloramientos de la veta el Brechón y vetas y vetillas menores, subparalelas en sentido NO-SE (Fig. 5-19) compuestas principalmente de baritina y en menor medida de sulfuros.

\section{Veta El Brechón}

Esta veta consiste en una brecha con clastos de roca de caja y relleno de baritina, escasa calcosina y óxidos de hierro con azimut 116 e inclinación $80^{\circ} \mathrm{NE}$. La potencia, si bien variable, alcanza hasta $4 \mathrm{~m}$ de espesor y una corrida superior a los $200 \mathrm{~m}$ (Fig. 
5-20). Los contactos con la caja se resuelven en un stockwork de baritina que disminuye progresivamente hacia fuera de la veta.

La secuencia mineralógica determinada en la veta El Brechón es similar a las descriptas anteriormente, aunque se destaca un amplio predominio de baritina respecto a los carbonatos.

Las vetas asociadas espacialmente a la veta El Brechón presentan cuarzo incoloro o blanco con cristales subhedrales cortados por vetillas finas de óxido de hierro y siderita (Fig. 5-21).

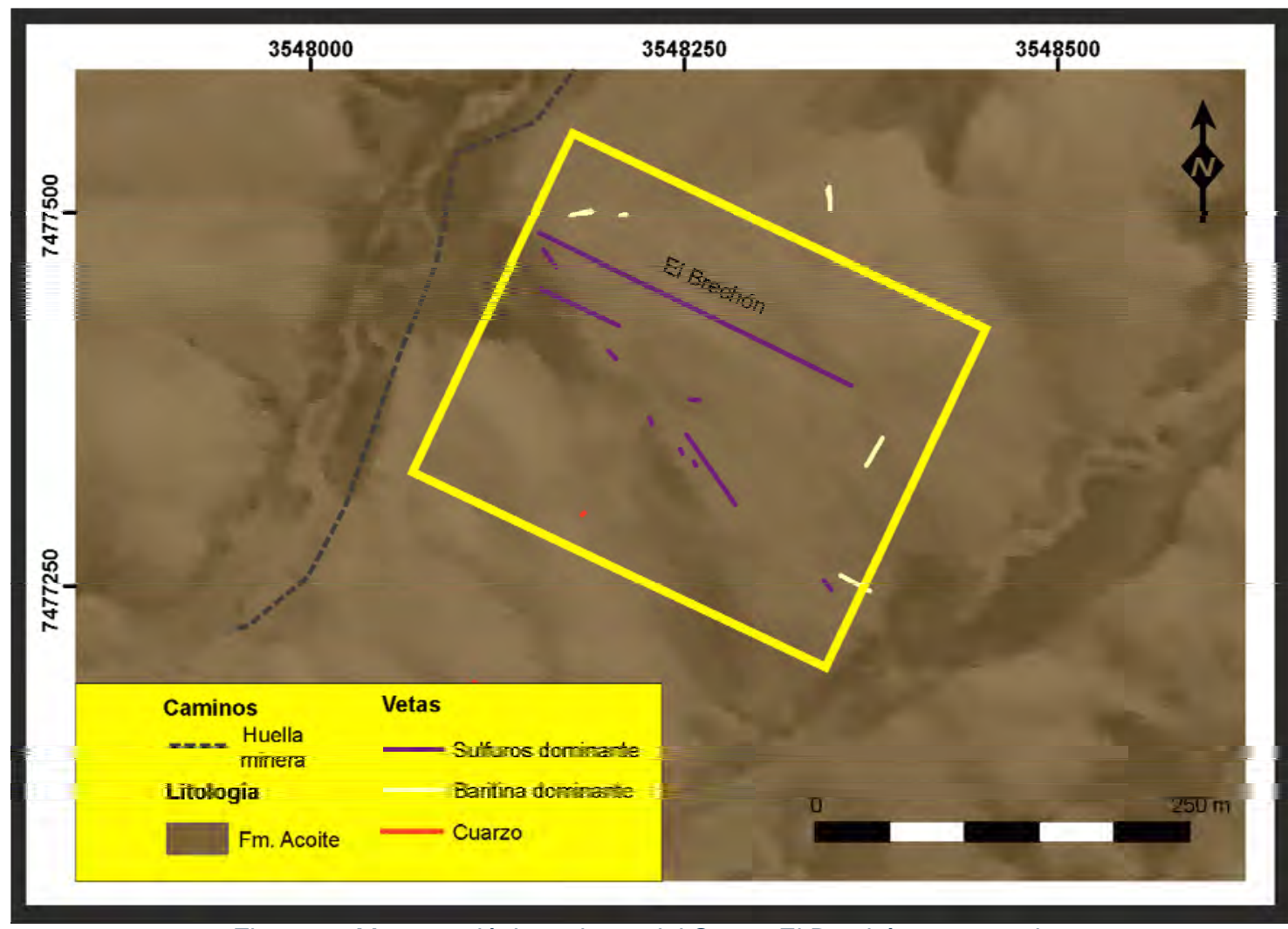

Fig. 5-19. Mapa geológico-minero del Sector El Brechón en recuadro 
El mineral opaco predominante es la calcosina masiva con escasa bornita intercrecida, calcopirita y covelina (Fig. 5-22A). La gersdorffita fue el único sulfoarseniuros reconocido (Fig. 5-22B).

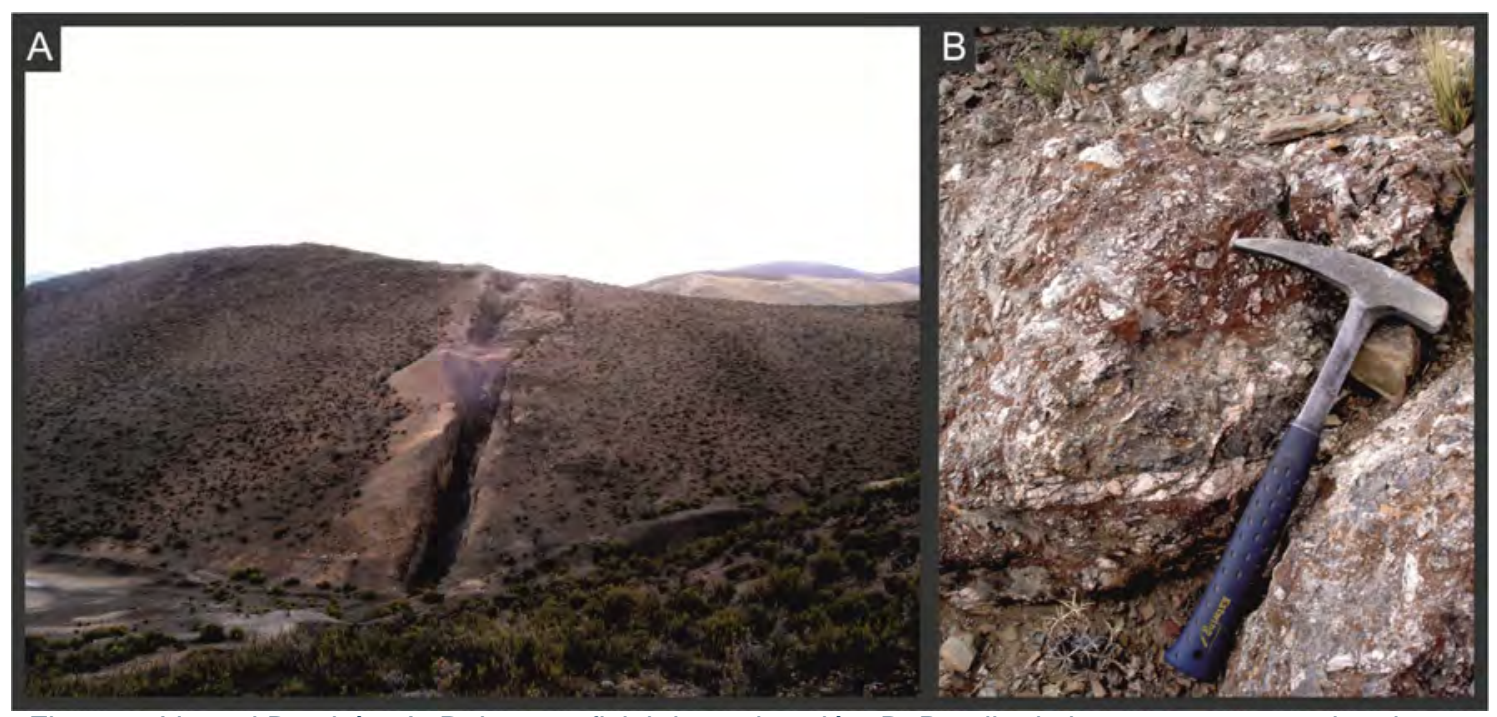

Fig. 5-20 Veta el Brechón. A. Rajo superficial de explotación. B. Detalle de la veta con textura brechosa con clastos de roca de caja, escasos sulfuros, baritina y óxidos de hierro.

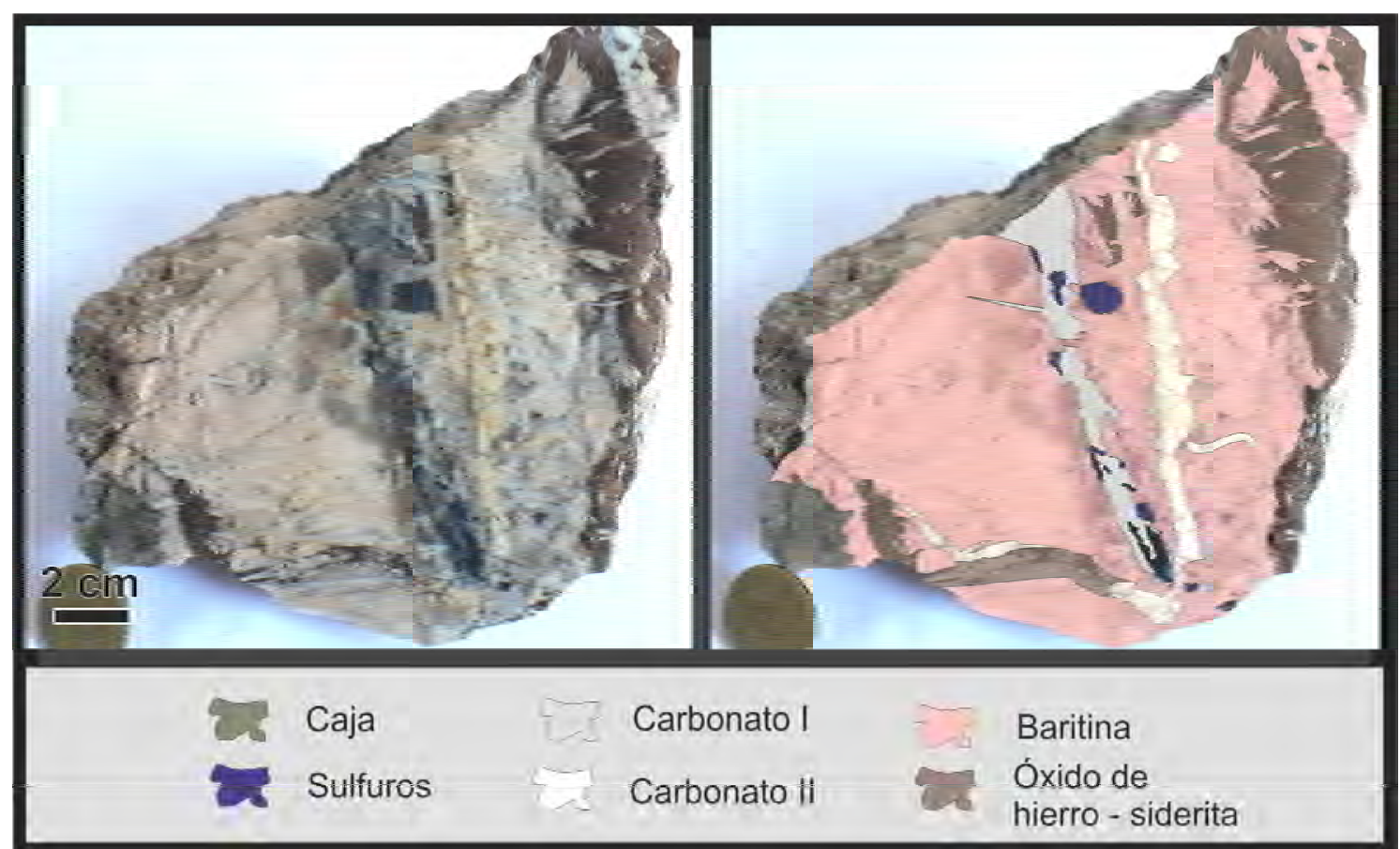

Fig. 5-21. Mineralogía y relaciones de corte en muestras de mano correspondiente a la veta El Brechón. La precipitación comienza con el carbonato I y sulfuros, posteriormente precipita el carbonato II. Luego continúa la precipitación de baritina, componente principal de la veta. Culmina la secuencia finas vetillas de óxidos de hierro y siderita. 


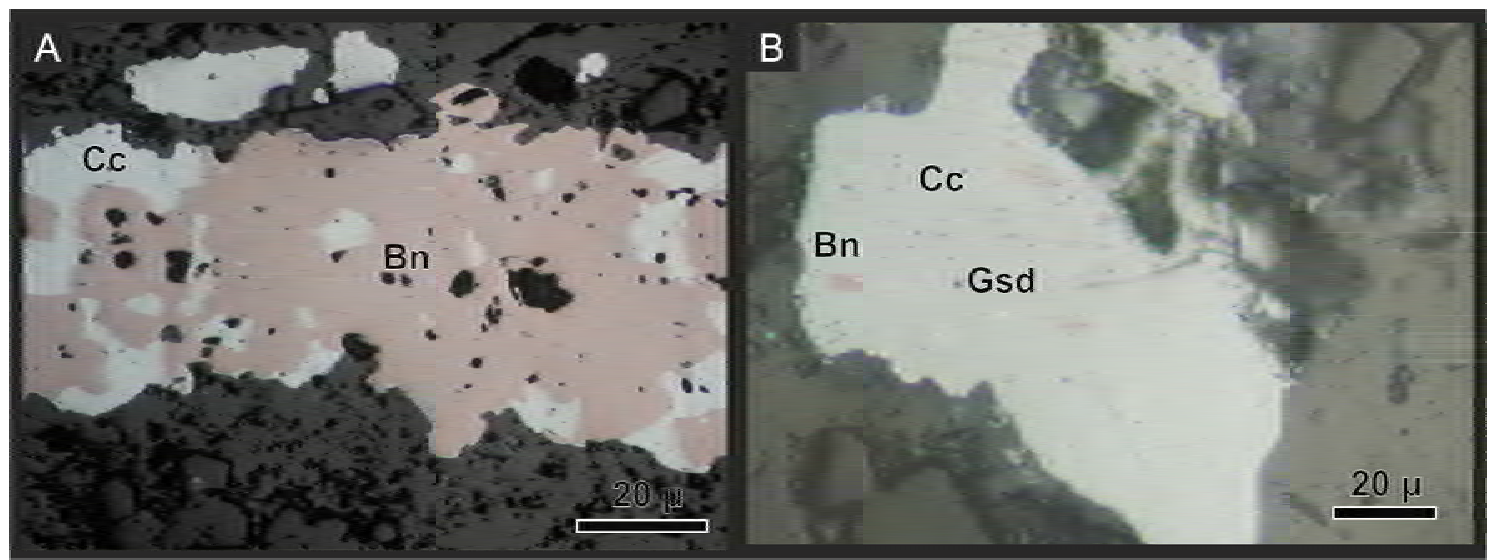

Fig. 5-22. A. Calcosina (Cc) intercrecida con bornita (Bn). B. Cristal de calcosina con pequeñas inclusiones de gersdorffita (Gsd) y de bornita. En ambos casos las fotografías se tomaron sin analizador.

\section{Sector La Nueva}

El sector La Nueva se encuentra ubicado en al noreste del distrito cubriendo un área de forma rectangular de $600 \mathrm{~m}$ de largo y $200 \mathrm{~m}$ de ancho en sentido ESE-ONO (Fig. 5-23). Fue definido por la presencia de la veta La Nueva y vetas y vetillas de sulfuros y baritina dominante asociadas.

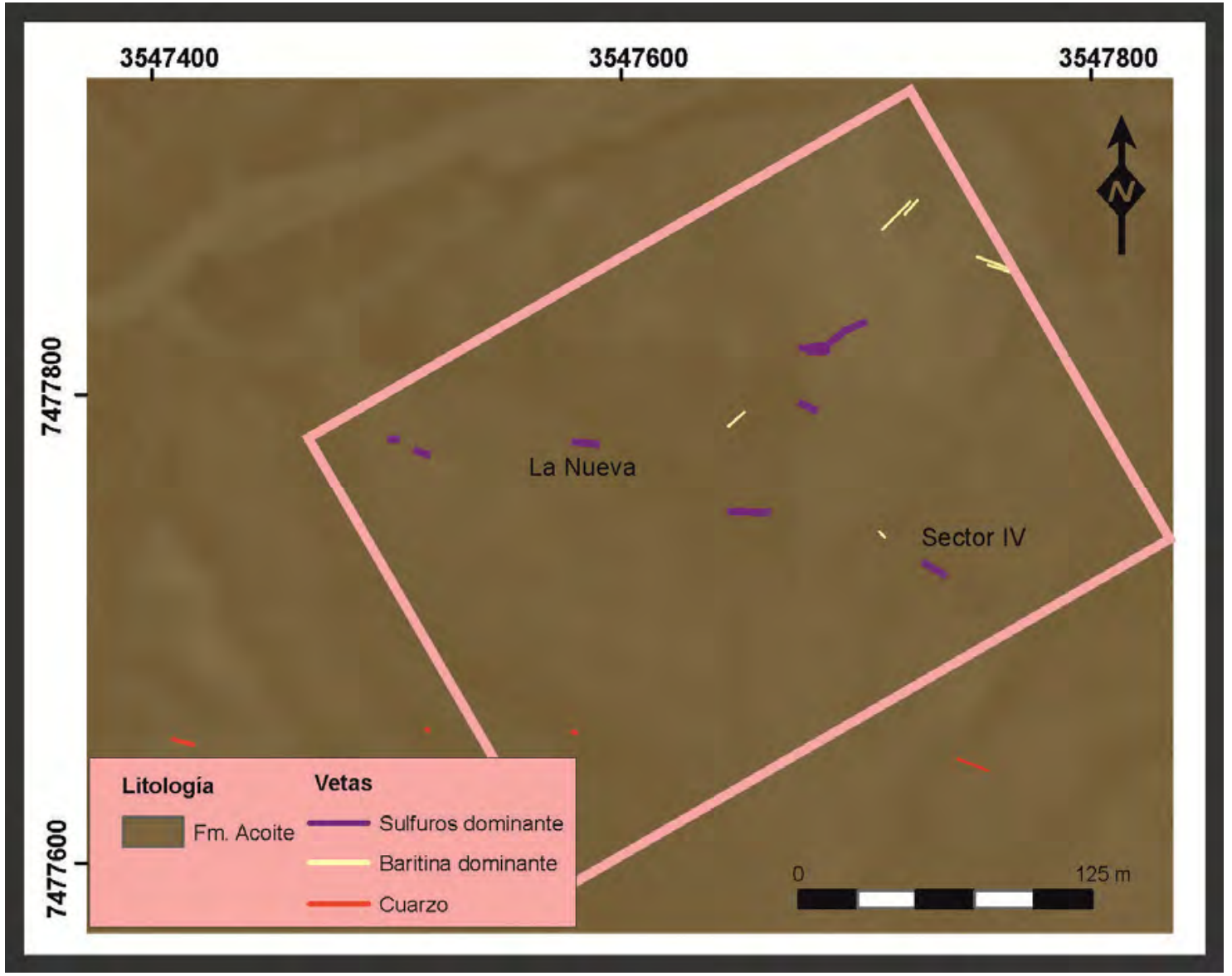

Fig. 5-23. Mapa geológico-minero del Sector La Nueva en recuadro 


\section{Veta La Nueva}

En esta veta se registró el mayor contenido de sulfuros de todo el distrito Purísima Rumicruz, tanto en afloramiento como en la escombrera, y es a su vez la que menor grado de explotación presenta. La veta es una brecha con clastos de roca de caja y sulfuros, principalmente calcosina, cementada por carbonatos, baritina y óxidos de hierro (Fig. 5-24A), presenta azimut $275^{\circ}$ e inclina $84^{\circ}$ hacia el norte. Esta estructura es acompañada por una faja de cizalla subparalela con abundantes vetillas de óxidos de hierro que inclina $70^{\circ}$ al norte (Fig. 5-24A).

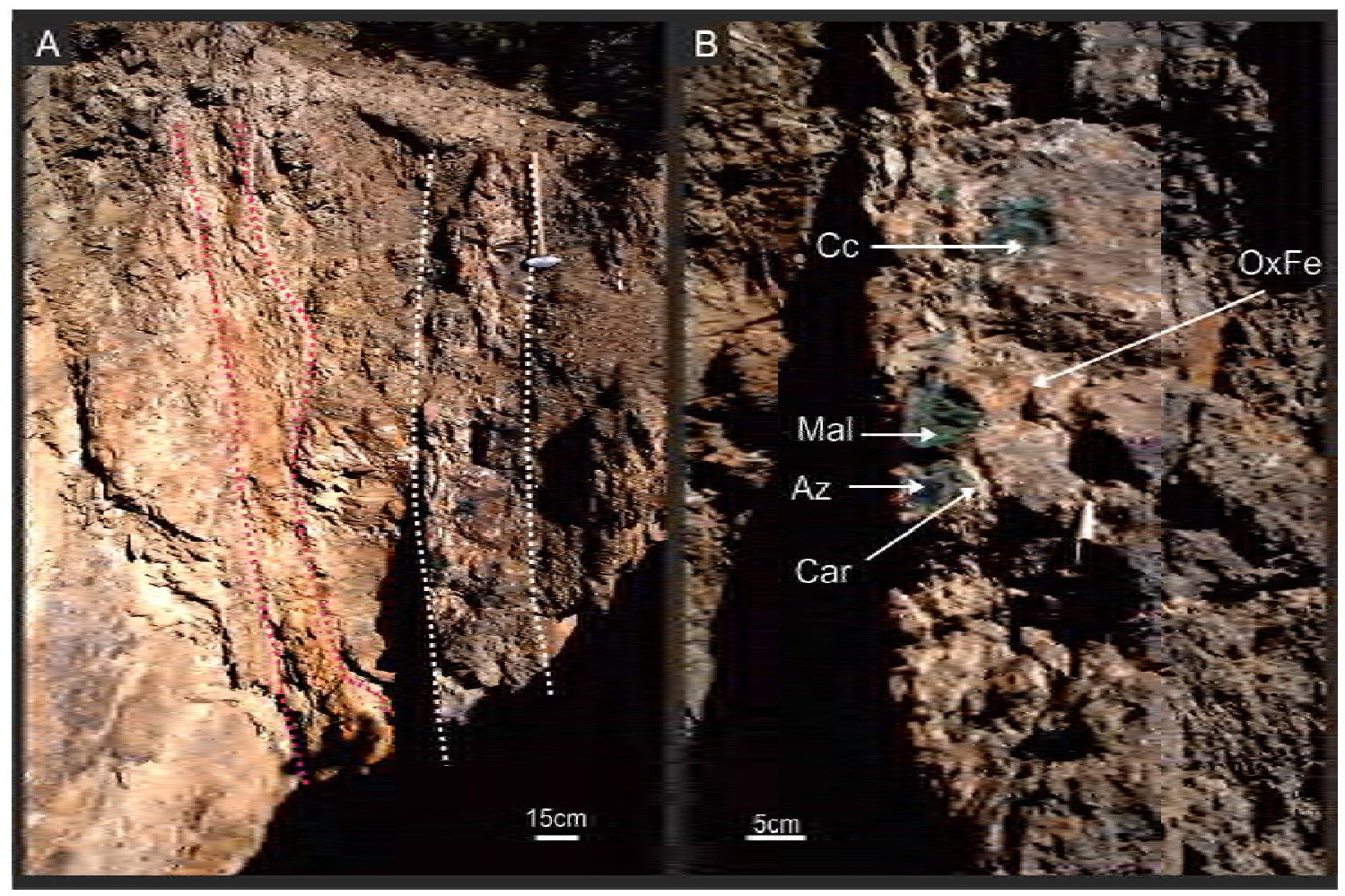

Fig. 5-24. Veta La Nueva A. Veta La Nueva (línea punteada blanca) con una faja de cizalla subparalela (línea punteada rojo). B. Detalle de la veta La Nueva compuesta principalmente por calcosina, calcita y óxidos de hierro. Son frecuentes los minerales secundarios, malaquita y azurita.

La veta La Nueva, al igual que las anteriores presenta una estructura brechosa, multiepisódica (Fig. 5-25), donde se reconoció un primer pulso que consta de cuarzo con dos variedades, uno microcristalino con textura de reemplazo de un mineral fibroso en enrejado, posiblemente calcita (platy) (Fig. 5-26A), y otro con cristales de morfología euhedral en las oquedades (Fig. 5-26C). Se sucede un brechamiento y precipitación de sulfuros. Luego precipita escaso carbonato, seguida por óxidos de hierro y siderita. Posteriormente ocurre un nuevo episodio de brechamiento y precipita baritina conformada por cristales gruesos y prismáticos, que ocasionalmente reemplaza a calcita. Culmina la secuencia con la precipitación de vetillas de calcita con malaquita y azurita (Fig. 5-26 B). 


\section{Sulfuros/sulfoarseniuros/óxidos}

De este grupo el mineral preponderante es calcosina con hábito tanto masivo (Fig. 5-27A), como lamelar (Fig. 5-27B), acompañado por bornita con cristales de hasta 10 micrones de diámetro y calcopirita (Fig. 5-27C). Covelina de hábito prismático, reemplaza a la calcosina a partir de fracturas (Fig. 5-27A). Cristales muy pequeños menores a $3 \mu$, posiblemente de gersdorffita, se encuentran también dentro de la calcosina. Mediante imágenes de electrones dispersados se reconoció un óxido de cerio y lantano alojado en oquedades (Fig. 5-27D), sin embargo estos elementos pueden ser contaminación en la preparación de la muestra.

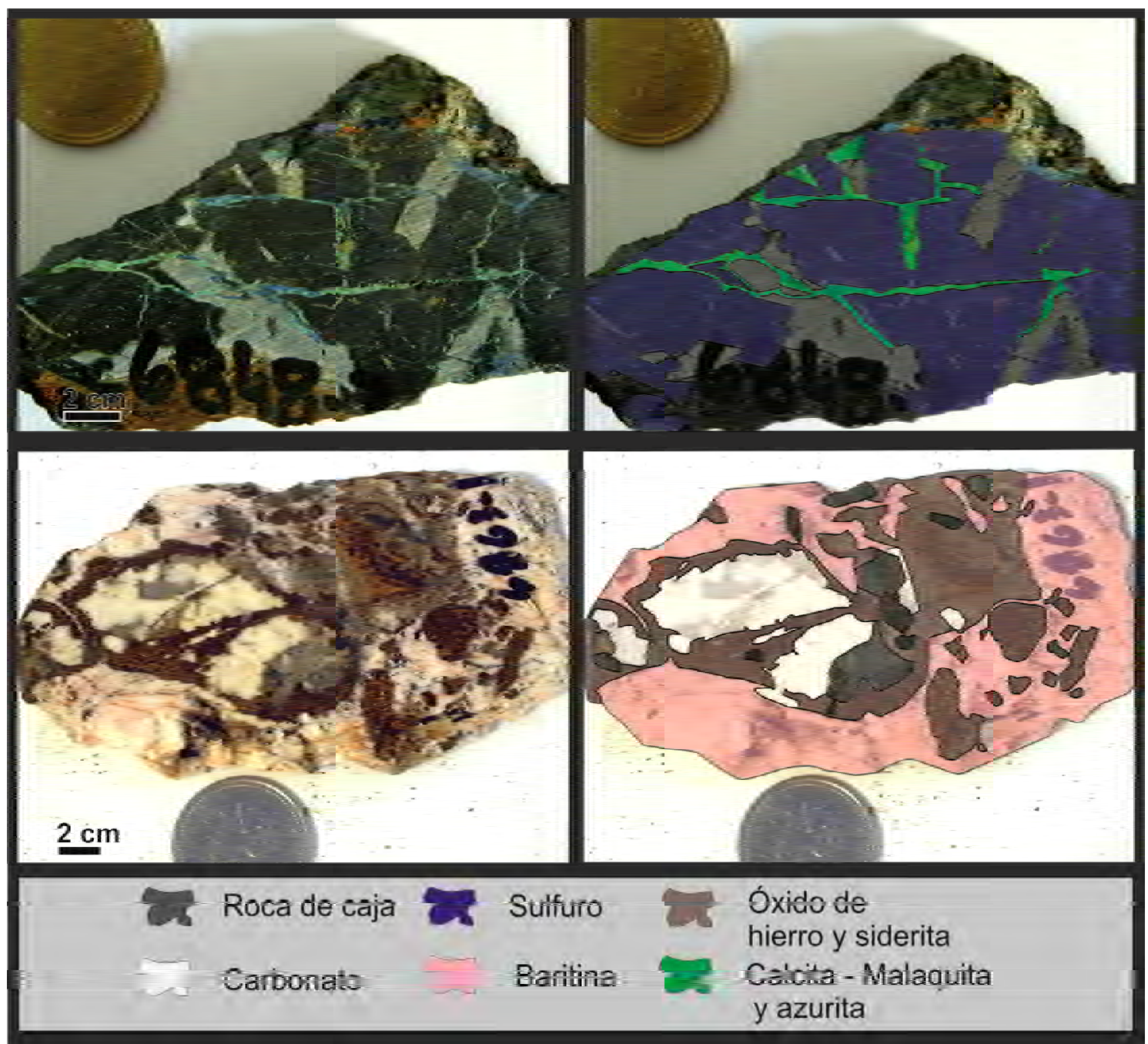

Fig. 5-25. Mineralogía y relaciones de corte en muestras de mano correspondiente a la veta La Nueva. El primer pulso es de dos variedades de cuarzo microcristalino y con cristales mayores euhedrales posteriormente precipitan sulfuros, seguidos por calcita, luego óxidos de hierro y siderita. Continua con un evento de de brechamiento con precipitación de baritina. Finalmente la secuencia es cortada por vetillas de calcita con malaquita y azurita. 

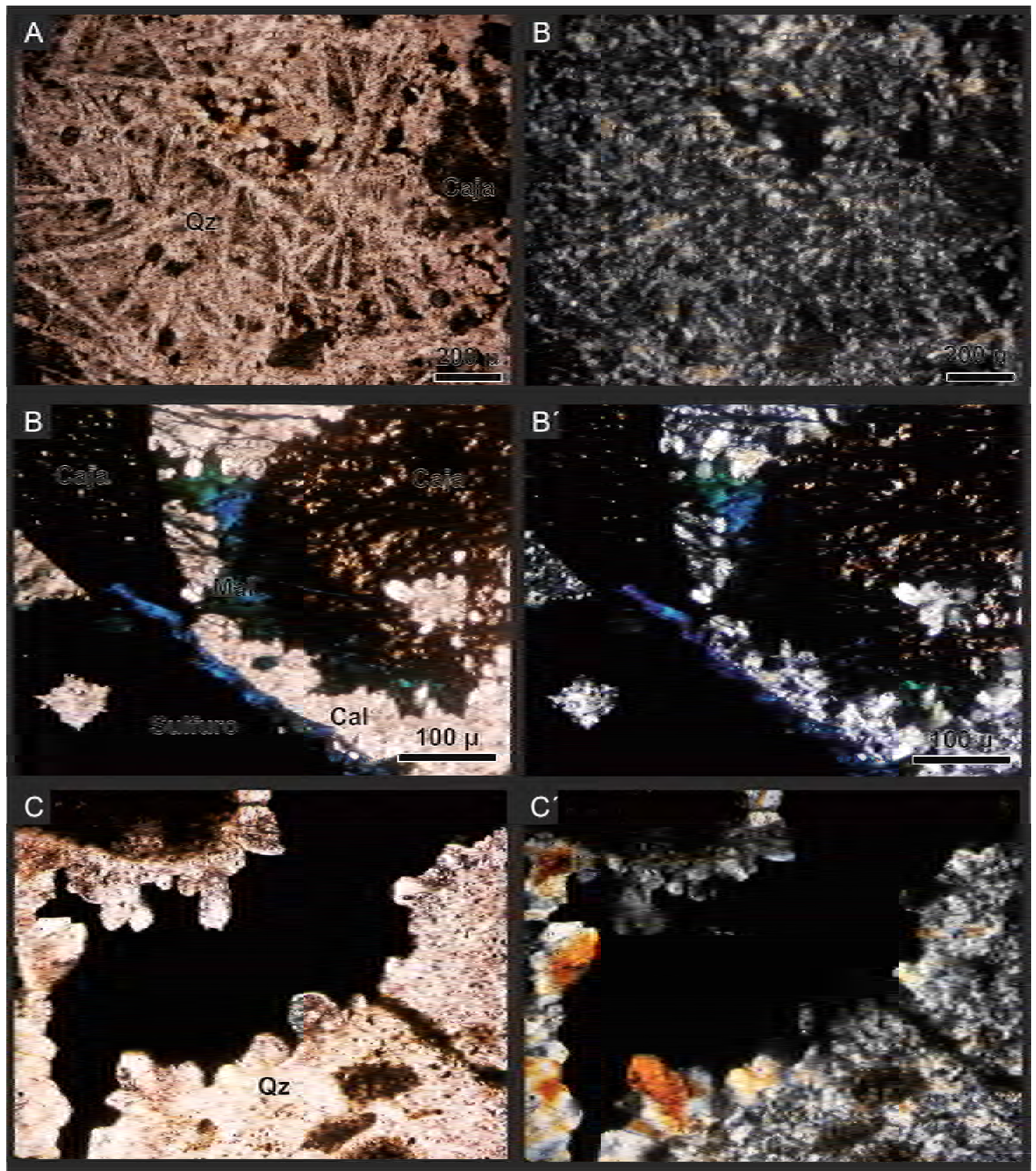

Fig. 5-26. A y A'. Textura de reemplazo de cuarzo microcristalino sobre platy calcita, sin y con analizador. B y B'. Vetillas de malaquita y azurita rodeando clastos de sulfuros y de roca de caja, sin y con analizador. C y C'. Cristales de cuarzo creciendo en cavidad rellena posteriormente con calcosina, sin y con analizador. 


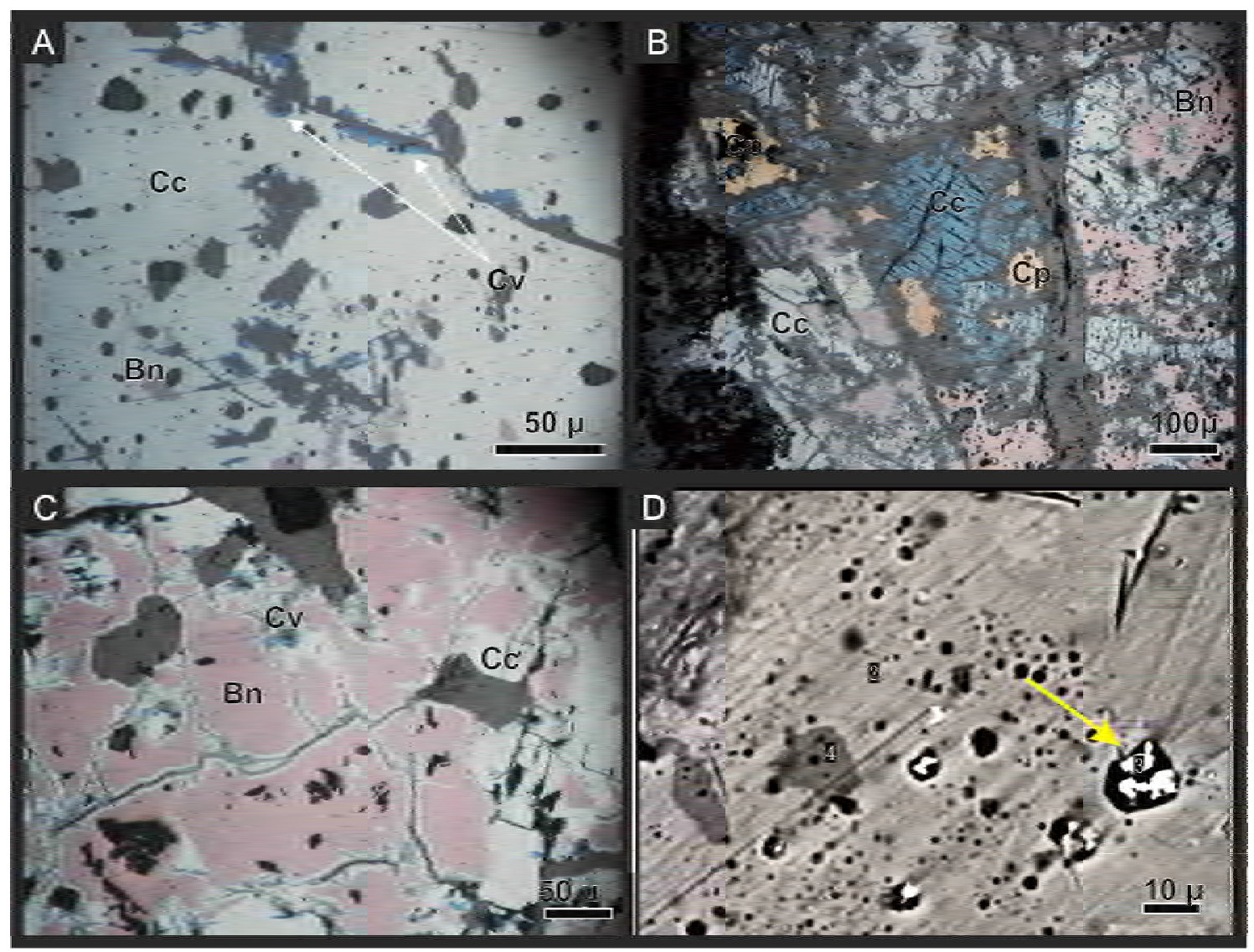

Fig. 5-27. A. Calcosina (Cc) con reemplazo de covelina en fracturas. La calcosina es el sulfuro más abundante de la veta La Nueva. B. Calcosina, calcosina lamelar, bornita (Bn) y calcopirita atravesada por vetilleo de óxidos de hierro. C. Calcosina rodeando cristales de bornita y crecimiento de covelina (Cv) a partir de fracturas. D. Calcosina con inclusiones de óxido de cobre, en las oquedades se aloja un óxido de cerio y lantano indicado con flecha amarilla.

\section{Área Jesuitas (Sector III)}

La veta Jesuitas o Sector III se encuentra al oeste del sector La Nueva (Fig. 5-28). Esta estructura fue estudiada debido a la existencia de un pique derrumbado siguiendo a una estructura subvertical definida por fracturas rellenas con óxidos de hierro (Fig. 529). Se registraron finas vetillas, ocasionalmente concordantes con la estratificación de las sedimentitas, con un espesor máximo de $2 \mathrm{~cm}$ con cristales de galena. En la escombrera de esta labor se obtuvieron muestras para los análisis mineralógicos, geoquímicos e isotópicos. 


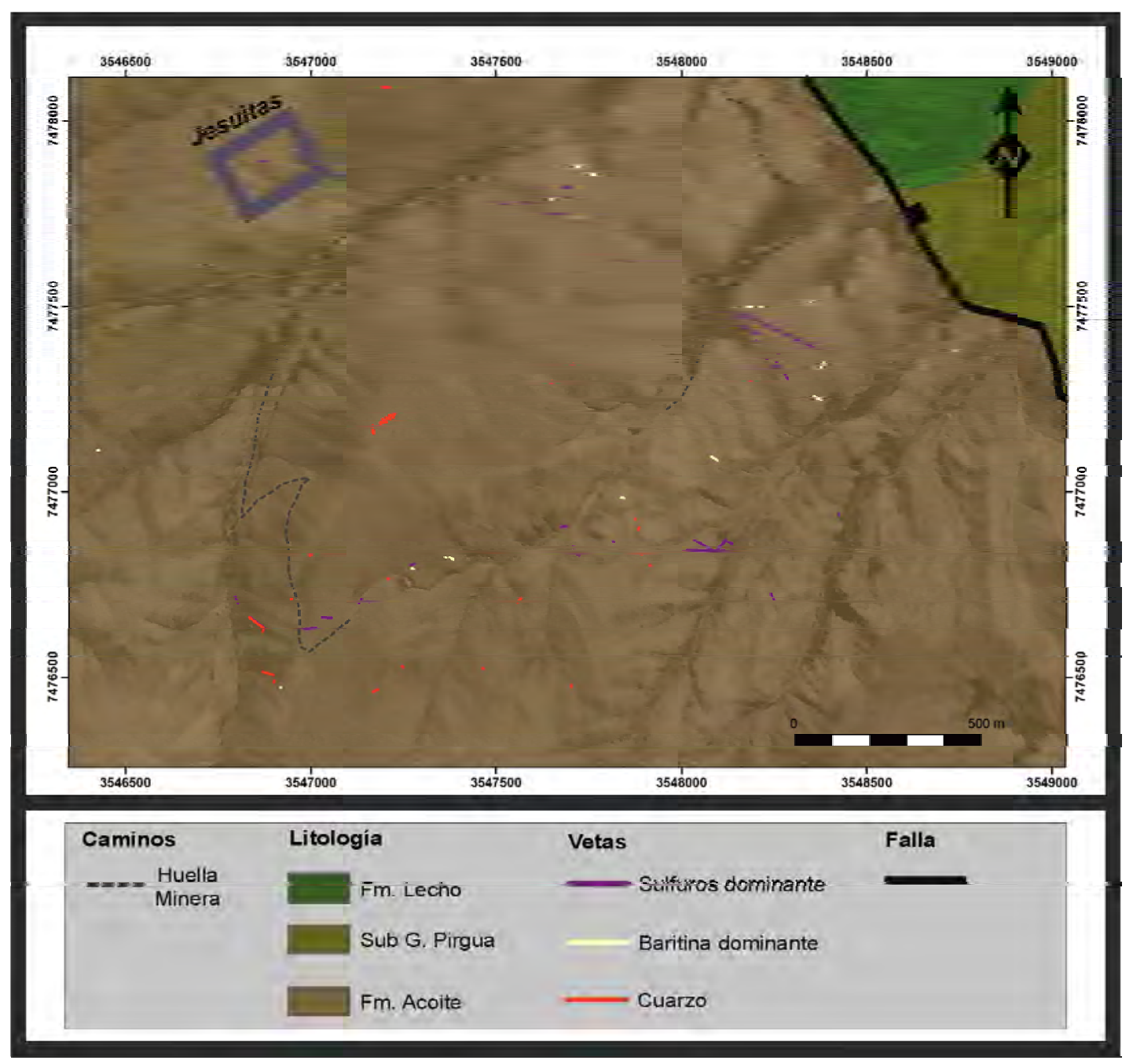

Fig. 5-28. Mapa de ubicación de la veta Jesuitas.

\section{Sulfuros/sulfoarseniuros/óxidos.}

El mineral metalífero preponderante en la veta Jesuitas es la galena, luego calcopirita, falhore y pirita/bravoíta (Fig. 5-30A).

La galena se presenta con cristales de hasta $1 \mathrm{~cm}$ idiomorfos, con evidencias de deformación frágil y dúctil, la primera caracterizada por brechamiento (Fig. 5-30B), y la segunda representada con flexiones y combamiento reflejadas en los planos de exfoliación (Fig. 5-30C y 5-30D). 


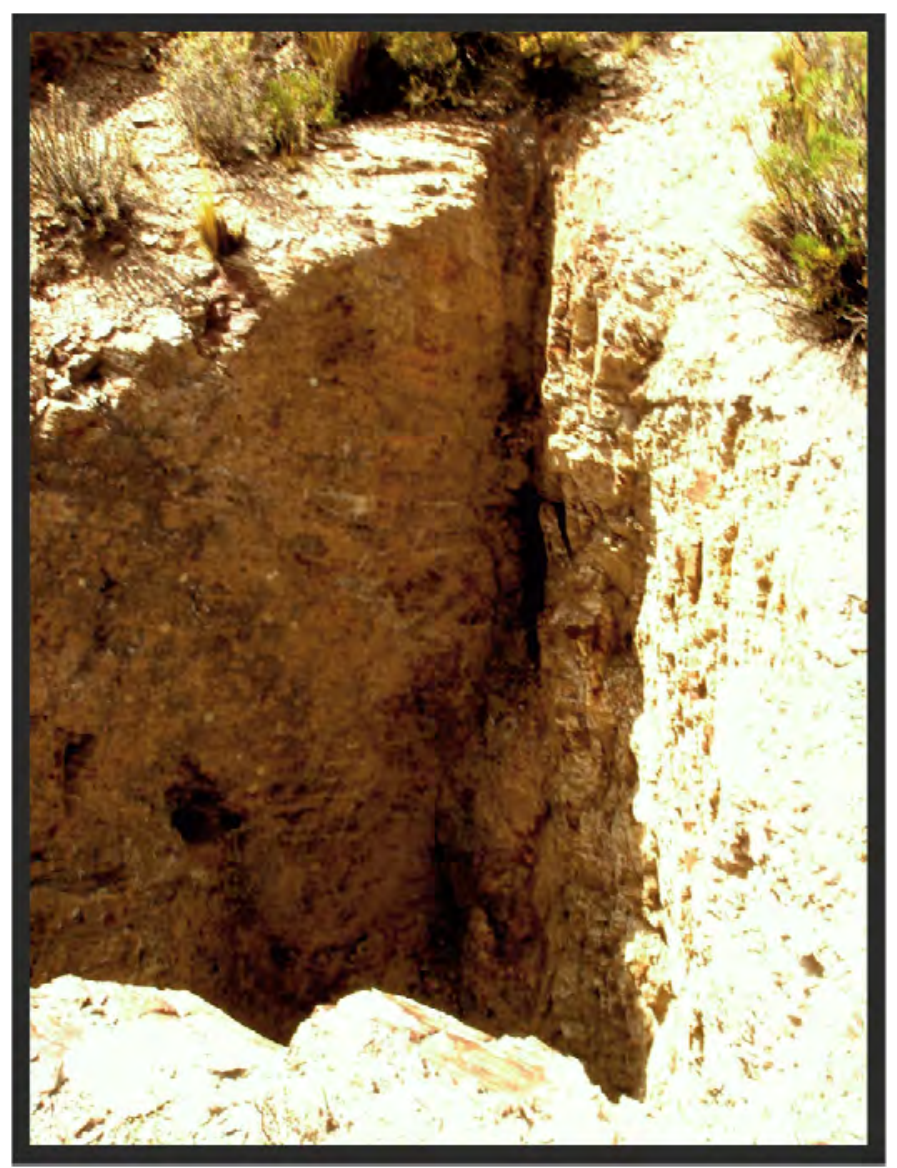

Fig. 5-29 Pique de la veta Jesuitas.

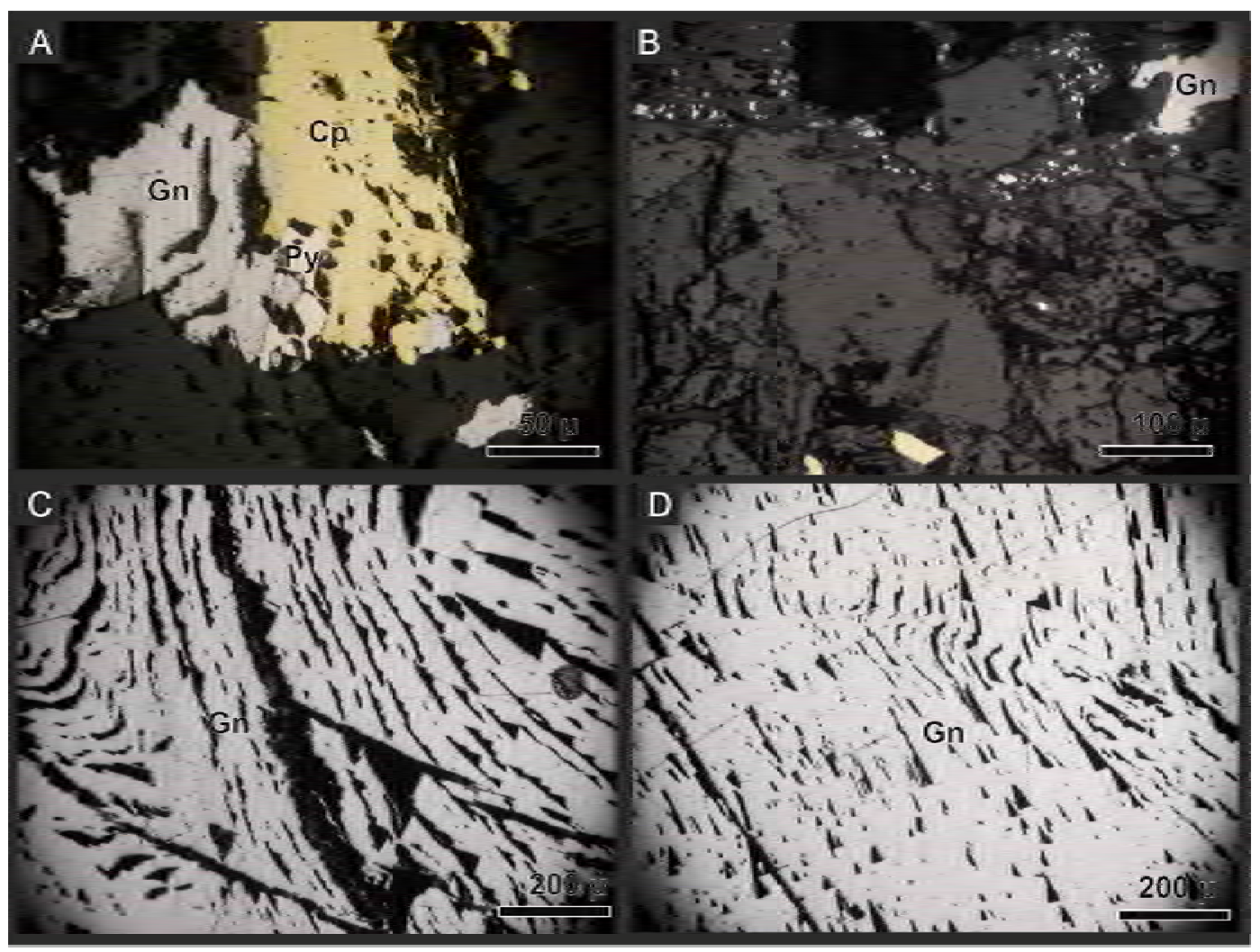

Fig. 5-30. A. Cristales de galena, calcopirita y pirita. B. Clastos de galena con deformación frágil en una vetilla. C y D. Galena que exhibe deformación en sus planos de exfoliación, evidenciada en los pits. 
Sobre la base de las texturas y relaciones entre los minerales identificados en las vetas Purísima, Rumicruz, Liliana, El Brechón, La Nueva y Jesuitas y a modo de síntesis de las características descriptas se presenta la secuencia paragenética para el distrito Purísima-Rumicruz.

Se definieron tres estadios principales de precipitación hipogénica, un cuarto pulso correspondiente a enriquecimiento supergénico, y un quinto pulso de naturaleza supergénica que removiliza parte de los elementos previamente depositados (Fig. 531). El primer estadio está compuesto por carbonato (I) y cuarzo que ocasionalmente reemplaza platy calcita. Continúa la precipitación de sulfuros de metales base entre los que se encuentra galena, calcopirita, bornita, tetrahedrita-tennantita, pirita y calcosina en ganga de carbonato.

El segundo estadio está compuesto por arseniuros y sulfoarseniuros de $\mathrm{Ni}-\mathrm{Co}$ y pechblenda. Los sulfoarseniuros identificados fueron niquelina, gersdorffita, gersdorffita cobaltífera y ullmanita. Como ganga continúa la precipitación de carbonatos. Se han identificado microvetillas de niquelina cortando tetrahedritatennantita, por lo tanto la precipitación de niquelina es posterior a la tetrahedritatennantita del primer estadio. La pechblenda posiblemente haya co-precipitado con la niquelina, esta relación surge debido a que se ha identificado cristales de niquelina rodeados de pechblenda y posteriormente este conjunto rodeado de niquelina. La gersdorffita se ubica rellenando grietas en la pechblenda (Fig. 5-8B).

En el tercer estadio la calcosina es abundante, acompañada por calcopirita, tetrahedrita-tennantita, bornita y digenita. La precipitación de esta asociación se estable debido a que se registró gersdorffita y niquelina de la segunda etapa como inclusiones en calcosina y tetrahedrita-tennantita (e.g. Fig. 5-18C y Fig. 5-18D), y vinculados a ellos se identificó calcopirita, digenita y bornita. La millerita probablemente pertenezca a este estadio debido a que su génesis puede vincularse como alteración de minerales de níquel, como la niquelina o gersdorfita, debido a un aumento en la fugacidad del azufre. En la ganga persiste la precipitación de carbonatos. Esta etapa culmina con un pulso que deposita abundante baritina brechando a la secuencia anterior.

El cuarto estadio corresponde a un enriquecimiento supergénico donde se identificó covelina, asimismo se reconoció siderita e hidróxidos de hierro, posiblemente limonitas. 
Finalmente el quinto estadio se presenta como finas vetillas rellenas con calcita euhedral, acompañada de malaquita y azurita formando cristales con textura fibrosa fina.

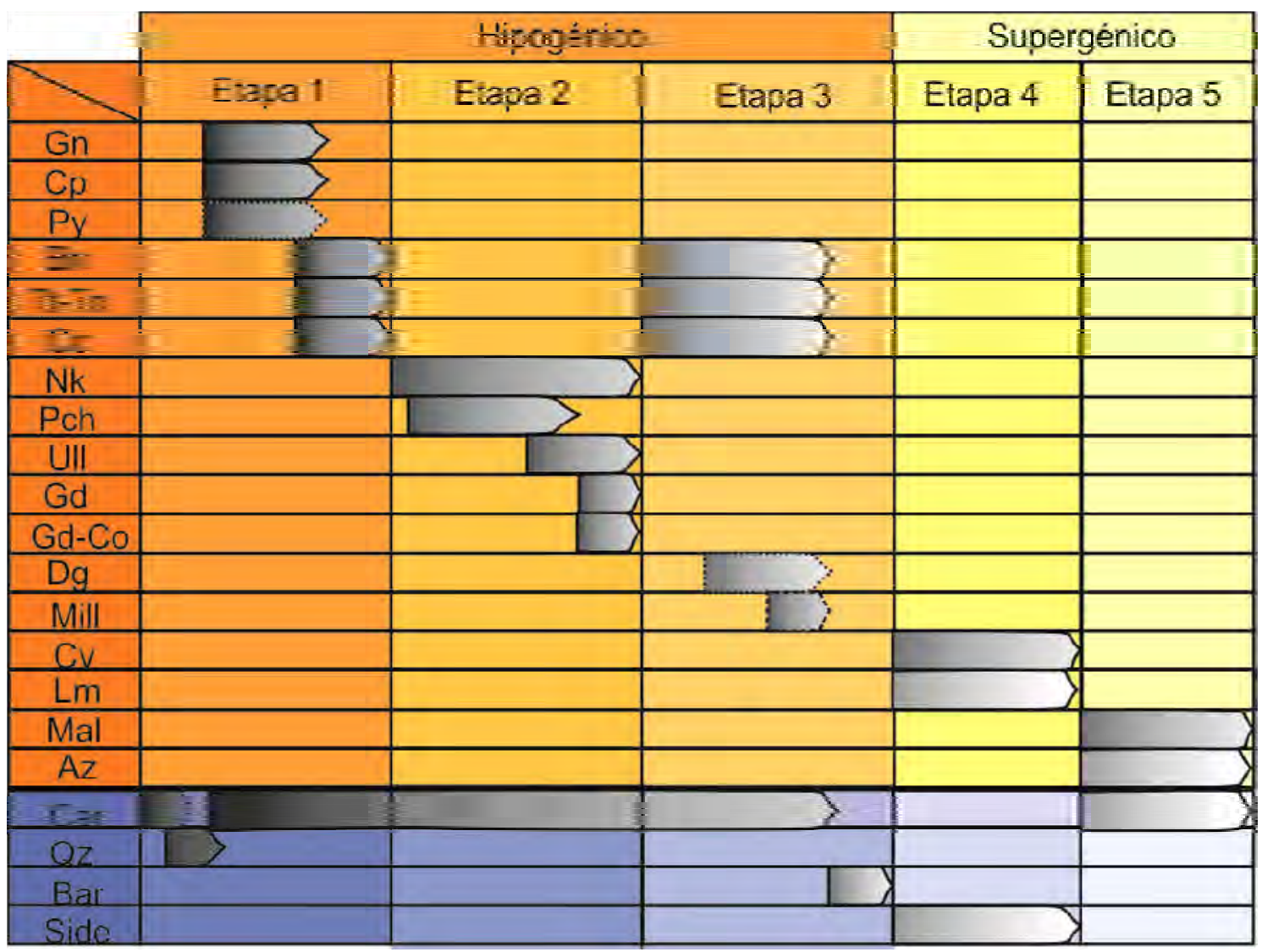

Fig. 5-31. Esquema paragenético del distrito polimetálico Purísima-Rumicruz. Gn: galena; Cp: calcopirita; Py: pirita; Bn: bornita; Tt-Tn: tetrahedrita-tennantita; Cc: calcosina; Nk: niquelina; Pch: pechblenda: Ull: ullmanita; Gd: gersdorffita; Gd-Co: gersdorffita cobaltífera; Dg: digenita; Mill: millerita; Cv: covelina; Lm:

limonita; Mal: malaquita; Az: azurita. Car: carbonatos (dolomita, ankerita, calcita); Qz: cuarzo; Bar: baritina; Side: siderita. Las líneas punteadas representan posiciones paragenéticas poco claras

\section{ÁREAS ANEXAS}

Se describen a continuación una serie de vetas relevadas durante las etapas de mapeo que se encuentran fuera del distrito Purísima-Rumicruz que registraron labores de exploración y explotación. Estas vetas se encuentran en dos áreas, El Marciano y San Agustín.

\section{El Marciano}

El área, distante a 3,7 Km al NO de Purísima-Rumicruz, fue explorada mediante un rajo de $35 \mathrm{~m}$ donde se distinguió una veta con azimut $340^{\circ}$, subvertical y discordante con la estratificación de la roca de caja compuesta por areniscas y pelitas de la Formación Acoite (Fig. 5-32). Las dimensiones aflorante son 13 m de longitud y 2 de 
potencia. La textura de la veta es brechosa y el contacto con la roca de caja se resuelve en un stockwork de cuarzo que disminuye progresivamente de espesor y abundancia de las vetillas hacia fuera de la veta. Está compuesta por cuarzo gris de grano fino que rodea clastos de roca de caja brechado por cuarzo blanco de grano grueso y finalmente esto es rebrechado y precipitan como relleno escasos sulfuros y óxidos de hierro (Fig. 5-33; Fig. 5-34).

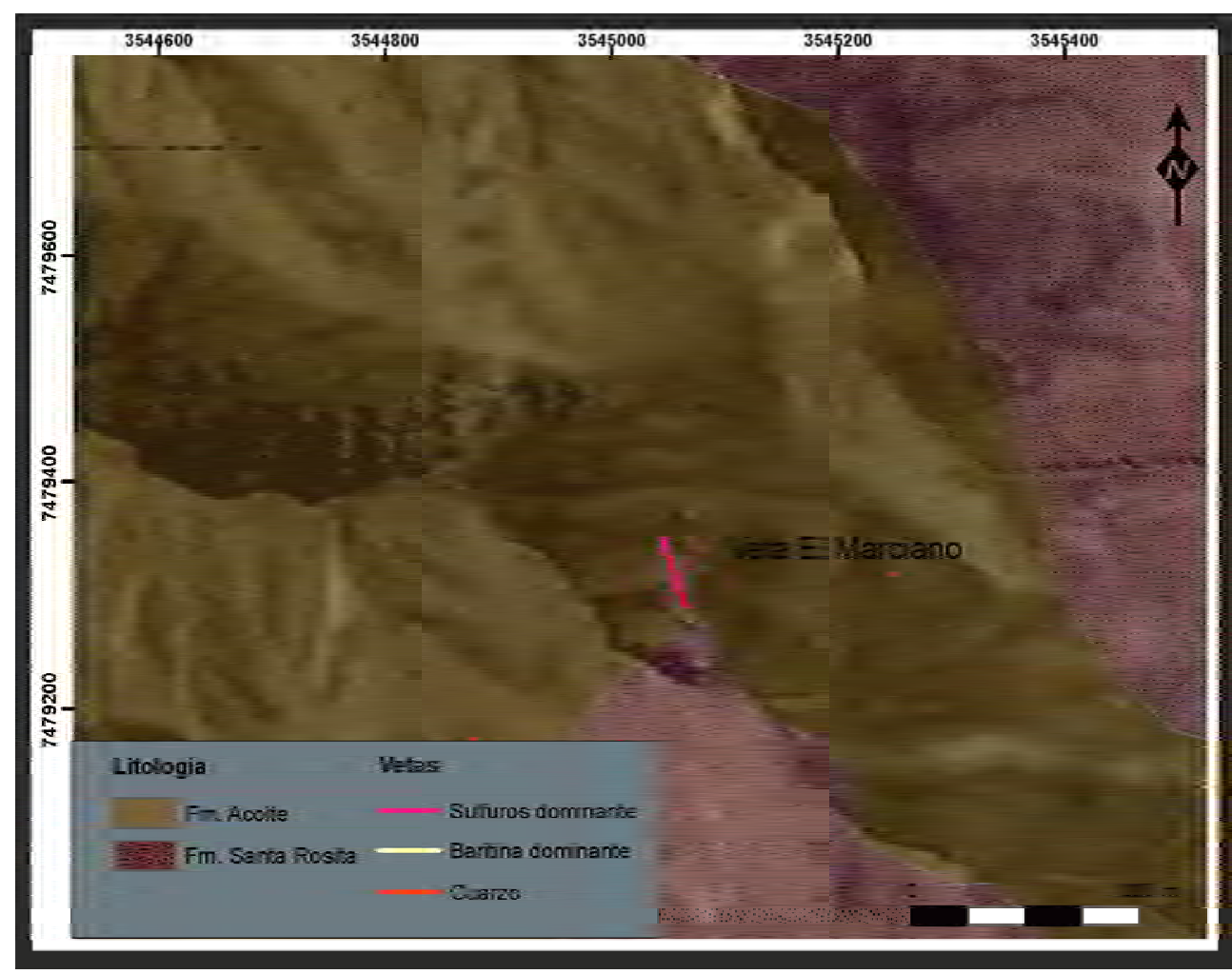

Fig. 32. Mapa geológico-minero del sector de la veta El Marciano. 


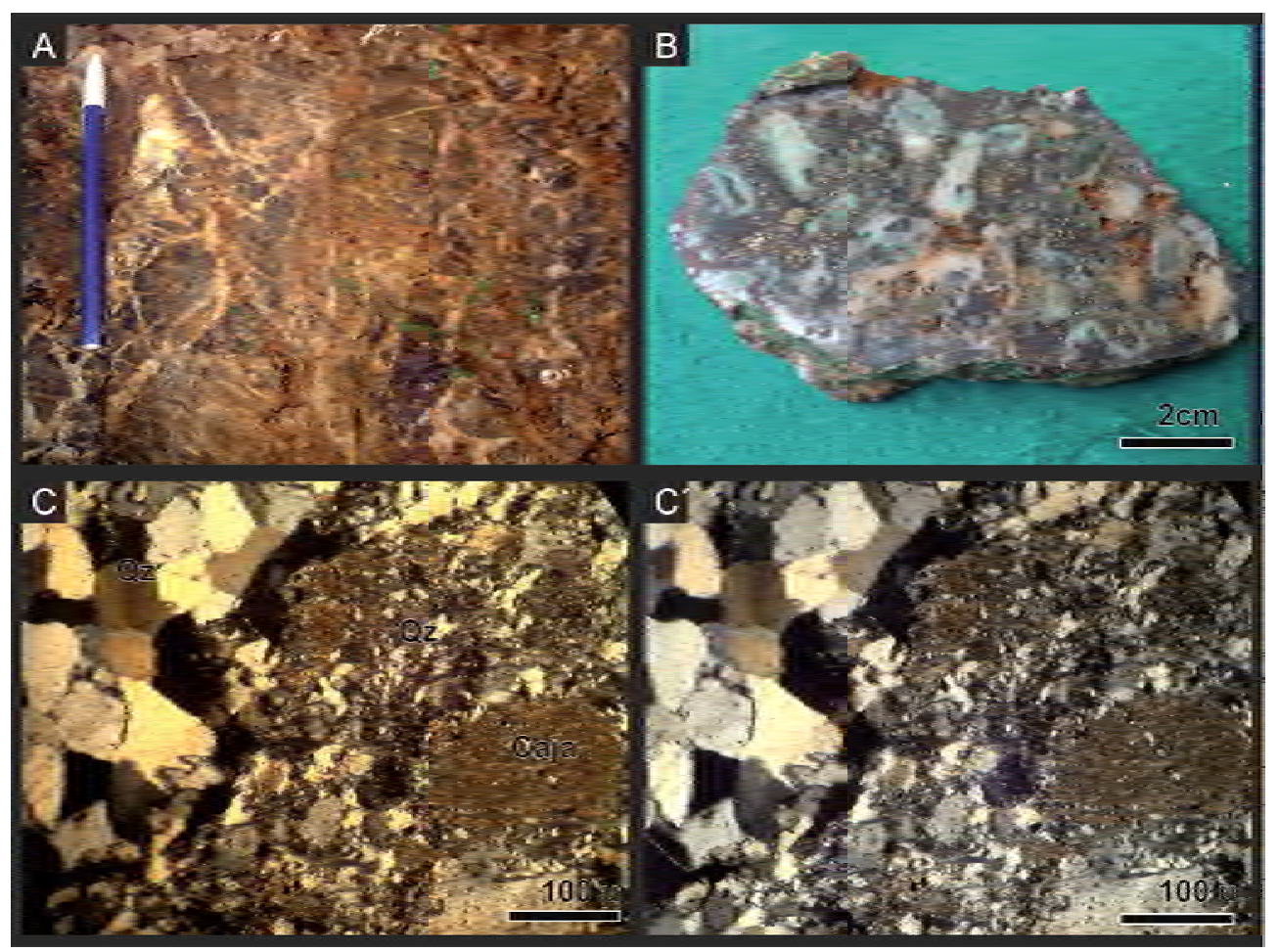

Fig. 5-33 A. Veta el Marciano en afloramiento con textura brechosa y en stockwork. B. Textura brechosa de la veta y pulsos de cuarzo y sulfuros. C y $C^{\prime}$. Clasto de roca caja pelítico con rodeada por cuarzo fino en contacto con cuarzo grueso.

El pulso de sulfuros brecha ambos pulsos de cuarzo y está constituido por calcopirita, bornita y en menor proporción pirita, galena y tetrahedrita-tennantita.

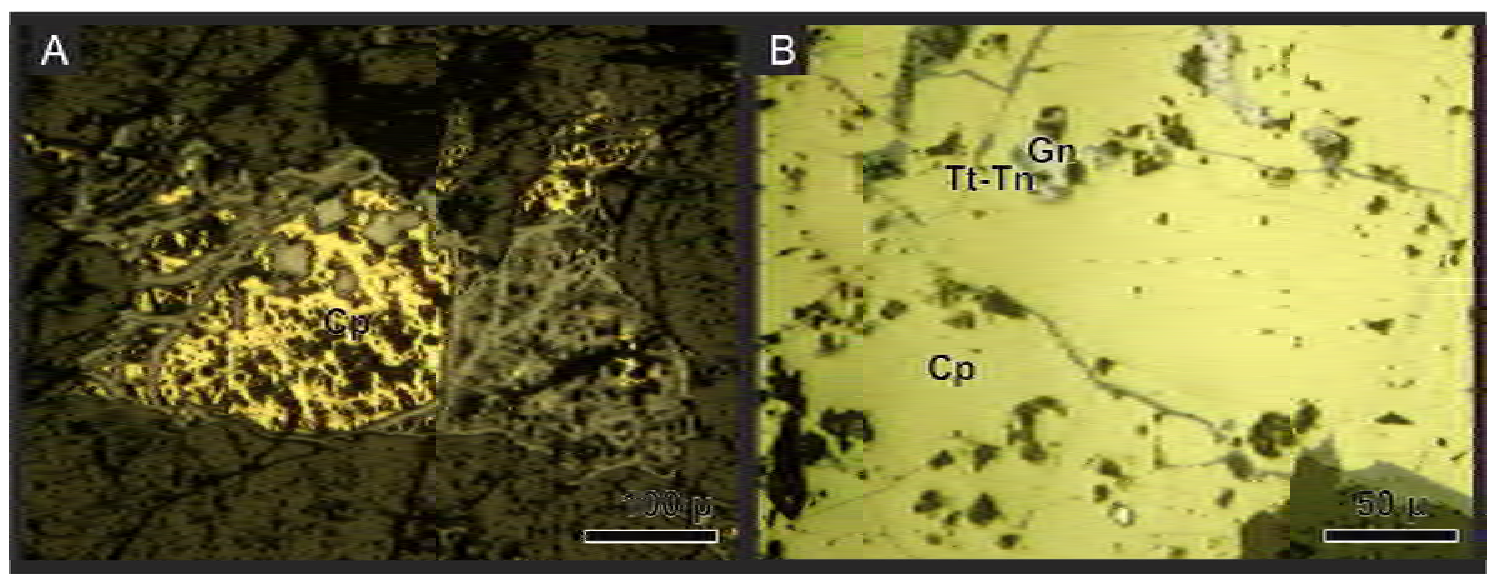

Fig. 5- 34 A. Cristal de calcopirita (Cp) con oxidación hacia los bordes y en vetillas. Boxwork de pirita. B. Predominio de calcopirita, donde se distinguen pequeños cristales de pirita (Py), galena (Gn) y tetrahedrita-tennantita (Tt-Tn).

\section{San Agustín}

Ubicada en el cerro homónimo, a 3,5 Km al SE del distrito Purísima-Rumicruz (Fig. 5-35), consiste en un conjunto de vetas con textura brechosa y relleno principalmente de baritina masiva blanca (Fig. 5-36). Se disponen discordantemente con la roca de 
caja que consiste en areniscas y pelitas de la Formación Acoite. Las vetas de San Agustín han sido explotadas por baritina en forma subterránea y mediante pequeños rajos superficiales.

Las vetas son brechas con fragmentos de tamaño variable de roca de caja. El relleno consiste en baritina blanca, con cristales gruesos de hábito tabular.

\section{CONSIDERACIONES MINERALÓGICAS Y GENÉTICAS}

Sobre la base de lo descripto anteriormente se determinó que las vetas que componen el distrito polimetálico Purísima-Rumicruz consisten en brechas con múltiples episodios de rebrechamiento donde precipitaron rellenos hidrotermales con diversas asociaciones mineralógicas, de las cuales pueden interpretarse variaciones en las condiciones físico-químicas del fluido hidrotermal.

La mineralización se caracteriza por tener dos pulsos de sulfuros, principalmente de cobre-plomo, separada por un pulso de sulfoarseniuros de níquel y cobalto, mientras que la ganga está representada principalmente por carbonatos y baritina. Por su parte, el cuarzo es escaso, solo presente en el estado inicial.

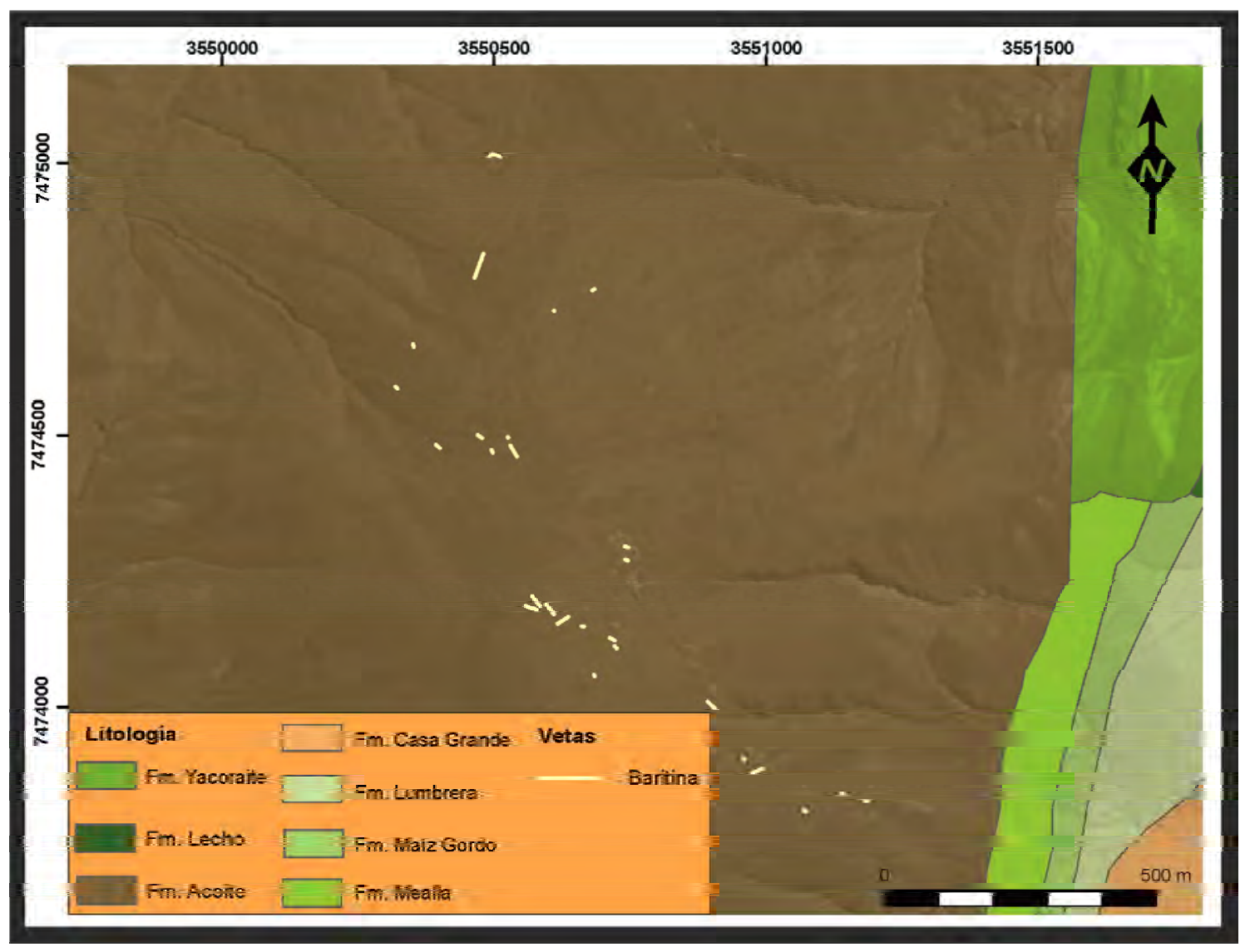

Fig. 5-35. Mapa Geológico minero del Área San Agustín. 


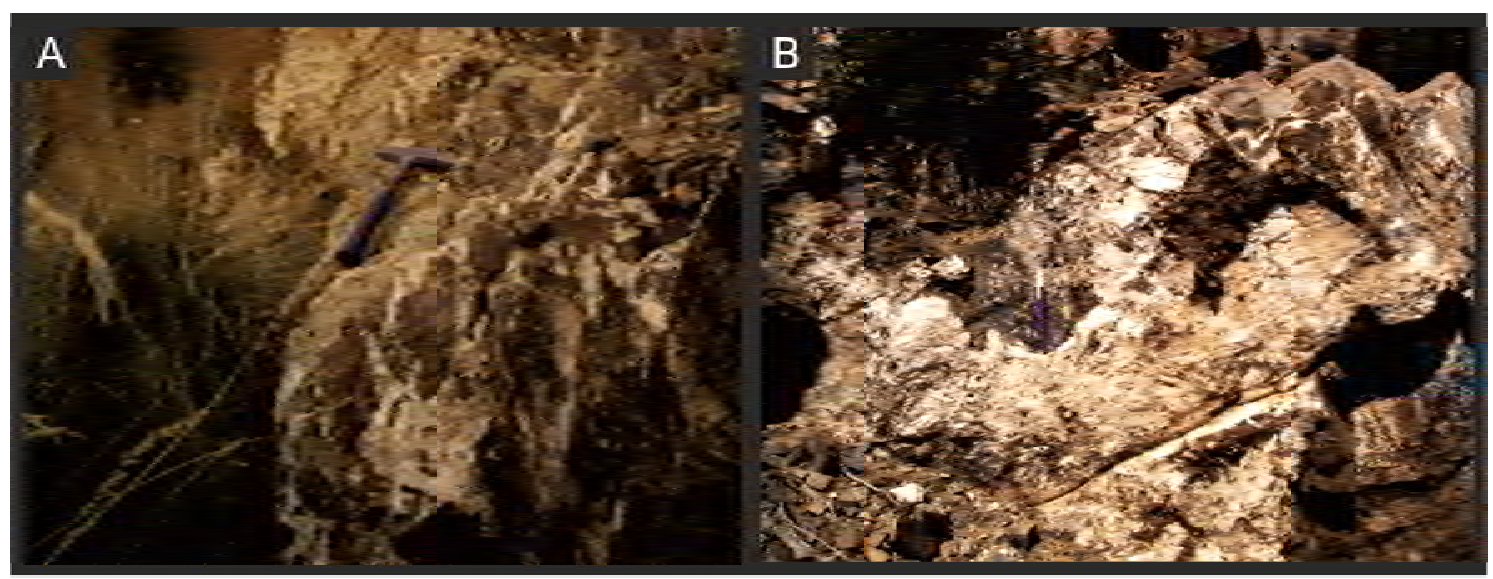

Fig. 5-36. Vetas con texturas brechosas del área San Agustín.

La millierita es un mineral que frecuentemente se forma a partir del níquel de otras especies precipitadas anteriormente luego de un aporte hidrotermal con alta fugacidad de S (Brodtkorb, 1965), como es el caso de la tercer etapa.

Los pronunciados cambios, principalmente en la composición química del fluido son evidenciados por las texturas de corrosión de los cristales, particularmente presentes en la galena y calcosina. Otra evidencia de estos cambios es la precipitación de arseniuros entre pulsos de sulfuros. El arsénico es un elemento fuertemente calcófilo por lo cual debió existir algún mecanismo de segregación entre estos dos elementos, fundamentalmente en el pulso dos, donde la fugacidad del azufre presenta una disminución drástica, permitiendo la precipitación de arseniuros.

A temperaturas elevadas existe un campo extenso de soluciones sólidas de sulfuros de Fe-Cu (e.g. bornita, calcopirita). Cuando la temperatura desciende son comunes las exoluciones (Vaughan y Craig, 1997), como las registradas lamelas de calcopirita en bornita. La tendencia de formar estas lamelas es mayor cuando más lento fue el período de enfriamiento.

Sin embargo las texturas de desmezclas descriptas anteriormente, como las mirmequitas entre bornita y calcosina, o la calcopirita en llamas dentro de bornita, no generan geotermómetros adecuados, tal como lo registró Brett (1964) experimentalmente. Las texturas no solo dependen de la temperatura, sino también el grado de sobresaturación y de la tasa de enfriamiento. Incluso texturas similares a las exoluciones pueden formarse por reemplazo selectivo o meteorización (Brett, 1964). Sin embargo, un posible geotermómetro podría ser la calcosina lamelar, ya que este mineral es formado posteriormente a la descomposición de la digenita cúbica, por debajo de los $78^{\circ} \mathrm{C}$ (Ramdhor, 1980). 
Los anillos de covelina rodeando a os sulfuros pueden generarse debido a procesos supergénicos. Cuando se produce meteorización de sulfuros de Cu-Fe, se genera una extracción preferencial del Fe, lo cual redunda en una concentración residual del $\mathrm{Cu}$ que origina minerales secundarios como la digenita o la covelina mientras permanecen las condiciones reductoras (Fig. 5-37). El Fe por su parte, reprecipita en la zona de oxidación como óxidos e hidróxidos en fracturas u oquedades.

La presencia de la asociación malaquita $\mathrm{Cu}_{2}(\mathrm{OH})_{2} \mathrm{CO}_{3}$ - azurita $\mathrm{Cu}_{3}(\mathrm{OH})_{2}(\mathrm{CO})_{2}$ CuO, como producto de alteración/removilización sugiere que los fluidos que producen la precipitación son de levemente ácidos a alcalinos y con variables valores de $\mathrm{P}^{\circ}$ de $\mathrm{CO}_{2}$. La malaquita y azurita presentan una dependencia débil con la temperatura siendo entonces las variable preponderantes el $\mathrm{pH}$ y la presión de $\mathrm{CO}_{2}$ (Preis y Gamsjäger, 2002) (Fig. 5-38).

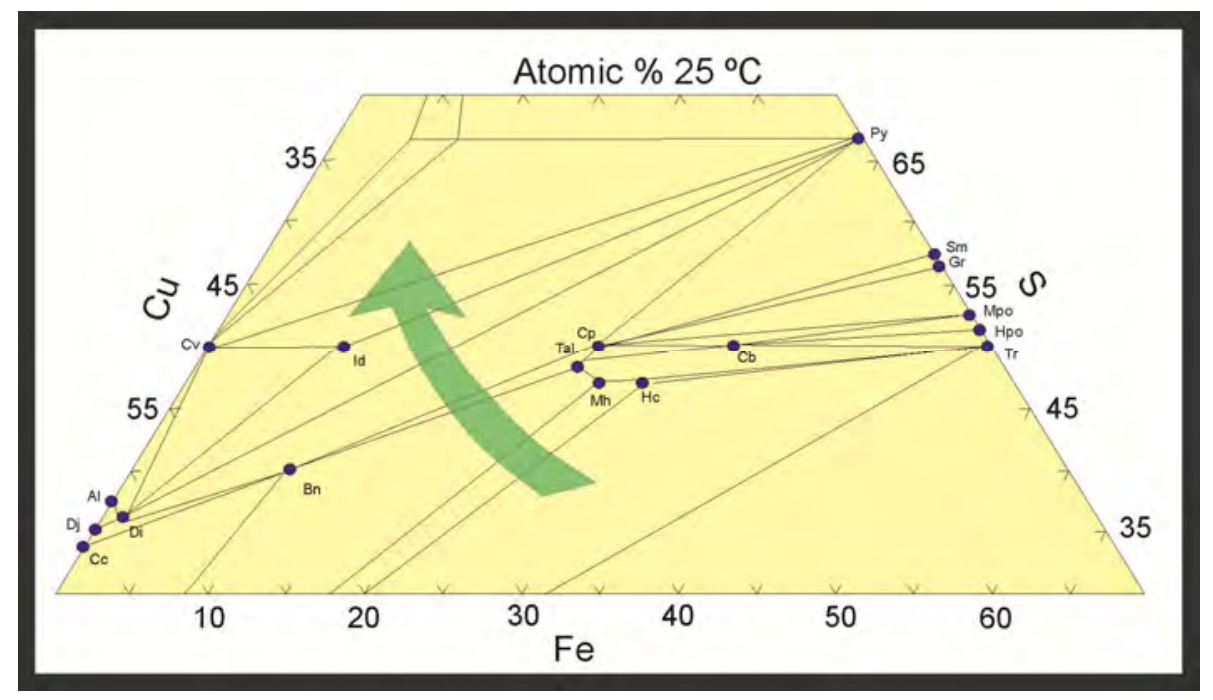

Fig. 5-37. Tendencia de composición general de sulfuros de cobre y hierro durante la meteorización. La removilización de hierro es seguida por la de cobre con la consecuente formación de covelina. El hierro removido reprecipita como óxidos mientras que el cobre los hace como sulfuros o es sustraído del sistema. Modificado de Vaughan y Craig (1997).

La asociación mineralógica es similar a las descriptas para otros depósitos hidrotermales (e.g. Anarak, Irán; Zalesí, República. Checa; Bou Azzer, Marruecos). La asociación paragenética, concomitante a los datos geoquímicos coadyuva a realizar un paralelismo con depósitos similares clasificados como Five Element Deposits (FED), reforzando la clasificación realizada por Lurgo Mayón (1999) para este depósito. 


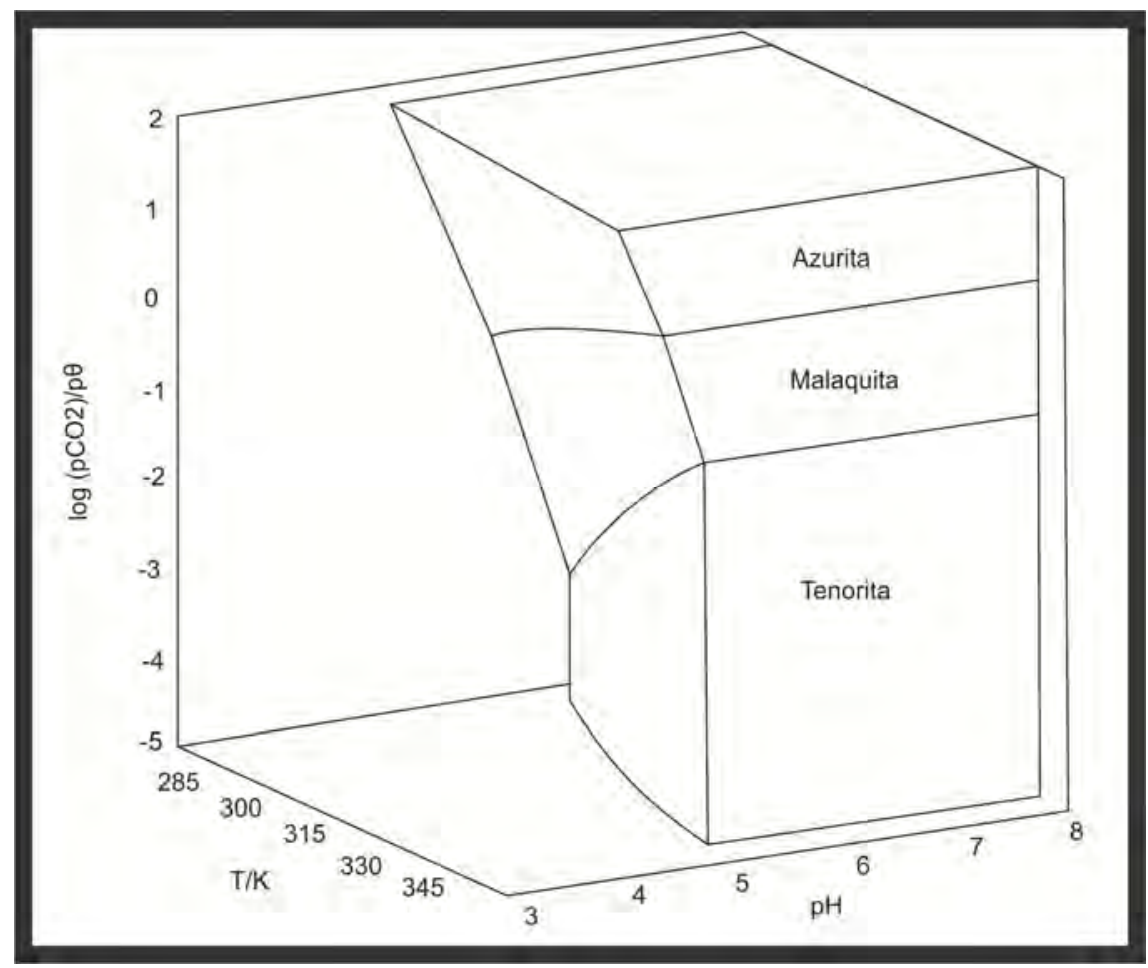

Fig. 5-38. Diagrama de pH, temperatura y actividad de la fugacidad del dióxido de carbono, modificado de Preis y Gamsjäger, (2002). 


\section{CAPITULO V}

GEOQUIIMICA Y QUÍMICA MINERAL 


\section{GEOQUÍMICA DE SUPERFICIE}

El muestreo geoquímico de superficie se realizó sobre las vetas de sulfuros y en las vetas de cuarzo. En las primeras, corresponden tanto a estructuras aflorantes, como también a las escombreras próximas a las mismas. Se analizó un total de 31 muestras de las vetas con sulfuros y 6 muestras de las vetas de cuarzo distribuidas en los sectores que componen el distrito. La distribución espacial de las mismas se exhibe en la Fig. 7-1.

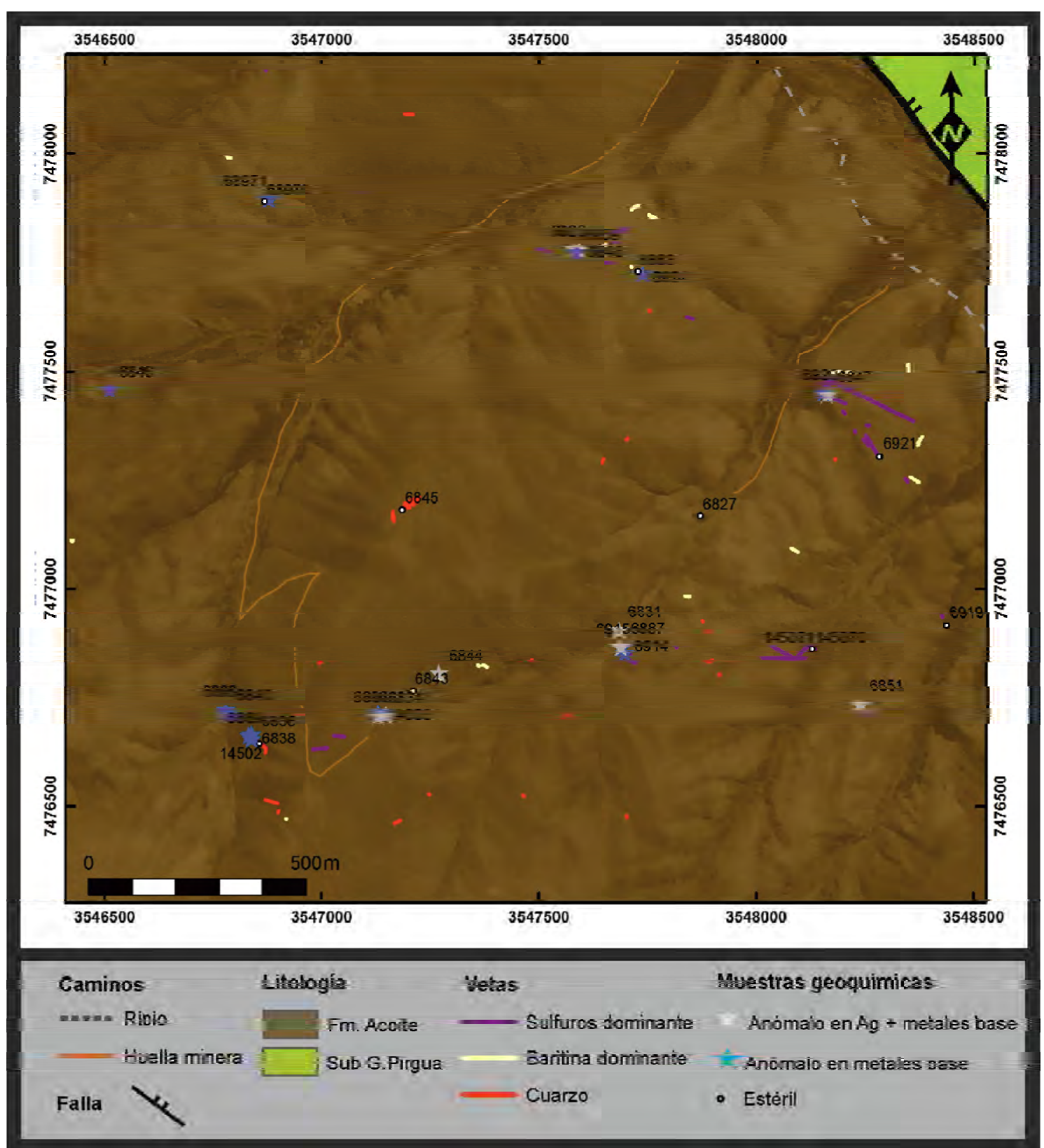

Fig. 7- 1. Mapa con la distribución del muestreo geoquímico del distrito Purísima-Rumicruz, identificando las anomalías en metales preciosos y en metales base 
A partir de los análisis geoquímicos de las muestras correspondientes a las vetas de sulfuros, se detectaron valores elevados en plomo, cobre, plata, níquel, cobalto, arsénico y zinc (Tabla 7-1).

Se determinaron altos valores de $\mathrm{Pb}$ y $\mathrm{Cu}$ ( $\mathrm{Pb}$ valor máximo 10,4\% y media de 0,75\% y Cu valor máximo superior al $50 \%$ y medio $4,63 \%$ ) y significativos tenores de Ag con hasta 595 ppm y 77,58 ppm de media. El valor máximo de Ni es 811 ppm, mientras que su media es de 135 ppm, por su parte el máximo para el Co es de 230 ppm y su valor medio es de 60 ppm. A partir de estos registros se estableció una relación Ni/Co de 2,2.

Para los análisis estadísticos subsiguientes se realizó un test para comprobar la distribución de los datos. Se analizó la normalidad y log normalidad de los datos mediante las pruebas Kolmorov y Smirnov y de Lilefords. En todos los casos se comprobó que las muestras no muestran una distribución normal $(p<0,01)$, y solo el $\mathrm{Ni}$, S y Zn muestran una distribución log normal. Debido a esto, los cálculos de correlación entre los elementos se realizaron calculando el coeficiente de correlación $\mathrm{R}$ no paramétrico de Spearman (Tabla 7-2).

\begin{tabular}{rrrrrrrrrr} 
& $\begin{array}{r}\mathrm{Ag} \\
\text { ppm }\end{array}$ & $\begin{array}{r}\mathrm{As} \\
\text { ppm }\end{array}$ & $\begin{array}{r}\mathrm{Co} \\
\mathrm{ppm}\end{array}$ & $\begin{array}{c}\mathrm{Cu} \\
\%\end{array}$ & $\begin{array}{c}\mathrm{Ni} \\
\mathrm{ppm}\end{array}$ & $\begin{array}{c}\mathrm{Pb} \\
\%\end{array}$ & $\begin{array}{c}\mathrm{S} \\
\%\end{array}$ & $\begin{array}{c}\mathrm{Sb} \\
\mathrm{ppm}\end{array}$ & $\begin{array}{c}\mathrm{Zn} \\
\mathrm{ppm}\end{array}$ \\
\hline 6827 & 8 & 190 & 82 & 0,46 & 127 & 0,01 & 0,22 & 112 & 163 \\
6829 & 530 & 1610 & 73 & 5,00 & 160 & 0,01 & 2,72 & 645 & 315 \\
6831 & 93 & 831 & 80 & 7,52 & 150 & 0,51 & 0,91 & 273 & 205 \\
6834 & 73 & 377 & 47 & 3,76 & 108 & 0,01 & 0,08 & 42 & 126 \\
6836 & 17 & 944 & 70 & 1,14 & 120 & 3,95 & 1,04 & 425 & 372 \\
6840 & 6 & 565 & 104 & 0,45 & 162 & 2,89 & 0,95 & 242 & 282 \\
6844 & 173 & 1980 & 54 & 13,70 & 88 & 0,22 & 1,22 & 383 & 344 \\
6846 & 31 & 27 & 7 & 0,34 & 21 & 10,40 & 1,68 & 98 & 50 \\
6847 & 83 & 57 & 10 & 7,39 & 14 & 0,01 & 1,16 & 37 & 39 \\
6848 & 595 & 535 & 18 & 50,00 & 72 & 0,04 & 2,37 & 177 & 76 \\
6851 & 271 & 1730 & 230 & 20,70 & 500 & 0,01 & 1,95 & 759 & 1380 \\
6859 & 22 & 638 & 57 & 1,00 & 98 & 0,22 & 0,25 & 102 & 180 \\
6863 & 4 & 157 & 53 & 0,48 & 44 & 0,01 & 0,26 & 129 & 56 \\
6887 & 52 & 769 & 76 & 1,00 & 121 & 0,21 & 0,93 & 436 & 368 \\
6888 & 4 & 129 & 77 & 0,09 & 142 & $>0,01$ & 0,46 & 85 & 194 \\
6889 & 6 & 531 & 123 & 0,28 & 270 & $>0,01$ & 0,50 & 244 & 341 \\
6896 & $>200$ & 1206 & 152 & $>0,01$ & 344 & 0,03 & 1,42 & 66 & 84 \\
68970 & $<0,5$ & 18 & 12 & 0,01 & 46 & 0,02 & 0,49 & $<5$ & 131 \\
68971 & 45 & 40 & 13 & 0,10 & 50 & $>0,01$ & 2,80 & 102 & 71 \\
6914 & 38 & 1422 & 60 & $>0,01$ & 811 & 0,01 & 0,60 & 306 & 179 \\
6915 & 43 & 550 & 50 & $>0,01$ & 67 & 1,00 & 1,14 & 367 & 220 \\
6919 & 2 & 16 & 47 & 0,33 & 20 & 0,01 & 0,44 & $<5$ & 19
\end{tabular}




\begin{tabular}{crrrrrrrrr}
6920 & 6 & 51 & 19 & 0,82 & 17 & 0,01 & 0,18 & $<5$ & 32 \\
6921 & 1 & 37 & 19 & 0,08 & 27 & 0,01 & 0,24 & $<5$ & 29 \\
6923 & $>200$ & 374 & 54 & $>0,01$ & 86 & 0,30 & 2,93 & 176 & 149 \\
6924 & 14 & 117 & 42 & $>0,01$ & 53 & 0,01 & 0,36 & 49 & 48 \\
14502 & 9 & 296 & 79 & 0,25 & 128 & $>0,01$ & 0,50 & 178 & 144 \\
14503 & 37 & 361 & 64 & $>0,01$ & 180 & 0,01 & 0,33 & 98 & 124 \\
14505 & 1 & 8 & 2 & 0,02 & 3 & 0,01 & 0,40 & $<5$ & 16 \\
145070 & 4 & 22 & 48 & 0,39 & 85 & 0,46 & 0,40 & $<5$ & 108 \\
145071 & 4 & 76 & 48 & 0,36 & 57 & 0,01 & 0,31 & 62 & 62 \\
\hline Promedio & $\mathbf{7 8}$ & $\mathbf{5 0 5}$ & $\mathbf{6 0}$ & $\mathbf{4 , 6 3}$ & $\mathbf{1 3 5}$ & $\mathbf{0 , 7 5}$ & $\mathbf{0 , 9 4}$ & $\mathbf{2 2 4}$ & $\mathbf{1 9 1}$ \\
Valor Máx. & 595 & 1980 & 230 & $>50$ & 811 & 10,40 & 2,93 & 759 & 19 \\
Valor Min. & $<0,5$ & 8 & 7 & 0,01 & 21 & $<0,01$ & 0,08 & $<5$ & 1380 \\
Desvío & 146 & 561 & 47 & 9,66 & 163 & 1,99 & 0,83 & 191 & 246 \\
No $^{\circ}$ LDD & 1 & - & - & 6 & - & 4 & - & 6 & - \\
\hline
\end{tabular}

Tabla 7- 1. Resultados de análisis geoquímicos de los elementos anómalos en las muestras correspondientes a las vetas de sulfuros. $\mathrm{N}^{\circ}<$ LDD: Número de muestras con valores por debajo del límite inferior de detección.

Sobre la base de los guarismos obtenidos de estas relaciones se estableció que los elementos analizados muestran en general una alta correlación (Tabla 7-2). Sin embargo hay ciertos elementos que mostraron alta afinidad, de esta forma, se agruparon los elementos en dos asociaciones, la primera reúne Ni-Co-Zn-Sb-As, y la segunda con incluye Ag-Cu-(As-S-Sb). El plomo mostró una pobre asociación con los elementos aquí consignados, solo con el $\mathrm{S}$ y en menor medida con el $\mathrm{Sb}$ y el Zn, incluso mostró una muy leve correlación negativa con el $\mathrm{Cu}$. Una posible explicación de esta particularidad es que el único mineral identificado que concentra este elemento es la galena y se encuentra frecuentemente conformando grandes individuos aislados.

\begin{tabular}{lccccccccc}
\hline & $\mathrm{Ag}$ & $\mathrm{As}$ & $\mathrm{Co}$ & $\mathrm{Cu}$ & $\mathrm{Ni}$ & $\mathrm{Pb}$ & $\mathrm{S}$ & $\mathrm{Sb}$ & $\mathrm{Zn}$ \\
\hline Ag & 1,0000 & & & & & & & & \\
As & 0,7130 & 1,0000 & & & & & & & \\
$\mathrm{Co}$ & 0,2747 & 0,7008 & 1,0000 & & & & & & \\
$\mathrm{Cu}$ & 0,8300 & 0,7290 & 0,2473 & 1,0000 & & & & & \\
$\mathrm{Ni}$ & 0,4176 & 0,7637 & 0,8891 & 0,3312 & 1,0000 & & & & \\
$\mathrm{~Pb}$ & 0,1878 & 0,2017 & 0,1880 & $-0,0467$ & 0,2320 & 1,0000 & & & \\
$\mathrm{~S}$ & 0,6677 & 0,3976 & 0,1133 & 0,3465 & 0,2048 & 0,5404 & 1,0000 & & \\
$\mathrm{Sb}$ & 0,6085 & 0,8368 & 0,6197 & 0,5283 & 0,6296 & 0,3852 & 0,5566 & 1,0000 & \\
$\mathrm{Zn}$ & 0,4192 & 0,7948 & 0,7371 & 0,4034 & 0,7468 & 0,4539 & 0,3544 & 0,8342 & 1,0000 \\
\hline
\end{tabular}

Tabla 7- 2. Índices de correlación R (no paramétrico) entre elementos de las vetas de sulfuros. En color verde se destacan los que resultaron tener una correlación $p<0,05$.

Se representaron relaciones entre pares de elementos de ambas asociaciones, para la primera han sido graficadas las relaciones As-Ni, Co-Ni, Zn-Ni, Sb-Ni, Zn-As, $\mathrm{Zn}-\mathrm{Sb}, \mathrm{Zn}$-Co y As-Co (Fig. 7-2). Por otro lado han sido representadas las relaciones Ag-Cu, Ag-S, Ag-As, Pb-Cu (Fig. 7-3). 
En la Fig. 7-2 se observa una muy fuerte correlación positiva entre el Ni-Co. El Zn tiene una alta correlación con el As y el Sb, acorde con la presencia de falhore rico en $\mathrm{Zn}$.

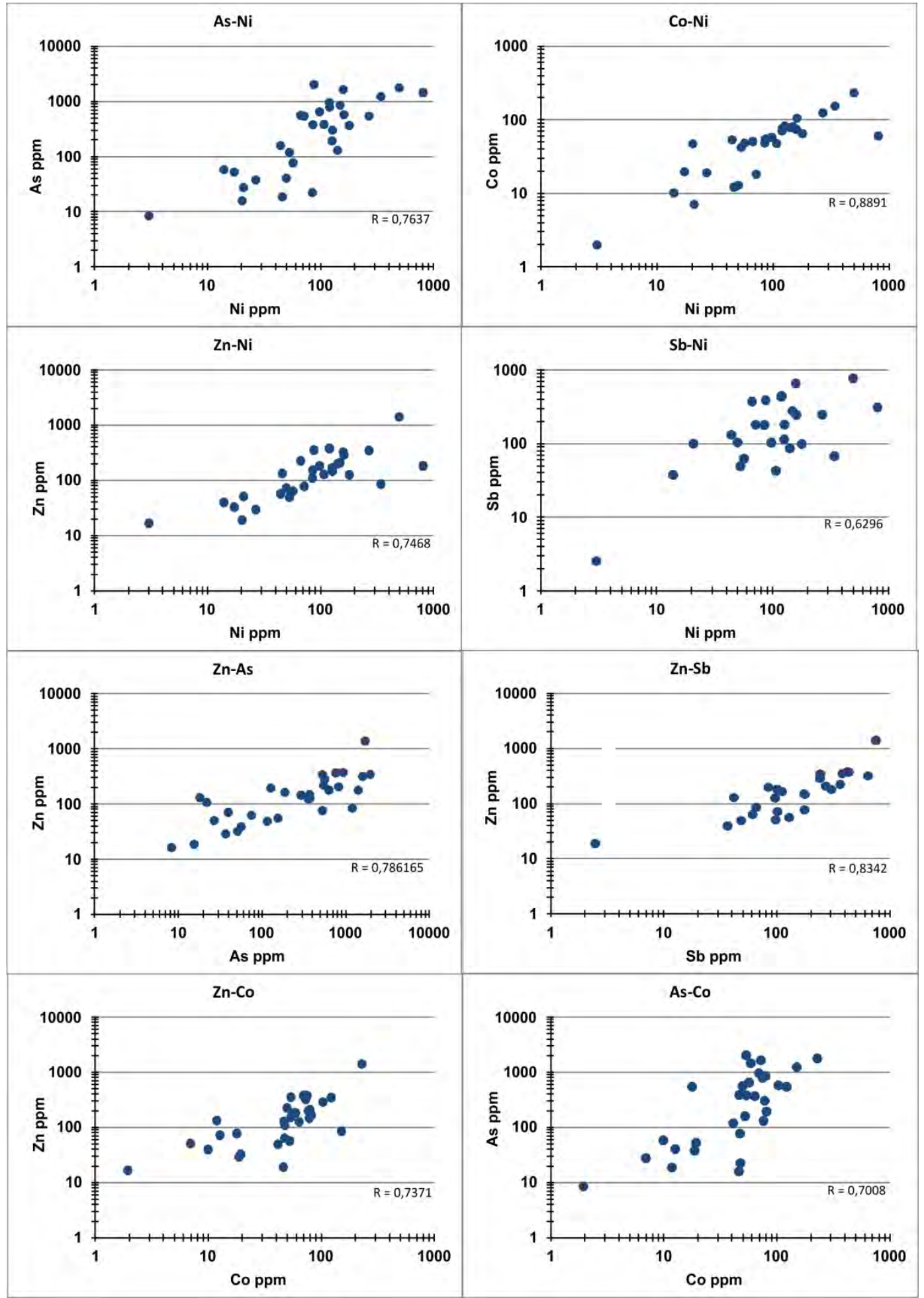

Fig. 7- 2 Relación entre elementos de la asociación Ni-Co-As-Sb-Zn 
En la Fig.7-3, se exhibe una alta correlación entre el cobre y la plata, asimismo se observa una buena correlacion entre la plata y el arsénico, esta es levemente mayor que entre la plata y el azufre. La representación de las concentraciones de plomo y cobre muestran una alta dispersión de los datos, sin mostrar correlación.

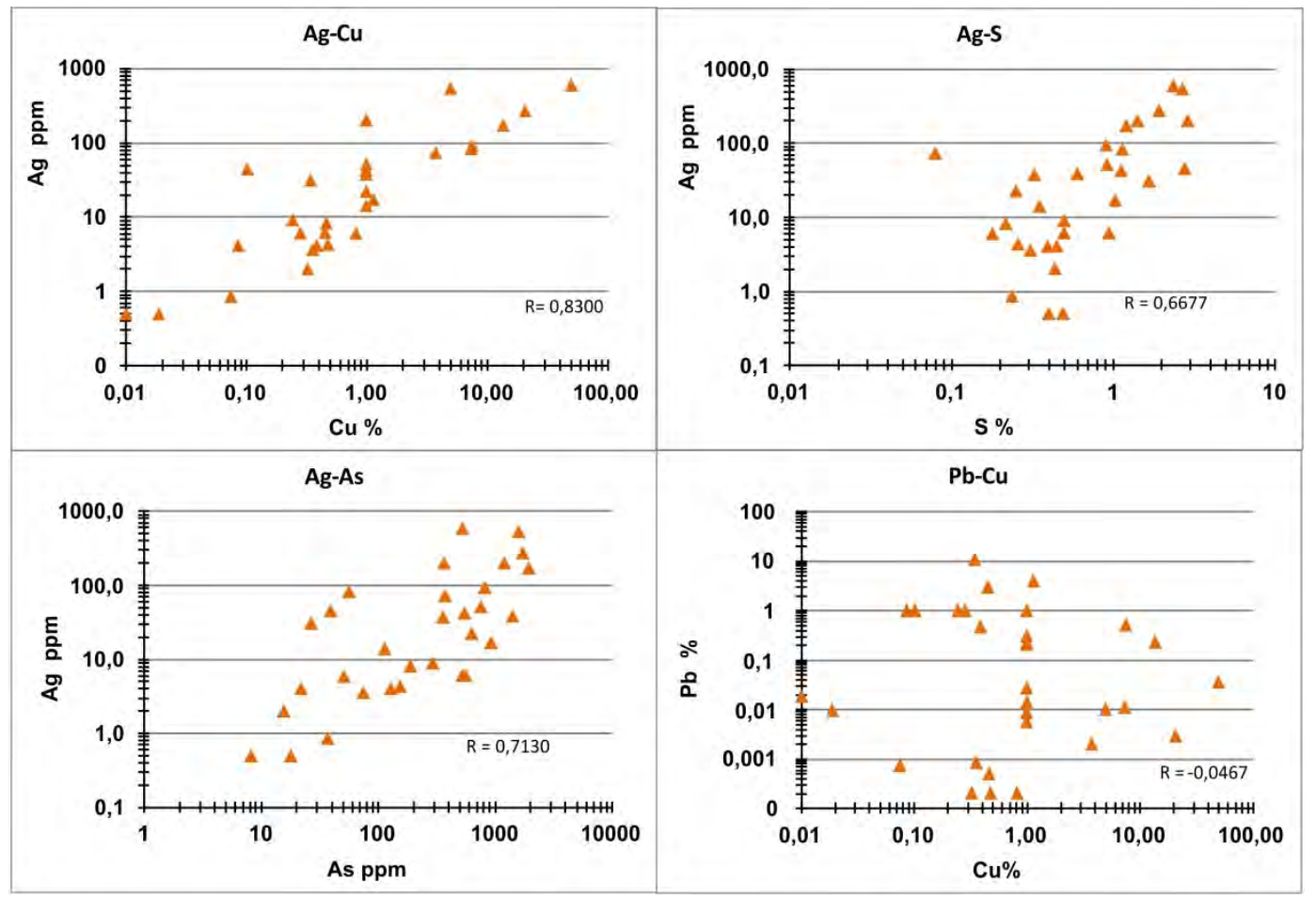

Fig. 7- 3. Relación entre elementos de la asociación Cu-Ag-(As-S). En el gráfico que relaciona el Cu y el $\mathrm{Pb}$ existe una alta dispersión con una correlación muy levemente negativa.

\section{Geoquímica de las vetas de cuarzo}

Se recolectaron un total de 6 muestras correspondientes a vetas de cuarzo, los resultados de los análisis geoquímicos han permitido establecer que los contenidos de metales preciosos $(\mathrm{Au}, \mathrm{Ag})$ y de metales base $(\mathrm{Cu}, \mathrm{Pb}, \mathrm{Zn})$, en términos generales, son bajos. La media de Au y Ag fue de 0,004 y 0,85 ppm, mientras que los valores máximos alcanzaron 0,006 y 2,1 ppm respectivamente. En cuanto a los metales base, el cobre (máximo 1610 y 479,5 ppm), el plomo (máximo 560 y media 156 ppm), y el zinc (máximo 41 y media 21,5 ppm), evidencian valores moderados (Tabla 7-4).

\begin{tabular}{lrrrrrrr}
\hline Muestra & $\mathrm{Au}$ & $\mathrm{Ag}$ & $\mathrm{As}$ & $\mathrm{Cu}$ & $\mathrm{Pb}$ & $\mathrm{S}$ & $\mathrm{Zn}$ \\
\hline 6838 & 0,003 & 0,7 & 100 & 312 & 560 & 0,09 & 7 \\
6843 & 0,003 & 0,5 & 139 & 74 & 226 & 0,11 & 25 \\
6845 & 0,003 & 0,4 & 19 & 58 & 42 & 0,02 & 17 \\
6852 & 0,006 & 2,1 & 95 & 1610 & 82 & 0,06 & 41 \\
6853 & 0,005 & 1,2 & 23 & 708 & 10 & 0,09 & 23 \\
6854 & 0,003 & 0,2 & $\mathbf{4}$ & 115 & $\mathbf{1 7}$ & 0,04 & 4 \\
\hline Promedio & $\mathbf{0 , 0 0 4}$ & $\mathbf{0 , 9}$ & $\mathbf{6 3}$ & $\mathbf{4 8 0}$ & $\mathbf{1 5 6}$ & $\mathbf{0 , 0 7}$ & $\mathbf{2 0}$
\end{tabular}




$\begin{array}{lrrrrrrr}\text { Valor máx } & 0,006 & 0,2 & 139 & 1610 & 560 & 0,02 & 41 \\ \text { Valor min } & 0,003 & 2,1 & 4 & 74 & 10 & 0,11 & 4 \\ \text { Desvío } & 0,002 & 1 & 55 & 606 & 213 & 0,03 & 13\end{array}$

Tabla 7- 3. Resultados químicos de metales preciosos y base para las vetas de cuarzo. Todos resultados están expresados en ppm salvo el azufre expresado en porcentaje.

El proceso estadístico de los datos fue similar al desarrollado para las vetas de sulfuros y los resultados del coeficiente de correlación $\mathrm{R}$ no paramétrico de Spearman se exhiben en la Tabla 7-4. En la misma se determinó que a pesar de no presentar concentraciones elevadas existe una marcada asociación importante entre $\mathrm{Cu}$ y $\mathrm{Ag}$ y entre As y $\mathrm{S}$.

\begin{tabular}{lcccccc}
\hline & $\mathrm{Ag}$ & $\mathrm{As}$ & $\mathrm{Cu}$ & $\mathrm{Pb}$ & $\mathrm{S}$ & $\mathrm{Zn}$ \\
\hline $\mathrm{Ag}$ & 1,0000 & \multicolumn{6}{c}{} \\
$\mathrm{As}$ & 0,4857 & 1,0000 & & & & \\
$\mathrm{Cu}$ & 0,8286 & 0,1429 & 1,0000 & & & \\
$\mathrm{~Pb}$ & 0,1429 & 0,7714 & $-0,0857$ & 1,0000 & & \\
$\mathrm{~S}$ & 0,4058 & 0,8407 & 0,2319 & 0,4058 & 1,0000 & \\
$\mathrm{Zn}$ & 0,7143 & 0,5429 & 0,3714 & 0,1429 & 0,3769 & 1,0000 \\
\hline
\end{tabular}

Tabla 7- 4. Índices de correlación entre elementos de las vetas de cuarzo. En color verde se exhiben los índices de correlación determinados con una correlación p<0,05.

\section{Consideraciones geoquímicas de superficie}

Los resultados de los análisis geoquímicos en las vetas de sulfuros, permiten diferenciar dos asociaciones de elementos: Ni-Co-Zn-Sb-As y otra Ag-Cu-(As-S). Estas asociaciones se corresponden con una diferente proporción mineralógica de los minerales portadores de los elementos metálicos, aspecto que fue abordado en la sección de mineralogía (Capítulo IV). El cobalto registra una menor abundancia que el níquel en la mayoría de los ambientes naturales (Bastin 1939, Misra, 2000) (Tabla 75). La relación entre estos elementos presentes en algunos minerales permite realizar inferencias sobre proveniencia o fuentes de origen.

\begin{tabular}{|c|c|c|c|c|}
\hline & Rocas & Co & $\mathrm{Ni}$ & $\mathrm{Co}: \mathrm{Ni}$ \\
\hline \multirow{4}{*}{ 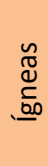 } & Ultrabásicas & 150 & 2000 & 0,075 \\
\hline & Basálticas & 48 & 130 & 0,369 \\
\hline & Graníticas & 7 & 15 & 0,467 \\
\hline & Sieníticas & 1 & 4 & 0,250 \\
\hline \multirow{3}{*}{ 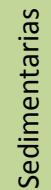 } & Pelitas & 19 & 68 & 0,279 \\
\hline & Areniscas & 0,3 & 2 & 0,150 \\
\hline & Carbonatos & 0,1 & 20 & 0,005 \\
\hline
\end{tabular}

Tabla 7- 5. Concentraciones medias (expresadas en ppm) de cobalto y níquel en rocas crustales. (Turekian \& Wedepohl, 1961). 
Las determinaciones de microsonda electrónica han aportado información sobre la composición cuantitativa y las variaciones en la distribución de los elementos en las diferentes especies minerales reconocidas en el depósito estudiado. Asimismo ha permitido identificar las especies que no pudieron ser establecidas mediante microscopía óptica.

Los valores de los análisis de la microsonda están expresados como los valores totales obtenidos y no están clausurados al 100\% (Aitchison, 1986). Al tratarse de valores composicionales ha de considerarse que los valores se encuentran interrelacionados por lo tanto cuando el valor de una variable aumenta el valor de otra debe disminuir indefectiblemente. Para sortear este escollo Aitchison (1986), propone un marco teórico-metodológico que contempla esta característica, y particularmente su espacio muestreal el Simplex $\left(\mathrm{S}^{\mathrm{D}}\right)$. Para el análisis de los datos se utilizan como medidas de tendencia central al vector medias geométricas llamado el Centro de la composición $G_{m}$ y como medidas de dispersión a la Varianza Total (Aitchison, 1986). Los cálculos estadísticos se realizaron con el software Excel-base CoDaPack (Thio, 2004).

\section{Pechblenda $\left(\mathrm{UO}_{2}\right)$}

La uraninita es un óxido combinado de $\mathrm{UO}_{2}$ con cantidades menores de $\mathrm{UO}_{3}, \mathrm{PbO}$ y Tho en su composición. Se utiliza el término pechblenda para la variedad amorfa que desarrolla textura típicamente botroidal. Se realizaron ocho análisis sobre pechblenda donde se determinó que el óxido de uranio es el compuesto mayoritario, mientras que el resto de los elementos encontrados como $\mathrm{Ni}$, As, $\mathrm{Cu}$ y $\mathrm{S}$ pueden tratarse de impurezas y/o la incorporación en el análisis de muy pequeños cristales de gersdorfita asociados a pechblenda (Tabla 7-6).

\begin{tabular}{ccccccc}
\hline № & $\mathrm{SO}_{3}$ & $\mathrm{NiO}$ & $\mathrm{UO}_{2}$ & $\mathrm{CuO}$ & $\mathrm{As}_{2} \mathrm{O}_{5}$ & Total \\
\hline 1 & 0.06 & 0.17 & 84.69 & 0.04 & 1.69 & $\mathbf{8 6 . 6 5}$ \\
2 & 3.50 & 2.72 & 81.23 & 1.08 & 5.07 & $\mathbf{9 3 . 6 0}$ \\
3 & 2.48 & 1.40 & 80.92 & 1.72 & 3.88 & $\mathbf{9 0 . 3 9}$ \\
4 & 0.06 & 0.05 & 83.93 & 0.07 & 1.21 & $\mathbf{8 5 . 3 3}$ \\
5 & 4.08 & 2.33 & 80.18 & 1.82 & 5.06 & $\mathbf{9 3 . 4 6}$ \\
6 & 0.04 & 0.03 & 85.99 & 0.00 & 1.52 & $\mathbf{8 7 . 5 8}$ \\
7 & 0.03 & 0.05 & 85.97 & 0.07 & 1.58 & $\mathbf{8 7 . 6 9}$ \\
8 & 0.00 & 0.07 & 86.01 & 0.07 & 1.46 & $\mathbf{8 7 . 6 1}$
\end{tabular}

Tabla 7- 6. Resultados geoquímicos sobre muestras puntuales de uraninita expresada en porciento en peso de óxidos. 
La calcosina/digenita es el sulfuro más abundante de las vetas del distrito PurísimaRumicruz. Los resultados de los análisis químicos muestran que la composición de este bisulfuro de cobre se ajusta tanto a la fórmula estequeométrica de la digenita $\mathrm{Cu}_{1,96} \mathrm{~S}$ como de la calcosina $\mathrm{Cu}_{2} \mathrm{~S}$ (Tabla7-7). Asimismo mediante calcografía han sido reconocidas ambas variedades mediante sus propiedades ópticas. La bornita es el segundo sulfuro más abundante. Su fórmula ideal es $\mathrm{Cu}_{5} \mathrm{FeS}_{6}$, sin embargo las muestras analizadas están algo disminuidas en Fe. De los análisis producidos sobre bornita, solo dos estuvieron comprendidos dentro del rango $\pm 2 \%$ de error (Tabla 7-7). La galena analizada corresponde a la veta Rumicruz, los análisis obtenidos se ajustan a la composición estequeométrica ideal PbS. La millerita también arrojó composiciones asignables a su fórmula ideal NiS (Tabla 7-7).

\begin{tabular}{|c|c|c|c|c|c|c|c|c|c|c|c|c|c|c|c|c|c|c|}
\hline \multirow{9}{*}{ Calcosina } & \multicolumn{10}{|c|}{ Composición (\% en peso) } & \multicolumn{8}{|c|}{ Unidad de átomos por fórmula } \\
\hline & $\mathrm{N}^{0}$ & $\mathbf{A g}$ & $\mathrm{Cu}$ & $\mathrm{Fe}$ & Co & $\mathrm{Ni}$ & $\mathbf{s}$ & Sb & As & Total & $\mathbf{A g}$ & $\mathrm{Cu}$ & $\mathrm{Fe}$ & Co & $\mathrm{Ni}$ & $\mathbf{s}$ & Sb & As \\
\hline & 78 & 0,17 & 77,15 & 0,03 & 0,00 & 0,05 & 21,29 & 0,04 & 0,00 & 98,74 & 0,003 & 1,936 & 0,001 & 0,000 & 0,001 & 1,059 & 0,001 & 0,000 \\
\hline & 79 & 0,35 & 77,40 & 0,08 & 0,00 & 0,01 & 20,84 & 0,00 & 0,03 & 98,71 & 0,005 & 1,951 & 0,002 & 0,000 & 0,000 & 1,041 & 0,000 & 0,001 \\
\hline & 34 & 0,32 & 78,05 & 0,49 & 0,02 & 0,00 & 21,21 & 0,00 & 0,12 & 100,20 & 0,005 & 1,939 & 0,012 & 0,000 & 0,000 & 1,044 & 0,000 & 0,003 \\
\hline & 88 & 0,29 & 79,22 & 0,10 & 0,04 & 0,05 & 20,30 & 0,00 & 0,00 & 100,01 & 0,004 & 1,983 & 0,003 & 0,001 & 0,001 & 1,007 & 0,000 & 0,000 \\
\hline & 99 & 0,16 & 80,07 & 0,00 & 0,00 & 0,00 & 20,64 & 0,01 & 0,06 & 100,94 & 0,002 & 1,984 & 0,000 & 0,000 & 0,000 & 1,013 & 0,000 & 0,001 \\
\hline & $\mathrm{Gm}$ & 0,25 & 78,73 & 0,05 & 0,01 & 0,01 & 20,95 & 0,01 & 0,01 & & 0,00 & 1,96 & 0,00 & 0,00 & 0,00 & 1,03 & 0,00 & 0,00 \\
\hline & Total Var & 1,19 & 1,22 & 2,60 & 2,38 & 3,03 & 1,22 & 2,99 & 3,94 & 18,58 & & & & & & & & \\
\hline \multirow{7}{*}{ Galena } & & & omposic & ón $(\% \mathrm{er}$ & peso) & & & & & & \multicolumn{5}{|c|}{ Unidad de átomos por fórmula } & & & \\
\hline & $\mathbf{N}^{\circ}$ & $\mathrm{Pb}$ & $\mathrm{Zn}$ & $\mathrm{Cu}$ & $\mathbf{s}$ & Sb & Total & & & & $\mathbf{P b}$ & $\mathrm{Zn}$ & $\mathrm{Cu}$ & $\mathbf{s}$ & Sb & & & \\
\hline & 42 & 86,32 & 0,01 & 0,11 & 13,21 & 0,02 & 99,70 & & & & 1,002 & 0,000 & 0,004 & 0,993 & 0,000 & & & \\
\hline & 43 & 87,71 & 0,04 & 0,02 & 13,08 & 0,00 & 100,85 & & & & 1,017 & 0,001 & 0,001 & 0,981 & 0,000 & & & \\
\hline & 44 & 87,40 & 0,11 & 0,02 & 13,16 & 0,00 & 100,69 & & & & 1,010 & 0,004 & 0,001 & 0,985 & 0,000 & & & \\
\hline & $\mathrm{Gm}$ & 86,83 & 0,04 & 0,03 & 13,10 & 0,01 & & & & & 1,010 & 0,002 & 0,002 & 0,986 & 0,000 & & & \\
\hline & Total Var & 0,54 & 1,50 & 0,68 & 0,54 & 1,49 & 4,75 & & & & & & & & & & & \\
\hline \multirow{6}{*}{ Bornita } & \multicolumn{8}{|c|}{ Composición (\% en peso) } & & & \multicolumn{6}{|c|}{ Unidad de átomos por fórmula } & & \\
\hline & $\mathbf{N}^{\circ}$ & $\mathrm{Cu}$ & $\mathrm{Fe}$ & $\mathrm{Ni}$ & $\mathbf{s}$ & $\mathrm{Sb}$ & As & Total & & & $\mathrm{Cu}$ & $\mathrm{Fe}$ & $\mathrm{Ni}$ & $\mathrm{s}$ & Sb & As & & \\
\hline & 27 & 63,37 & 10,98 & 0,00 & 26,26 & 0,00 & 0,10 & 100,86 & & & 5,026 & 0,840 & 0,000 & 4,127 & 0,000 & 0,007 & & \\
\hline & 33 & 63,84 & 10,69 & 0,00 & 25,79 & 0,00 & 0,01 & 100,62 & & & 5,096 & 0,824 & 0,000 & 4,079 & 0,000 & 0,000 & & \\
\hline & $\mathrm{Gm}$ & 63,30 & 10,78 & 0,00 & 25,90 & 0,00 & 0,0221 & & & & 5,061 & 0,832 & 0,000 & 4,103 & 0,000 & 0,003 & & \\
\hline & Total Var & 0,37 & 0,37 & 0,37 & 0,367 & 0,37 & 1,848 & 3,70 & & & & & & & & & & \\
\hline \multirow{7}{*}{ Millierita } & \multicolumn{9}{|c|}{ Composición (\% en peso) } & & \multicolumn{7}{|c|}{ Unidad de átomos por fórmula } & \\
\hline & $\mathrm{N}^{\circ}$ & $\mathrm{Cu}$ & $\mathrm{Fe}$ & Co & $\mathrm{Ni}$ & $\mathrm{s}$ & $\mathbf{S b}$ & As & Total & & $\mathrm{Cu}$ & $\mathrm{Fe}$ & Co & $\mathrm{Ni}$ & $\mathbf{s}$ & $\mathrm{Sb}$ & As & \\
\hline & 9 & 0,01 & 0,04 & 0,40 & 61,90 & 36,24 & 0,00 & 0,15 & 98,74 & & 0,000 & 0,001 & 0,006 & 0,993 & 1,064 & 0,000 & 0,002 & \\
\hline & 10 & 0,63 & 0,05 & 0,32 & 62,16 & 36,01 & 0,03 & 0,18 & 99,40 & & 0,009 & 0,001 & 0,005 & 0,985 & 1,044 & 0,000 & 0,002 & \\
\hline & 11 & 0,36 & 0,05 & 0,39 & 61,59 & 36,31 & 0,00 & 0,46 & 99,20 & & 0,005 & 0,001 & 0,006 & 0,988 & 1,066 & 0,000 & 0,006 & \\
\hline & $\mathrm{Gm}$ & 0,11 & 0,04 & 0,38 & 62,62 & 36,61 & 0,01 & 0,23 & & & 0,005 & 0,001 & 0,006 & 0,989 & 1,058 & 0,000 & 0,003 & \\
\hline & Total Var & 2,51 & 0,70 & 0,85 & 0,78 & 0,78 & 1,87 & 0,85 & 8,34 & & & & & & & & & \\
\hline
\end{tabular}

Tabla 7- 7. Composición expresada como \% en peso y como unidades de átomos por unidad de fórmula de calcosina, galena, bornita y millerita. 
La niquelina es un monoarseniuro de níquel, que en su estructura puede incorporar principalmente Fe y Co como cationes y $\mathrm{S}$ y cantidades menores de Sb como aniones. La niquelina correspondientes al distrito minero Purísima-Rumicruz presenta valores cercanos a su composición estequeométrica (Tabla 7-8). La zonación identificada en el estudio petrográfico no se corresponde con variaciones composicionales significativas.

\begin{tabular}{|c|c|c|c|c|c|c|c|c|c|c|c|c|c|c|c|c|}
\hline & \multicolumn{9}{|c|}{ Composición (\% en peso) } & \multicolumn{7}{|c|}{ Unidad de átomos por fórmula } \\
\hline & $\mathrm{N}^{\circ}$ & $\mathrm{Cu}$ & $\mathrm{Fe}$ & Co & $\mathrm{Ni}$ & $\mathbf{S}$ & Sb & As & Total & $\mathrm{Cu}$ & $\mathrm{Fe}$ & Co & $\mathrm{Ni}$ & $\mathbf{S}$ & $\mathrm{Sb}$ & As \\
\hline Purísima & 1 & 0,00 & 0,00 & 0,18 & 44,37 & 0,28 & 0,44 & 54,97 & 100,23 & 0,000 & 0,000 & 0,004 & 0,996 & 0,012 & 0,005 & 0,967 \\
\hline \multirow[t]{15}{*}{$\mathrm{n}=15$} & 2 & 0,00 & 0,00 & 0,24 & 44,16 & 0,56 & 0,43 & 54,17 & 99,58 & 0,000 & 0,000 & 0,005 & 0,995 & 0,023 & 0,005 & 0,956 \\
\hline & 3 & 0,00 & 0,03 & 0,26 & 43,88 & 0,18 & 0,33 & 54,87 & 99,56 & 0,000 & 0,001 & 0,006 & 0,994 & 0,008 & 0,004 & 0,973 \\
\hline & 4 & 0,00 & 0,00 & 0,24 & 44,14 & 0,54 & 0,56 & 54,16 & 99,64 & 0,000 & 0,000 & 0,005 & 0,995 & 0,022 & 0,006 & 0,956 \\
\hline & 5 & 0,02 & 0,02 & 0,10 & 43,31 & 0,04 & 1,27 & 54,43 & 99,21 & 0,000 & 0,000 & 0,002 & 0,997 & 0,002 & 0,014 & 0,982 \\
\hline & 6 & 0,00 & 0,00 & 0,25 & 43,31 & 0,49 & 0,66 & 53,86 & 98,61 & 0,000 & 0,000 & 0,006 & 0,994 & 0,021 & 0,007 & 0,968 \\
\hline & 7 & 0,00 & 0,01 & 0,13 & 43,16 & 0,05 & 0,29 & 54,98 & 98,62 & 0,000 & 0,000 & 0,003 & 0,997 & 0,002 & 0,003 & 0,995 \\
\hline & 8 & 0,00 & 0,03 & 0,29 & 44,18 & 0,30 & 0,28 & 55,39 & 100,46 & 0,000 & 0,001 & 0,007 & 0,993 & 0,012 & 0,003 & 0,975 \\
\hline & 22 & 0,00 & 0,00 & 0,27 & 43,61 & 1,86 & 0,93 & 52,61 & 99,36 & 0,000 & 0,000 & 0,006 & 0,994 & 0,078 & 0,010 & 0,939 \\
\hline & 35 & 0,00 & 0,00 & 0,18 & 44,82 & 0,66 & 0,53 & 54,43 & 100,63 & 0,000 & 0,000 & 0,004 & 0,996 & 0,027 & 0,006 & 0,948 \\
\hline & 36 & 0,00 & 0,02 & 0,29 & 44,63 & 2,85 & 0,44 & 50,21 & 98,45 & 0,000 & 0,000 & 0,006 & 0,993 & 0,116 & 0,005 & 0,875 \\
\hline & 37 & 0,00 & 0,00 & 0,19 & 45,63 & 3,03 & 0,46 & 50,83 & 100,15 & 0,000 & 0,000 & 0,004 & 0,996 & 0,121 & 0,005 & 0,869 \\
\hline & 38 & 0,00 & 0,02 & 0,04 & 43,63 & 0,05 & 1,13 & 53,14 & 98,01 & 0,000 & 0,000 & 0,001 & 0,999 & 0,002 & 0,012 & 0,953 \\
\hline & 82 & 3,80 & 0,29 & 0,29 & 40,37 & 0,41 & 0,78 & 52,48 & 98,59 & 0,079 & 0,006 & 0,006 & 0,909 & 0,017 & 0,009 & 0,926 \\
\hline & 87 & 4,48 & 0,76 & 0,32 & 40,48 & 0,93 & 1,39 & 53,34 & 101,83 & 0,079 & 0,006 & 0,006 & 0,909 & 0,017 & 0,009 & 0,926 \\
\hline & $\mathrm{Gm}$ & 0,00 & 0,01 & 0,20 & 44,31 & 0,40 & 0,59 & 54,49 & & 0,01 & 0,00 & 0,00 & 0,98 & 0,03 & 0,01 & 0,95 \\
\hline Total & Var & 3,27 & 2,19 & 1,11 & 1,16 & 1,85 & 1,10 & 1,15 & 11,83 & & & & & & & \\
\hline
\end{tabular}

Tabla 7- 8. Composición expresada como \% en peso y como unidades de átomos por unidad de fórmula de niquelina, $\mathrm{n}=19$.

La incorporación tanto de Fe como de Co es muy limitada, alcanzando un valor máximo de 0,6 y 0,7\% molar respectivamente. Asimismo, el reemplazo de As por $\mathrm{S}$, también es limitado, sin embargo algunos análisis puntuales se alejan de la composición ideal y contienen hasta $12 \%$ de S molar (Fig. 7-4). La proporción de S en la fórmula no está vinculada a la relación entre Co-Ni. Esto es representado en la relación S/As+S vs. Co/Ni+Co. (Fig. 5), con un índice de correlación de Pearson de 0,25. Esta inclusión de $\mathrm{S}$ a la fórmula podría estar dada por impurezas. 

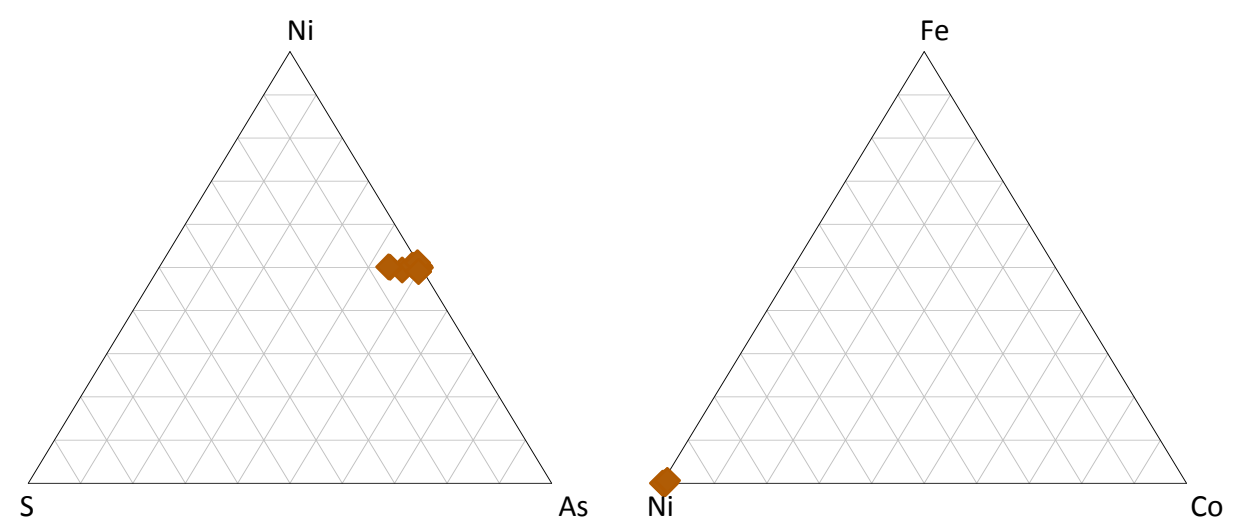

Fig. 7- 4. A. Diagrama triangulares de composiciones de niquelina. A. Ni-As-S. B. Ni-Co-Fe. Los valores en este último diagrama se concentran en el vértice Ni.

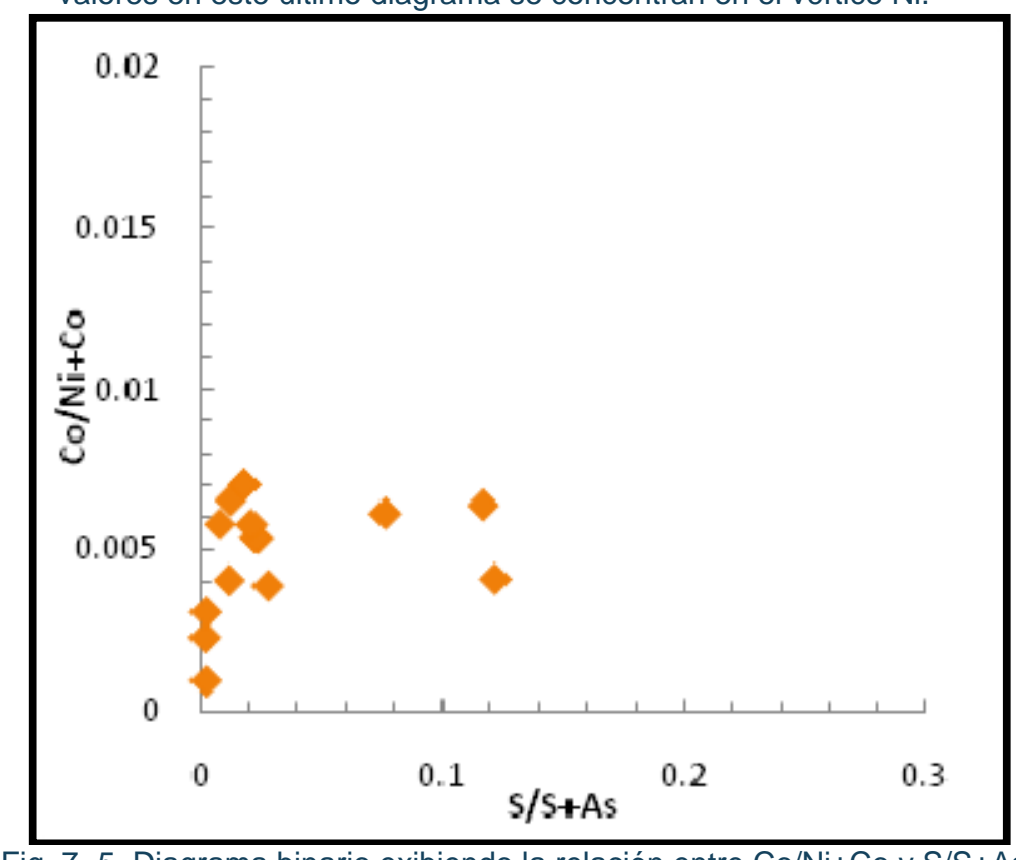

Fig. 7- 5. Diagrama binario exibiendo la relación entre Co/Ni+Co y S/S+As.

Tetrahedrita-Tennantita $\left[\mathrm{Cu}_{10}(\mathrm{Fe}, \mathrm{Zn})_{2} \mathrm{Sb}_{4} \mathrm{~S}_{13}-\mathrm{Cu}_{10}(\mathrm{Fe}, \mathrm{Zn})_{2} \mathrm{As}_{4} \mathrm{~S}_{13}\right]$

La solución sólida tetraedrita-tennantita, $\mathrm{Cu}_{10}(\mathrm{Fe}, \mathrm{Zn})_{2} \mathrm{Sb}_{4} \mathrm{~S}_{13}-\mathrm{Cu}_{10}(\mathrm{Fe}, \mathrm{Zn})_{2} \mathrm{As}_{4} \mathrm{~S}_{13} \mathrm{es}$ un constituyente común de depósitos polimetálicos epi y mesotermales a escala mundial. En la serie es frecuente el reemplazo de $\mathrm{Ag}^{+}$sustituyendo al $\mathrm{Cu}^{+}$en posición triangular, y el reemplazo de Fe-Zn ocupando posiciones tetraédricas por $\mathrm{Hg}$, Co y $\mathrm{Ni}$ (Staude et al., 2010). Las posiciones triangulares del As-Sb pueden ser ocupadas por $\mathrm{Bi}$ y Te, mientras que el $\mathrm{S}$ que ocupa una posición hexagonal puede ser reemplazado por Se (Staude et al., 2010).

La fórmula de la tetrahedrita-tennantita ideal puede de esa manera resumirse en la siguiente expresión: $(\mathrm{Cu}, \mathrm{Ag})_{6} \mathrm{Cu}_{4}(\mathrm{Fe}, \mathrm{Zn}, \mathrm{Cu}, \mathrm{Hg}, \mathrm{Cd})_{2}(\mathrm{As}, \mathrm{Sb}, \mathrm{Bi}, \mathrm{Te})_{4}(\mathrm{~S}, \mathrm{Se})_{13}$. (Johnson et 
al., 1986), indicando que el Cd puede asimismo sustituir parcialmente la posición tetraédrica del Fe-Zn. Los cambios que se producen en la composición del mineral y su amplia distribución en los yacimientos permiten utilizar la tetrahedrita-tennantita como indicador de la composición de los fluidos y de los procesos genéticos en los depósitos donde se encuentra (Sack et al., 2003; Staude et al., 2010).

En el depósito Purísima-Rumicruz estas variaciones composicionales han sido reconocidas y cuantificadas mediante microsonda en un total de 20 análisis desarrollados sobre tetrahedrita-tennantita de las vetas Purísima y Rumicruz (Tabla 79).

De las muestras analizadas se desprende que la composición de la tetrahedritatennantita registró una sustitución continua de $\mathrm{As}$ con $\mathrm{Sb}$, exhibiendo un leve enriquecimiento en As la tetrahedrita-tennantita correspondientes a la veta Purísima y en Sb los de Rumicruz (Fig. 7-6A). El catión bivalente preponderante es el Zn que varía entre 1,64 y 1,83 unidad de átomos por fórmula (a.p.u.f.) mientras que los valores de $\mathrm{Fe}$ son bajos con un promedio de 0,17 a.p.u.f. Las máximas concentraciones de $\mathrm{Zn}$ se identificaron en las muestras correspondientes a la veta Rumicruz, mientras que las de Fe se registraron en Purísima (Fig. 7-6B).

\begin{tabular}{|c|c|c|c|c|c|c|c|c|c|c|c|c|c|c|c|c|c|c|c|c|}
\hline & \multicolumn{2}{|c|}{ A } & \multicolumn{9}{|c|}{ Composición (\% en peso) } & \multicolumn{9}{|c|}{ Unidad de átomos por fórmula } \\
\hline & $\mathrm{N}^{\circ}$ & $\mathrm{Cu}$ & $\mathrm{Ag}$ & $\mathrm{Fe}$ & $\mathrm{Zn}$ & As & Sb & $\mathbf{s}$ & Co & $\mathrm{Ni}$ & Total & $\mathrm{Cu}$ & $\mathrm{Ag}$ & $\mathrm{Fe}$ & $\mathrm{Zn}$ & As & Sb & $\mathbf{s}$ & Co & $\mathrm{Ni}$ \\
\hline \multirow[t]{13}{*}{ Purísima } & 47 & 38,55 & 0,09 & 1,33 & 7,12 & 12,41 & 11,80 & 27,62 & 0,04 & 0,00 & 99,08 & 9,45 & 0,01 & 0,31 & 1,70 & 2,58 & 1,51 & 13,42 & 0,01 & 0,00 \\
\hline & 54 & 38,22 & 0,15 & 0,43 & 7,34 & 5,79 & 21,77 & 26,14 & 0,00 & 0,00 & 99,83 & 9,729 & 0,022 & 0,105 & 1,816 & 1,250 & 2,892 & 13,186 & 0,000 & 0,000 \\
\hline & 55 & 37,94 & 0,09 & 0,58 & 7,03 & 7,74 & 18,63 & 26,72 & 0,00 & 0,00 & 98,72 & 9,600 & 0,013 & 0,142 & 1,729 & 1,660 & 2,460 & 13,396 & 0,000 & 0,000 \\
\hline & 56 & 37,83 & 0,20 & 0,43 & 7,38 & 4,46 & 23,83 & 26,23 & 0,03 & 0,00 & 100,38 & 9,643 & 0,029 & 0,106 & 1,827 & 0,964 & 3,170 & 13,252 & 0,009 & 0,000 \\
\hline & 57 & 38,87 & 0,10 & 0,70 & 7,15 & 9,62 & 15,42 & 27,02 & 0,00 & 0,00 & 98,87 & 9,692 & 0,015 & 0,168 & 1,732 & 2,034 & 2,007 & 13,352 & 0,000 & 0,000 \\
\hline & 58 & 36,39 & 0,23 & 0,50 & 6,99 & 3,90 & 24,94 & 25,73 & 0,03 & 0,00 & 98,87 & 9,495 & 0,035 & 0,126 & 1,771 & 0,863 & 3,396 & 13,305 & 0,009 & 0,000 \\
\hline & 67 & 37,70 & 0,13 & 0,74 & 6,89 & 10,16 & 14,84 & 27,45 & 0,09 & 0,24 & 98,23 & 9,400 & 0,019 & 0,178 & 1,669 & 2,150 & 1,931 & 13,564 & 0,024 & 0,065 \\
\hline & 68 & 37,38 & 0,09 & 0,84 & 6,74 & 9,78 & 15,50 & 27,16 & 0,10 & 0,32 & 97,90 & 9,390 & 0,014 & 0,202 & 1,645 & 2,084 & 2,032 & 13,519 & 0,026 & 0,087 \\
\hline & 69 & 38,00 & 0,08 & 0,93 & 6,87 & 10,96 & 13,93 & 27,34 & 0,11 & 0,39 & 98,59 & 9,428 & 0,012 & 0,221 & 1,655 & 2,307 & 1,804 & 13,441 & 0,029 & 0,104 \\
\hline & $\mathrm{Gm}$ & 38,79 & 0,12 & 0,69 & 7,22 & 7,94 & 17,74 & 27,47 & 0,02 & 0,01 & & 9,537 & 0,019 & 0,174 & 1,727 & 1,766 & 2,356 & 13,382 & 0,012 & 0,028 \\
\hline & I Var & 0,73 & 0,85 & 0,70 & 0,74 & 0,72 & 0,82 & 0,72 & 1,94 & 3,46 & 10,69 & & & & & & & & & \\
\hline & $B$ & \multicolumn{10}{|c|}{ Composición (\% en peso) } & \multicolumn{9}{|c|}{ Unidad de átomos por fórmula } \\
\hline & $\mathrm{N}^{0}$ & $\mathrm{Cu}$ & $\mathrm{Ag}$ & $\mathrm{Fe}$ & $\mathrm{Zn}$ & As & Sb & s & Co & $\mathrm{Ni}$ & Total & $\mathrm{Cu}$ & $\mathrm{Ag}$ & $\mathrm{Fe}$ & $\mathrm{Zn}$ & As & $\mathrm{Sb}$ & s & Co & $\mathrm{Ni}$ \\
\hline \multirow[t]{13}{*}{ Rumicruz } & 24 & 38,56 & 0,46 & 0,37 & 7,06 & 3,45 & 25,24 & 25,15 & 0,09 & 0,14 & 100,53 & 9,962 & 0,071 & 0,091 & 1,772 & 0,756 & 3,404 & 12,879 & 0,026 & 0,038 \\
\hline & 80 & 37,36 & 0,06 & 0,21 & 7,65 & 6,90 & 19,92 & 26,74 & 0,06 & 0,00 & 99,01 & 9,476 & 0,009 & 0,051 & 1,885 & 1,484 & 2,637 & 13,441 & 0,017 & 0,000 \\
\hline & 81 & 37,39 & 0,12 & 0,31 & 7,65 & 7,82 & 18,16 & 26,51 & 0,01 & 0,01 & 98,02 & 9,523 & 0,018 & 0,075 & 1,893 & 1,689 & 2,414 & 13,384 & 0,003 & 0,002 \\
\hline & 89 & 41,31 & 0,14 & 0,37 & 8,01 & 8,66 & 16,45 & 25,71 & 0,01 & 0,01 & 100,66 & 10,289 & 0,020 & 0,089 & 1,937 & 1,830 & 2,139 & 12,690 & 0,003 & 0,002 \\
\hline & 91 & 41,39 & 0,05 & 0,33 & 7,95 & 9,75 & 15,06 & 26,37 & 0,05 & 0,06 & 101,11 & 10,176 & 0,007 & 0,077 & 1,899 & 2,032 & 1,932 & 12,848 & 0,013 & 0,016 \\
\hline & 92 & 42,10 & 0,03 & 0,25 & 7,85 & 8,24 & 17,07 & 25,95 & 0,02 & 0,12 & 101,69 & 10,395 & 0,004 & 0,060 & 1,884 & 1,725 & 2,200 & 12,695 & 0,004 & 0,033 \\
\hline & 93 & 39,62 & 0,10 & 0,13 & 7,77 & 1,96 & 27,13 & 24,89 & 0,00 & 0,06 & 101,66 & 10,206 & 0,015 & 0,032 & 1,945 & 0,428 & 3,648 & 12,708 & 0,000 & 0,017 \\
\hline & 94 & 41,31 & 0,04 & 0,27 & 8,05 & 8,21 & 17,30 & 26,24 & 0,02 & 0,06 & 101,50 & 10,195 & 0,006 & 0,064 & 1,931 & 1,718 & 2,229 & 12,835 & 0,006 & 0,016 \\
\hline & 96 & 41,12 & 0,15 & 0,38 & 8,05 & 9,34 & 15,29 & 26,24 & 0,00 & 0,04 & 100,63 & 10,164 & 0,021 & 0,090 & 1,933 & 1,957 & 1,973 & 12,853 & 0,000 & 0,010 \\
\hline & 97 & 40,48 & 0,12 & 0,30 & 7,91 & 7,26 & 18,51 & 25,78 & 0,03 & 0,01 & 100,40 & 10,166 & 0,018 & 0,073 & 1,931 & 1,546 & 2,426 & 12,828 & 0,008 & 0,003 \\
\hline & 98 & 39,97 & 0,06 & 0,18 & 7,93 & 5,04 & 22,38 & 25,92 & 0,00 & 0,04 & 101,53 & 10,058 & 0,009 & 0,043 & 1,938 & 1,075 & 2,939 & 12,928 & 0,000 & 0,010 \\
\hline & $\mathrm{Gm}$ & 40,22 & 0,09 & 0,27 & 7,84 & 6,41 & 19,07 & 26,07 & 0,01 & 0,03 & & 10,056 & 0,018 & 0,068 & 1,904 & 1,476 & 2,540 & 12,917 & 0,007 & 0,013 \\
\hline & Var & 0,34 & 0,55 & 0,33 & 0,34 & 0,44 & 0,36 & 0,34 & 1,46 & 1,26 &, 40 & & & & & & & & & \\
\hline
\end{tabular}

Tabla 7- 9. Composición expresada como \% en peso y como unidades de átomos por unidad de fórmula de tetrahedrita-tennantita. A. Análisis sobre muestras de la veta Purísima n=9. B. Análisis sobre muestras de la veta Rumicruz=11. 


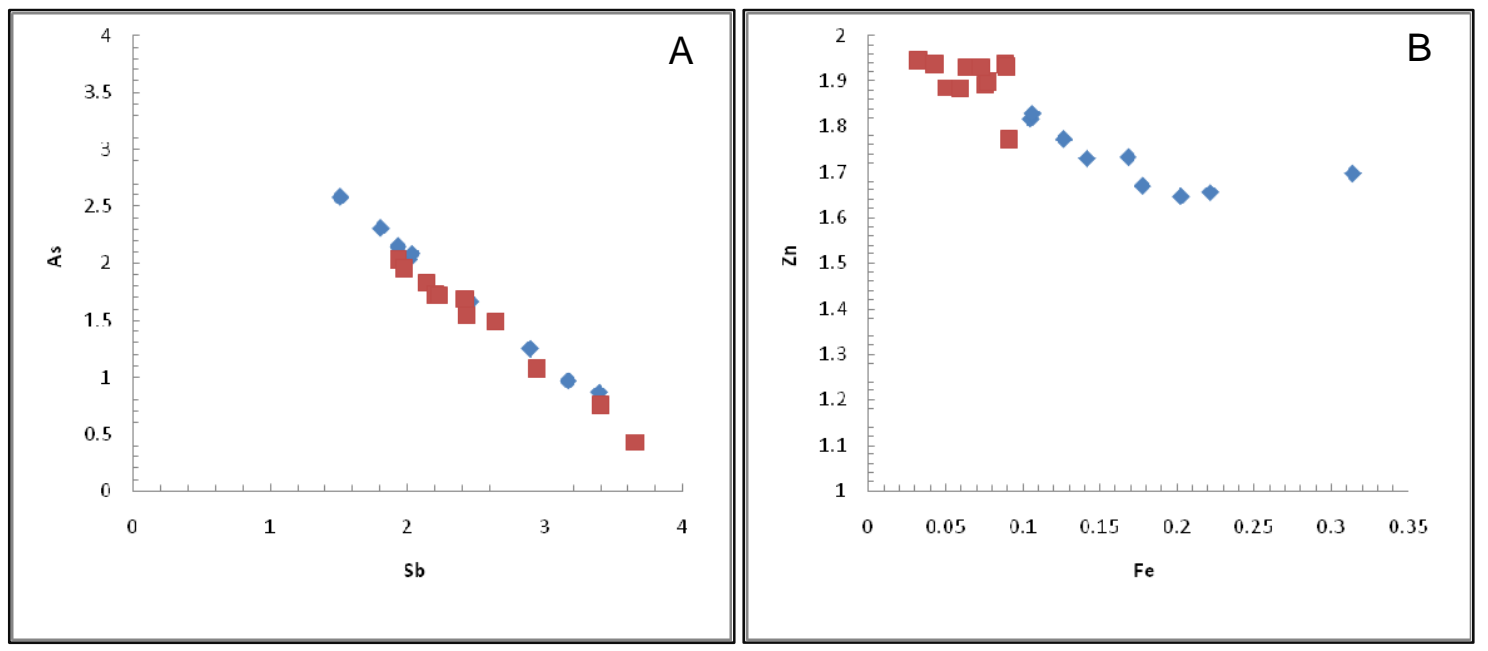

Fig. 7- 6 . Diagrama binario expresado en a.p.u.f. A. Relación de la concentración de arsénico y antimonio. B. Relación de la concentración de zinc y hierro. Cuadros rojos Rumicruz, rombos azules, Purísima.

La relación entre los cationes y aniones analizados anteriormente, queda explicitada en la Fig. 7-7A donde se observa una correlación negativa entre el Zn y el As fundamentalmente en los análisis correspondientes a la veta Purísima, $(r=-0,84)$. Con respecto a los cationes se determinó que la tetrahedrita-tennantita del distrito presenta concentraciones muy bajas de Ag (Fig. 7-7B).

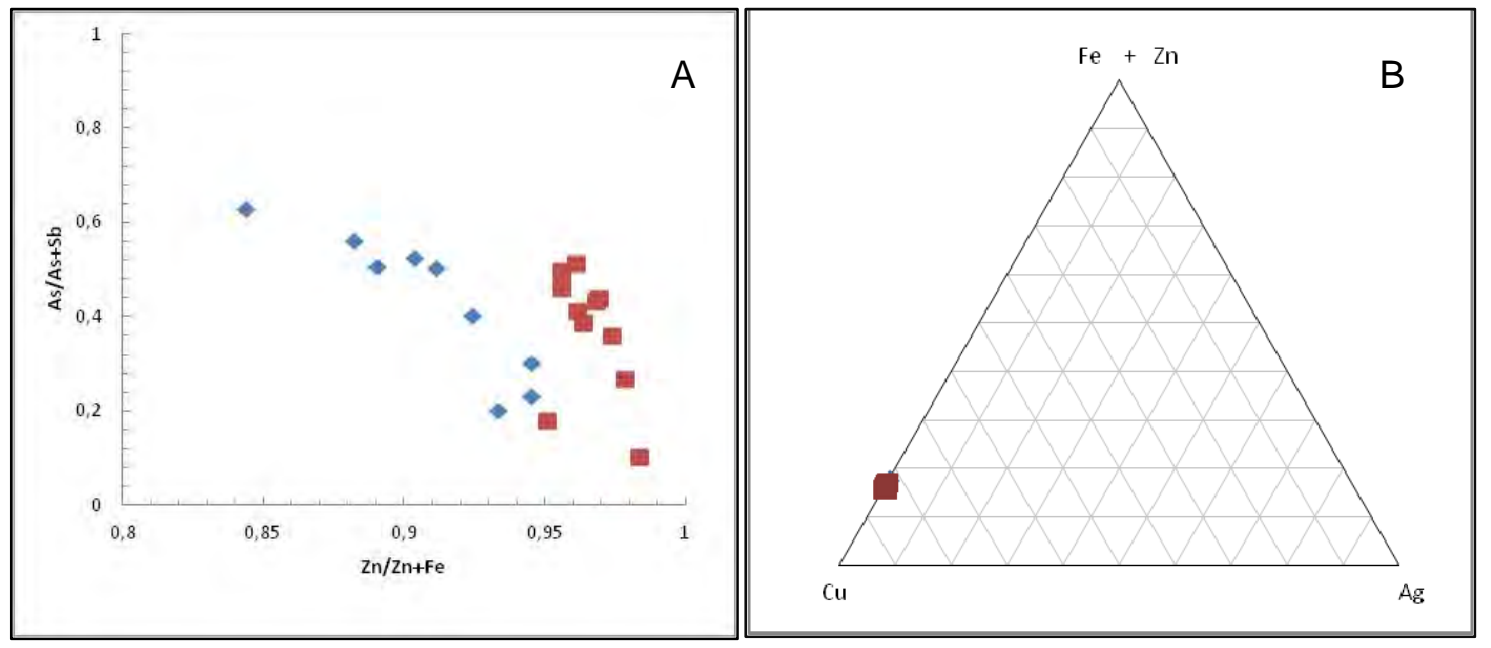

Fig. 7- 7. A. Relación entre As y Zn de la tetrahedrita-tennantita. B. Relación entre los cationes uni y bivalentes. Cuadros rojos Rumicruz, rombos azules, Purísima. En la figura B los puntos correspondientes a Rumicruz se encuentran por encima de los de Purísima.

Los bajos valores de $\mathrm{Ag}$ son coherentes con las observaciones de Johnson et al. (1986), quienes establecieron una correlación negativa entre los valores de Ag y los valores de As y Zn (Fig. 7-8). 


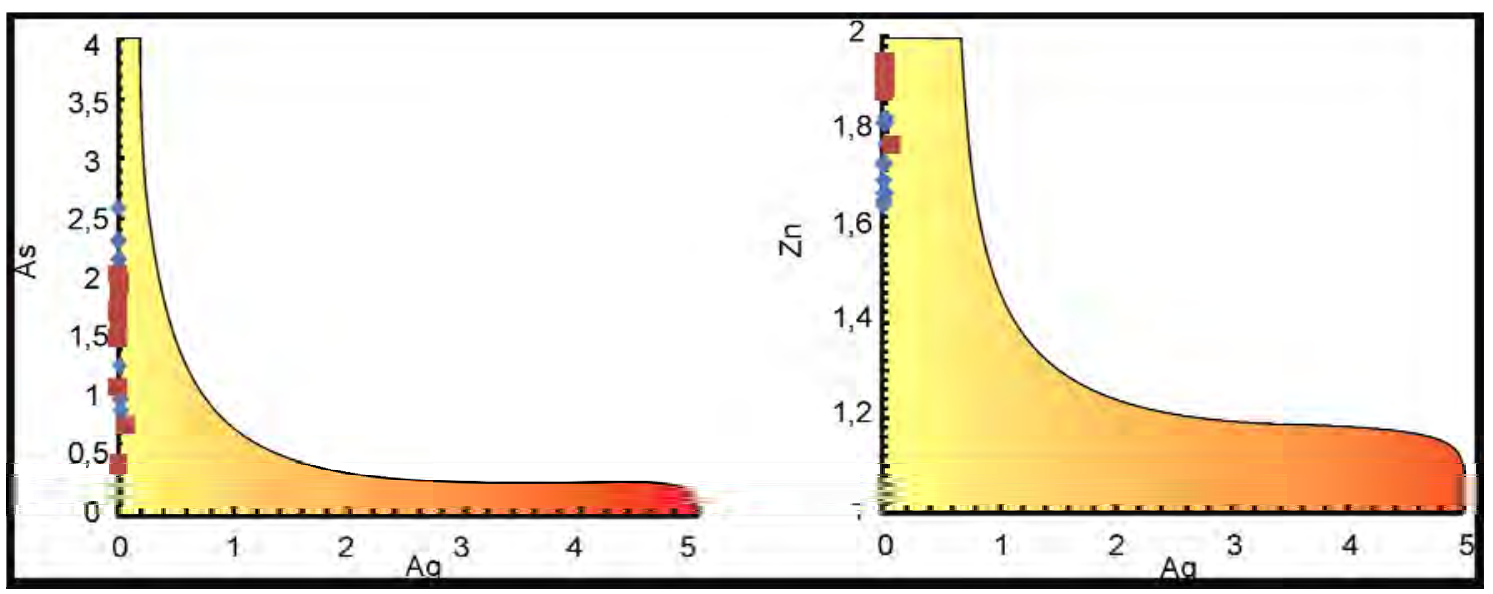

Fig. 7- 8. Valores de Purísima-Rumicruz comparados con el campo de mayor frecuencia establecido por Johnson (1986). El campo sombreado corresponde a las relaciones más frecuentes en tetrahedritatennantita. A. Correlación negativa entre el As y Ag y B. Correlación negativa entre Zn y Ag.

Las imágenes generadas por electrones retrodifundidos evidencian que los cristales presentan una clara zonación. Sin embargo, no ha sido posible correlacionar las variaciones composicionales a un patrón de zonación en los cristales de tetrahedritatennantita, es decir, no se observa cambios progresivos y continuos desde el centro hacia los bordes de los cristales zonados.

\section{Gersdorffita (NiAsS)}

La gersdorffita (NiAsS) aparece en depósitos hidrotermales vetiformes a temperaturas moderadas (Harms, 2010), o bajas (Fanlo y Subías, 2006), así como también en sistemas magmáticos sulfurados (Marshall et al., 2004). El Ni puede ser sustituido por Co y Fe formando una solución sólida completa a temperaturas superiores a $650^{\circ} \mathrm{C}$. Asimismo el As puede formar una solución sólida completa con el $\mathrm{S}$ hasta los términos de krutovita $\left(\mathrm{NiAs}_{2}\right)$ y vaesita $\left(\mathrm{NiS}_{2}\right)$. Estos cambios composicionales ofrecen una herramienta para la diferenciación de sistemas hidrotermales.

Hem (2006), reconoce dos variedades de gersdorffita referidas como ordered NiAsS y disorderer $\mathrm{NiAs}_{1,23} \mathrm{~S}_{0,77}$ que cristalizan en distinto grupo espacial. En el distrito Purísima-Rumicruz, la composición de la gersdorffita es variable y puede resumirse en la fórmula $\mathrm{Ni}_{0,542-0.966} \mathrm{AS}_{0.939-1.409} \mathrm{~S}_{0,438-1,09}$. En base a los diagramas entre elementos pueden reconocerse las dos variedades indicadas por Hem (2006), presentes en las vetas Purísima y Rumicruz (Tabla, 7-10; Fig. 7-9). 
Si bien se ha consignado anteriormente la moderada fugacidad de As con respecto a la de $\mathrm{S}$ en la segunda etapa de precipitación, esta fugacidad ha sido lo suficientemente alta para precipitar monoarseniuros, pero no lo suficientemente alta para precipitar diarseniuros o skutterudita $\left(\mathrm{NiAs}_{3}\right)$.

En los diagramas binarios entre Ni-Co-Fe presentados (Fig. 7-9), la correlación entre el Co y el Fe es ligeramente positiva, aunque con una alta dispersión (Fig. 7-9). Se registra una fuerte correlación negativa entre $\mathrm{Ni}$ y $\mathrm{Co}$, con valores altos de coeficiente de correlación ( $r=-0,915)$, evidenciado una fácil sustitución de $\mathrm{Ni}$ y Co en la estructura cristalina de la gersdorffita. En el sentido contrario la relación entre $\mathrm{Fe}$ y $\mathrm{Ni}$ muestra una moderada dispersión ( $r=-0,327)$.

En la Figura 7-10A se observa la relación entre los cationes presentes en la gersdorffita y las variaciones correspondientes entre As y Ni. En este sentido se diferencian las variedades descriptas por Hem (2006) ordered y disordered. Asimismo, se presentan las variaciones composicionales de la gersdorffita en el sistema Co-Ni-S.

En el apartado sobre mineralogía se trató las diversas texturas que suele presentar la gersdorffita. Allí, se mencionan principalmente tres: (1) como cristales gruesos, ipidiomorfos, rodeando cristales tanto de sulfuros como de niquelina; (2) como pequeñas inclusiones de gersdorffita \pm niquelina dentro de sulfuros; o (3) rellenando fracturas de pechblenda. Esta última textura fue reconocida principalmente en la veta Purisima, mientras que el resto de las texturas mencionadas predominan en la veta Rumicruz.

\begin{tabular}{|c|c|c|c|c|c|c|c|c|c|c|c|c|c|c|c|c|c|}
\hline \multirow[t]{2}{*}{ A } & \multicolumn{8}{|c|}{ Composición (\% en peso) } & \multicolumn{9}{|c|}{ Unidad de átomos por fórmula } \\
\hline & $\mathrm{Cu}$ & $\mathrm{Fe}$ & Co & $\mathrm{Ni}$ & $\mathbf{S}$ & Sb & As & Total & $\mathrm{Cu}$ & $\mathrm{Fe}$ & Co & $\mathrm{Ni}$ & $\mathbf{S}$ & Sb & As & As/S & As/As+ \\
\hline 12 & 0,35 & 0,03 & 82 & 33,28 & 20,11 & 07 & 44,15 & 98,81 & 0,009 & 0,001 & 0,024 & 0,966 & 1,069 & 0,001 & 1,004 & 0,940 & 0,484 \\
\hline 13 & 0,26 & 0,02 & 0,38 & 34,95 & 20,48 & 09 & 45,26 & 101,44 & 007 & 0,000 & 0,011 & 0,982 & 1,054 & 0,001 & 0,997 & 0,946 & 0,486 \\
\hline 15 & 0,02 & 0,06 & 2,16 & 31,95 & 19,80 & 0,86 & 43,71 & 98,56 & 0,000 & 0,001 & 0,063 & 0,935 & 1,060 & 0,012 & 1,002 & 0,945 & 0,486 \\
\hline 17 & 0,56 & 1,74 & 0,95 & 33,19 & 19,88 & 0,00 & 44,15 & 100,48 & 14 & 0,043 & 0,026 & 0,917 & 1,005 & 0,000 & 0,955 & 0,950 & 0,487 \\
\hline 18 & 6,43 & 0,28 & 3,71 & 22,24 & 12,07 & 5,09 & 50,38 & 100 & 85 & 0,008 & 0,115 & 0,692 & 0,688 & 0,076 & 1,229 & 1,786 & 0,641 \\
\hline 19 & 0,6 & 0,43 & 2,42 & 27,76 & 13,72 & 0,28 & 55,94 & 101,30 & 0,018 & 0,012 & 0,077 & 0,892 & 0,807 & 0,004 & 1,409 & 1,746 & 0,636 \\
\hline 26 & 2,38 & 0,14 & 2,75 & 33,49 & 9,22 & 0,37 & 48,87 & 98,12 & 0,057 & 0,003 & 0,071 & 0,869 & 0,438 & 0,005 & 0,993 & 2,268 & 0,694 \\
\hline 31 & 6,69 & 0,19 & 4,05 & 21,88 & 11,38 & 5,86 & 47,46 & 98,46 & 0,192 & 0,005 & 0,125 & 0,678 & 0,646 & 0,088 & 1,152 & 1,785 & 0,641 \\
\hline 39 & 1,57 & 0,08 & 0,48 & 33,58 & 19,93 & 0,27 & 43,02 & 99,06 & 0,041 & 0,002 & 0,013 & 0,944 & 1,026 & 0,004 & 0,947 & 0,924 & 0,480 \\
\hline 40 & 2,55 & 0,04 & 0,54 & 33,13 & 19,34 & 0,31 & 43,63 & 99,75 & 0,065 & 0,001 & 0,015 & 0,919 & 0,981 & 0,004 & 0,948 & 0,966 & 0,491 \\
\hline 74 & 4,03 & 0,02 & 0,10 & 32,60 & 19,83 & 0,40 & 43,67 & 100,74 & 0,102 & 0,000 & 0,003 & 0,895 & 0,996 & 0,005 & 0,939 & 0,943 & 0,485 \\
\hline 75 & 3,76 & 0,03 & 0,42 & 32,70 & 18,93 & 0,12 & 45,27 & 101,46 & 0,095 & 0,001 & 0,011 & 0,893 & 0,946 & 0,002 & 0,969 & 1,024 & 0,506 \\
\hline & 2,43 & 0,25 & 1,56 & 0,90 & 17,06 & 1,14 & 46,29 & & 0,065 & 0,007 & 0,046 & 0,882 & 0,893 & 0,017 & 1,045 & 1,268 & 0,543 \\
\hline Total Var & 5,54 & 0,24 & 1,94 & 19,95 & 17,35 & 4,17 & 14,59 & 1,55 & & & & & & & & & \\
\hline
\end{tabular}


B

\begin{tabular}{|c|c|c|c|c|c|c|c|c|c|c|c|c|c|c|c|c|c|}
\hline $\mathrm{N}^{0}$ & $\mathrm{Cu}$ & $\mathrm{Fe}$ & Co & $\mathrm{Ni}$ & $\mathrm{s}$ & Sb & As & Total & $\mathrm{Cu}$ & $\mathrm{Fe}$ & Co & $\mathrm{Ni}$ & $\mathrm{s}$ & Sb & As & As/S & As/As+ \\
\hline 59 & 1,69 & 0,41 & 5,47 & 26,97 & 19,83 & 0,03 & 44,39 & 99,43 & 0,045 & 0,011 & 0,159 & 0,785 & 1,056 & 0,000 & 1,012 & 0,958 & 0,489 \\
\hline 60 & 1,76 & 0,58 & 14,23 & 19,31 & 19,82 & 0,03 & 44,79 & 101,10 & 0,046 & 0,014 & 0,398 & 0,542 & 1,018 & 0,000 & 0,985 & 0,967 & 0,492 \\
\hline 61 & 1,77 & 0,54 & 14,14 & 19,50 & 19,86 & 0,00 & 44,91 & 101,28 & 0,046 & 0,013 & 0,394 & 0,546 & 1,018 & 0,000 & 0,986 & 0,968 & 0,492 \\
\hline 63 & 1,46 & 0,80 & 6,77 & 23,95 & 14,54 & 0,00 & 52,10 & 99,89 & 0,041 & 0,022 & 0,206 & 0,731 & 0,813 & 0,000 & 1,344 & 1,654 & 0,623 \\
\hline 64 & 1,68 & 0,73 & 6,42 & 24,01 & 14,51 & 0,02 & 51,98 & 99,88 & 0,048 & 0,020 & 0,196 & 0,736 & 0,814 & 0,000 & 1,249 & 1,534 & 0,605 \\
\hline 65 & 1,85 & 0,86 & 7,01 & 23,55 & 14,17 & 0,00 & 52,35 & 100,25 & 0,052 & 0,023 & 0,212 & 0,713 & 0,786 & 0,000 & 1,243 & 1,581 & 0,613 \\
\hline 70 & 4,45 & 0,34 & 1,46 & 27,53 & 19,93 & 1,52 & 4 & 100,29 & 3 & 9 & 0,044 & 0,824 & 1,092 & 22 & 1,035 & 0,948 & 0,487 \\
\hline 71 & 1,12 & 0,22 & 5,31 & 27,79 & 19,62 & 0,05 & 44,67 & 99,14 & 0,030 & 0,006 & 0,154 & 0,810 & 1,046 & 0,001 & 1,020 & 0,975 & 0,494 \\
\hline 72 & 0,72 & 0,22 & 2,65 & 30,08 & 19,84 & 0,06 & 44,38 & 98,37 & 0,020 & 0,006 & 0,079 & 0,896 & 1,082 & 0,001 & 1,036 & 0,957 & 0,489 \\
\hline & 1,83 & 0,52 & 7,05 & 4,74 & 8,01 & 0,19 & 47,08 & & 0,050 & 0,014 & 0,205 & 0,732 & 0,970 & 0,003 & 1,101 & 1,171 & 0,531 \\
\hline
\end{tabular}

Tabla 7- 10. Composición expresada como por ciento en peso y como unidades de átomos por unidad de fórmula de gersdorffita. A. Análisis sobre muestras de la veta Purísima n=12. B. Análisis sobre muestras de la veta Rumicruz=9.

\section{CONSIDERACIONES FINALES}

La química mineral resultó ser una herramienta importante para la identificación mineralógica y para establecer las relaciones entre los elementos formadores de las distintas especies. Estos resultados permiten a su vez realizar interpretaciones genéticas de los minerales. Como se mencionó en la sección previa, la niquelina corresponde a la etapa 2 de la secuencia paragenética del distrito polimetálico Purísima-Rumicruz. El mismo está caracterizado por una moderada fugacidad de As. Asimismo, la baja proporción de $\mathrm{S}$ detectada en la niquelina podría ser un indicativo de baja temperatura de formación. A $300^{\circ} \mathrm{C}$ la niquelina suele incorporar hasta $5 \%$ en peso de NiS (Wagner y Lorentz, 2002).

La asociación niquelina-gersdorffita es común en algunas depósitos, estos minerales exhiben complejas variaciones texturales y composicionales reflejando un ambiente con rápidas fluctuaciones en temperatura y actividades químicas (Power et al., 2004; Fanlo et al., 2004; Fanlo y Subías, 2006).

Las texturas de reemplazo sugieren un rol activo en la fase fluida del sistema. En el caso que nos ocupa, la aparición de un fluido con una actividad del S sustancialmente más elevada en la etapa 3 puede resultar en la desestabilización de la niquelina y la precipitación de gersdorffita.

En las texturas de reemplazo es en ocasiones invocada una retroalimentación entre la nucleación de los nuevos cristales y la porosidad que ésta genera, incrementando la tasa de disolución de la fase parental (Putnis, 2002).

$$
\mathrm{NiAs}+\mathrm{H} 2 \mathrm{~S}+1 / 2 \mathrm{O}_{2} \longrightarrow \mathrm{NiAsS}+\mathrm{H}_{2} \mathrm{O}
$$



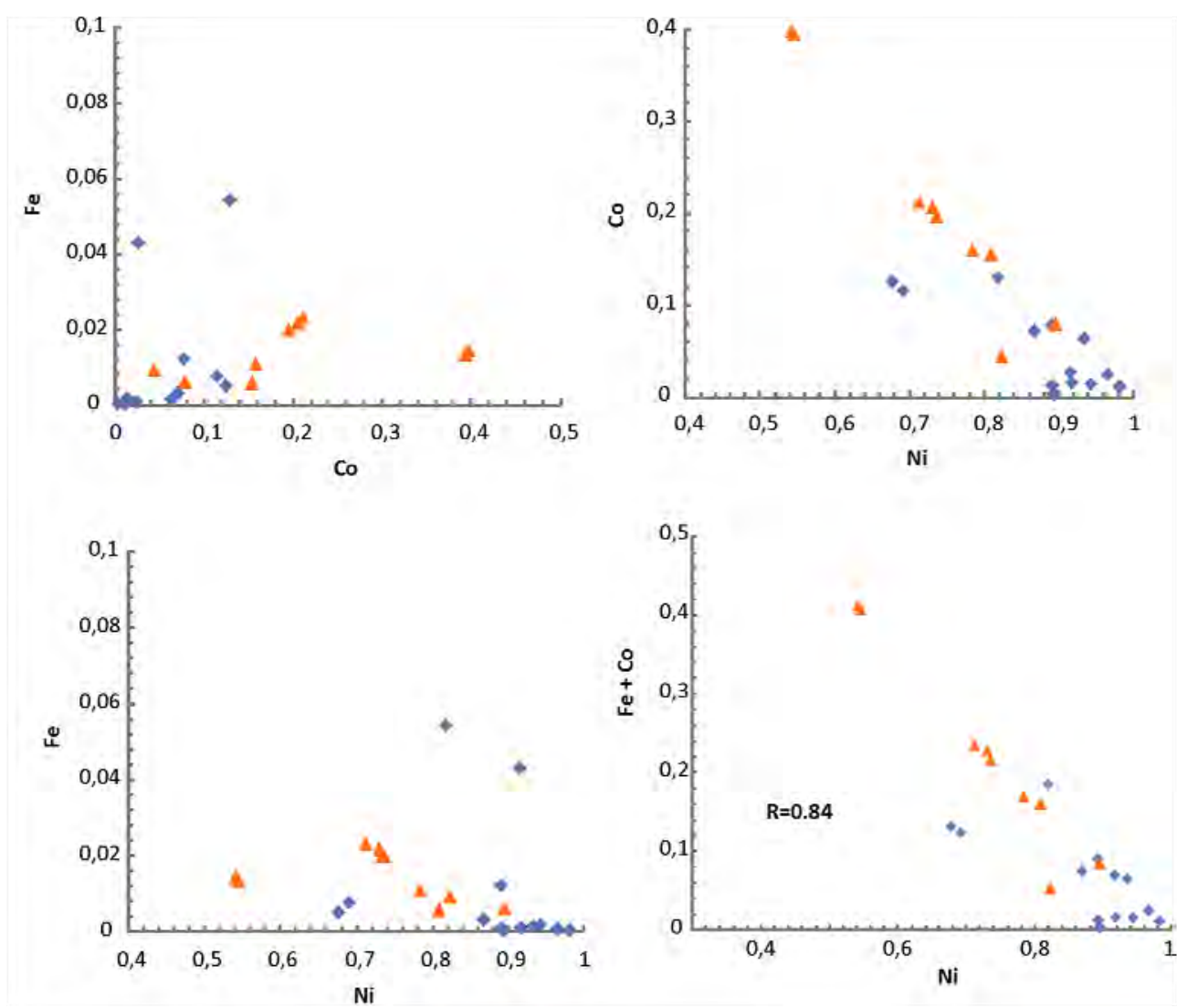

Fig. 7- 9. Distribución de los cationes en gersdorffita. Triángulos naranjas Rumicruz, rombos azules, Purísima.
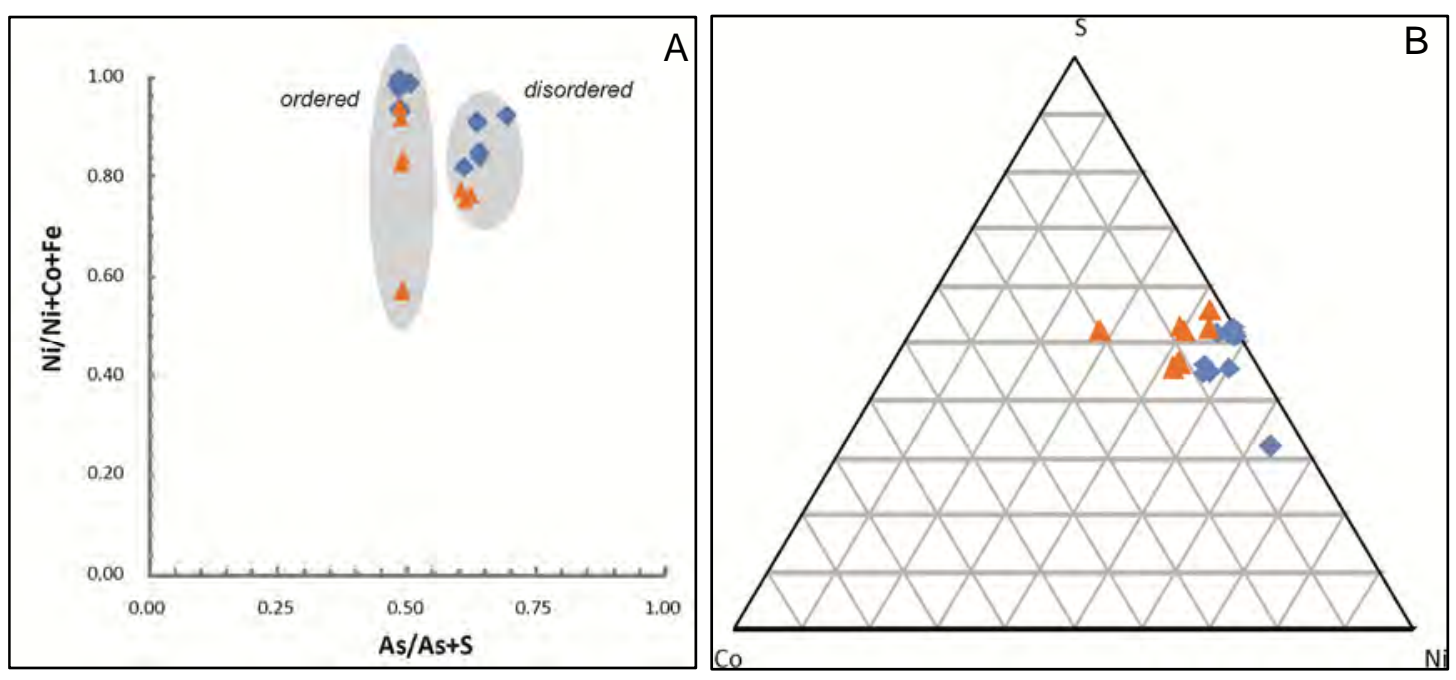

Fig. 7- 10. A. Relación entre los cationes presentes en la gersdorffita y sus variaciones de As y Co. Pueden distinguirse las variedades descriptas por Hem (2006). B. Variaciones composicionales de la gersdorffita en el sistema Co-Ni-S. Triángulos naranjas Rumicruz, rombos azules, Purísima.

En el caso del reemplazo de la gersdorffita con la niquelina esto no ocurre, debido a que el cambio mineralógico conlleva un considerable aumento de volumen (alrededor de un 60\%); sin embargo, el microbrechamiento podría haber actuado en el sentido 
contrario y facilitado el contacto entre la solución y los cristales de niquelina, permitiendo la difusión y el reemplazo.

Como ha sido mencionado en el Capítulo IV, la gersdorffita y la niquelina se encuentran tanto en la etapa de precipitación II y III, en esta última como pequeñas inclusiones dentro de sulfuros. Esto podría explicarse con un enriquecimiento progresivo de $\mathrm{S}$ en el fluido, de esta forma, la niquelina sería más estable en los estadios iniciales y posteriormente, precipitaría gersdorffita, rodeando a la niquelina y finalmente sulfuros, principalmente de $\mathrm{Cu}$ y Fe, correspondientes a la etapa III rodean a estos cristales.

El diagrama de solvus de Klemm (1965) (Fig. 7-11), no es aplicable a sistemas con texturas de reemplazo o desequilibrio, por lo tanto fueron seleccionados aquellos análisis puntuales de gersdorffita que no muestran sustitución de As y $\mathrm{S}$ o reequilibrio. De acuerdo a Fanlo y Subías (2006), los valores As/S cercanos a 1 indican el equilibrio entre la gersdorffita y la solución residual. Particularmente para este estudio el rango As/S seleccionado comprende entre 0,92 y 1,02. De esta forma, los datos volcados en el diagrama muestran que la gersdorffita fue formada a temperaturas bajas, ya que la extensión de la solución sólida Ni-Co y Ni-Fe es limitada a bajas temperaturas (menores a $\left.300^{\circ} \mathrm{C}\right)$ (Hem y Makovicky, 2004).

Durante la precipitación de la gersdorffita se registran variaciones composicionales del fluido hidrotermal, evidenciándose en una amplia dispersión en los valores de las relaciones de As/S (Fig. 7-12). Esta dispersión puede explicarse como resultado de desequilibrios durante la cristalización (Harms, 2010). Otra posible interpretación podría vincularse a procesos de re-equilibrio a baja temperatura (Fanlo y Subías, 2006), que generarían esta dispersión. 


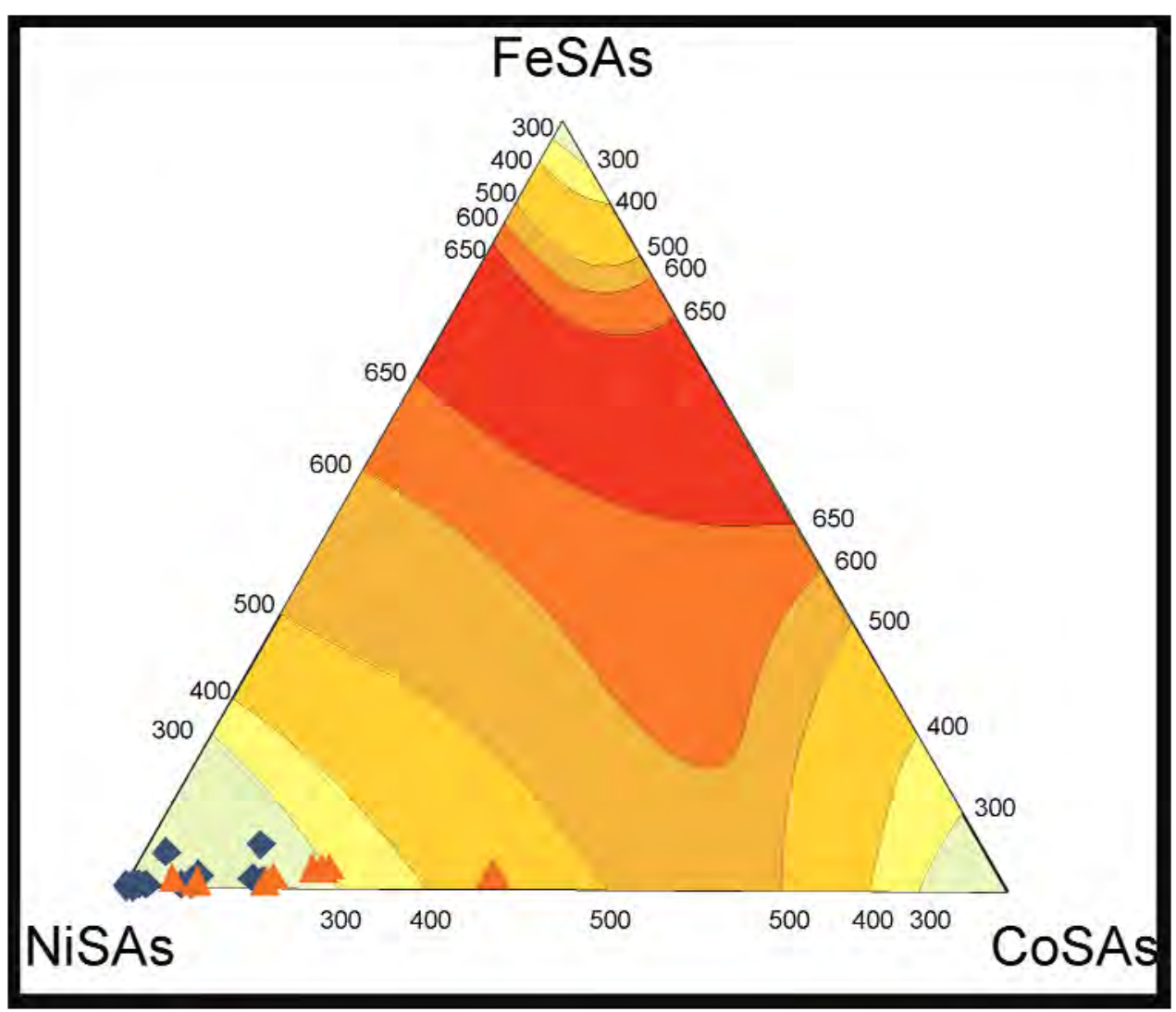

Fig. 7- 11. Diagrama de estabilidad tomado de Klem (1965).

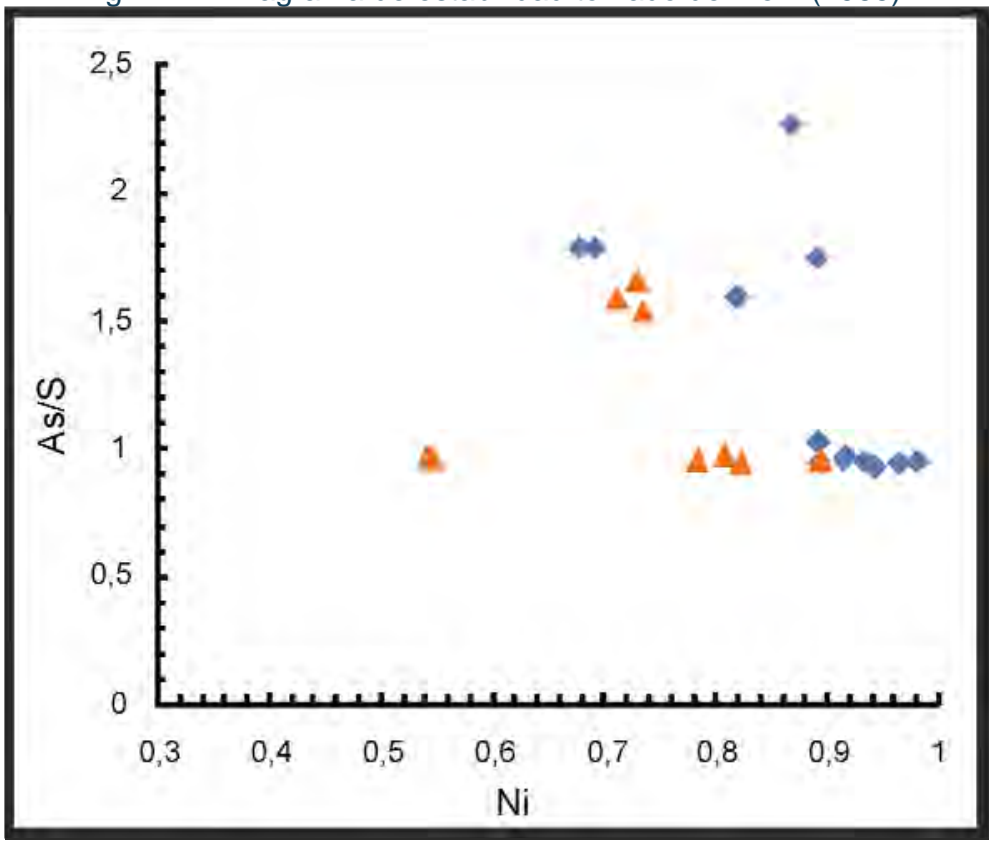

Fig. 7- 12. Relación As/s versus Ni expresado en átomos por unidad de fórmula. Triángulos naranjas Rumicruz, rombos azules, Purísima. 


\section{CAPÍTULO VI}

\section{GEOLOGÍA ESTRUCTURAL Y CONTROLES ESTRUCTURALES DE LA MINERALIZACIÓN PURÍSIMA- RUMICRUZ}




\section{INTRODUCCIÓN}

En este capítulo se aborda el análisis estructural del área de estudio, teniendo en consideración los antecedentes publicados y el marco regional, las observaciones y datos relevados en el campo y las interpretaciones de lineamientos definidos sobre imágenes satelitales y fotografías aéreas. Asimismo, se abordará el control estructural de la mineralización Purísima-Rumicruz.

Si bien en el área de estudio las edades de las rocas más antiguas corresponden a la sedimentación acaecida durante el Ciclo Famatiniano, se describirá también la deformación correspondiente al Ciclo Pampeano, debido a que uno de los aspectos destacados en el presente capítulo es el control estructural que genera la presencia de estructuras previas. Se describirá a continuación, los eventos deformacionales ocurridos en el NOA con énfasis en el sector norte del límite entre las provincias geológicas de Puna y Cordillera Oriental.

\section{Ciclo Pampeano}

Como ha sido descripto en el Capítulo I, el basamento que aflora en el NOA corresponde la Formación Puncoviscana, con características estructurales heterogéneas, (Mon y Hongn, 1988, 1991; Hongn y Mon 1999; Hongn et al., 2008). La discordancia que separa estos sedimentos de las unidades suprayacentes es conocida como discordancia Tilcárica (Turner y Méndez, 1975), y se establece como el límite de los procesos orogénicos Pampeanos de los Famatinianos. Estructuralmente el basamento pre-Famatiniano está deformado con un plegamiento apretado, con clivaje de plano axial, sin embargo sus orientaciones son variables (Hongn et al., 2008), evidenciando la heterogeneidad estructural dentro de Puncoviscana.

La discordancia Tilcárica podría vincularse al arco pampeano (525 Ma), y la sedimentación ser sinorogénica, esto explicaría la presencia de los circones volcánicos pampeanos al tope de la Formación Puncoviscana (Hongn et al., 2008). Conocer la edad y contexto geotectónico de emplazamiento de los granitos de la orogenia Pampea permite también restringir la edad de la deformación. Los granitos asignables a la orogenia Pampeana son los de Tipayoc y Santa Rosa de Tastil. De acuerdo a la interpretación de Astini (2008), ambos granitos, serían postectónicos y según Hongn et al. (2009), el marco geotectónico del emplazamiento de este batolito, se correspondería a un ambiente extensional. Esta extensión estaría vinculada a la 
separación de bloques continentales posteriores a la amalgamación del terreno Arequipa-Antofalla durante el proterozoico superior (Ramos, 2008), o con extensiones relacionadas a roll back de la placa protopacífica (Tubía et al., 2008). Este evento sería el responsable del desarrollo de las cuencas del paleozoico inferior, y marcaría el inicio del ciclo Famatiniano, excluyéndolo del ciclo Pampeano como tradicionalmente fue establecido (Omarini et al., 1999). Este período con dominio extensional estaría acotado por dos eventos contraccionales, la orogenia Pampeana (Tilcárica) y la orogenia Famatiniana.

El origen de la discordancia Irúyica registrada entre los depósitos del grupo Mesón y el Grupo Santa Victoria es motivo de debate, mientras que algunos autores la consideran resultado de movimientos tectónicos (Turner, 1960; Turner y Méndez, 1975; Russo y Barcat, 1978), ha ganado apoyo la idea de un origen eustático de esta discordancia (Moya, 1998; Buatois et al., 2000; Buatois y Mángano, 2003) o una combinación de ambos (Moya, 2008).

\section{Ciclo Famatiniano}

La fase de deformación característica del Ciclo Famatiniano se corresponde a la orogenia Oclóyica. Estudios recientes indican la presencia de un evento deformacional previo, ubicado entre los depósitos de la Formación Santa Rosita y los de la Formación Acoite (Moya, 2008, Hongn et al., 2010). Esta deformación, intraordovícica, se habría desarrollado durante el Tremadociano superior-Arenigiano inferior. La deformación intraordovícica marca el pasaje de un proceso extensional a uno compresivo. Los procesos extensionales permitieron el desarrollo de las cuencas del Grupos Mesón y Santa Victoria, mientras que la tectónica compresiva, generó cuencas de tipo antepaís caracterizados por los depósitos del Arenigiano (Bahlburg, 1990; Astini, 2003). La interpretación de esta discontinuidad tiene más sustento estratigráfico que estructural (Hongn et al., 2008) y es conocida como Guandacol del Arenigiano, (Salfity et al., 1984), Tumbaya del Tremadociano (Moya, 1997), o Los Colorados del Arenigiano (Astini, 2003).

La fase Oclóyica, asignada al Ordovícico superior, se vincula con una importante deformación registrada en la sedimentación Paleozoica temprana, por debajo del Ashgilliano, y su génesis estaría relacionada a la colisión del terreno Arequipa-BelénAntofalla con el borde occidental de Gondwana (Ramos 1986, Forsythe et al., 1993, Bahlburg y Hervé, 1997). La naturaleza de la fase Oclóyica es controversial, Moya 
(1999), sugiere que la edad de esta orogenia es más moderna que el Ordovícico superior o que la deformación es más antigua y corresponde a la Fase Tumbaya (Moya, 2008), ya que no observa discordancia angular entre las secuencias Ordovícicas superiores y las del Ashgilliano. Sin embargo Astini (2003), sostiene que la persistencia lateral del horizonte glacial que se apoya sobre diferentes secuencias ordovícicas sería una evidencia de la presencia de esta orogenia. Mon y Hongn (1987), describen la deformación de la fase Oclóyica, afectando principalmente a las sedimentitas ordovícicas, produciendo pliegues apretados y clivaje de plano axial subvertical. La vergencia tectónica de los plegamientos al norte del paralelo $24^{\circ} \mathrm{S}$ no presenta una definición clara (Hongn et al., 2008).

La Fase Chánica solo se registra en el NOA en las Sierras Subandinas separando mediante una suave discordancia las unidades Siluro-Devónica de las CarboníferoPérmica (Starck et al., 1992). En el área de estudio no hay registros de esta deformación.

Ciclo Patagonídico. Etapa extensional de intraplaca (CretácicoPaleógeno)

A partir del Cretácico inferior se produjo en el NOA y en otras provincias geológicas de Argentina, una extendida tectónica extensional de intraplaca vinculada a la extensión en el retroarco de una subducción de alto ángulo y a la apertura del océano Atlántico (Ramos, 1999). En el Noroeste Argentino esta extensión generó un rifting de intraplaca, mediante fallas directas de alto ángulo, con la consiguiente generación de hemigrabenes. El sistema de rift desarrollado en el NOA está compuesto por varios segmentos donde el más septentrional se lo conoce como Rift de Tres Cruces, exhibiendo un rumbo N-S y se continúa en territorio boliviano, configurando la cuenca Andina (Reyes y Salfity, 1972) o también denominada cuenca de rift del Altiplano (Welsink et al., 1995).

En el depocentro de Tres Cruces las orientaciones de las fallas principales presentan un rumbo aproximado $\mathrm{N}-\mathrm{S}$, en el sector septentrional las inclinaciones de los planos de falla son hacia el Este, mientras que en el sector austral presentan una inclinación opuesta (Monaldi et al., 2008). Ambas zonas están conectadas por una zona de acomodación con orientación NO-SE (Monaldi et al., 2008), donde se encuentra la falla Tabladitas, contacto entre los depósitos de sinrift Cretácico ubicados 
en el Cerro Colorado de Cobre y los depósitos Ordovícicos de la Formación Acoite (Fig. 4-1).

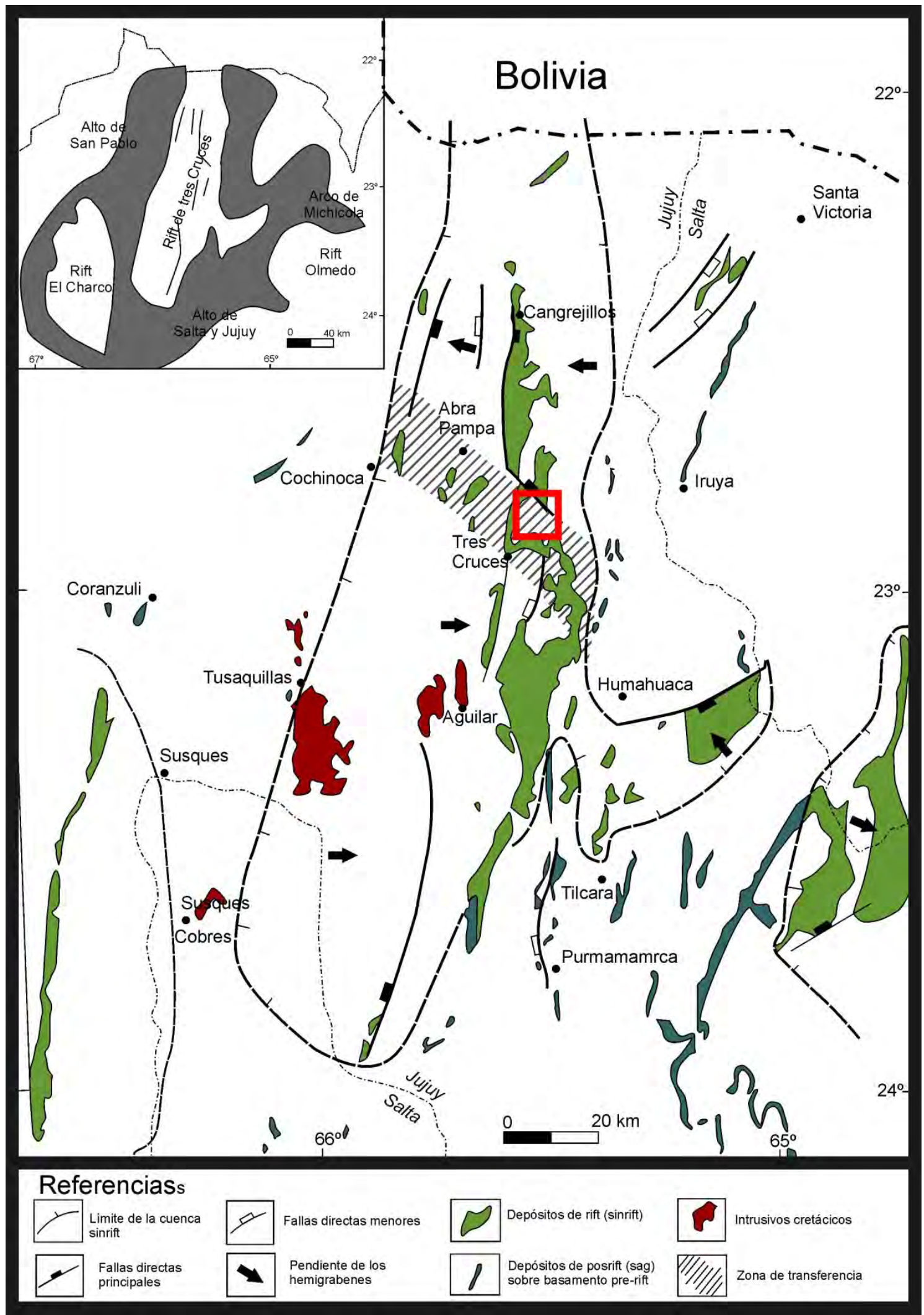

Fig. 4-1. Mapa de los principales rasgos estructurales desarrollados durante el rifting del ciclo Patagonídico. En recuadro, área de estudio. Modificado de Monaldi et al. (2008). 
Numerosas estructuras generadas durante el rifting fueron reactivadas durante el la compresión del Ciclo Ándico (Salfity et al., 1994; Hongn et al., 2010), formando estructuras paralelas $\mathrm{u}$ oblicuas al rumbo andino regional.

\section{Ciclo Ándico. Etapa compresiva (Paleógeno-Holoceno)}

La tectónica Andina está representada por un conjunto de estructuras con rumbo general norte-sur, sin embargo el estilo tectónico estuvo condicionado por las estructuras previas.

La expresión de la deformación consiste en una sucesión de láminas de corrimientos desarrolladas por un empuje tectónico de orientación oeste-este, donde la morfología de las fallas es de tipo lístrico (Rubiolo, 1999). La vergencia dominante es hacia el este, sin embargo en la Cordillera Oriental son frecuentes las estructuras con vergencia hacia el oeste (interpretadas como retrocorrimientos o fallas fuera de secuencia). La compresión comenzó en el Mioceno medio a tardío generando en la Cordillera Oriental corrimientos de piel gruesa (Ramos, 1999). Los ejes de los pliegues generados en los estratos Cretácicos en el sector de Tres Cruces se caracterizan por presentar ejes de pliegues de corta extensión y con una deformación frágil con orientación NE-SO.

\section{GEOLOGÍA ESTRUCTURAL DEL SECTOR SUR DEL CERRO COLORADO DE COBRE}

En el área del Cerro Colorado de Cobre, donde se emplaza el distrito minero Purísima-Rumicruz, se reconocieron elementos estructurales producto de deformación dúctil y frágil (Fig. 4-2). Las estructuras sobresalientes del área son un intenso plegamiento de distintos órdenes, identificable a distintas escalas de trabajo, donde los ejes de los pliegues corren en sentido norte-sur y mayoritariamente son buzantes hacia el sur. Esta característica se mantiene a mayor escala en el área de las vetas del distrito polimetálico Purísima-Rumicruz. Asimismo los afloramientos de rocas de edad Ordovícica están limitados en sentido meridional por corrimientos que presentan vergencia hacia el oeste en el borde occidental, mientras que en el límite oriental es principalmente hacia el este. El contacto hacia el sur entre los sedimentos de edad Cretácica que conforman el Cerro Colorado de Cobre con la sedimentación Ordovícica se produce bajo un fallamiento conocido como Falla Tabladitas (Zanettini, 1973) de tipo normal (Coira, 1979; Rubiolo, 2003), también descripta como una falla con 
componente de rumbo (Zanettini, 1973) pudiendo interpretarse como una zona de transferencia con orientación NO-SE (Monaldi et al., 2008), como ha sido descriptos para otros sectores de la región (Hongn et al., 2010). Esta falla fue reactivada como una falla inversa durante la contracción del ciclo Ándico (Monaldi et al., 2008).

\section{Deformación dúctil}

La Formación Acoite registra distintos tipo de deformación de acuerdo a la competencia de las litologías dominantes, las areniscas presentan pliegues bien desarrollados, apretados, con ejes buzantes (Fig. 4-3A), cilíndricos (Fig. 4-3B), mientras que las pelitas desarrollan un marcado clivaje de plano axial, perpendicular a la laminación que produce estructuras en lápiz (Fig. 3-4A). Las diferentes litologías exhiben estos estilos estructurales (Fig. 4-3C).

Para definir las orientaciones e inclinaciones de los ejes de los pliegues han sido medidos rumbo e inclinación de las capas y reconstruidos los pliegues sobre la red estereográfica de Wulff, así como también, cuando ha sido posible se levantaron mediciones directas sobre los ejes de los pliegues en el campo. Los resultados han sido representados en la figura 4-4, donde se identifican tres zonas con distintas orientaciones para los afloramientos de la Formación Acoite. A su vez estos datos correspondientes con afloramientos de rocas de edad Ordovícica han sido discriminados de los datos estructurales correspondientes a los estratos de edad Cretácica, representados por los sedimentos del Grupo Salta.

En el sector del distrito minero Purísima-Rumicruz se determinó que los estratos buzan tanto hacia el este como al oeste, con ángulos generalmente menores a $40^{\circ}$, aunque se registraron inclinaciones de estratos subverticales. Los pliegues son levemente asimétricos con vergencia hacia el este. Los ejes de los pliegues presentan una dirección promedio de $194^{\circ}$ y son buzantes con un promedio de $11^{\circ}$ al sur. Sin embargo se identificaron buzamientos de hasta $50^{\circ}$.

En el sector Bola Blanca se discriminaron los datos pertenecientes a los afloramientos de la Formación Acoite de aquellos registrados sobre los estratos psamíticos que han sido asignados tentativamente a la Formación Santa Rosita. En los primeros, los estratos mayoritariamente buzan hacia el este con inclinaciones suaves. Para la secuencia psamítica los datos arrojan direcciones de inclinación de estratos en sentido Este y Oeste definiendo un suave plegamiento con eje buzante con un azimut de $9^{\circ}$ e inclinación de $9^{\circ}$ hacia el norte. En el sector San Agustín los datos presentan una mayor dispersión. Los estratos presentan rumbos de buzamiento hacia 
el NO y hacia el NE configurando pliegues con ejes con un azimut promedio de $355^{\circ} \mathrm{e}$ inclinación media de $17^{\circ}$ hacia el norte. El sector correspondiente al Cerro Colorado de Cobre exhibe pliegues amplios y abiertos con ejes buzantes principalmente hacia el

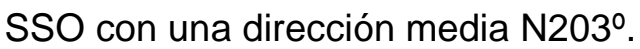

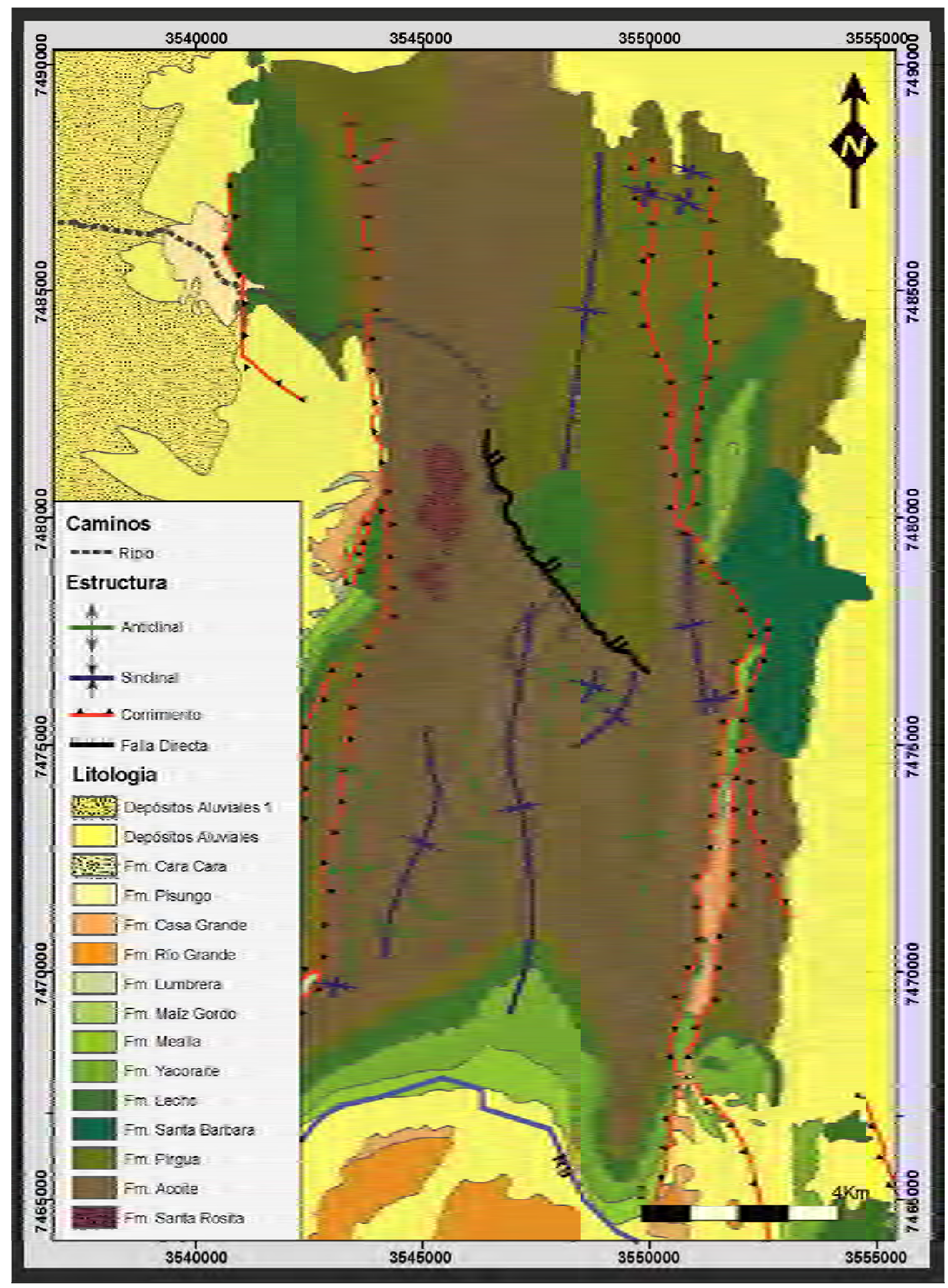

Fig. 4-2. Mapa geológico. Modificado de Zanettini (1973), Coira (1979) y Rubiolo (2003) 


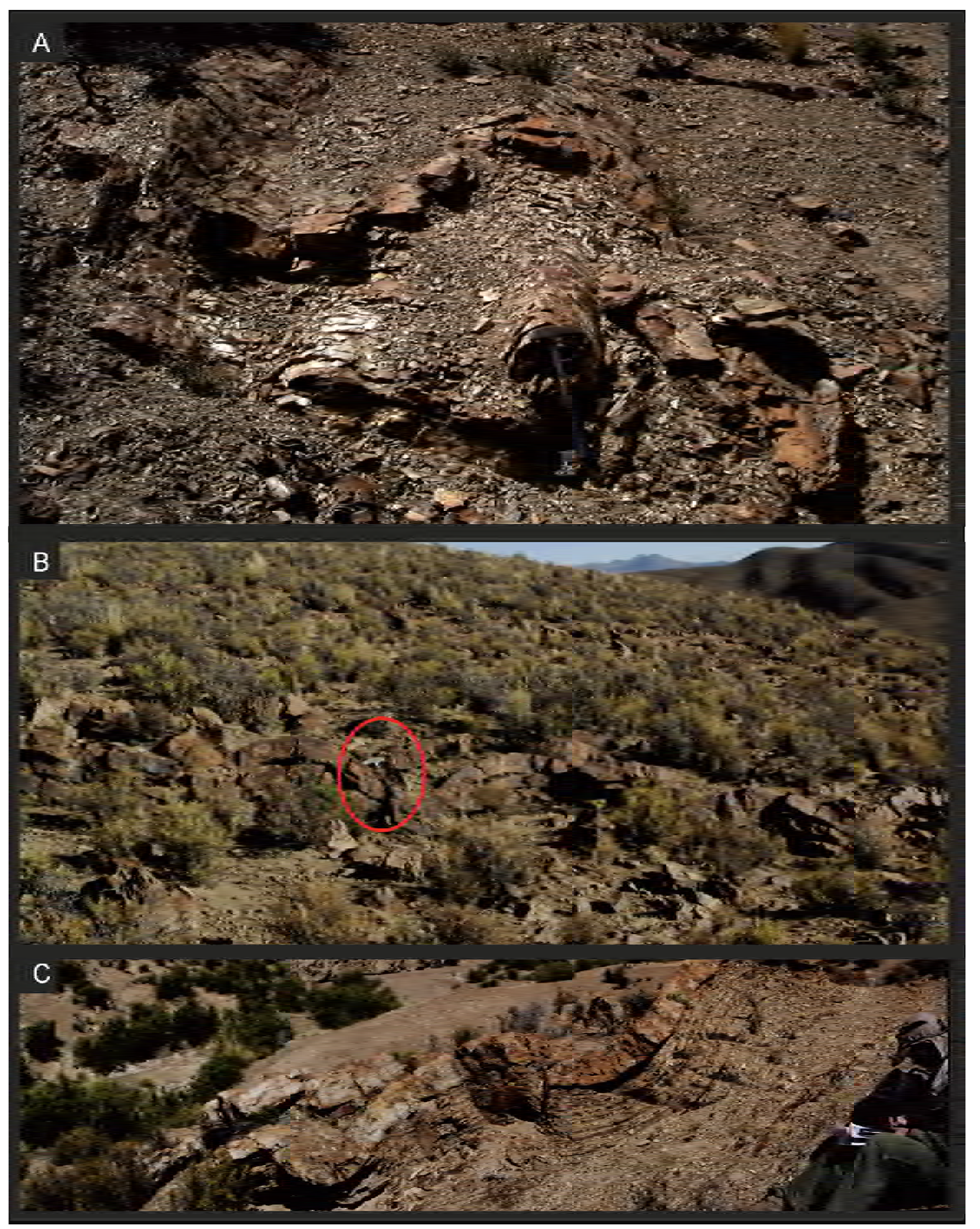

Fig. 4-3. Estratos de la Formación Acoite exhibiendo evidencias de deformación dúctil. A. Plegamiento apretado con eje buzante. B. Pliegues cilíndricos, con plano axial subvertical. C. Distintos estilos deformacionales entre capas con alta y baja competencia. 


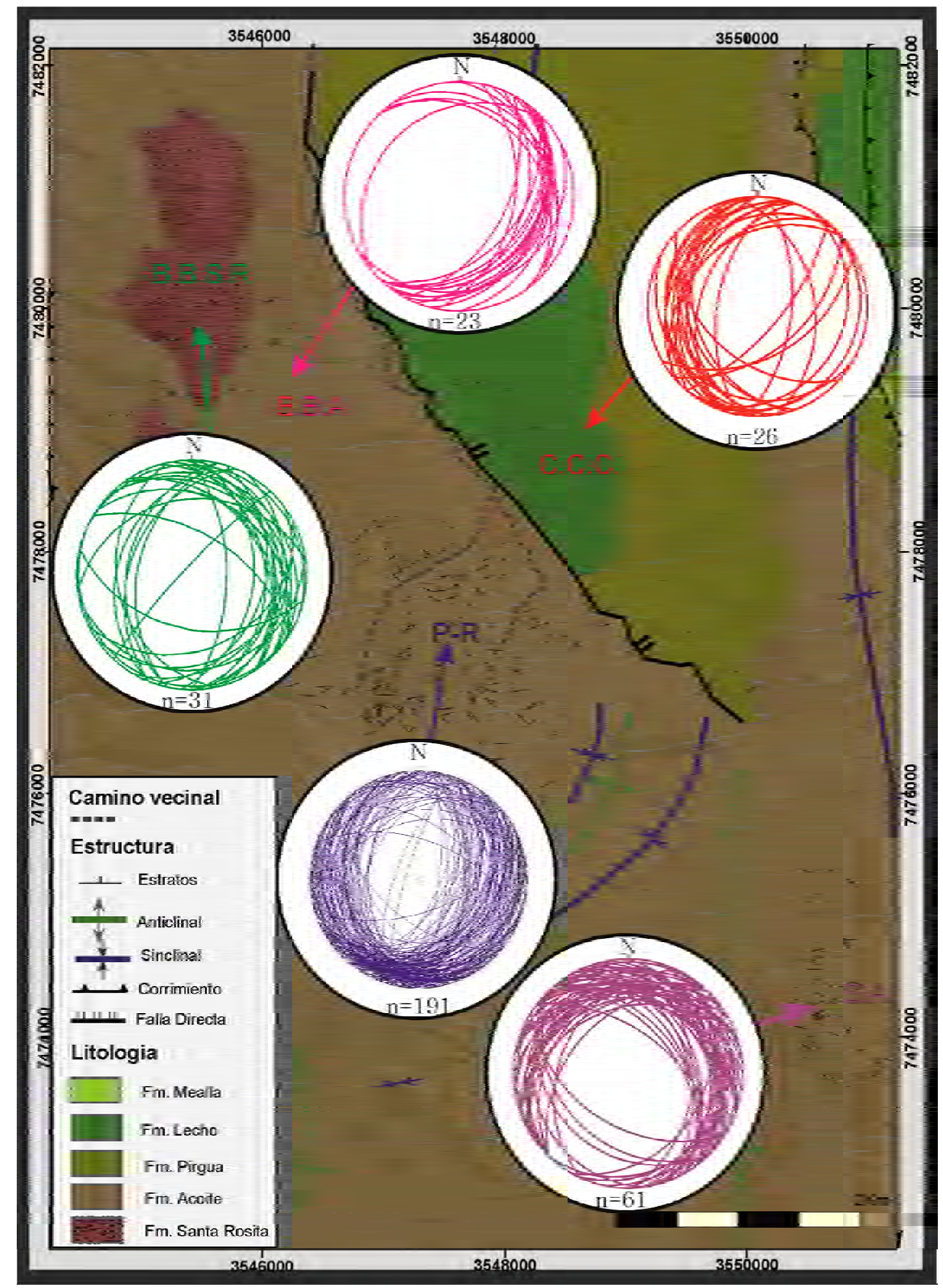

Fig. 4-4. Mapa geológico del sector sur del Cerro Colorado de Cobre y diagramas estereográficos representando azimut e inclinación de la estratificación, los mismos se encuentran discriminados de acuerdo al sector y al tipo litológico. B.B.S.R: Bola Blanca, Santa Rosita. B.B.A.: Bola Blanca Acoite. P-R:

Purísima Rumicruz S.A.: San Agustín. C.C.C.: Cerro Colorado de Cobre. Las proyecciones en los estereogramas se encuentran en el hemisferio inferior. 


\section{Deformación Frágil}

\section{Lineamientos}

En el área de trabajo se identificaron numerosos lineamientos (Fig. 4-5), y se analizaron sus orientaciones. Una dificultad inherente en este tipo de análisis surge debido a que estos lineamientos pueden corresponderse con una variedad de estructuras geológicas como rupturas frágiles, ejes o flancos de pliegues, contactos geológicos o líneas de drenaje, lo que dificulta su interpretación para realizar análisis estructurales. Esta dificultad es mayor cuando ambos tipo de deformación (frágil y dúctil), están marcadamente representadas, como es el caso del área estudio.

Con el objetivo de lograr una asignación temporal de los lineamientos, los mismos se discriminaron de acuerdo a las edades de las rocas que afectan. En este sentido, se contemplaron cuatro grupos de rocas de acuerdo a sus edades. Estas edades se corresponden con los eventos tectónicos que fueron descriptos en la introducción del presente capítulo. De esta manera se distinguieron aquellos que afectaron a las unidades del Grupo Santa Victoria de edad Ordovícica inferior a media, los identificados sobre las rocas del Grupo Salta, correspondientes a los eventos del sinrift y posrift temprano ocurrido desde el Cretácico inferior al Paleoceno y los eventos tectónicos que afectaron a las rocas de edad Terciaria entre las asignadas a edades del paleógeno de aquellas que se depositaron desde el Mioceno hasta la actualidad correspondientes al Neógeno.

Las rocas del Grupo Santa Victoria, donde se aloja la mineralización polimetálica Purísima-Rumicruz, presenta cuatro direcciones principales de lineamientos, N-S y NO-SE son las dominantes mientras que las direcciones NE-SO y E-O se encuentran subordinadas. Las unidades pertenecientes a los depósitos del Grupo Salta exhiben lineamientos con una orientación predominante N-S, sin embargo los rumbos NO-SE, E-W y NE-SO se encuentran representados. Las orientaciones de los lineamientos identificadas en las litologías correspondientes al paleógeno muestran una distribución de las orientaciones dispuestas en sentido NO-SE, N-S y NE. La orientación E-O se encuentra presente aunque subordinada. Los depósitos asignados al Neógeno, muestran una orientación de los lineamientos en marcado sentido NO-SE, aunque las orientaciones N-S, NE-SO y E-O también están representadas. 


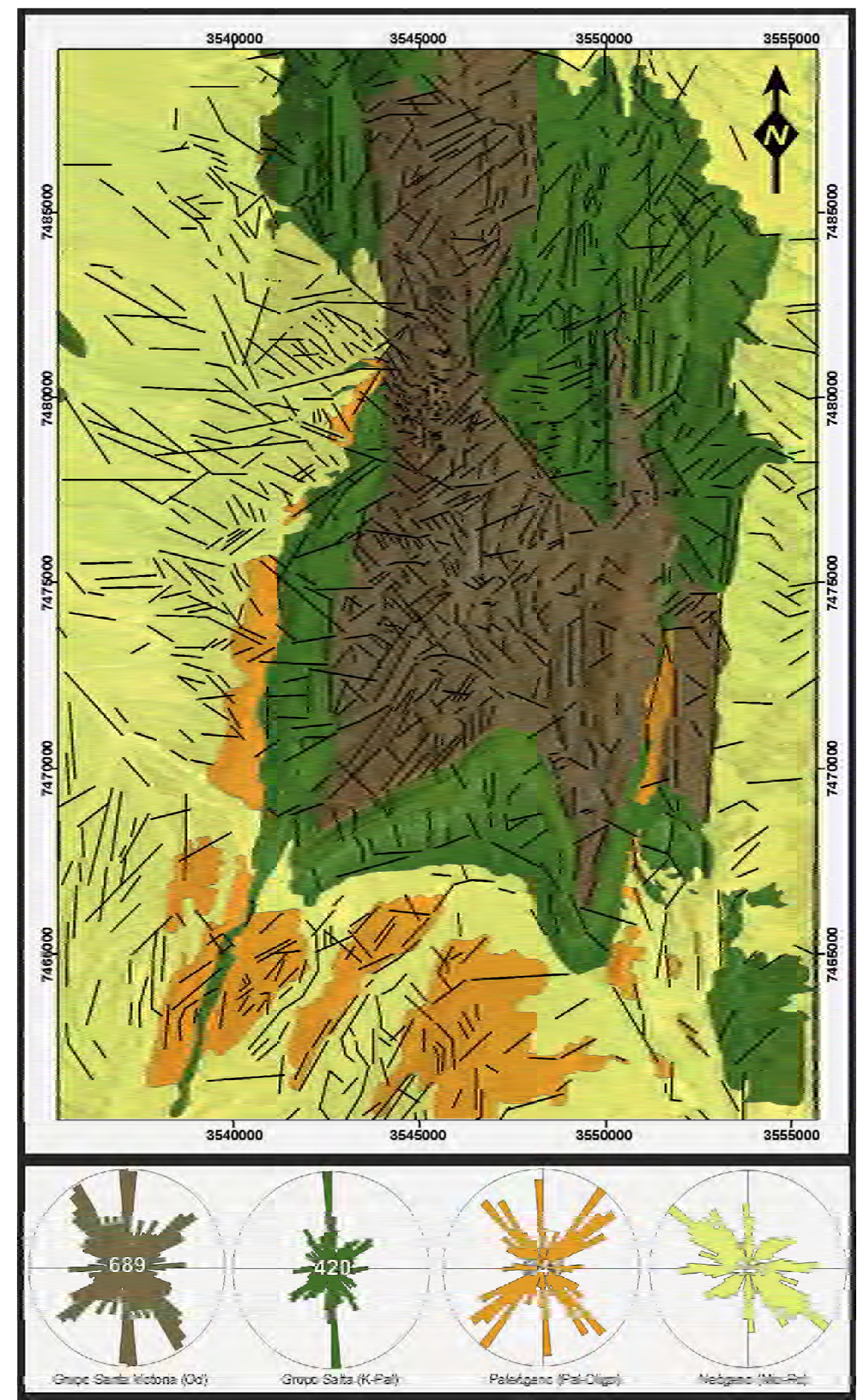

Fig. 4-5. Mapa y diagramas de rosas de frecuencia de lineamientos del sector sur del Cerro Colorado de Cobre discriminados por la litología. La amplitud de cada dirección es de 5º. Od: Ordovícico, K: Cretácico, Pal: Paleógeno, Oligo: Oligoceno, Mio: Mioceno, Rc: Reciente. 
Ha sido posible medir un total de 26 fallas en el campo, y teniendo en cuenta sus orientaciones, pueden realizarse algunas consideraciones respecto de los lineamientos previamente analizados. Estas fallas fueron medidas mayoritariamente en las rocas correspondientes a la Formación Acoite. Es destacable que la orientación $\mathrm{N}-\mathrm{S}$, identificada claramente en los lineamientos, no se encuentra representada en las orientaciones de las fallas. Las orientaciones mejor representadas son los azimutes $90^{\circ}$ y $110^{\circ}$ y en una dirección subordinada con azimut $140^{\circ}$ (Fig. 4-6).

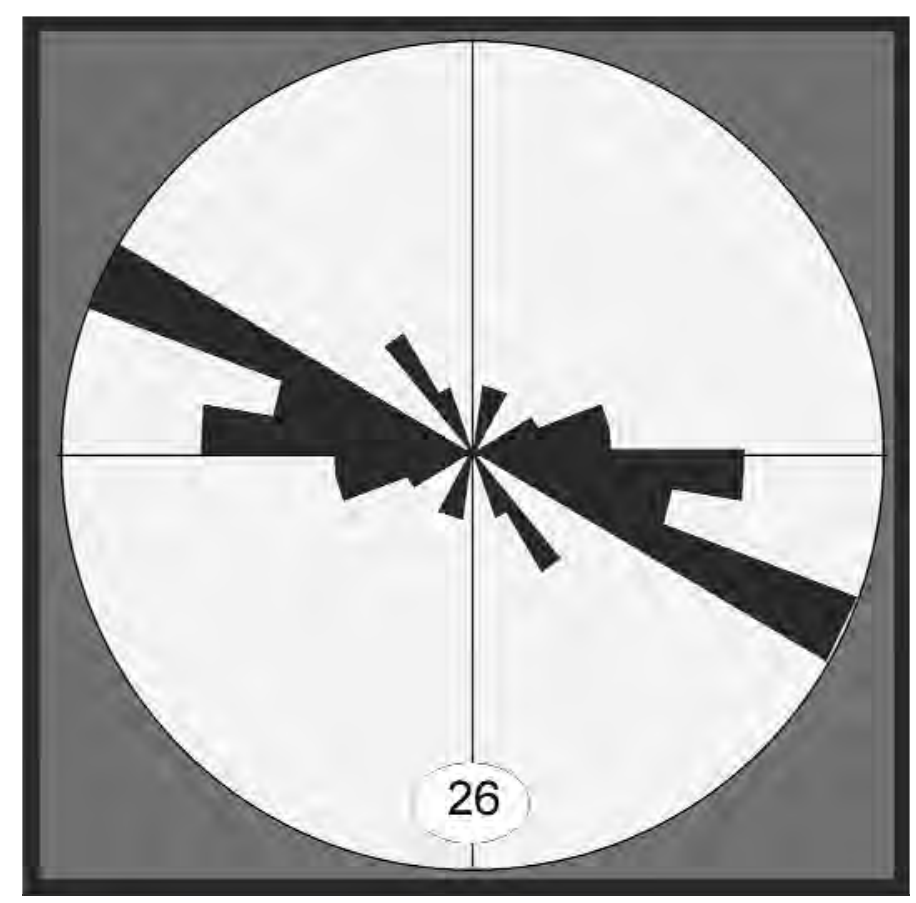

Fig. 4-6. Diagramas de rosas representando las orientaciones de las fallas reconocidas.

CONTROLES ESTRUCTURALES DE LAS VETAS DEL DISTRITO PURÍSIMA-RUMICRUZ

Las vetas que componen el distrito polimetálico Purísima-Rumicruz pueden agruparse de acuerdo a su composición dominante, aspecto que ha sido ampliado en el capítulo de mineralogía (Capítulo IV). De esta forma se pueden discriminar aquellas vetas con sulfuro dominante, vetas de baritina dominante donde los sulfuros también se encuentran presentes y vetas de cuarzo. Para el análisis de los datos de orientaciones de las vetas, se representaron las vetas en cuatro categorías de acuerdo a su composición: vetas de sulfuro (sulfuro dominante), vetas de baritina (baritina dominante), vetas de baritina y sulfuro (se consideraron las sumatoria de las vetas de baritina dominante y sulfuro dominante) y vetas de cuarzo. 
En el sector en estudio, se ha podido reconocer dos sistemas de vetas con contenidos de sulfuros, denominados Purísima-Rumicruz y Brechón. En el primero, caracterizado por una orientación este-oeste, se advierte una mayor proporción de mena rica en sulfuros, incluye a las vetas Purísima, Rumicruz, La Nueva y Liliana. El segundo sistema tiene una orientación noroeste-sudeste, la baritina se encuentra con mayor representación que en el grupo anterior y está compuesto por la veta El Brechón y un conjunto vetillas subparalelas asociadas. En ambos sistemas las vetas presentan inclinaciones desde subverticales a $70^{\circ}$, tanto al norte como al sur y texturas brechosas, con clastos angulosos de roca de caja y de mena, con al menos cuatro episodios de brechamiento.

En las vetas sulfuro dominante la frecuencia más importante se registra entre $80^{\circ} \mathrm{y}$ $90^{\circ}$, sin embargo cuando las direcciones de las vetas son ponderadas por su longitud, puede apreciarse que exhiben una dirección preponderante muy definida con orientación $120^{\circ}$. La ponderación de la longitud surge de la sumatoria de las longitudes de cada una de las vetas correspondientes a un rango de direccción. Las vetas baritina dominante presentan dos direcciones principales, $\mathrm{N} 120^{\circ}$ y N130 . Al combinar ambos tipos de vetas se observa una dirección muy definida de las vetas con azimut $120^{\circ}$, tanto si se considera la frecuencia como ponderando los resultados por la longitud. En cuanto a las vetas de cuarzo, manifiestan una alta dispersión en las direcciones cuando se considera la frecuencia, sin embargo si estos datos son ponderados por la longitud se observan dos orientaciones definidas, la mayor en dirección $\mathrm{N} 110^{\circ}$ y una subordinada con un azimut de $10^{\circ}$ (Fig. 4-7). Este arreglo permite inferir que las vetas de cuarzo posiblemente no estén vinculadas genéticamente a las vetas de sulfuros y baritina.

Como síntesis, en el diagrama de rosas de las vetas totales (Fig. 4-7) se compilan las direcciones de las vetas y vetillas del distrito, independientemente de su composición. De esta forma, de acuerdo al análisis de las orientaciones de las estructuras vetiformes reconocidas en el área, se determinó una orientación principal con azimut $120^{\circ}$ y tres direcciones subordinadas con orientaciones $\mathrm{N} 10^{\circ}, \mathrm{N}^{\circ}$ y N105․ 


\section{ORIENTACIONES DE LAS VETAS Y VETILLAS DEL DEPÓSITO PURISIMA-RUMICRUZ - LONGITUD}

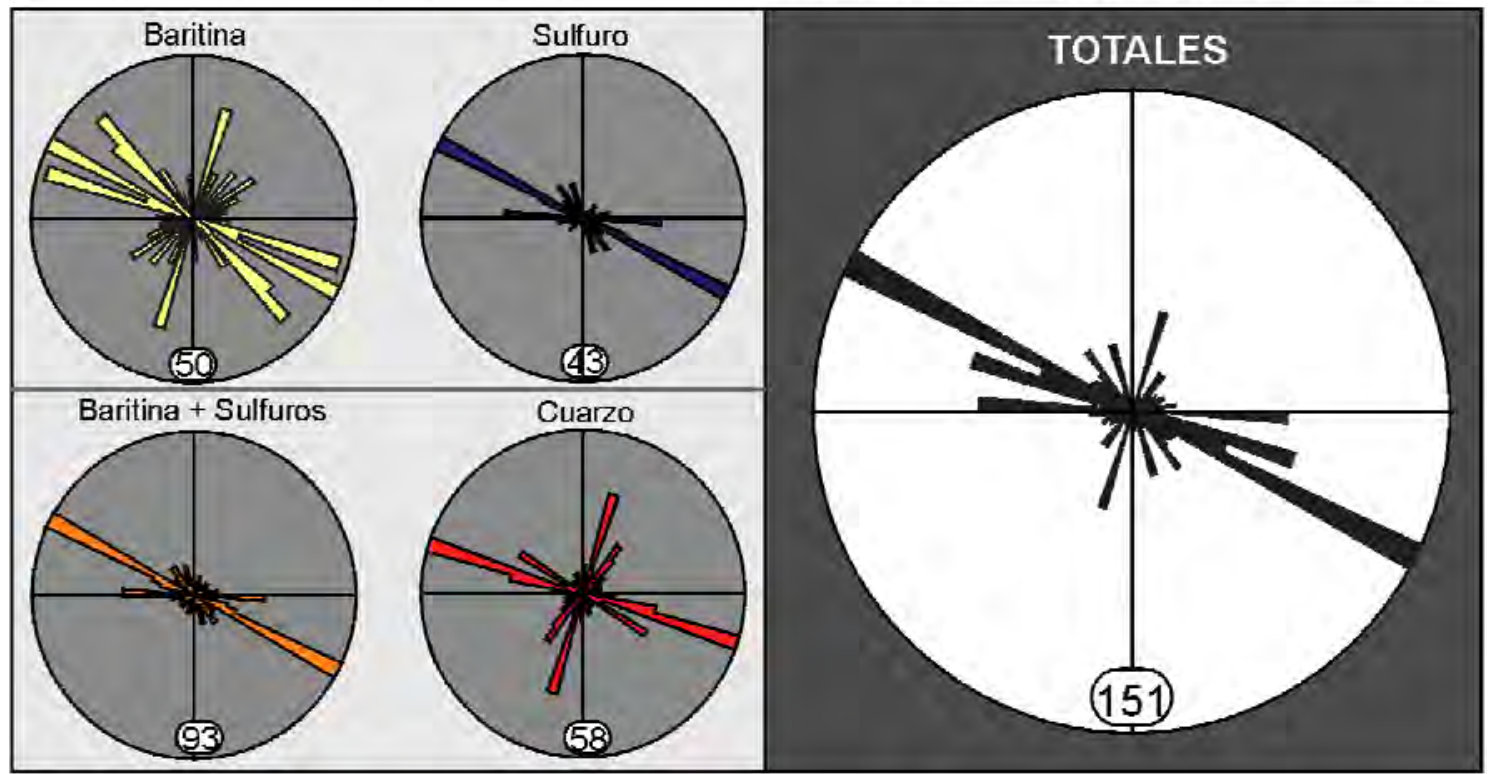

ORIENTACIONES DE LAS VETAS Y VETILLAS DEL DEPÓSITO PURISIMA-RUMICRUZ - FRECUENCIA
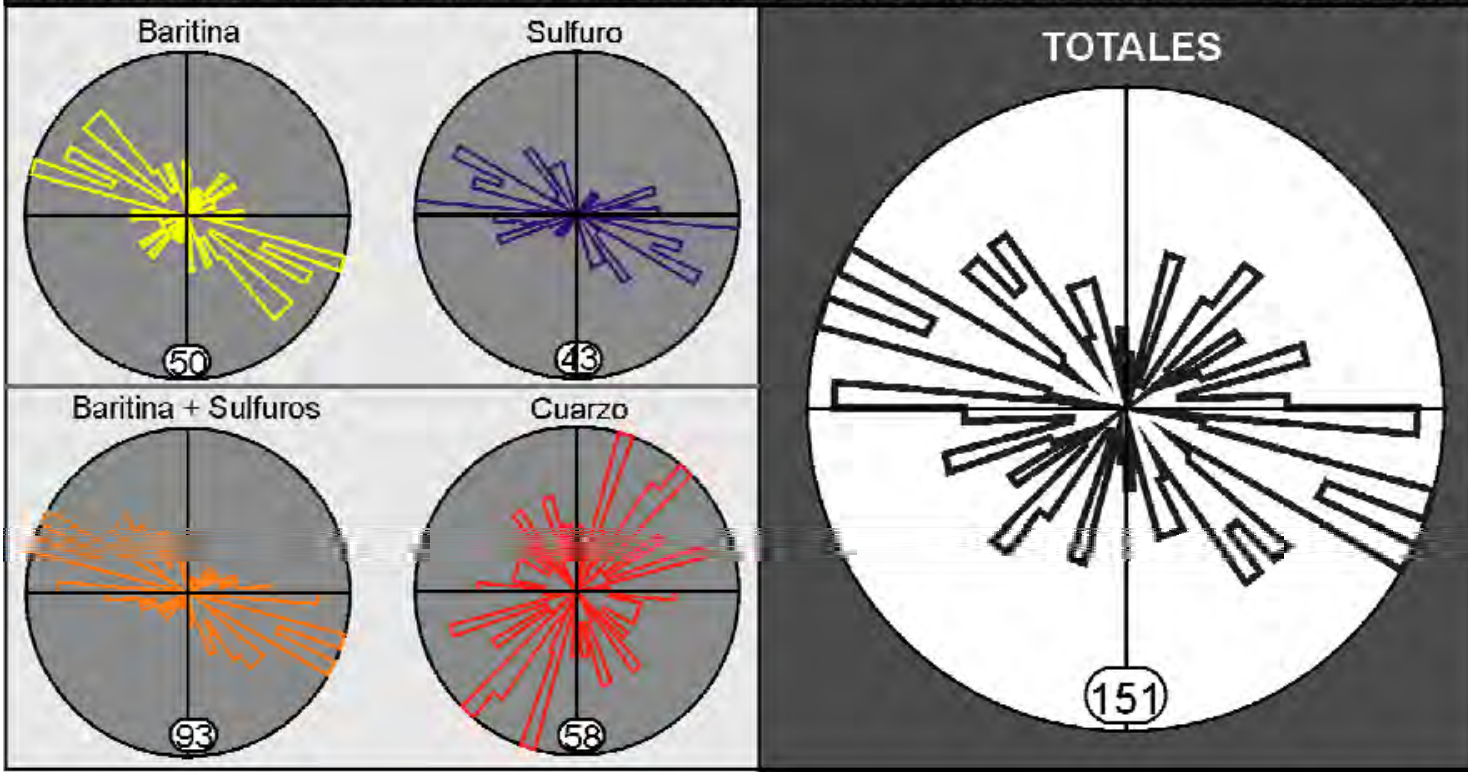

Fig. 4-7. Diagramas de rosas de las vetas y vetillas del distrito polimetálico Purísima-Rumicruz. El intervalo de las direcciones es de $5^{\circ}$. 


\section{DISCUSIÓN}

Las rocas aflorantes en la región estudiada presentan evidencias de deformación frágil y dúctil. Los eventos de deformación han sido vinculados a cuatro contextos geotectónicos, desarrollados dos de ellos durante el Precámbrico superior-Paleozoico inferior y los restantes desde el Cretácico hasta la actualidad. Si bien las edades de las unidades estudiadas son post-pampeanas, se ha tenido en cuenta esta deformación debido a que podría haber sido importante como generadora de fracturas o zonas de debilidad que pudieron haber condicionado a las orientaciones y estilos estructurales de las deformaciones subsecuentes. El plegamiento con ejes N-S desarrollado sobre la Formación Acoite, posiblemente haya sido generado principalmente durante la orogenia Oclóyica. La orientación de las estructuras producidas durante el Cretácico y el Cenozoico fueron condicionadas por la deformación previa, la similitud en las orientaciones entre las estructuras Ordovícicas y las Cretácico-Cenozoicas es condición suficiente para proponer un control estructural paleozoico (Hongn et al., 2010). La deformación dúctil registrada en los sedimentos del Grupo Salta correspondería a eventos compresivos Neógenos, en ambos el esfuerzo principal compresivo se ubicaría aproximadamente E-W.

Las vetas que conforman el distrito polimetálico Purísima-Rumicruz presentan textura brechosa, cuya descripción ha sido ampliado en el Capítulo IV. Tomando en consideración la textura, el tamaño y la forma de los clastos, de acuerdo a la clasificación de Jébrak (1997), estas brechas fueron interpretadas como el resultado del relleno de zonas de cizalla con una componente dilatacional asociada, sobre las que actuaron procesos de brechamiento mecánico y en menor medida corrosión química durante la depositación mineral.

Para la determinación de la dirección de los esfuerzos principales actuantes durante la generación de las vetas que componen el distrito, se propone un modelo integrador de acuerdo al sistema conjugado de cizallas de Riedel (Fig. 4-8A), donde se considera la dirección de las fallas, las interpretaciones tectónicas vigentes en la historia geológica de la región y las orientaciones de las vetas que conforman el distrito Purísima-Rumicruz. Para interpretar un sistema de Riedel debe conocerse la cinemática de las estructuras, en las vetas estudiadas esto no ha sido posible, por lo que se presenta solo una interpretación geométrica del sistema de Riedel. Asimismo, este modelo se aplica sobre materiales isótropos y debe considerarse que el material en el que se encajan las vetas es anisótropo debido a la orogenia Oclóyica. 
De esta forma, el esfuerzo principal compresivo ( $\sigma 1)$, se ubica en posición ONOESE, mientras que el menor esfuerzo (б3) se ubica en posición ENE-OSO. Esta dirección de los esfuerzos, donde el principal extensional se encuentra en un azimut $60^{\circ}$, es coherente con el desarrollo la falla de tipo extensional Tabladitas, con una orientación aproximada $\mathrm{N} 140^{\circ}$.

De acuerdo a esta interpretación la dirección principal de las vetas, con azimut $120^{\circ}$ corresponde con la orientación de las fracturas $\mathrm{R}$, las vetas con orientación E-O con las fracturas $\mathrm{P}$ y las $\mathrm{N} 105^{\circ}$ a las $\mathrm{Y}$ del modelo de Riedel. De estas fracturas la dirección principal de las vetas $(R)$ es la que se presenta la dirección más normal al esfuerzo o3. (Fig. 4-8B, Fig. 4-9). 


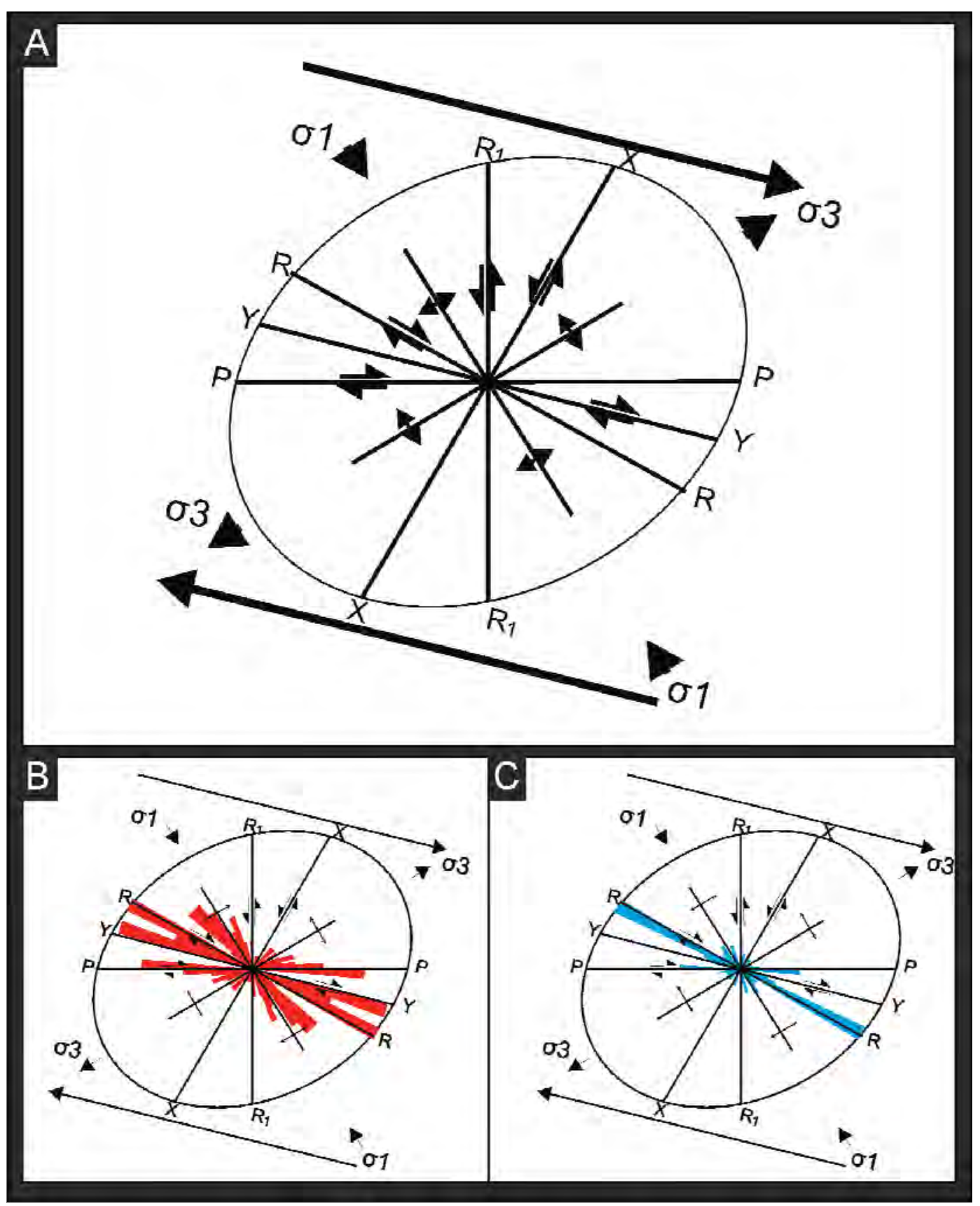

Fig. 4-8. A. Diagrama de Riedel exhibiendo las orientaciones de los esfuerzos principales. Modificado de Rossello, 2001. B. En rojo se ubican las orientaciones según su frecuencia de las vetas de sulfuro y baritina sobre el modelo geométrico de Riedel. C. En azul se ubican las orientaciones ponderadas por la longitud de las vetas de sulfuro y baritina sobre el modelo geométrico de Riedel. 


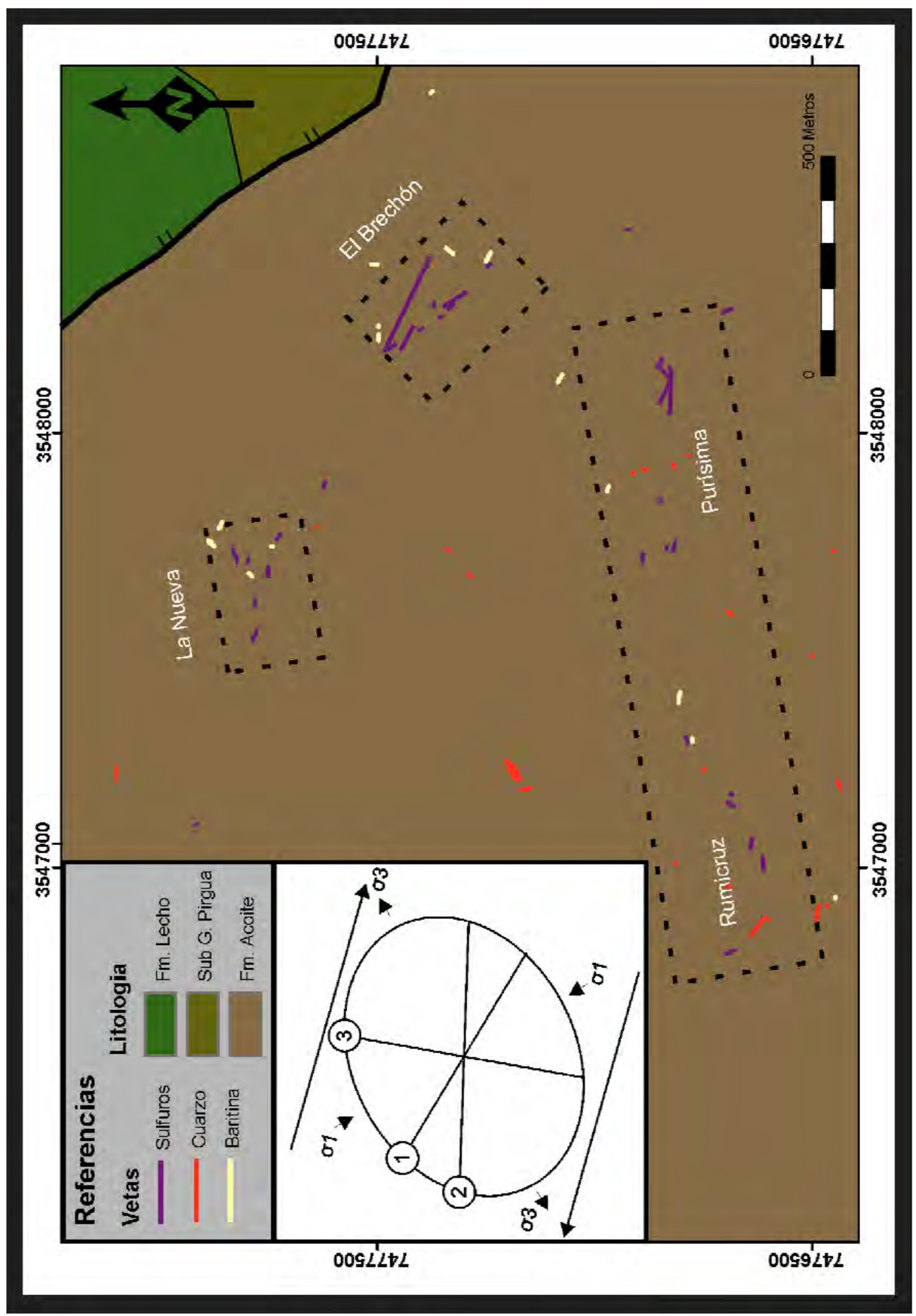

Fig. 4-9. Mapa geológico. Se presentan las vetas del distrito y la interpretación estructural propuesta. Las vetas clasificadas como sulfuro dominante se orientan principalmente de acuerdo a la orientación 1 y 2. 


\section{CAPÍTULO VII}

\section{ESTUDIO GEOELÉCTRICO DEL DEPÓSITO PURÍSIMA-RUMICRUZ}




\section{INTRODUCCIÓN}

Los métodos de prospección que emplean las propiedades eléctricas de los materiales terrestres para detectar concentraciones anómalas de minerales de interés económico, pueden dividirse en pasivos (i.e. potencial espontáneo), que registran la generación de corrientes eléctricas naturales derivadas de reacciones de oxidoreducción entre los minerales y la solución con la que están en contacto, y los métodos geoeléctricos activos, donde se introduce corriente eléctrica al subsuelo mediante un par de electrodos y se determina la diferencia de potencial con otro par de electrodos. Los factores que modifican la diferencia de este potencial son la resistividad de la roca, la presencia de minerales polarizables, la distancia entre los electrodos y la corriente inyectada, siendo las dos últimas variables controladas.

La resistividad es la resistencia que ofrece un material al paso de una corriente eléctrica bajo un determinado potencial eléctrico. Las altas anomalías de resistividad surgen cuando un mal conductor, como una veta de cuarzo, se encuentra entre rocas con menores valores de resistividad. Asimismo la resistividad, además de estar controlada por el tipo de roca (Fig. 6-1), es influenciada fuertemente por la porosidad, permeabilidad y presencia de agua, con grandes variaciones dependiendo de los solutos disueltos en ella.

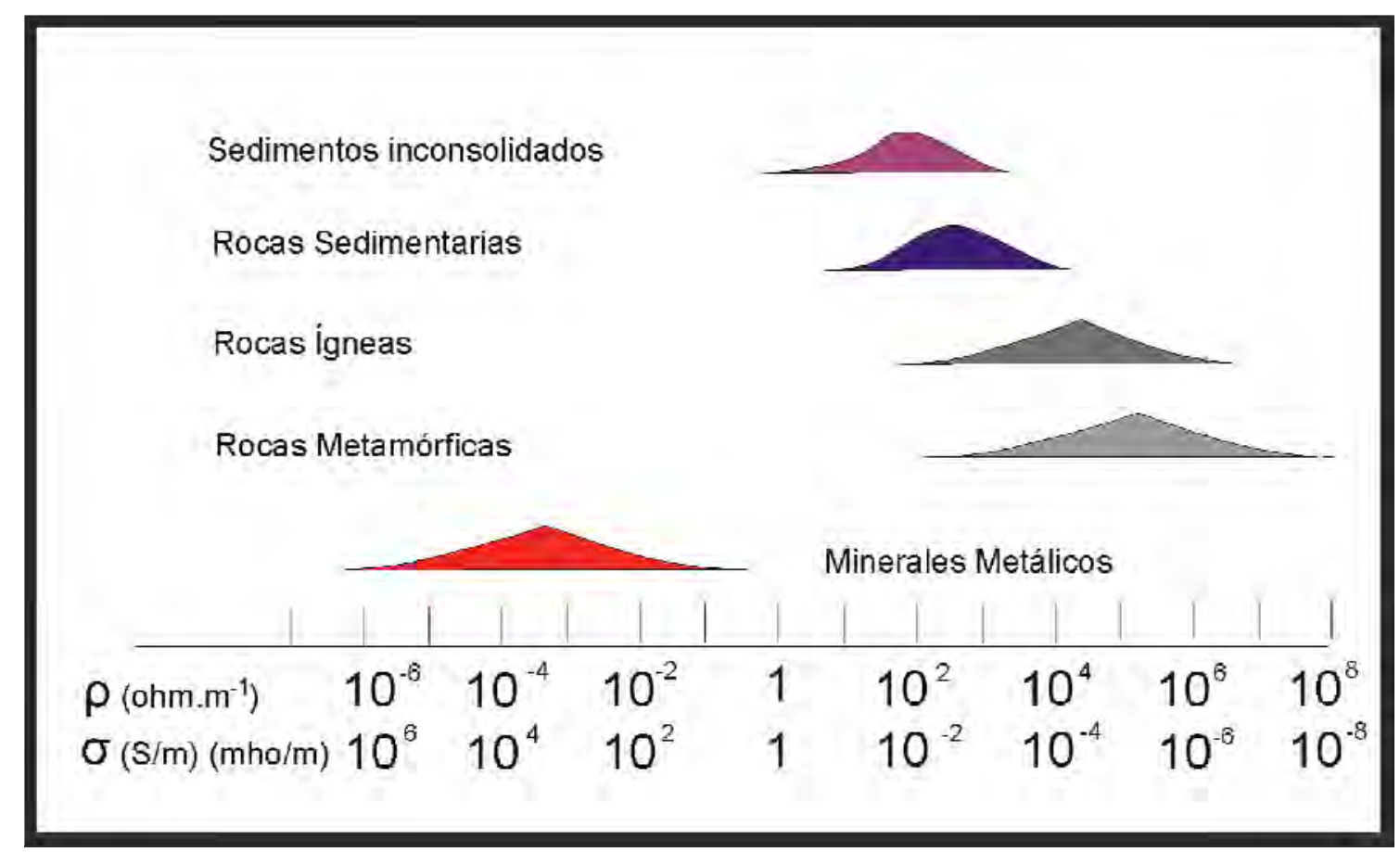

Fig. 6-1. Rangos de valores de resistividad entre distintos tipos litológicos y depósitos metálicos (Modificado de Tykajlo y Donohue, 2007). 
La resistividad aparente se calcula según la expresión:

$$
\rho_{a p}=K \frac{\Delta V}{I}
$$

donde $\mathrm{K}$ es la constante geométrica del dispositivo utilizado $\Delta V$ es la variación de voltaje e I es la intensidad. Los valores se expresan en ohm.m.

El potencial inducido (IP), se produce debido a que los minerales metálicos conducen la electricidad de forma electrónica. Al circular la corriente en el subsuelo, los iones del electrolito son forzados a permanecer en la superficie de los minerales conductores, los iones positivos y negativos en las superficies enfrentadas a los electrodos negativos y positivos respectivamente. Cuando la corriente cesa estos iones se difunden lentamente hasta llegar al equilibrio eléctrico generando una corriente secundaria, que puede ser medida, directamente proporcional a la cantidad de partículas polarizadas.

Para su determinación en la técnica "Dominio de Tiempo" se inyectan cargas positivas y negativas alternadas, separadas por periodos sin carga. Cuando la corriente es interrumpida el voltaje en los electrodos no decrece inmediatamente a 0 sino que se inicia abruptamente y luego lo hace lentamente durante algunos milisegundos. (Fig. 6-2).

(a) corriente inducida

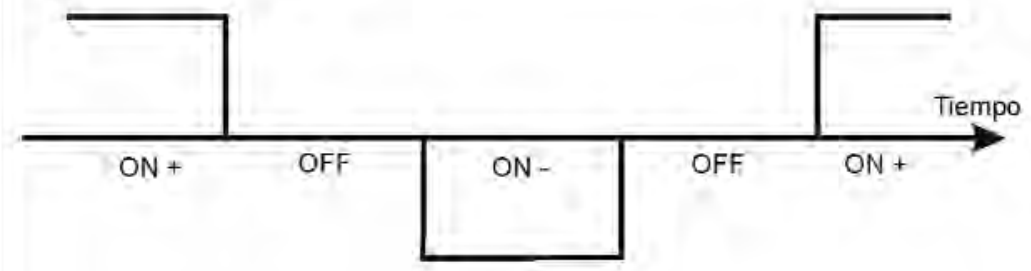

(b) potencial medido

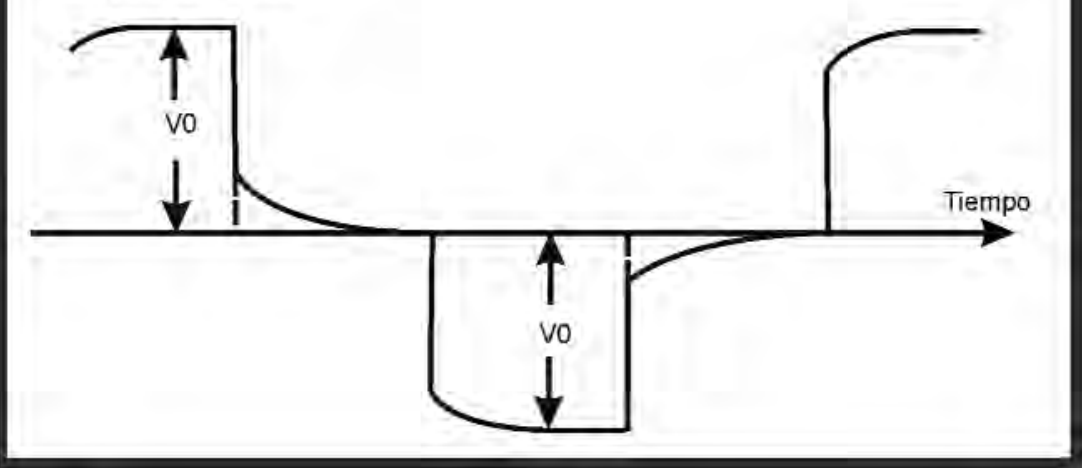

Fig. 6-2. Relación entre la corriente inducida y el potencial medido en función del tiempo en ciclos alternados de voltaje. Modificado de Lowrie (2007) 
En los sistemas de vetas con contenido de elementos metalíferos, las anomalías de IP están asociadas al contenido de minerales polarizables, especialmente sulfuros, presentes en las vetas y en la roca de caja inmediata a la estructura mineralizada. Cuando se analizan los resultados de potencial inducido debe tenerse en cuenta que los minerales metalíferos polarizables pueden ser de origen hidrotermal, o bien pueden estar contenidos en la roca de caja, por procesos ajenos al evento metalogenético.

\section{POTENCIAL INDUCIDO Y RESISTIVIDAD EN EL DISTRITO PURÍSIMA-RUMICRUZ}

Uno de los factores condicionantes en la exploración del distrito minero PurísimaRumicruz es la discontinuidad de las estructuras mineralizadas en superficie. Se realizó un relevamiento geoeléctrico con el objetivo de establecer la prolongación de las vetas, tanto en planta como en profundidad y para determinar la presencia de anomalías de potencial inducido y resistividad asociadas a vetas no aflorantes.

En el distrito Purísima-Rumicruz se han registrado altos valores de IP, superiores a $90 \mathrm{mv} / \mathrm{v}$. Teniendo en cuenta la distribución de los valores, aquellos que superaron los $50 \mathrm{mv} / \mathrm{v}$ fueron considerados anómalos, utilizando como analogía el depósito polimetálico Pingüino (Guido et al., 2009). Los rangos utilizados para la representación de los resultados fue una escala constante de $10 \mathrm{mv} / \mathrm{v}$.

Las interpretaciones de las anomalías de resistividad en exploración de yacimientos vetiformes suele ser más complejas que las de potencial inducido. Cuando la ganga de las vetas es cuarzo, las anomalías altas de resistividad son asignadas potencialmente a la presencia de vetas, debido a que este mineral suele ser más resistivo que la roca encajante. Sin embargo también pueden obtenerse altos valores de resistividad en rocas de caja con baja porosidad o en presencia de niveles silicificados. Asimismo, en sistemas muy fracturados, con una alta deformación frágil y estructuras brechosas, se genera porosidad secundaria, que pueden producir anomalías bajas de resistividad.

Los valores de resistividad encontrados fueron bajos, raramente superan los 500 ohm.m. Los rangos seleccionados para su representación gráfica fueron: 0-50, 50-100, 100-150, 150-300, 300-500 y mayor de 500 ohm.m. Categorías análogas han sido establecidas en otros sistemas de vetas polimetálicas (e.g. prospecto El Pingüino en la provincia de Santa Cruz) (Guido et al., 2009).

Los resultados de la inversión de datos geoeléctricos, resistividades y cargabilidades verdaderas, revelan que las rocas de la Formación Acoite poseen 
valores de resistividad propios de rocas sedimentarias, con un valor medio de 319 ohm.m. Los valores de polarización inducida obtenidos del modelo de inversión son en general muy altos, con algunos valores superiores a $150 \mathrm{mV} / \mathrm{V}$ y un valor medio para los tres sectores investigados de $23 \mathrm{mV} / \mathrm{V}$. En la Tabla I se consignan los estadísticos de tendencia central (media, mediana y moda), desvío estándar, máximo y mínimo de resistividad y cargabilidad para cada zona.

\begin{tabular}{|l|c|c|c|c|c|c|c|c|}
\cline { 2 - 9 } \multicolumn{1}{c|}{} & \multicolumn{3}{c|}{ La Nueva (n: 984) } & \multicolumn{2}{c|}{ Purísima (n: 4208) } & \multicolumn{2}{c|}{ Brechón (n: 1862) } & \multicolumn{2}{c|}{ Todos (n: 7054) } \\
\cline { 2 - 9 } \multicolumn{1}{c|}{} & Res & IP & Res & IP & Res & IP & Res & IP \\
\hline Media & 259 & 37 & 384 & 21 & 206 & 21 & 319 & 23 \\
\hline Mediana & 157 & 32 & 254 & 19 & 129 & 16 & 192 & 20 \\
\hline Moda & 60 & 26 & 116 & 14 & 144 & 8 & 144 & 10 \\
\hline Desvío St & 454 & 26 & 781 & 12 & 427 & 19 & 669 & 18 \\
\hline Mx & 5813 & 177 & 20325 & 154 & 8828 & 145 & 20325 & 177 \\
\hline Mn & 14,74 & 0,11 & 13 & 0,02 & 5,82 & 0,03 & 6 & 0 \\
\hline Anom. IP & & $>89$ & & $>45$ & & $>59$ & & $>59$ \\
\hline
\end{tabular}

Valores de resistividad en ohm.m, cargabilidad en mV/V. Las anomalías de cargabilidad corresponden a la media más dos desvíos estándar

Las variables consideradas para la evaluación y clasificación de las anomalías de potencial inducido y resistividad fueron, además de los valores de estos dos parámetros, la correlación de estas anomalías en profundidad con vetas registradas en superficie y la continuidad lateral de las anomalías, de acuerdo a si las mismas fueron reconocidas en dos o más líneas sucesivas (Fig. 6-3).

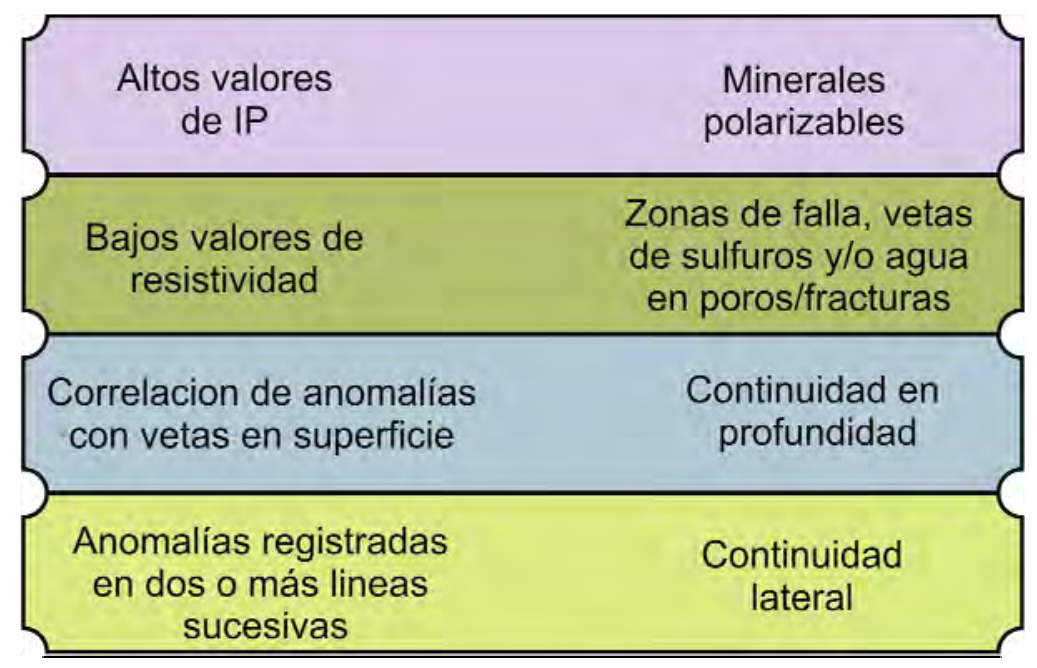

Fig. 6-3. Síntesis de los parámetros favorables y su significancia en la prospección geoeléctrica del área Purísima-Rumicruz.

Para establecer los valores de cargabilidad normales (background o fondo) se usó el método que se emplea en la determinación de las anomalías geoquímicas en la 
prospección mineral (Lepeltier, 1969), asumiendo que la distribución de valores de cargabilidad se ajustan a un modelo log-normal. Se determinó un umbral o límite superior del fondo correspondiente al valor de la media más dos veces el desvío estándar, los valores de cargabilidad superiores al umbral fueron considerados anómalos.

Para la ubicación y orientación de las líneas se dividió al distrito en tres sectores, Purísima-Rumicruz (PR), La Nueva (LN) y El Brechón (EB) (Fig. 6-4). En cada uno de los sectores se consideró la orientación de las vetas para ubicar a las líneas en dirección normal a las mismas. De esta forma, las líneas en el sector PurísimaRumicruz y en el sector La Nueva presentaron un azimut de $\mathrm{N} 170^{\circ}$, mientras que las líneas correspondientes al sector El Brechón se orientaron con un azimut de $\mathrm{N} 40^{\circ}$.

El análisis de los la información se efectuó mediante el estudio de los perfiles de cada una de las líneas relevadas o pseudosecciones (en sentido de Horton et al., 1985), y se contó con una modelización de las anomalías en planta a una profundidad de $-57 \mathrm{~m}$ por debajo de la superficie que permitió la integración de los datos lineales.

\section{Purísima-Rumicruz}

El sector Purísima-Rumicruz, concentró más de la mitad del relevamiento geoeléctrico efectuado en el distrito. Se levantó un total de nueve líneas paralelas con un distanciamiento de $200 \mathrm{~m}$ entre cada una con una longitud de 500m y una orientación N $170^{\circ}$ (Fig. 6-5).

En este sector se registraron valores altos de potencial inducido correlacionables con vetas en superficie. En este sentido, al Norte tanto de la veta Purísima como de la veta Liliana se registraron anomalías, en el primer caso intersectada por dos líneas.

También se localizaron dos anomalías de potencial inducido sin expresión superficial, una de ellas al sur de la veta Liliana, que se destaca por su continuidad lateral teniendo una longitud mayor a $600 \mathrm{~m}$; la segunda se ubica al NO de la veta Liliana, presenta valores de potencial inducido mayores a $70 \mathrm{mV} . \mathrm{v}$ y es cortada por tres líneas. Si bien no se consignaron anomalías directamente relacionadas a la veta en el sector Rumicruz, la línea 1600 registró dos anomalías positivas quedando las mismas abiertas hacia el SO. Asimismo, se registró que las cargabilidades al sur del eje del valle son en general más altas de las registradas al norte. 


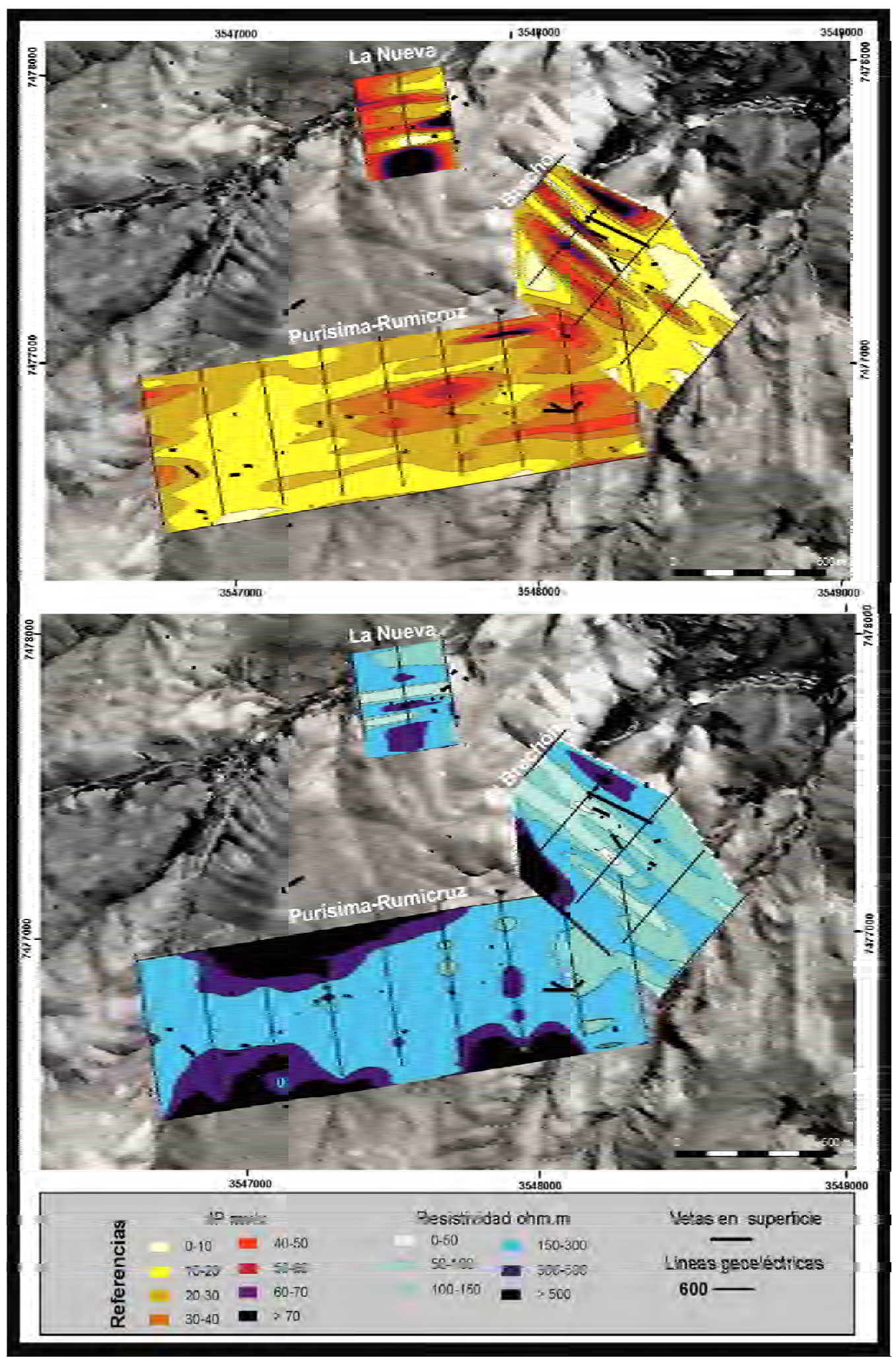

Fig. 6-4. Proyección en planta de los valores geoeléctricos registrados a $57 \mathrm{~m}$ por debajo de la superficie del distrito minero Purísima Rumicruz integrando la totalidad de los perfiles llevados a cabo en los sectores Purísima-Rumicruz, La Nueva y El Brechón. A) Potencial inducido. B) Resistividad. 


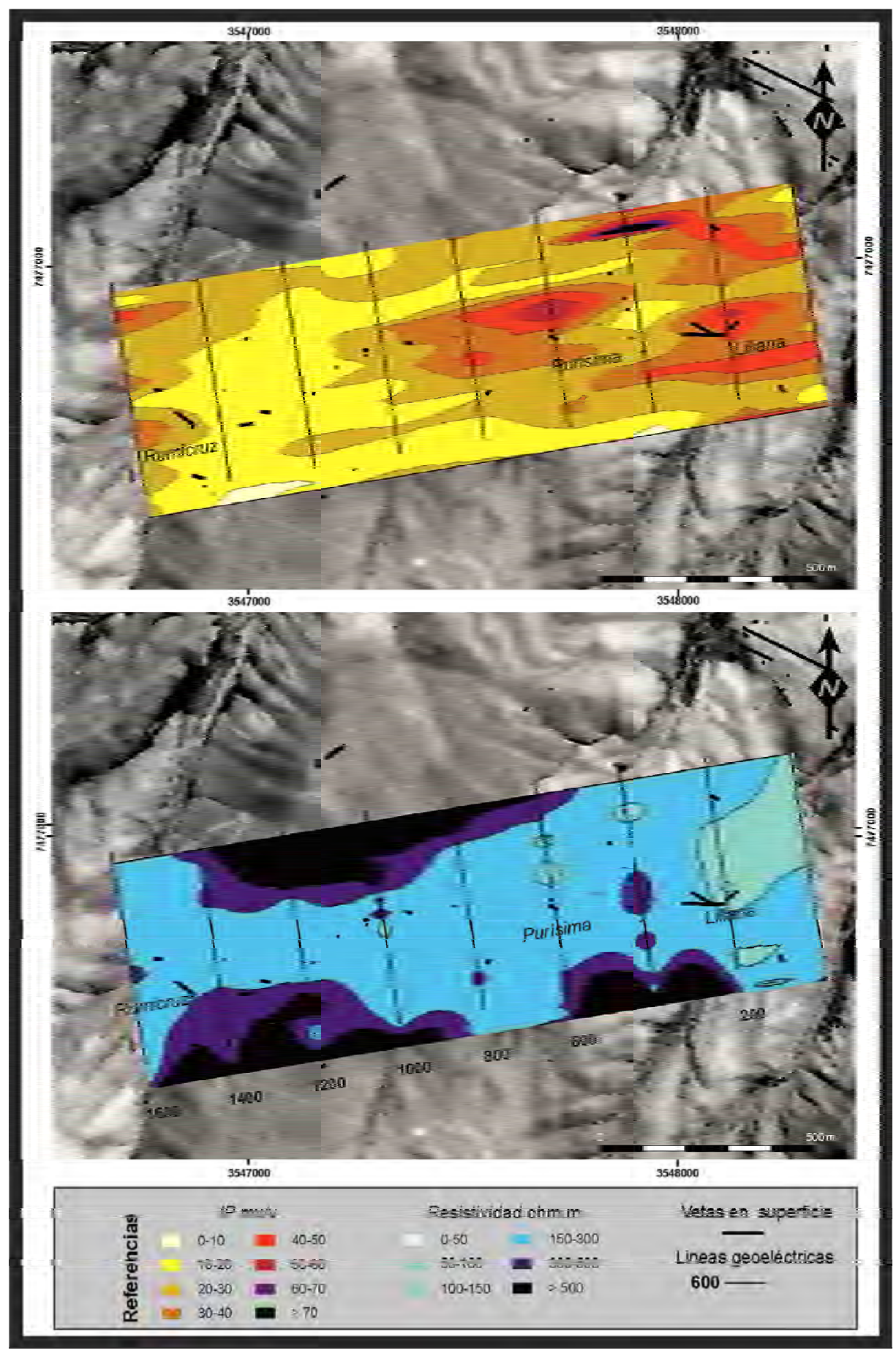

Fig. 6-5. Proyección en planta de los valores geoeléctricos registrados a $57 \mathrm{~m}$ por debajo de la superficie del sector Purísima-Rumicruz. A) Potencial inducido, altos valores son correlacionables con vetas en superficie. B) Resistividad, bajos valores son coincidentes con las anomalías positivas de potencial inducido.

Las zonas con baja resistividad (anomalías negativas de resistividad), son arealmente pequeñas, y sus valores son próximos al valor de fondo. Sin embargo, la ubicación de estas anomalías de baja resistividad se condice con las aéreas de anomalías positivas de potencial inducido. Las zonas profundas de las vetas cortadas 
por el perfil 600 se asocian espacialmente a una de las zonas de baja resistividad, ubicada al sur del eje del valle (Fig. 6-6).

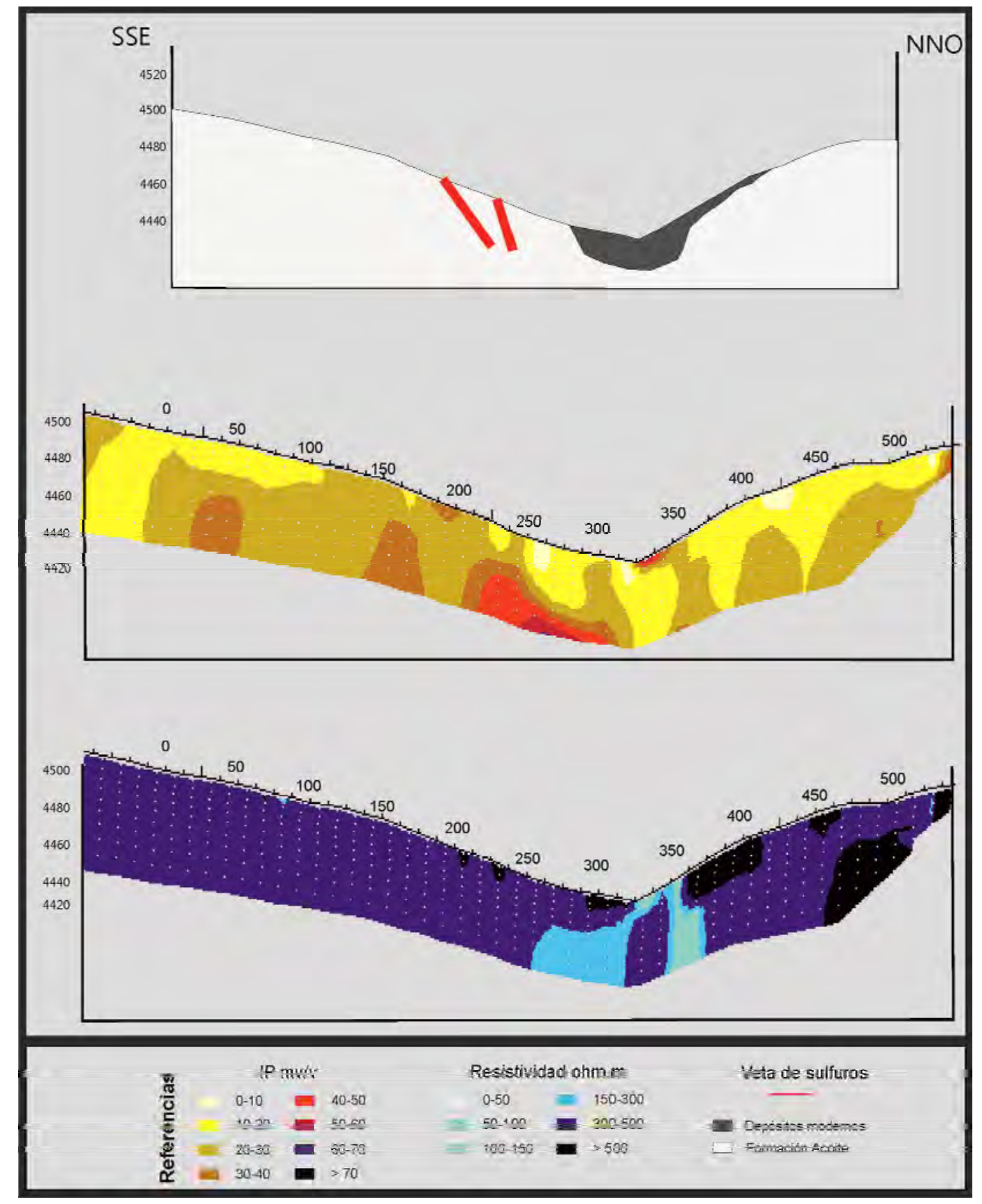

Fig. 6-6. Perfil geológico, potencial inducido y resistividad de la línea 600 del sector Purísima-Rumicruz. Las vetas identificadas en superficie coinciden con anomalías de alta cargabilidad y baja resistividad en subsuelo.

\section{El Brechón}

En el sector El Brechón se levantaron cinco perfiles de longitud variable entre 200 y 500 m con una longitud total de 1900 m (Fig. 6-7). El espaciado entre las líneas fue de $200 \mathrm{~m}$ y el azimut de $\mathrm{N} 40^{\circ}$. 


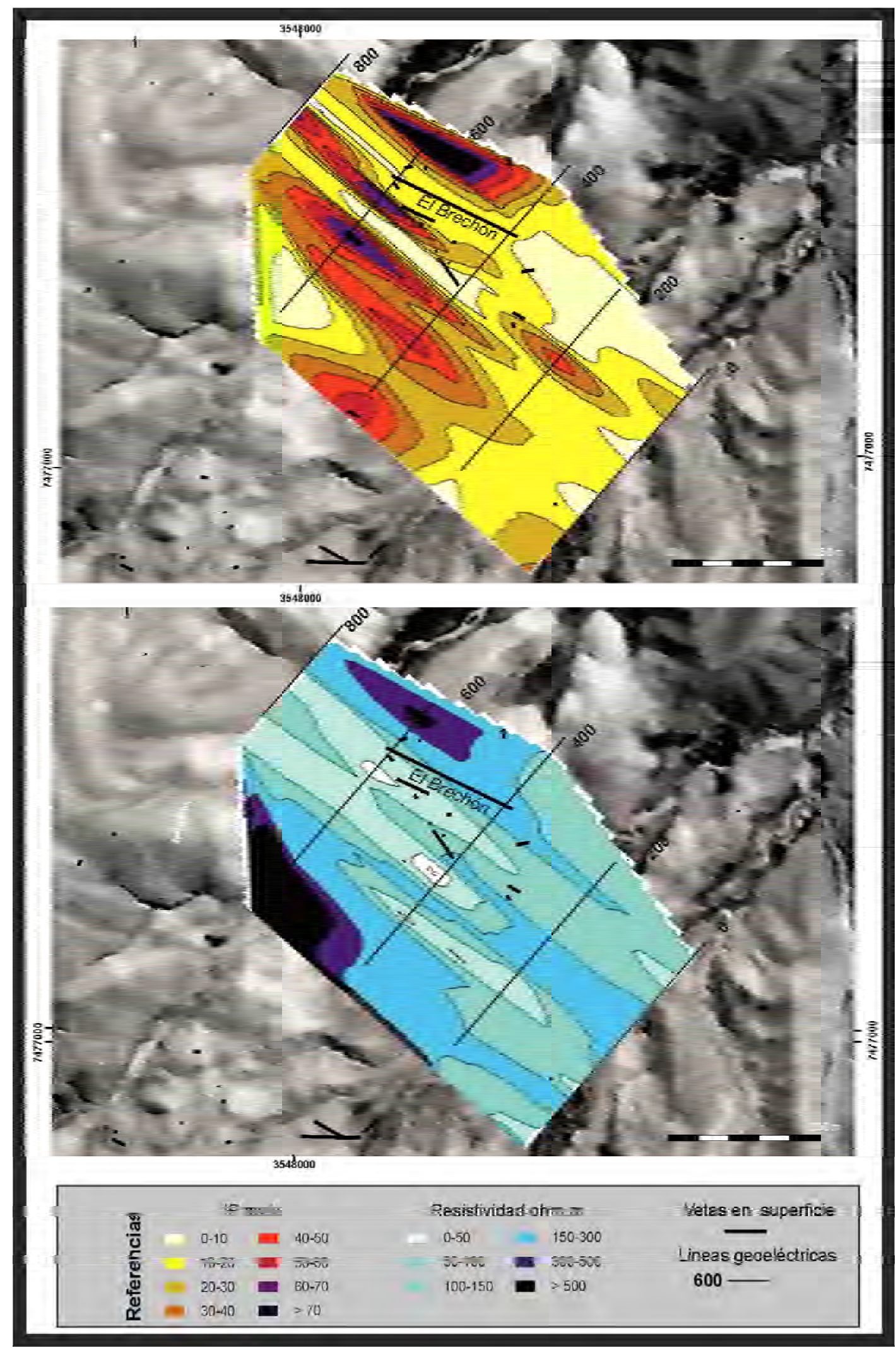

Fig. 6-7. Proyección en planta de los valores geoeléctricos registrados a $57 \mathrm{~m}$ por debajo de la superficie del sector El Brechón. A) Potencial inducido. B) Resistividad. La el sector donde se concentran las vetas presenta muy bajos valores de resistividad. 
La zona de la veta coincide espacialmente con una zona de muy baja resistividad de forma tabular, en este caso inferior a 50 ohm.m. La distribución de resistividades del resto del perfil es bastante heterogénea, aunque en general el sector NE resulta algo más resistivo que el SO. La distribución de las cargabilidades es también muy heterogénea, la zona anómala está desvinculada con la veta reconocida en el sector, sin embargo puede reconocerse una pequeña zona con alta cargabilidad ubicada a $40 \mathrm{~m}$ en la dirección proyectada de la veta en profundidad.

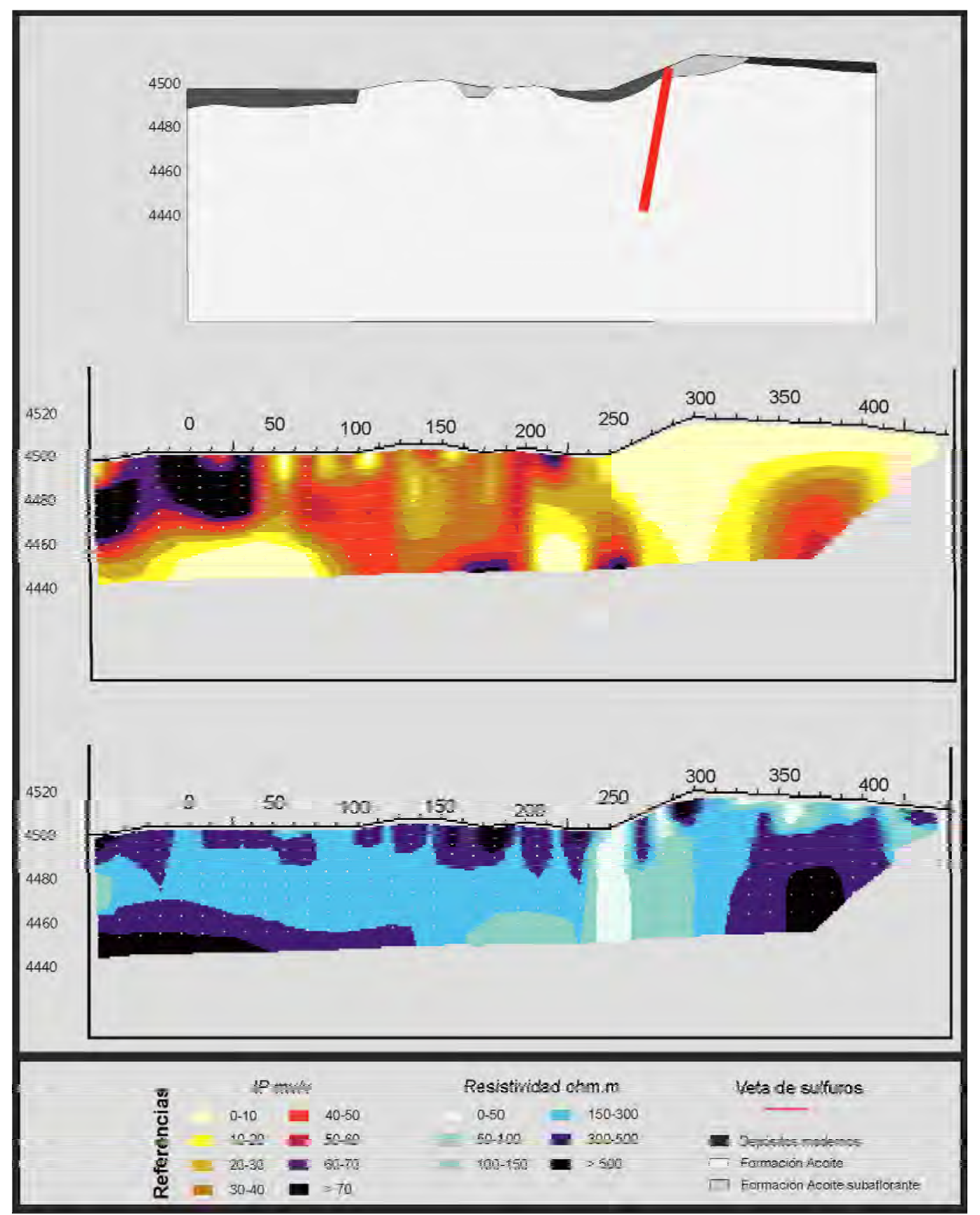

Fig. 6-8 Perfil geológico, potencial inducido y resistividad de la línea 600 del sector El Brechón. La veta en superficie se corresponde con valores bajos en resistividad, Los valores de cargabilidad se expresan de forma heterogénea en el perfil. 
En el sector La Nueva se realizaron un total de tres perfiles de $300 \mathrm{~m}$ de largo y un espaciado de $150 \mathrm{~m}$ entre cada una de ellas, totalizándose $900 \mathrm{~m}$ lineales de perfilaje geoeléctrico (Fig. 6-9).

En los perfiles (Fig. 6-10), se observa que la distribución de resistividades es bastante irregular aunque a grandes rasgos se puede mencionar que la zona de baja resistividad ubicada en el margen sur de la veta La Nueva separa una zona sur bastante homogénea, de resistividades moderadas, de una zona norte, más heterogénea, que aunque presenta pequeñas zonas someras de altas resistividades es mayoritariamente de baja resistividad. En el perfil de cargabilidad se aprecia una amplia zona anómala desplazada unos $50 \mathrm{~m}$ al sur de la veta y separada de esta por una faja de muy baja cargabilidad coincidente de manera ajustada con la de baja resistividad. Al norte de la veta la cargabilidad es comparativamente moderada a baja. 


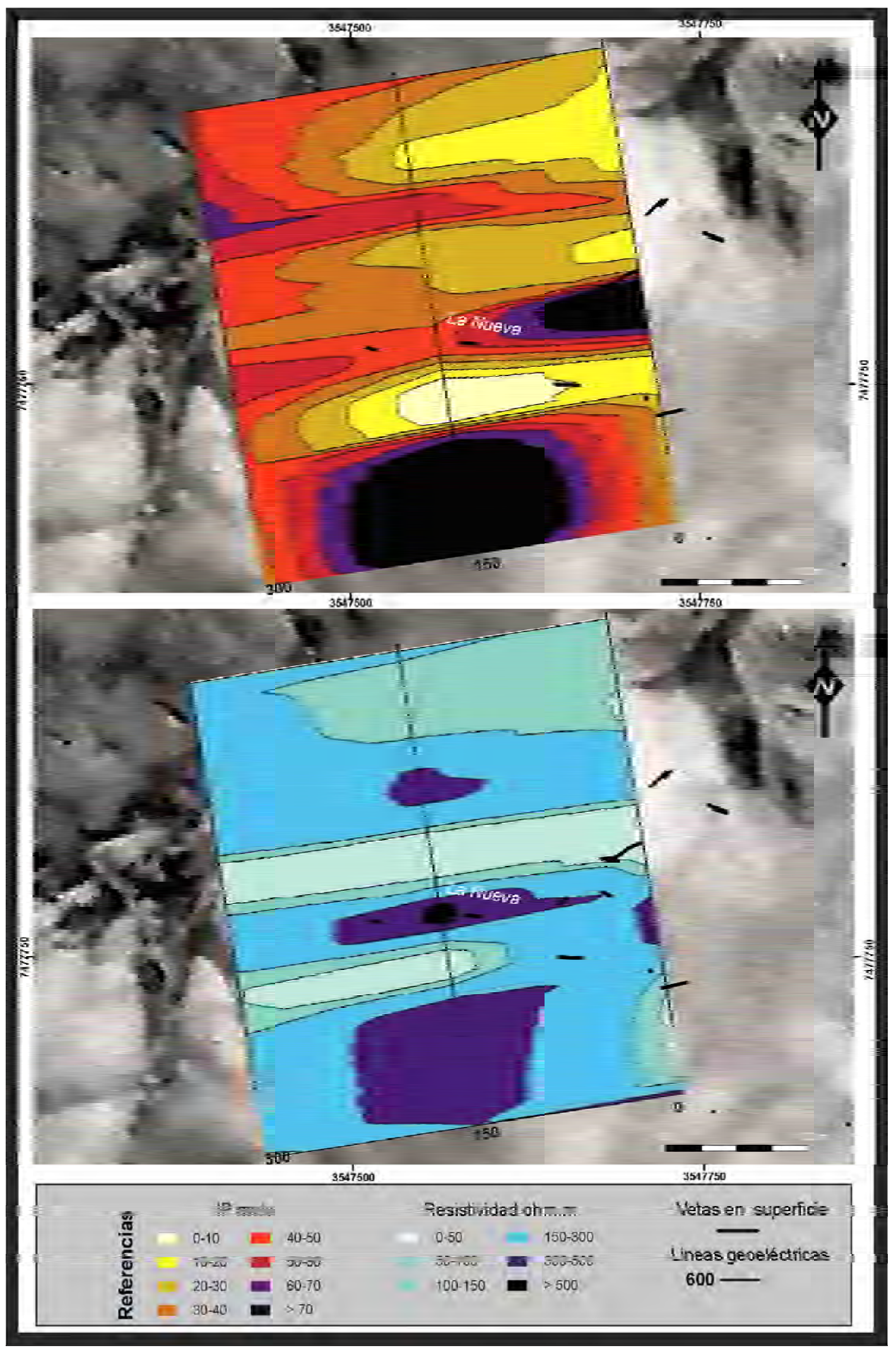

Fig. 6-9. Proyección en planta de los valores geoeléctricos registrados a $57 \mathrm{~m}$ por debajo de la superficie del sector La Nueva. A) Potencial inducido. B) Resistividad. Hacia el sur de la veta La Nueva se determinó un sector con baja cargabilidad coincidente con baja resistividad, 


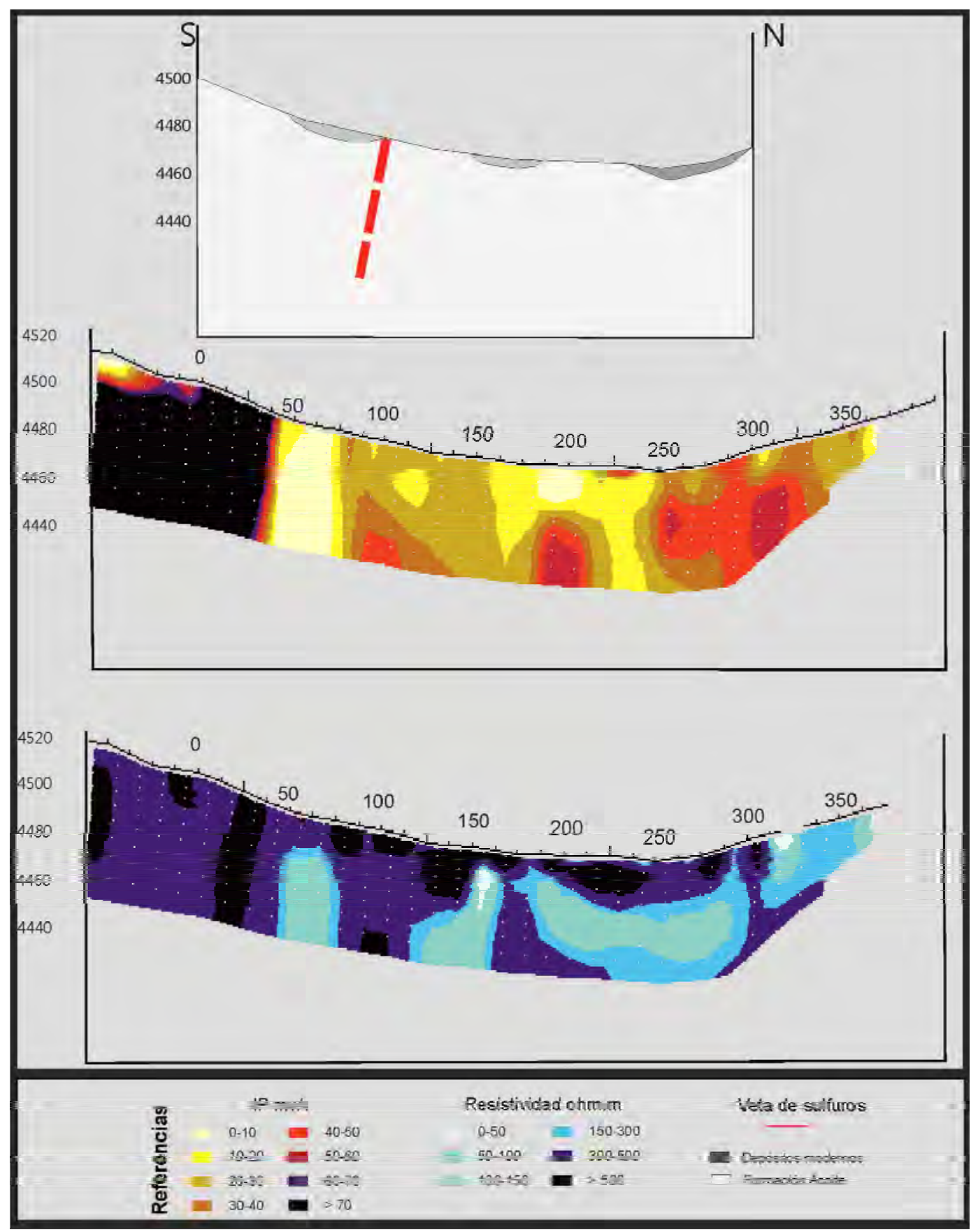

Fig. 6-10.Perfil geológico, potencial inducido y resistividad de la línea 300 del sector La Nueva. Al igual que lo que se observa en planta, en profundidad la veta La Nueva es coincidente con bajos valores de cargabilidad y de resistividad. 
Una de las particularidades que presenta el área es el abrupto relieve topográfico. Este factor dificulta la correlación entre las líneas geoeléctricos sucesivas. Para salvar este escollo se realizó un modelado tridimensional de las anomalías de potencial inducido (Fig. 6-11).

Se determinó así la presencia, continuidad y geometría de las anomalías de potencial inducido mayores a $50 \mathrm{Mv} / \mathrm{v}$ desde superficie hasta $60 \mathrm{~m}$ por debajo de ella, consignando la totalidad de la información registrada en los pseudoperfiles.

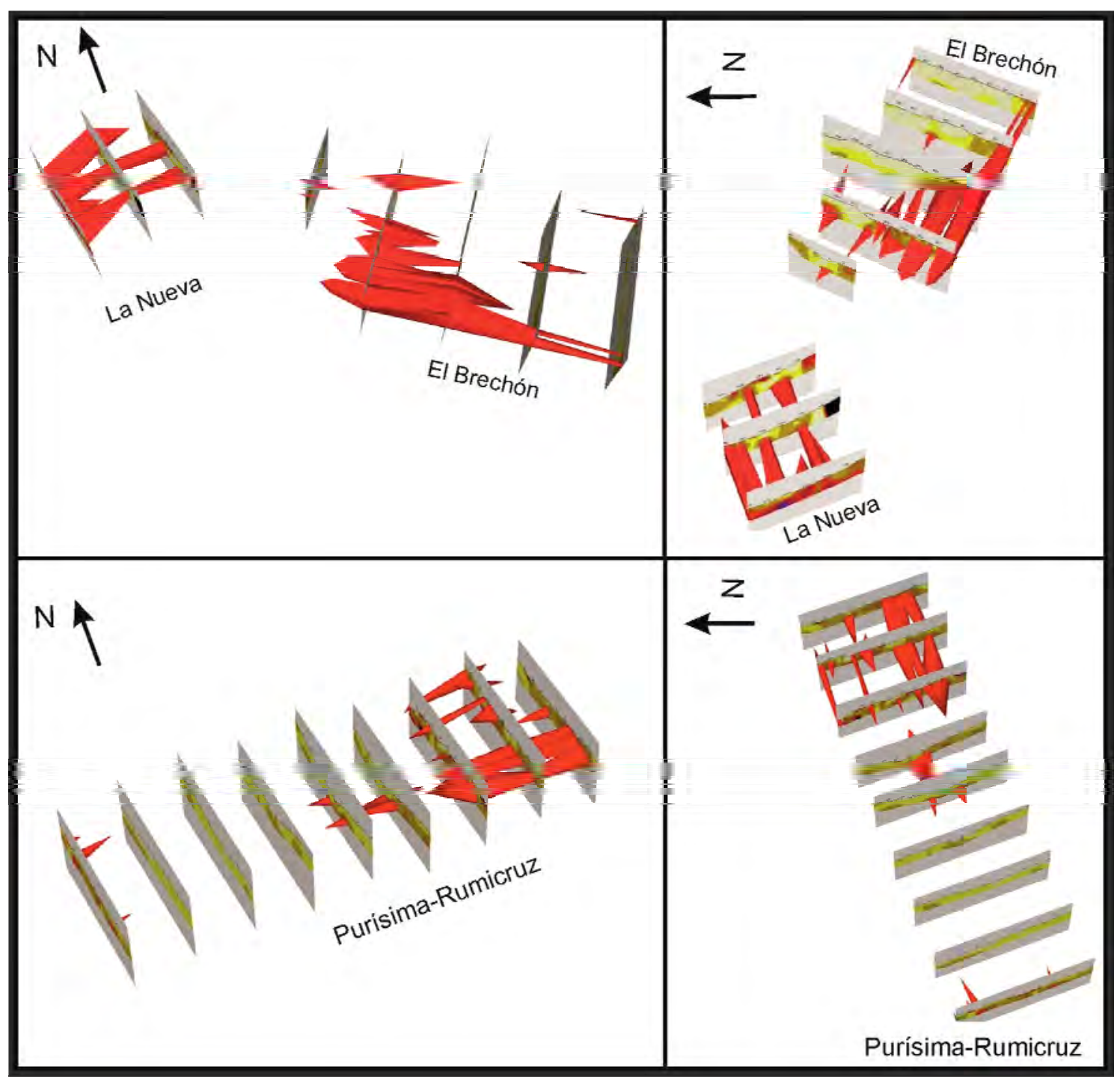

Fig. 6-11. Interpretación 3D de los valores de potencial inducido superiores a 50 Mv/v.

Importantes anomalías de potencial inducido fueron registradas en el distrito minero Purísima Rumicruz desde la superficie hasta los $57 \mathrm{~m}$ por debajo de la superficie. La presencia de las anomalías desde la superficie sugiere el pobre o nulo desarrollo de 
una zona de intensa oxidación (i.e. gossan), común en otros distritos de menas sulfuradas (Proyecto Pingüino, Guido et al., 2009; Wadi Bidah, Arabia Saudita, Smith et al., 1983; West Shasta, Estados Unidos de América, Horton et al., 1985). Los niveles de alteración meteórica registran valores variables de polarización inducida dependiendo íntimamente de los procesos y grados de meteorización. (Raines et al., 1985).

\section{DISCUSIÓN E INTERPRETACIÓN}

En el caso de la prospección de estructuras mineralizadas como las identificadas en el distrito Purísima-Rumicruz, donde las vetas ocupan zonas de fallas multiepisódicas, la resistividad puede aportar importante información en la detección de estas estructuras. Por un lado, las fajas fracturadas, suelen generar zonas de baja resistividad por un fuerte aumento en la porosidad producido por la fracturación de la roca (Fazzito et al., 2009; Giano et al., 2000; Demanet et al., 2001; Colella et al., 2004; Awad Sultan et al. 2009) y por otro, poner en contacto rocas de diferente resistividades (Fazzito et al., 2009) a ambos lados de la zona de falla.

En los tres sectores relevados en el distrito se reconocieron zonas de baja resistividad que pueden ser interpretadas como resultado del aumento de la porosidad efectiva producido por fallamiento. La forma tabular de algunas de estas zonas y su asociación espacial con estructuras mineralizadas (La Nueva y El Brechón) indica también que pueden ser zonas de falla. En el caso del sector Purísima, si bien la zona de baja resistividad coincidente con las zonas profundas de las vetas cortadas por el perfil 600 no tiene forma tabular, la superposición con el eje del valle también revela que puede estar asociada a una zona de falla. Los valores de resistividad de estas zonas, de 0 a 150 ohm.m son similares a los registrados por Suzuki et al. (2000), en pizarras paleozoicas con alto grado de cataclasis producida por fallas. Estos autores indican también que la resistividad disminuye gradualmente en función de la intensidad de cataclasis. El valor promedio de resistividad de las pizarras es de 450 ohm.m, similar a la de las metamorfitas de bajo grado de la Formación Acoite.

En cuanto a la cargabilidad, los valores reconocidos son infrecuentes en rocas sedimentarias "normales". Se registraron valores tan altos de cargabilidad como los de algunos pórfidos de cobre y oro (White et al., 2001). Si bien la presencia de grafito, arcillas y la composición mineralógica de algunas rocas básicas pueden producir cargabilidades altas (Evans y Burley, 1969), en el caso de la Formación Acoite, la presencia de pirita diseminada relativamente abundante de posible origen diagenético 
sería la responsable de este fenómeno. La mayoría de los granos de pirita presente en Acoite tiene textura framboidal, típica de aquellos precipitados en ambiente euxínicoanóxico durante la diagénesis de la roca y por lo tanto, desvinculados genéticamente de la mineralización polimetálica presente en el distrito minero. El tamaño de grano promedio de la pirita framboidal reconocida en la Formación Acoite, menores a 20 micrones, favorece al aumento en la polarización inducida. El tamaño de grano es una variable importante en el registro de IP, ya que una granulometría fina en los minerales polarizables equivalen a una mayor superficie (si el volumen se mantiene constante) y genera un consecuente aumento en la cargabilidad (Wong, 1979).

Tanto en el caso del sector La Nueva como en el sector el Brechón, las zonas anómalas de cargabilidad (> $90 \mathrm{mV} / \mathrm{V}$ y $>59 \mathrm{mV} / \mathrm{V}$ respectivamente) de mayor volumen se encuentran espacialmente desvinculada de la zona donde afloran las vetas y la amplitud en sus desarrollos induce a pensar que se encuentran asociadas a la diseminación de pirita diagenética en la roca de caja más que a una mineralización polimetálica de origen hidrotermal. Por otra parte en el sector La Nueva, la existencia de afloramientos fuertemente teñidos por óxidos de hierro sobre la anomalía, probablemente producto de la alteración meteórica de pirita propio una de zona de oxidación, refuerza la idea de que las zonas anómalas en cargabilidad están vinculadas a la fuerte piritización de la roca de caja.

En los sectores Purísima y El Brechón, por debajo de 40 y 50 m respectivamente, aparecen pequeñas anomalías de cargabilidad asociadas espacialmente a las vetas que pueden ser atribuidas a la sumatoria de una mineralización hidrotermal epigénica dispuesta en un encajante piritizado.

La metodología geoeléctrica empleada (potencial inducido - resistividad) demostró ser una adecuada herramienta de exploración en este depósito. A pesar que en el distrito polimetálico Purísima-Rumicruz se han registrado valores altos de potencial inducido en las vetas y en las rocas de caja de la Formación Acoite, esta técnica ha permitido identificar anomalías de potencial inducido y resistividad que pueden ser asociadas con la presencia de vetas polimetálicas en profundidad. Esto se asociación será más ajustada cuando los valores anómalamente altos de cargabilidad presentan una correlación negativa con bajos valores de resistividad, y también cuando estas anomalías exhiben continuidad lateral y vinculación espacial con las vetas registradas en superficie. 


\section{CAPÍTULO VIII}

\section{CARACTERIZACIÓN DE LOS FLUIDOS HIDROTERMALES}




\section{Introducción}

Las inclusiones fluidas son pequeños volúmenes de fluidos fósiles atrapados en los cristales durante su formación (Roedder y Bodnar, 1980). Su estudio es considerado fundamental para comprender las condiciones de formación de los minerales precipitados de soluciones hidrotermales, ya que proporcionan información principalmente de temperatura y composición de las mismas. Asimismo es posible calcular las condiciones de presión y por lo tanto estimar la profundidad donde de formación los depósitos.

\section{Petrografía de las inclusiones}

Se realizó el estudio de las inclusiones fluidas de muestras provenientes de las vetas Purísima, Rumicruz, El Brechón y La Nueva. Las inclusiones analizadas se alojan en calcita (Vetas Purísima - Rumicruz) y cuarzo (Veta Rumicruz - La Nueva Brechón), pues la caracterización de inclusiones fluidas en baritina y en minerales de mena (e.g. calcosina), no pudieron realizarse debido a que ambos resultaron ser opacos bajo luz normal e infrarroja. Las inclusiones fluidas estudiadas corresponden a las vetas clasificadas como sulfuro dominantes de las vetas polimetálicas (etapa 1) (Capítulo IV). Se empleó la clasificación descripta por Velasco (2004), para asignar categorías a la morfología de las inclusiones, de esta forma se distinguen inclusiones regulares, tabulares, ovoides e irregulares (Fig. 8-1).

Asimismo se diferenció a las inclusiones de acuerdo a su origen en primarias y secundarias. Las inclusiones primarias son aquellas formadas durante el crecimiento del mineral huésped, mientras que las inclusiones secundarias alojan a fluidos que circularon posteriormente a la formación del mineral. La diferenciación entre estas dos tipos es fundamental para obtener la temperatura y salinidad del fluido que formó al mineral. Los criterios que se utilizaron para clasificar como primarias a las inclusiones fueron la distribución de las inclusiones paralelas a las caras de cristales, la distribución al azar en tres dimensiones y las inclusiones aisladas y de mayor tamaño que el resto. Las secundarias forman grupos numerosos y alineados a microfisuras oblicuas a los bordes de los cristales (Velasco, 2004) 


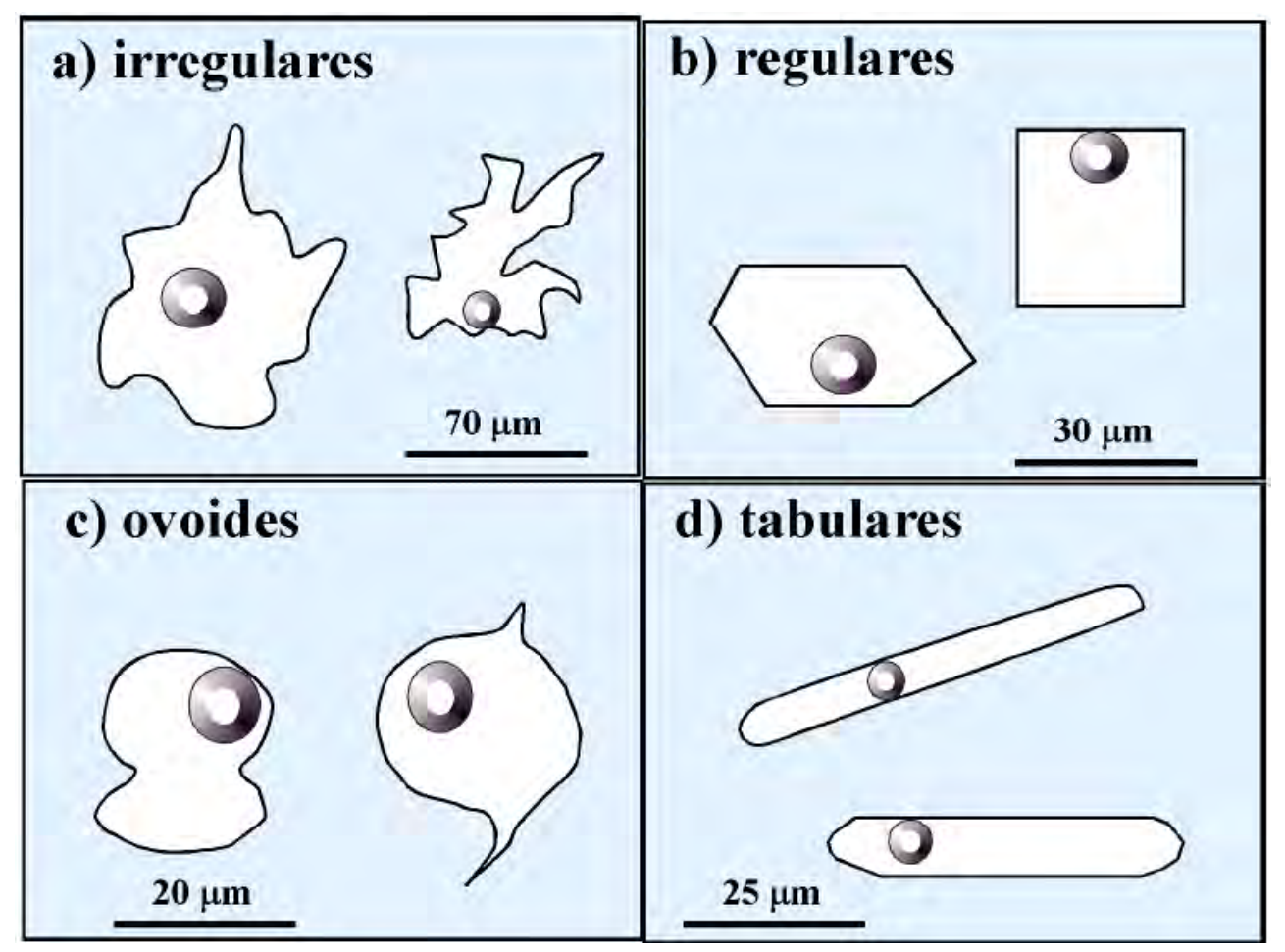

Fig. 8- 1. Clasificación de las morfologías de las inclusiones fluidas. Tomado de Velasco, 2004.

\section{Calcita}

Se reconocieron inclusiones primarias y secundarias. Las morfologías, si bien son variables, predominan las regulares, seguidas por las tabulares. Los tamaños alcanzan hasta $30 \mu$, aunque el promedio no supera los $9 \mu$. De acuerdo al contenido de fases identificadas, corresponden mayoritariamente a inclusiones bifásicas líquido-vapor (LV), y solo se han registrado escasas inclusiones trifásica líquido-vapor-sólido (L-V-S) (posiblemente halita) en la veta Purísima. El grado de relleno (f), que es la relación entre el relleno de líquido y vapor, en las muestras analizadas varía entre 0,7 a 0,95 (promedio 0,9) (Fig. 8-2 A y B). Debido a la dificultad para establecer el pulso de carbonato mediante microscopía, como se mencionó en el capítulo $\mathrm{V}$, no ha sido posible realizar una distinción sobre a que pulso de carbonato pertenecen las inclusiones estudiadas.

\section{$\underline{\text { Cuarzo }}$}

Dentro de los cristales de cuarzo también fueron identificadas inclusiones primarias y secundarias. Aquí, las morfologías irregulares son las predominantes junto con las ovoides. Los tamaños son generalmente menores que las de calcita aunque alcanzan los $20 \mu$ de diámetro, con un promedio de $7 \mu$. Son inclusiones bifásicas líquido-vapor (L-V) con un grado de relleno entre 0,7 y 0,95 (promedio 0,9) (Fig. 8-2 C y D). 


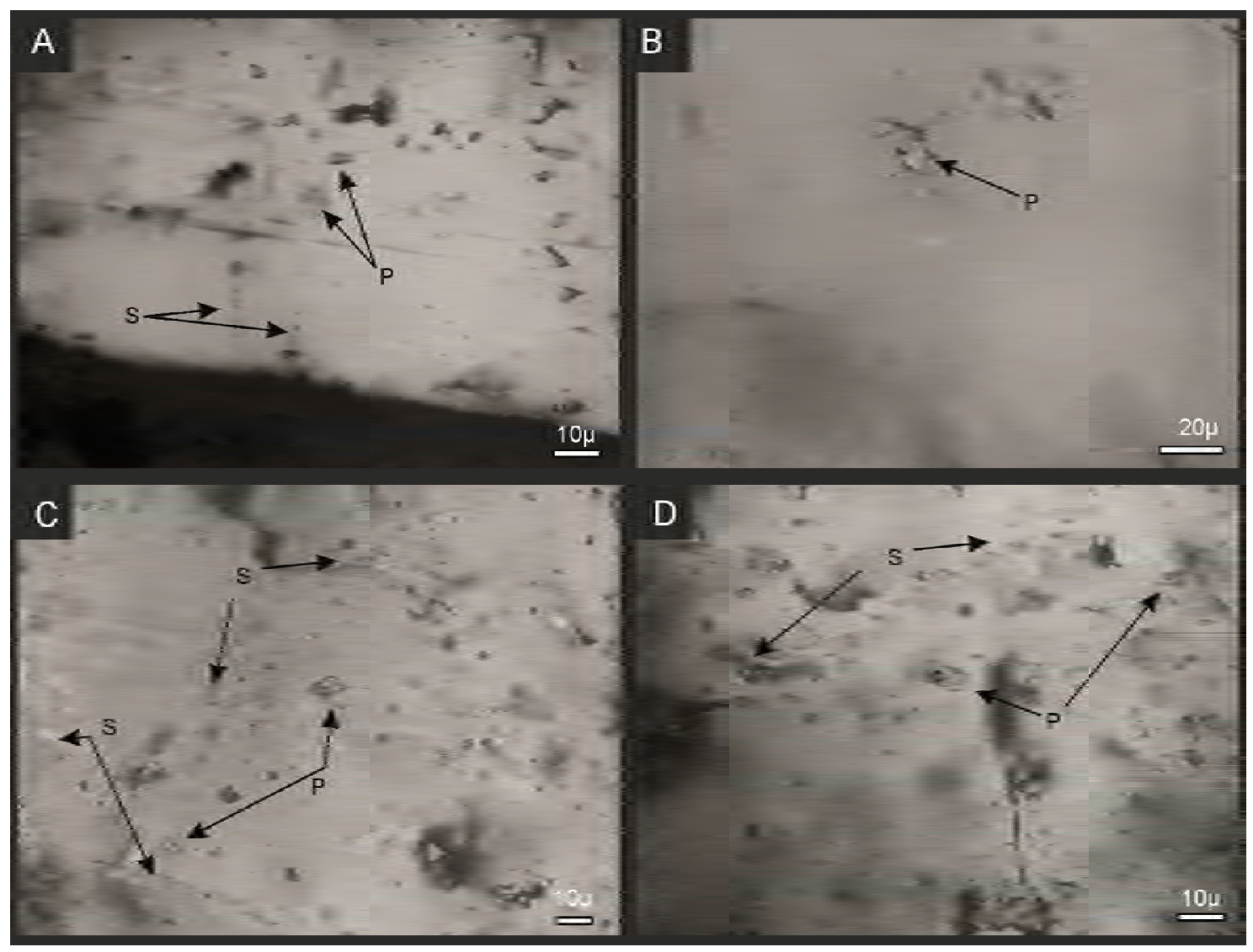

Fig. 8- 2. A. Inclusiones primarias bifásicas y secundarias en calcita, veta Purísima. B. Inclusión bifásica en calcita, veta Rumicruz. C y D. Inclusiones bifásicas primarias y secundarias en cuarzo, veta Rumicruz. P: Inclusiones primarias; S: Inclusiones secundarias.

\section{Estudio microtermométrico}

De la selección efectuada para realizar los estudios microtermométricos en calcita, solo una pequeña proporción pudo ser ensayada debido al pequeño tamaño, opacidad de las secciones y procesos de apertura y escape de fluidos durante los ensayos (decrepitación). En todos los casos se tomó la precaución de considerar solo las inclusiones primarias para estos estudios.

Con el fin de lograr la congelación total del líquido atrapado se sometió a cada muestra hasta temperaturas de $-100^{\circ} \mathrm{C}$ y se calentó gradual y controladamente hasta temperatura ambiente. En la Tabla 8-1, se sintetizan los valores obtenidos discriminados por vetas y composición mineral. Se identificó, cuando fue posible, la temperatura del eutéctico $(\mathrm{Te})$ que en las calcitas obtuvo valores promedio de $-55,6^{\circ} \mathrm{C}$ $(n=2 ; \sigma=10,46)$ y en los cuarzos entre $-40, y-55,2^{\circ} \mathrm{C}$, con un promedio de $-50,9^{\circ} \mathrm{C}(n=$ $10 ; \sigma=2,99)$. 
Las temperaturas de fusión del hielo (Tfh) fueron disímiles, en la calcita varió entre 24,8 y $-1^{\circ} \mathrm{C}$ con un promedio $-9,59^{\circ} \mathrm{C}$ y un desvío elevado $(n=12 ; \sigma=10,9)$, mientras que en los cuarzos las Tfh son notablemente menores y más homogéneas con un promedio de $-5,26^{\circ} \mathrm{C}(\mathrm{n}=58 ; \sigma=2,79)$, registrándose en las muestras de la veta Rumicruz Tfh ligeramente menores que para las vetas de La Nueva y El Brechón (Tabla 8-1).

Durante el proceso de calentamiento para lograr la temperatura de homogenización $(T h)$, en todos los casos las inclusiones homogeneizaron a líquido. Estas temperaturas (Th) presentaron una distribución más amplia en las inclusiones de calcita con valores entre 110 y $350^{\circ} \mathrm{C}$, promedio de $180,35^{\circ} \mathrm{C}(\mathrm{n}=$ y $\sigma=73,9)$, y más restringida en los cuarzos entre 113 a $276^{\circ} \mathrm{C}$, promedio $212,5^{\circ} \mathrm{C}(n=57 ; \sigma=40,64)($ Tabla 8-1).

\begin{tabular}{|c|c|c|c|c|c|c|c|c|}
\hline & & & $\begin{array}{c}\text { Tamaño } \\
\mu\end{array}$ & $\begin{array}{c}\text { Vapor } \\
\%\end{array}$ & $\begin{array}{c}\text { Th } \\
\text { (oC) }\end{array}$ & $\begin{array}{l}\text { Tfh } \\
\text { (oC) }\end{array}$ & $\begin{array}{c}\mathrm{Te} \\
(\stackrel{\mathrm{o}}{ } \mathrm{C})\end{array}$ & $\begin{array}{c}\text { Salinidad } \\
\% \text { peso } \\
\mathrm{NaCl} \text { eq. }\end{array}$ \\
\hline \multirow{4}{*}{ Purisima } & \multirow{4}{*}{ Calcita } & $\mathrm{n}$ & 10 & 10 & 7 & 5 & 2 & 5 \\
\hline & & Promedio & 7,2 & 0,9 & 277,2 & $-16,6$ & $-45,6$ & 19,92 \\
\hline & & Min & 5 & 0,8 & 113 & $-20,2$ & -63 & 11,93 \\
\hline & & Max & 17 & 0,95 & 351 & $-8,2$ & $-48,2$ & 22,51 \\
\hline \multirow{8}{*}{ Rumicruz } & \multirow{4}{*}{ Calcita } & $\bar{n}$ & 18 & 18 & 11 & 7 & & 7 \\
\hline & & Promedio & 8,6 & 0,9 & 177,9 & $-14,82$ & - & 18,48 \\
\hline & & Min & 5 & 0,7 & 110 & $-24,8$ & - & 1,74 \\
\hline & & Max & 30 & 0,95 & 230 & -1 & -1 & 25,46 \\
\hline & \multirow{4}{*}{ Cuarzo } & $\mathrm{n}$ & 52 & 52 & 25 & 45 & 2 & 45 \\
\hline & & Promedio & 11,2 & 0,9 & 218,6 & $-4,32$ & -43 & 6,91 \\
\hline & & Min & 7 & 0,8 & 185 & $-7,7$ & $-45,5$ & 5,71 \\
\hline & & Max & 20 & 0,95 & 262 & $-3,5$ & $-40,4$ & 11,34 \\
\hline \multirow{4}{*}{ La Nueva } & \multirow{4}{*}{ Cuarzo } & $\mathrm{n}$ & 35 & 35 & 29 & 6 & 4 & 6 \\
\hline & & Promedio & 8,3 & 0,9 & 204,4 & $-6,13$ & $-50,2$ & 9,38 \\
\hline & & Min & 5 & 0,8 & 113 & $-6,5$ & -53 & 8,95 \\
\hline & & Max & 10 & 0,95 & 276 & $-5,8$ & $-48,2$ & 9,86 \\
\hline \multirow{4}{*}{ El Brechón } & \multirow{4}{*}{ Cuarzo } & $\mathrm{n}$ & 9 & 9 & 3 & 7 & 4 & 7 \\
\hline & & Promedio & 11,9 & 0,9 & 241 & $-6,1$ & $-52,6$ & 9,34 \\
\hline & & Min & 5 & 0,8 & 213 & $-7,9$ & $-55,2$ & 7,17 \\
\hline & & Max & 20 & 0,95 & 260 & $-4,5$ & $-49,3$ & 11,58 \\
\hline \multirow{4}{*}{ Total } & \multirow{2}{*}{ Calcita } & Promedio & - & - & 180,4 & $-9,59$ & $-55,6$ & 19,08 \\
\hline & & Desvio & - & - & 73,9 & 10,9 & 10,5 & 14,46 \\
\hline & \multirow{2}{*}{ Cuarzo } & Promedio & - & - & 212,6 & $-5,56$ & $-50,9$ & 7,45 \\
\hline & & Desvio & - & - & 40,64 & 2,79 & 2,99 & 4,6 \\
\hline
\end{tabular}

Tabla 8- 1 Síntesis de los resultados de las características de las inclusiones fluidas para el depósito Purísima-Rumicruz. 
Los cálculos de la salinidad, indican valores generalmente elevados para las inclusiones de calcita, con contenidos de hasta $25 \%$ en peso de $\mathrm{NaCl}$ equivalente, coherente con la presencia de inclusiones trifásicas líquido-vapor-sólido. Las salinidades de las inclusiones en cuarzo se encuentran un rango más acotado y con valores menores, con promedio de 7,4 \% en peso $\mathrm{NaCl}$ eq. (Tabla. 8-1).

En la figura 8-3, se presentan los histogramas de frecuencias de las temperaturas de homogenización y salinidad obtenidas y en la fig. 8-4 se exhibe un diagrama donde se vincula la salinidad con la temperatura de homogenización de las inclusiones, diferenciando los valores por cada veta y a su vez por el mineral estudiado. A partir de esta vinculación, pueden establecerse dos campos distintivos. Un primer campo incluye aquellas inclusiones en cuarzo que presentan valores de salinidades medias (con promedios entre 6 y $10 \%$ en peso de $\mathrm{NaCl}$ eq.) y con temperaturas promedio entre 200 y $250^{\circ} \mathrm{C}$. El segundo campo involucra a las inclusiones en calcita, que presentan una mayor dispersión de estos parámetros. En este sentido, las salinidades varían entre 1,74 hasta $25,46 \%$ en peso $\mathrm{NaCl}$ eq. con una moda entre 20 y $22 \%$ en peso $\mathrm{NaCl}$ eq. y las temperaturas de homogeneización marcan dos modas, la primera comprendida entre 110 y $225^{\circ} \mathrm{C}$ representada principalmente en la veta Rumicruz, y la segunda presenta valores mayores, entre 290 y $351^{\circ} \mathrm{C}$ representada exclusivamente por la veta Purísima.

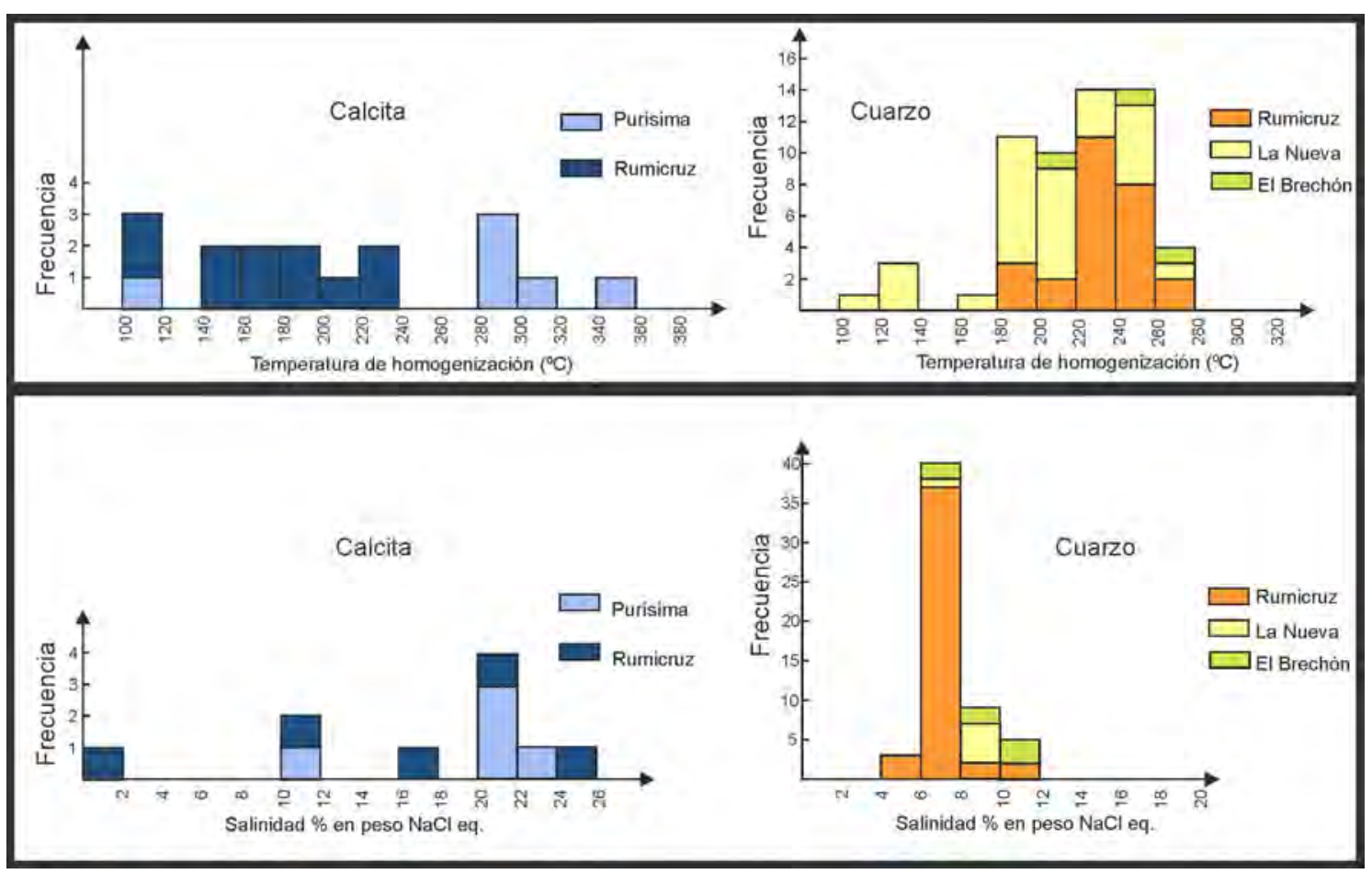

Fig. 8- 3. Histogramas de frecuencias de temperatura de homogenización y salinidad para las vetas del depósito Purísima-Rumicruz 


\section{Discusión}

La abundancia de las inclusiones fluidas ricas en $\mathrm{H}_{2} \mathrm{O}$ con ausencia de $\mathrm{CO}_{2}$ sugiere que la presencia de $\mathrm{CO}_{2}$ en el fluido es despreciable. Si bien con las técnicas empleadas no es posible establecer la composición exacta de la solución de la inclusión, la misma puede estimarse con la temperatura de su eutéctico. Los valores de temperatura del eutéctico obtenidas son bajas, entre -55 y $-50^{\circ} \mathrm{C}$. El eutéctico en el sistema $\mathrm{H}_{2} \mathrm{O}-\mathrm{NaCl}$ es a $-20,8^{\circ} \mathrm{C}$, mientras que el eutéctico obtenido es sustancialmente menor que el correspondiente a este sistema. Esta disminución es debida a la presencia de otro tipo de sales disueltas en el sistema que disminuyen estos valores. La temperatura del eutéctico registradas en este estudio pueden ser acordes a los sistema $\mathrm{H}_{2} \mathrm{O}-\mathrm{NaCl}-\mathrm{CaCl}_{2} \quad\left(-55^{\circ} \mathrm{C}\right) ; \mathrm{H}_{2} \mathrm{O}-\mathrm{CaCl}_{2}-\mathrm{MgCl}_{2} \quad\left(-52,2^{\circ} \mathrm{C}\right) ; \mathrm{H}_{2} \mathrm{O}-\mathrm{KCl}^{-\mathrm{CaCl}_{2}} \quad(-$ $\left.50,5^{\circ} \mathrm{C}\right)$, o en el sistema $\mathrm{H}_{2} \mathrm{O}-\mathrm{CaCl}_{2}(-49,8)$ (Velazco, 2004). A partir de esto es posible postular la presencia de $\mathrm{CaCl}_{2}$ en las inclusiones, que puede estar acompañado por $\mathrm{Na}, \mathrm{K}$ o Mg.

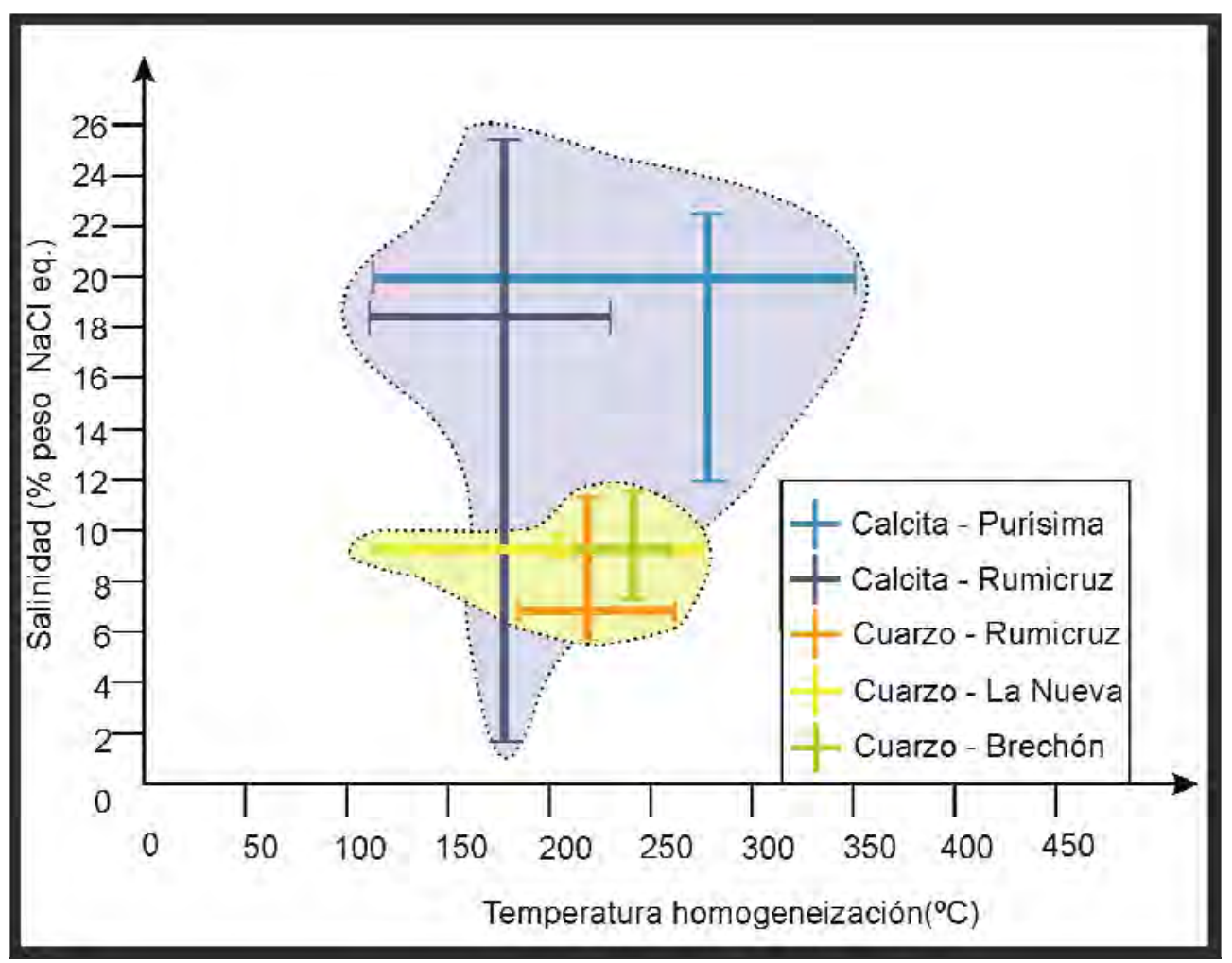

Fig. 8- 4. Relación Temperatura-Salinidad discriminado por veta y por mineral huésped de la inclusión.

La dispersión de los valores de temperaturas registrados en las muestras de calcita pueden indicar procesos de pérdida de parte del fluido a través del mineral huésped (leakage) o de estrangulamiento (necking down). En el caso de la calcita, los valores 
elevados de salinidad podrían no corresponderse con la composición del fluido en equilibrio. Es posible que los valores consignados se deban a la modificación del fluido, como consecuencia del marcado clivaje de la especie, post-entrampamiento (e.g. reequilibrio con otros fluidos secundarios).

Por lo expuesto, la calcita puede que no sea el mineral más adecuado para la investigación de las condiciones de temperatura y salinidad en el distrito Purísima Rumicruz. Sin embargo, debido a que los sulfuros y sulfoarseniuros se corresponden con la paragénesis de los carbonatos, se asignarán estos rangos como los potenciales para la precipitación de la mineralización. Por lo tanto, estas temperaturas estarían comprendidas entre 110 y $350^{\circ} \mathrm{C}$. Las salinidades probablemente se encuentren en los valores de la moda entre 20 y $22 \%$ en peso $\mathrm{NaCl}$ eq.

Las temperaturas y salinidades del cuarzo se mantuvieron en un rango relativamente estrecho de temperaturas mínimas de entrampamiento, variando entre $\sim 115$ y $270{ }^{\circ} \mathrm{C}$, con una moda $\sim 240^{\circ} \mathrm{C}$ mientras que la salinidad presenta un rango entre 6 a $12 \%$ peso de $\mathrm{NaCl}$ eq con una muy definida moda entre 6 y $8 \%$ peso de $\mathrm{NaCl}$ eq. 


\section{Introducción}

Los isótopos estables de O, C y S han sido utilizados como una fuente de información adicional para el modelado de los yacimientos minerales ya que aportan información acerca del origen de estos elementos y su evolución (Hoefs, 2009). Los datos isotópicos no proveen una única respuesta a los problemas geológicos, de esta forma, características isotópicas similares pueden ser producidas por diferentes procesos, e incluso un mismo proceso general suele generar características isotópicas distintas (Ohmoto, 1986). Sin embargo, los datos isotópicos complementados con estudios mineralógicos, geoquímicos y geológicos pueden proveer información importante respecto a la fuente de los fluidos hidrotermales (Misra, 2000).

Las variaciones en las relaciones isotópicas son causadas por la diferencia de masa entre los distintos isótopos de los elementos. Esta diferencia produce pequeños pero significativos cambios en el comportamiento físico-químico de los compuestos formados por estos elementos generando el fraccionamiento isotópico.

Se presentan aquí los resultados de $\delta^{34} S, \quad \delta^{18} \mathrm{O}$ y $\delta^{13} \mathrm{C}$ de minerales correspondientes a las vetas Purísima y Rumicruz. Las relaciones isotópicas son medidas respecto a un estándar internacional que varía para cada isótopo. La fórmula general puede expresarse de la siguiente manera.

$$
\delta_{x}=\left(\frac{R_{x}-R_{s t d}}{R_{s t d}}\right) x 10^{3}
$$

Siendo $\mathrm{R}_{\mathrm{x}}$ la relación isotópica en la muestra de estudio del isotopo pesado con respecto al liviano.

\section{Isótopos de azufre}

Se realizaron 9 mediciones de azufre, en calcosina, galena y baritina. La notación de los isótopos es expresada en $\delta^{34} \mathrm{~S} \%$ en relación al estándar CDT (Troilita del meteorito del Cañón del Diablo). 
Los valores de $\delta^{34} S_{\min }$ de los sulfuros estudiados en el depósito se encuentran entre $+5,8$ y $+7 \%$ o con un promedio de $+6,3 \%$ o (Fig. 8-5).

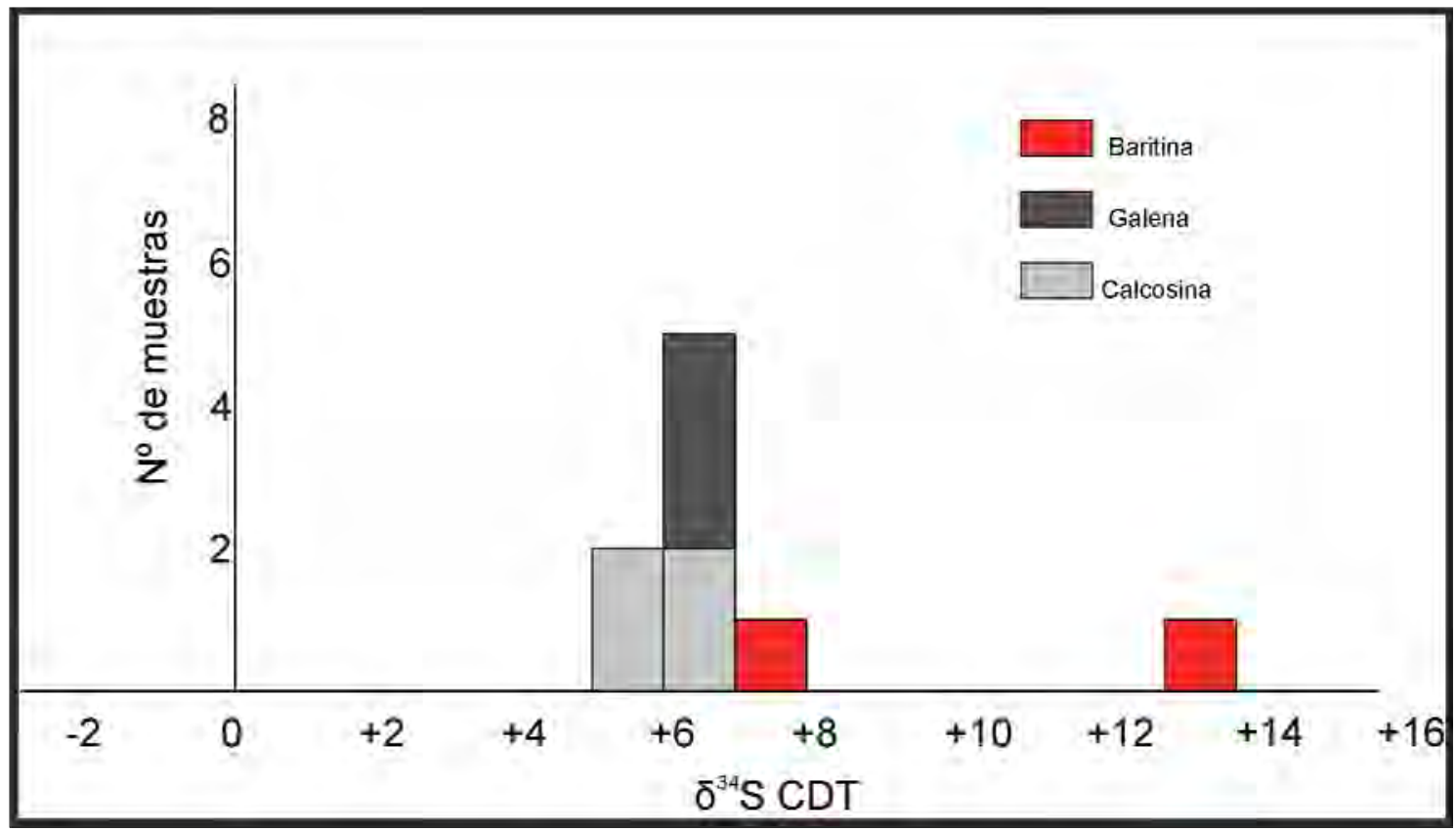

Fig. 8- 5. Gráfico de frecuencia de valores de $\delta^{34} \mathrm{~S} \%$, discriminados por mineral.

Los valores obtenidos en los sulfuros muestran una baja dispersión, por lo que se interpreta que la fuente del azufre corresponde a una fuente homogénea y constante. Para establecer la composición isotópica del $\delta^{34} S_{\text {fuido }}$ es necesario considerar, además de la temperatura, cual es especie de azufre dominante en el fluido ya que el mismo es función del $\mathrm{pH}$ y de la fugacidad del oxígeno. Asumiendo que la especie dominante

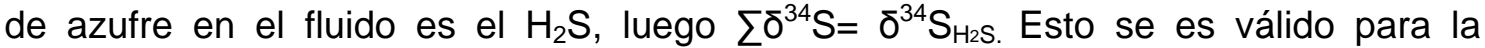
precipitación de los sulfuros, pero en la baritina precipitación de la baritina pueden ocurrir otros procesos como se profundizará en la discusión de los resultados. Se consideró que la temperatura de precipitación de los sulfuros fue constante. Los valores de $\delta^{34} \mathrm{~S}_{\mathrm{H}_{2} \mathrm{~S}}$ en los sulfuros, calculados a partir la ecuación de Ohmoto y Rye (1979), varían entre $7,73 \%$ y $8,93 \%$ calculados para una temperatura de $350^{\circ} \mathrm{C}$ y entre 10,39 y 12,03 para una temperatura de $110^{\circ} \mathrm{C}$. Se ha calculado para estas dos temperaturas debido a que son los rangos máximos y mínimos respectivamente de las temperaturas de homogenización en calcita. Dado que los fraccionamientos isotópicos son inversamente proporcionales a la temperatura, los valores calculados para la menor temperatura son mayores. (Tabla 8-2). 


\begin{tabular}{ccccc}
\hline Mineral & Veta & $\delta^{34} \mathrm{~S}_{\min } \%$ & $\begin{array}{c}\delta^{34} \mathrm{~S}_{\text {fluido }} \% \\
(350 \circ \mathrm{C})\end{array}$ & $\begin{array}{c}\delta^{34} \mathrm{~S}_{\text {fluido }} \% \\
(110 \circ \mathrm{C})\end{array}$ \\
\hline Calcosina & Purísima & 7 & 8,93 & 12,03 \\
Calcosina & Purísima & 5,8 & 7,73 & 10,83 \\
Calcosina & La Nueva & 6,4 & 8,33 & 11,43 \\
Calcosina & Liliana & 6 & 7,93 & 11,03 \\
\hline Galena & Rumicruz & 6,1 & 7,75 & 10,39 \\
Galena & Rumicruz & 6,6 & 8,25 & 10,89 \\
Galena & Rumicruz & 6,6 & 8,25 & 10,89 \\
\hline
\end{tabular}

Tabla 8- 2. Cálculo de $\delta^{34} \mathrm{~S}_{\mathrm{H}_{2} \mathrm{~S}}$ a partir de los valores de $\delta^{34} \mathrm{~S}_{\min }$ correspondientes a los sulfuros del distrito Purísima-Rumicruz.

\section{Isótopos de oxígeno en cuarzo}

Las muestras fueron tomadas de las vetas principales que componen el distrito Purísima-Rumicruz y se discriminaron las vetas donde el cuarzo forma parte de las vetas polimetálicas (Tabla 8-3), de aquellas vetas clasificadas como cuarzo dominante (Tabla 8-4). Se han obtenido doce valores de $\delta^{18} \mathrm{O}$ en cuarzo los resultados son expuestos en la tabla 8-3 y 8-4. Los resultados obtenidos expresan el valor de $\delta^{18} \mathrm{O}$ del mineral en valores por mil (\%) respecto del SMOW (Standard Mean Ocean Water). Para la determinación de la relación isotópica del fluido se asumió el equilibrio isotópico entre el fluido y el mineral correspondiente. En este sentido, se obtuvieron los valores de $\delta^{18} \mathrm{O}_{\text {SMow }}$ en calcita y cuarzo posibilitando así, el cálculo del valor de $\delta^{18} \mathrm{O}$ del fluido hidrotermal de acuerdo a la ecuación de Zheng (1993). Para los cálculos en cuarzo se utilizaron los valores de temperatura establecida mediante inclusiones fluidas (promedio $225^{\circ} \mathrm{C}$ ).

\begin{tabular}{ccc}
\hline Veta & $\delta^{18} \mathrm{O}_{\min }$ & $\begin{array}{c}\delta^{18} \mathrm{O}_{\mathrm{H} 2 \mathrm{O}} \\
\left(225 \mathrm{O}^{\mathrm{C}}\right)\end{array}$ \\
\hline Rumicruz & 17,5 & 7,30 \\
Rumicruz & 17,4 & 7,20 \\
El Brechón & 16,5 & 6,30 \\
El Brechón & 16,9 & 6,70 \\
Rumicruz & 19,5 & 9,30 \\
Rumicruz & 19,7 & 9,50 \\
\hline
\end{tabular}

Tabla 8- 3. Valores de $\delta^{18} \mathrm{O}_{\mathrm{H} 2 \mathrm{O}}$ a partir de los valores de $\delta^{18} \mathrm{O}_{\min }$ correspondientes a cuarzo de las vetas polimetálicas del distrito Purísima-Rumicruz a una temperatura de $225^{\circ} \mathrm{C}$. 


\begin{tabular}{ccc}
\hline Veta & $\delta^{18} \mathrm{O}_{\min }$ & $\begin{array}{r}\delta^{18} \mathrm{O}_{\mathrm{H} 2 \mathrm{O}} \\
(225 \mathrm{O})\end{array}$ \\
\hline Liliana S & 18 & 7,80 \\
Bola Blanca & 18,2 & 8,00 \\
Liliana SE & 16,8 & 6,60 \\
Bola Blanca & 15,4 & 5,20 \\
Marciano & 16,5 & 6,30 \\
Marciano & 16,2 & 6,00 \\
\hline
\end{tabular}

Tabla 8- 4. Valores de $\delta^{18} \mathrm{O}_{\mathrm{H} 2 \mathrm{O}}$ a partir de los valores de $\delta^{18} \mathrm{O}_{\min }$ correspondientes a cuarzo de las vetas de cuarzo dominante del distrito Purísima-Rumicruz a una temperatura de $225^{\circ} \mathrm{C}$.

El rango comprendido para el $\delta^{18} \mathrm{O}_{\text {SMOW }}$ de los fluidos en equilibrio con el cuarzo de las vetas polimetálicas está comprendido entre 6,3 y $9,5 \%$, con un promedio de $7,7 \%$. Para las vetas de cuarzo, los valores $\delta^{18} \mathrm{O}_{\text {SMow }}$ de los fluidos son ligeramente menores y oscilan en un rango entre 5,2 y $8 \%$, con un promedio de $6 \%$.

\section{Isótopos de C y O en carbonatos}

Los isótopos de carbono se expresan en relación al estándar definido como PDB (Belemnite de la Formación Pee Dee). Se analizaron un total de seis muestras de calcita correspondientes con las vetas Purísima, Rumicruz y Liliana. Los valores se distribuyen en un rango estrecho, lo que sugiere una fuente relativamente homogénea del carbono en los fluidos y además que las condiciones físico-químicas fueron estables durante la precipitación de los carbonatos. Los valores de $\delta^{13} C_{\mathrm{PDB}}$ varían entre -3 y $-4 \%$ (Tabla 8-5).

Las determinaciones de las temperaturas de las inclusiones fluidas en calcita pueden no ser concluyentes, por lo que se asigno el rango de temperatura entre $110 \mathrm{y}$ $350^{\circ} \mathrm{C}$ de temperatura y se obtuvo un rango para cada $\delta^{18} \mathrm{O}_{\text {fluido. }}$.

Para calcular el $\delta^{13} \mathrm{C}_{\text {fluido }}$ a partir del $\delta^{13} \mathrm{C}_{\text {calcita }}$ se consideró que $\sum \delta^{13} \mathrm{C}=\delta^{13} \mathrm{H}_{2} \mathrm{CO}_{3}$, debido a que el carbono en estos sistemas hidrotermales a temperaturas como las aquí consignadas, comúnmente se presenta de esta forma (Bagheri et al., 2007). La composición de los carbonatos por lo tanto será aproximadamente la $\delta^{13} \mathrm{C}$ del fluido (Ohmoto, 1972).

Para la determinación del $\delta^{18} \mathrm{O}_{\text {fluido }}$ se utilizó la fórmula de Zeng (1999), a partir de los valores de $\delta^{18} \mathrm{O}_{\text {cal }}$ obtenidos. Al igual que en los casos anteriores se calcularon estos valores considerando las temperaturas máximas y mínimas obtenidas. 


\begin{tabular}{lcccc}
\hline \multicolumn{1}{c}{ Veta } & $\delta^{13} C_{\text {PDB cal }}$ & $\delta^{18} O_{\text {PDB Cal }}$ & $\begin{array}{c}\delta^{18} \mathrm{O}_{\text {PDB }} \\
\text { Fluido }\left(350^{\circ} \mathrm{C}\right)\end{array}$ & $\begin{array}{c}\delta^{18} \mathrm{O}_{\mathrm{PDB}} \\
\text { Fluido }\left(110^{\circ} \mathrm{C}\right)\end{array}$ \\
\hline Liliana $\mathrm{S}$ & $-3,9$ & $-8,27$ & $-12,83$ & $-24,8$ \\
Rumicruz & $-4,07$ & $-6,65$ & $-11,21$ & $-23,18$ \\
Liliana & $-3,38$ & $-9,5$ & $-14,06$ & $-26,03$ \\
Purísima & $-3,38$ & $-5,86$ & $-10,42$ & $-22,39$ \\
Purísima & $-3,31$ & $-6,75$ & $-11,31$ & $-23,28$ \\
Purísima & $-3,05$ & $-6,68$ & $-11,24$ & $-23,21$ \\
\hline
\end{tabular}

Tabla 8- 5. Relaciones isotópicas de carbono (PDB) y oxígeno (PDB y SMOW) en calcitas de las vetas del distrito Purísima-Rumicruz.

Los valores de carbono presentan una distribución muy homogénea y levemente negativos. (Fig. 8-6).

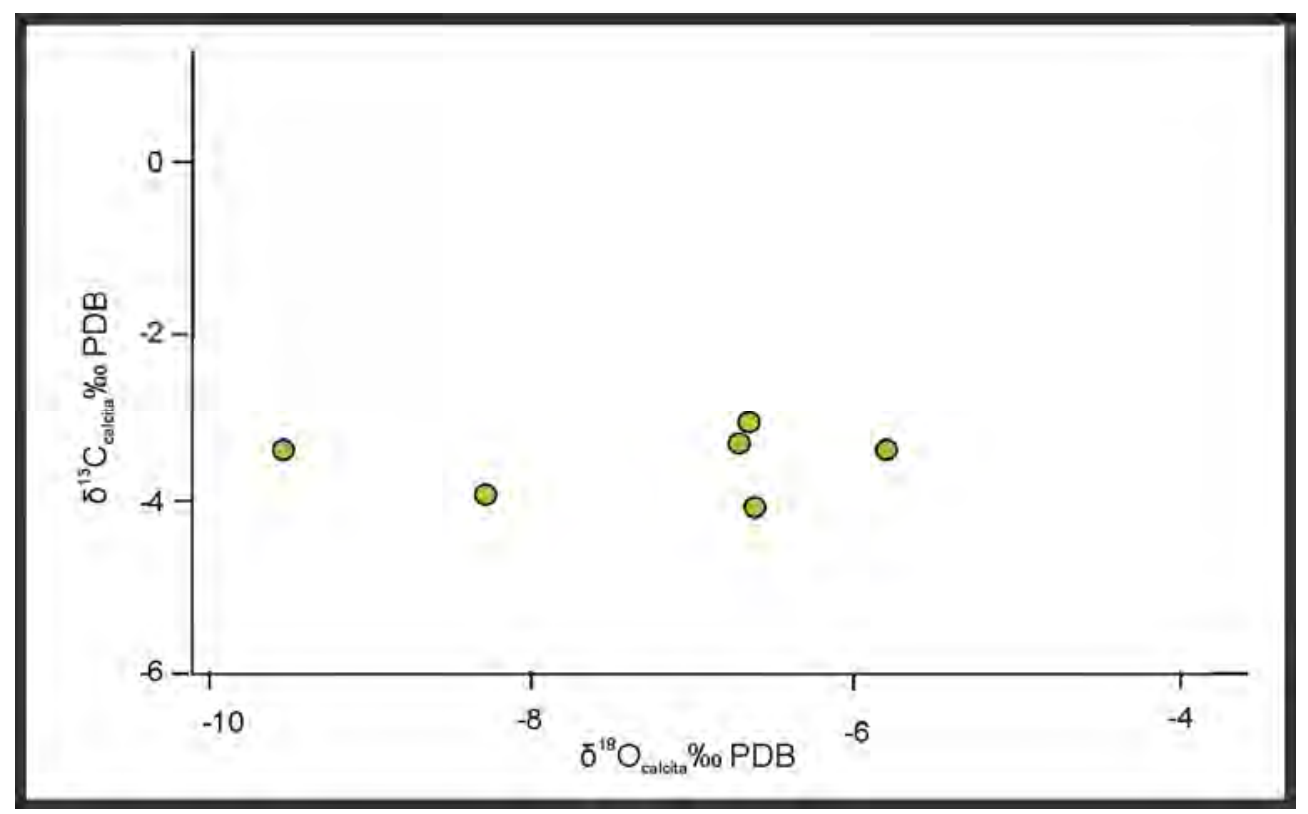

Fig. 8- 6. Relación entre los valores de $\delta^{13} \mathrm{CPDB}$ y $\delta^{18}$ Osmow. 


\section{Discusión}

\section{Isótopos de azufre}

El origen del azufre en depósitos hidrotermales puede relacionarse con fuentes profundas (manto o cortezas homogenizadas) con valores de $\delta^{34} S=0 \%$; de la lixiviación de rocas locales con valores altamente variables; o relacionarse a la reducción (bacteriana o termoquímica) de sulfatos marinos sedimentarios cuya composición isotópica ha variado en el trascurso del tiempo geológico de +11 a $+35 \%$ o (Rye y Ohmoto, 1974) (Fig. 8-7).

Los valores de $\delta^{34} \mathrm{~S}+5 \mathrm{y}+10 \%$ o del $\mathrm{H}_{2} \mathrm{~S}$ asociado a la precipitación del los sulfuros sugiere una fuente del S cortical, no mantélica. (Rye y Ohmoto, 1974). El único proceso capaz de producir valores enriquecidos en ${ }^{34} \mathrm{~S}$ es la reducción de sulfato marino. En los isótopos de azufre es común que el fraccionamiento no se produzca en equilibrio, sino durante reacciones de óxido-reducción o por reducción bacteriana anaeróbica. El sulfato precipitado del agua de mar puede ser reducido a $\mathrm{H}_{2} \mathrm{~S}$ por reducciones termo $\mathrm{u}$ organoquímicas, especialmente en presencia de bacterias reductoras como Disulfovibro desulfuricans (Mysra, 2000). La composición isotópica final del $\mathrm{H}_{2} \mathrm{~S}$ dependerá, entre otros factores, si esta reducción se produjo en un sistema abierto o cerrado; se considera un sistema abierto cuando la tasa de aporte de $\mathrm{SO}_{4}{ }^{=}$es mucho mayor que la tasa de reducción del sulfato. En los sistemas completamente cerrados, el $\delta^{34} S$ del $\mathrm{H}_{2} \mathrm{~S}$ resultará similar al $\delta^{34} \mathrm{~S}$ del $\mathrm{SO}_{4}{ }^{=}$(Ohmoto y Goldhaber, 1997), aunque también pueden darse situaciones de sistemas semicerrados.

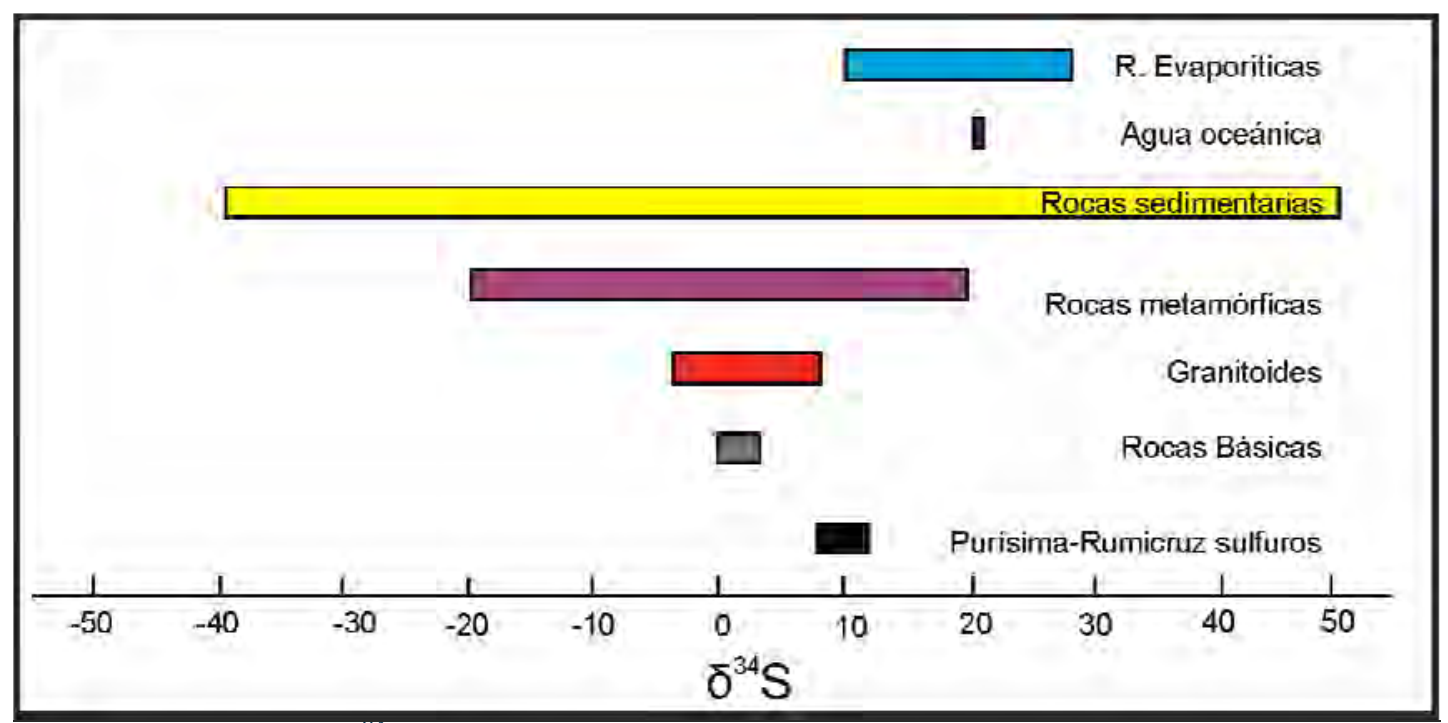

Fig. 8- 7. Valores de ${ }^{34} \mathrm{~S}$ de los sulfuros que componen las vetas del depósito Purísima-Rumicruz, comparados con los valores más frecuentes de las rocas corticales y el agua oceánica. 
Cuando se refiere a sistemas cerrados o semicerrados, se considera que existe una impermeabilidad a la difusión del sulfato disuelto en el sustrato. Cuando la transformación de sulfato a $\mathrm{H}_{2} \mathrm{~S}$ se produce en la superficie o inmediatamente por debajo de esta, el sistema generalmente es abierto. A medida que aumenta la profundidad a la cual se produce esta reacción se produce una transición gradual donde el suministro de sulfato comienza a ser limitado.

El $\mathrm{H}_{2} \mathrm{~S}$ generado puede reaccionar con hierro en las etapas iniciales de diagénesis para formar pirita (Sáez et al., 2011). En este caso, el hierro puede provenir a su vez de la reducción bacteriana de óxidos e hidróxidos presentes en el agua de mar (Ohmoto y Goldhaber, 1997).

Ante la ausencia de evaporitas próximas al distrito, potencial fuente de sulfato pesado reducido, una posibilidad de una fuente de azufre enriquecido en ${ }^{34} \mathrm{~S}$ pueden ser las piritas alojadas en la Formación Acoite, posiblemente por reducción bacteriana y conteniendo valores positivos de $\delta^{34} S$. Los valores positivos y elevados excluyen una fuente magmática para el azufre o, en caso de existir alguna participación de la misma, sería muy reducida respecto a una fuente enriquecida con isótopos pesados del azufre.

La baritina usualmente presenta valores de $\delta^{34} S$ considerablemente mayores que los de sulfuros. Esto es debido a que el fraccionamiento isotópico entre el $\mathrm{SO}_{4}{ }^{\circ} \mathrm{y} \mathrm{H}_{2} \mathrm{~S}$ en el equilibrio es elevado (e.g. a $200^{\circ} \mathrm{C}$ el fraccionamiento es de $29 \%$ ) (Ohmoto y Rye, 1979). De las dos muestras analizadas, puede observarse que una de ellas presenta valores coincidentes con los $\delta^{34} \mathrm{~S}$ de los sulfuros $(+7 \%$ ), mientras que la otra arrojó un valor considerablemente mayor $(+13 \%)$, este último puede corresponderse con una precipitación a partir de sulfato equilibrado isotópicamente con $\mathrm{H}_{2} \mathrm{~S}$.

El $\mathrm{BaSO}_{4}$ es una sustancia muy insoluble, por lo tanto, es incompatible el transporte del $\mathrm{Ba}^{+2}$ y el $\mathrm{SO}_{4}{ }^{=}$en una misma solución hidrotermal. Para generar las concentraciones determinadas en el distrito Purísima-Rumicruz se plantean dos escenarios; (a) el $\mathrm{SO}_{4}$ y el $\mathrm{Ba}$ se encontraban en fluidos distintos, que al mezclarse produjo una rápida saturación en $\mathrm{BaSO}_{4}$ generándose la precipitación de baritina; o (b) el origen de esta baritina podría ser supergénico, producto de la oxidación completa de los sulfuros, en cuyo caso no existiría fraccionamiento. En el caso de la baritina con el valor de $+7 \%$, esta última explicación sería la más probable. No pueden descartarse entonces dos generaciones distintas de baritina, que explicarían así las diferencias isotópicas obtenidas en las muestras analizadas. 


\section{Isótopos de oxígeno}

Los valores de $\delta^{18} \mathrm{O}_{\mathrm{H}_{2} \mathrm{O}}$ obtenidos sobre cuarzo en las vetas de cuarzo dominante comprenden un rango entre 6,6 y 9,5\% mientras que el de las vetas polimetálicas entre 5,2 y $8 \%$. Estos valores correspondientes al fluido hidrotermal a partir del cual precipitaron los minerales analizados no son diagnósticos de una fuente particular del fluido (Fig. 8-8). Composiciones similares pueden corresponder a fluidos de origen magmático típicamente de +5 a +10\% (Shepard, 1986). Una explicación alternativa podrías ser la de un fluido de origen superficial (meteórico o marino), que hubiera interactuado con los fluidos connatos a temperaturas entre 200 y $300^{\circ} \mathrm{C}$. Los valores de $\delta^{18} \mathrm{O}_{\mathrm{H}_{2} \mathrm{O}}$ en calcita comprende un rango más amplio, entre 4,6 y $20 \%$, esta amplitud es debida a que los cálculos fueron efectuados para las temperaturas máximas y mínimas obtenidas a partir de las inclusiones fluidas. Una posible explicación de los valores elevados de $\delta^{18} \mathrm{O}_{\mathrm{H}_{2} \mathrm{O}}$ en calcita podrían deberse a la interacción agua/roca del fluido hidrotermal a medida que evolucionó el sistema.

Las altas salinidades de las inclusiones fluidas, así como también la presencia de $\mathrm{CaCl}_{2}$ en las mismas, tampoco son discriminadoras del origen del fluido. Valores elevados en la salinidad de las inclusiones y la presencia de $\mathrm{CaCl}_{2}$ pueden encontrarse tanto en fluidos de origen magmático como en fluidos hidrotermales originados a partir de aguas connatas.

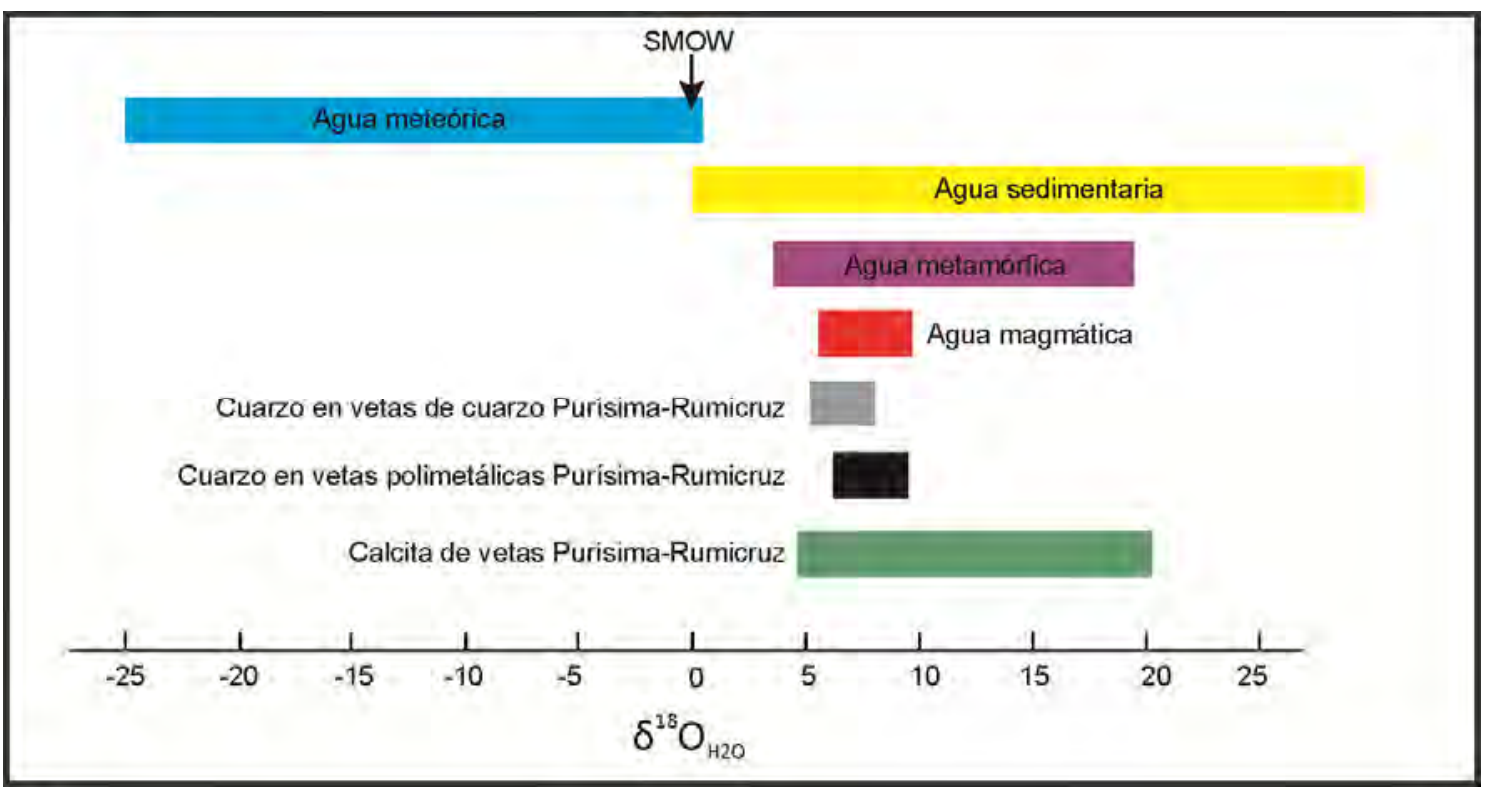

Fig. 8- 8. Comparación de las composiciones isotópicas de la $\delta^{18} \mathrm{O}_{\text {fluidos }}$ en las vetas del distrito PurísimaRumicruz con las principales fuentes de aguas presentes en la corteza. 


\section{$\underline{\text { Isótopos de carbono }}$}

Los valores ligeramente negativos $\left(-3\right.$ a $-4 \%$ ) del ${ }^{13} \mathrm{C}$ en los carbonatos sugieren una fuente cortical probablemente resultado de la interacción de los fluidos con carbonatos sedimentarios con participación de materia orgánica (Ohmoto y Goldhaber, 1997). Debido a que los tenores de la $\delta^{13} \mathrm{C}$ muestran una distribución restringida con valores levemente livianos, se interpreta que el carbón originado a partir de materia orgánica no ha jugado un rol significativo en el fluido hidrotermal (Fig. 8-9).

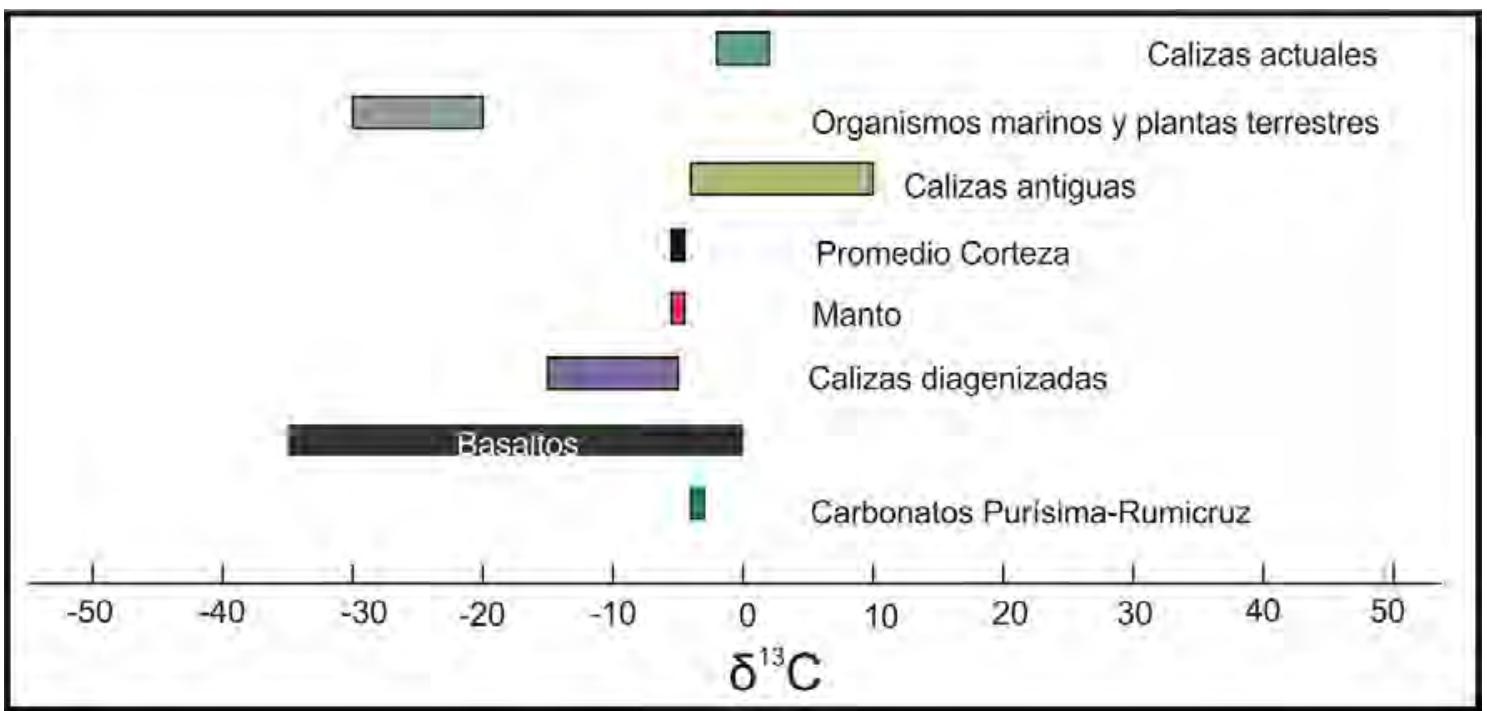

Fig. 8- 9. Rangos composicionales de ${ }^{13} \mathrm{C}$ en distintos ambientes geológicos y en los carbonatos de las vetas del distrito Purísima-Rumicruz. 


\section{Introducción}

Los isótopos son elementos que poseen un mismo número atómico, pero diferente masa atómica. Algunos elementos tienen isótopos que son inestables y con el paso del tiempo, decaen en otros elementos, liberando radiación. La tasa de decaimiento radioactivo solo depende del estado de energía del nucleido. El decaimiento es un proceso estocástico, es imposible predecir cuando un núcleo decaerá, sin embargo es posible calcular la probabilidad de decaer en un tiempo dado.

Los isótopos radioactivos pueden utilizarse para determinar la edad de un evento o proceso geológico (e.g. cristalización de un magma, mineralización, alteración, metamorfismo, etc.), así como para establecer la fuente de los fluidos y reconstruir la historia geológica de las soluciones hidrotermales. Cuando se aplican estas técnicas sobre depósitos hidrotermales, las precauciones en la interpretación han de extremarse. Esto se debe a que las historias de los sistemas hidrotermales presentan complejidades geológicas, térmicas y químicas y son habituales las sobreimposiciones de episodios sucesivos.

Han de asumirse dos premisas al utilizar las relaciones isotópicas radigénicas. En primer lugar, el sistema debe estar homogenizado en el tiempo inicial o tiempo $0\left(\mathrm{t}_{0}\right)$, es decir que en ese momento existe equilibrio isotópico y que la relación isotópica inicial de los elementos debe ser similar en todos los puntos del sistema. En segundo lugar, el sistema debe permanecer cerrado entre el $t_{0} y$ el presente, es decir que no hubo ingreso ni egreso del material parental ni hijo del sistema.

\section{Plomo-Plomo}

Los isótopos de plomo en los depósitos hidrotermales son utilizados frecuentemente para establecer la fuente del plomo y por lo tanto determinar el origen de los metales y del fluido mineralizante. A su vez, las relaciones isotópicas pueden postular una edad modelo de la mineralización. En este apartado se presentarán los resultados obtenidos sobre seis muestras de calcosina y cinco de galena 


\section{$\underline{\text { Resultados }}$}

Las composiciones isotópicas de las muestras analizadas son relativamente homogéneas, con relaciones ${ }^{206} \mathrm{~Pb} /{ }^{204} \mathrm{~Pb}$ entre 18,316 y $18,559,{ }^{207} \mathrm{~Pb} /{ }^{204} \mathrm{~Pb}$ entre 15,616 y 15,642 y para el ${ }^{208} \mathrm{~Pb} /{ }^{204} \mathrm{~Pb}$ entre 38,422 y 38,528 . (Tabla $8-6$ ).

\begin{tabular}{|c|c|c|c|c|c|c|c|c|}
\hline Veta & Muestra & Mineral & ${ }^{206} \mathrm{~Pb} /{ }^{204} \mathrm{~Pb}$ & Error \%(1ס) & ${ }^{207} \mathrm{~Pb} /{ }^{204} \mathrm{~Pb}$ & Error \%(1ס) & ${ }^{208} \mathrm{~Pb} /{ }^{204} \mathrm{~Pb}$ & Error \%(1ס) \\
\hline Jesuitas & $14510 a$ & Galena & 18,319 & 0,007 & 15,631 & 0,009 & 38,469 & 0,011 \\
\hline Jesuitas & $14510 b$ & Galena & 18,337 & 0,005 & 15,642 & 0,006 & 38,521 & 0,006 \\
\hline Rumicruz & $14502 a$ & Galena & 18,328 & 0,007 & 15,637 & 0,007 & 38,494 & 0,008 \\
\hline Rumicruz & $14502 b$ & Galena & 18,330 & 0,013 & 15,642 & 0,015 & 38,502 & 0,017 \\
\hline Rumicruz & $14502 c$ & Galena & 18,316 & 0,006 & 15,624 & 0,006 & 38,446 & 0,007 \\
\hline La Nueva & $6848 a$ & Calcosina & 18,395 & 0,006 & 15,648 & 0,006 & 38,528 & 0,006 \\
\hline La Nueva & $6848 b$ & Calcosina & 18,366 & 0,006 & 15,642 & 0,007 & 38,508 & 0,007 \\
\hline La Nueva & $6848 c$ & Calcosina & 18,367 & 0,005 & 15,616 & 0,005 & 38,422 & 0,006 \\
\hline Purísima & $6914 a$ & Calcosina & 18,536 & 0,008 & 15,633 & 0,008 & 38,460 & 0,009 \\
\hline Purísima & $6914 b$ & Calcosina & 18,559 & 0,008 & 15,640 & 0,010 & 38,477 & 0,012 \\
\hline El Brechón & $6920 a$ & Calcosina & 18,455 & 0,009 & 15,642 & 0,009 & 38,524 & 0,010 \\
\hline
\end{tabular}

Tabla 8- 6. Relaciones isotópicas de ${ }^{206} \mathrm{~Pb} /{ }^{204} \mathrm{~Pb},{ }^{207} \mathrm{~Pb} /{ }^{204} \mathrm{~Pb}$ y ${ }^{208} \mathrm{~Pb} /{ }^{204} \mathrm{~Pb}$ en sulfuros de las vetas Jesuitas, Rumicruz, La Nueva Purísima y El Brechón.

\section{$\underline{\text { Interpretación }}$}

Las razones isotópicas contrastadas en el diagrama uranogénico, que vincula los isotopos radiogénicos producidos por el uranio (Zartman y Doe, 1981), evidencian que la fuente principal de los metales presenta una muy fuerte afinidad con los valores correspondientes a la corteza superior (Fig. 8-10). Este diagrama demuestra que si bien puede existir mezcla en las fuentes, hay una clara preponderancia cortical de las características isotópicas de las muestras del distrito Purísima-Rumicruz.

El diagrama toriogénico (Zartman y Doe, 1981), que vincula ${ }^{208} \mathrm{~Pb} /{ }^{206} \mathrm{~Pb}$ es sumamente útil para diferenciar dentro de la corteza, si la fuente presenta una filiación cortical superior o inferior. Los resultados de las muestras analizadas ratifican que la fuente del plomo presente en el fluido hidrotermal, provino principalmente de la corteza superior (Fig. 8-9).

La edad modelo fue representada en el gráfico de Stacey \& Krammers (1975) (Fig. 8-11), en el mismo se observa como la línea media de los valores de las muestras proveniente de la mineralización intercepta la curva de evolución de isótopos de Pb. La línea de correlación para la obtención de la edad modelo intercepta en 235 Ma. (Triásica Medio), para la actividad hidrotermal formadora de la mineralización polimetálica sulfurada presente en el área de estudio. Sin embargo la dispersión de las 
muestras es muy amplia con un MSDW de 113, este valor imposibilita asignar un rango de error por lo que la edad obtenida solo es una aproximación indicativa de la edad de la mineralización.

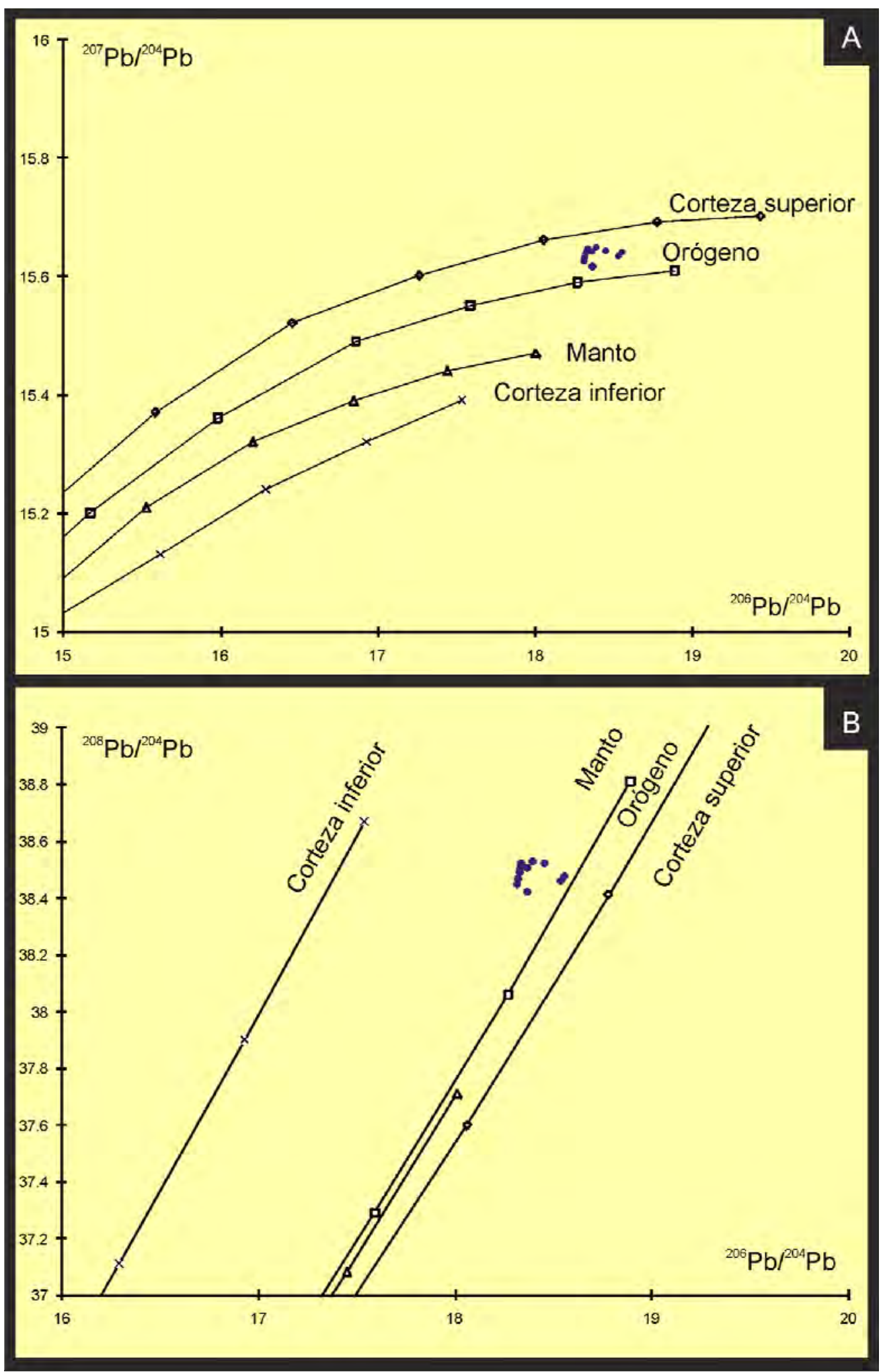

Fig. 8- 10. A. Las composiciones isotópicas obtenidas se disponen entre las curvas del orógeno y la corteza superior en el diagrama Uranogénico. B. Diagrama Toriogénico donde se discrimina principalmente la afinidad a la corteza superior o inferior. Modificado de Zartman y Doe (1981). 


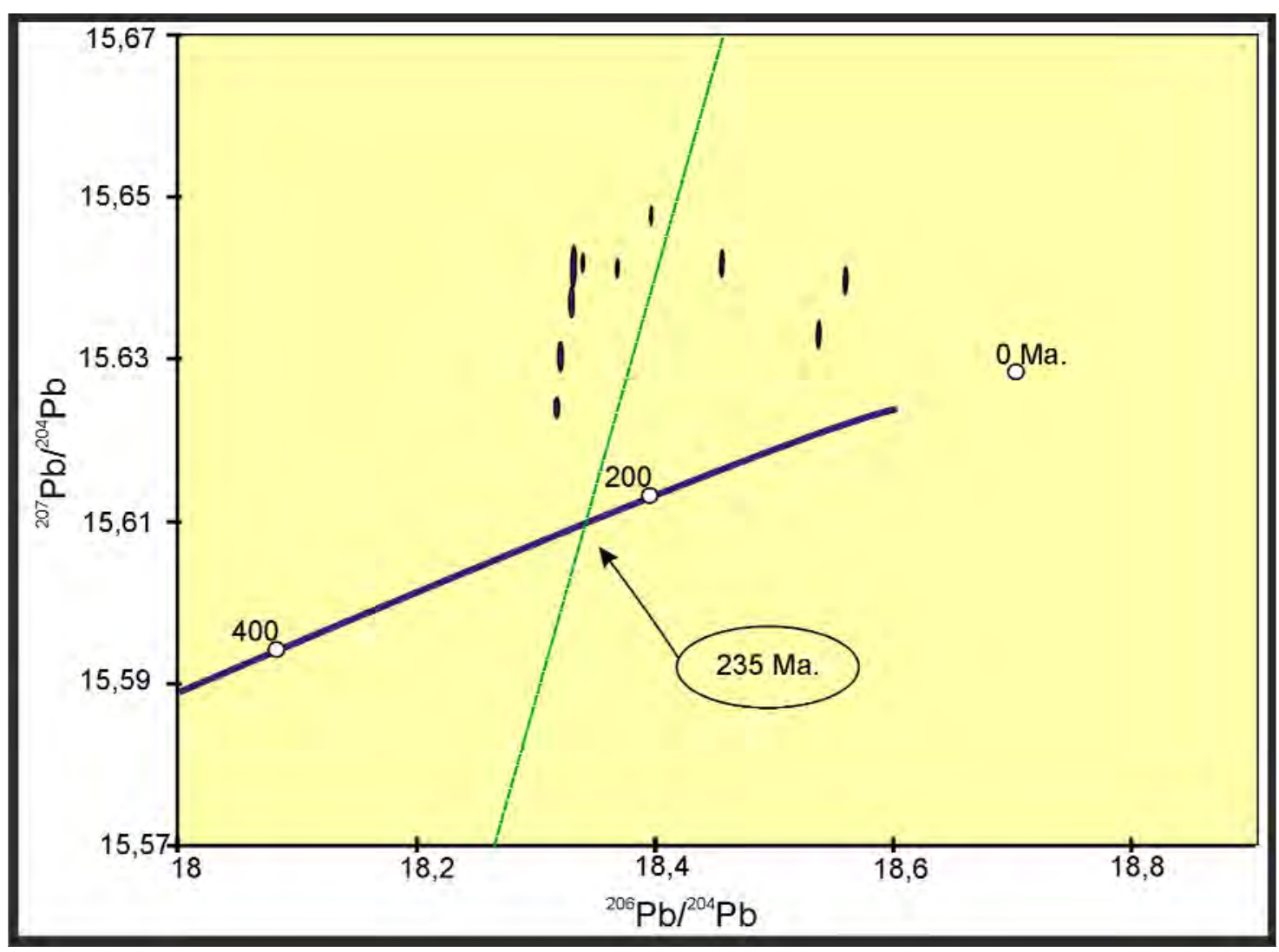

Fig. 8- 11. Edad modelo ${ }^{207} \mathrm{~Pb} /{ }^{206} \mathrm{~Pb}$ del depósito Purísima Rumicruz.

Es notable, sin embargo, que la edad modelo obtenida es coincidente con la edad $\mathrm{Pb}-\mathrm{Pb}$ de las vetas de Pumahuasi (Sangster y Sangster, 2002), y considerablemente más joven que la determinada para el yacimiento Aguilar de $480 \mathrm{Ma}$. (Gemmel et al., 1992), coincidente con la depositación de la Formación Acoite. 
Sintetizando lo anteriormente expuesto y si bien algunas de las interpretaciones no son totalmente concluyentes, pueden realizarse las siguientes consideraciones, vinculando los datos obtenidos mediante las distintas técnicas empleadas:

- Los minerales precipitaron a partir de un fluido hidrotermal con temperaturas moderadas a bajas, entre 350 y $110^{\circ} \mathrm{C}$. Los fluidos mineralizantes presentaban una salinidad moderada $\sim 7 \%$ peso $\mathrm{NaCl}$ eq. para el cuarzo a altas $\sim 20 \%$ peso $\mathrm{NaCl}$ eq para los carbonatos. Los valores de temperatura de homogenización de los carbonatos estarían modificados por procesos pos-entrampamiento tal como se desprende de la interpretación de las inclusiones fluidas.

- Las vetas del distrito Purísima-Rumicruz, son producto de sucesivos eventos de brechamiento-precipitación. Este mecanismo es evidenciado por en las texturas de las brechas que componen las vetas. Estas brechas presentan clastos de roca de caja cementados por minerales precipitados de una solución hidrotermal. Este conjunto a su vez es rebrechado sucesivamente, por fracturación mecánica (alta distribución de tamaño de clastos) acompañado por corrosión química (clastos de sulfuros redondeados).

- La precipitación de los minerales pudo desencadenarse por una serie de procesos físico-químicos como variaciones en la temperatura, presión, fugacidad, $\mathrm{pH}$, ebullición, entre otros. Definir con certeza el mecanismo de precipitación para la mineralización es arriesgado en base a los datos parciales con los que se cuenta, incluso pueden haber sido diferentes procesos para los distintos pulsos o etapas de mineralización. Al describir la textura del cuarzo, se mencionó el reemplazo de cuarzo por platy calcita, esta textura en los sistemas epitermales evidencia la ebullición de los fluidos (Dong et al., 1995; Simmons y Christenson, 1994; Simmons, 2000). Esta ebullición está ligada a la exsolución de la fase gaseosa del fluido hidrotermal debido a descompresión. Sin embargo en la calcita precipitada posteriormente no se ha encontrado evidencias de este tipo. Para la baritina se interpretó dos procesos posibles, en primera instancia, la precipitación de baritina a partir de sulfato equilibrado isotópicamente con $\mathrm{H}_{2} \mathrm{~S}$ y por lo tanto, con valores isotópicamente más pesado. En una segunda instancia la precipitación de la baritina podría estar vinculada a procesos de oxidación completa de sulfuros, donde no existiría fraccionamiento y la composición isotópica de la baritina tendría valores similares tanto en este sulfato como en los sulfuros que lo originaron. 
Para el resto de los minerales, no es posible definir con certeza los mecanismos de precipitación.

- La solución hidrotermal circuló por un sistema de fracturas subverticales que registró sucesivos episodios de cizallamiento. El fluido hidrotermal que circuló por estas fracturas, manifestó modificaciones en su composición química. Como fue mencionado en los apartados de la mineralogía y geoquímica, la fugacidad del azufre no fue constante en relación a la del arsénico. Asimismo el aumento en la fugacidad del As tiene una correlación positiva con la precipitación de elementos como Ni, Co y U. Previamente y posteriormente a esta etapa la fugacidad del As es baja en comparación con el azufre, y los metales que precipitan preponderantemente son $\mathrm{Pb}$, Cu y Zn.

- Se interpreta un origen cortical de los metales que probablemente haya sido generado en la corteza superior. Esto es sustentado principalmente por los datos de $\mathrm{Pb}-\mathrm{Pb}$ y es acorde con los resultados de los isótopos estables. Se descarta por lo tanto una filiación de los metales provenientes de un magmatismo básico-ultrabásico. Una interpretación del origen de los metales que se ajuste a los valores de los isótopos estables podría sugerir que tanto el azufre, como los metales provienen de la roca encajante de la mineralización, sin embargo, no puede descartarse un posible aporte magmático al fluido hidrotermal. 


\section{CAPITULO IX}

MODELO METALOGENÉTICO 


\section{ORIGEN, TRANSPORTE Y PRECIPITACION DE LOS METALES Y}

\section{FLUIDOS HIDROTERMALES}

Uno de los principales objetivos de esta investigación metalogenética fue determinar la evolución de los fluidos hidrotermales, desde su generación y transporte hasta los procesos que condujeron a la precipitación de las especies minerales derivadas de ellos. Se entrelazan así las consideraciones efectuadas sobre los fluidos hidrotermales, la mineralogía y geoquímica, la geología estructural, el ambiente geotectónico y las características de la roca encajante, con el fin de generar aportes para la resolución de estos interrogantes, y sobre esta base, proponer un escenario integrador y un modelo genético para la mineralización de las vetas del depósito Purísima-Rumicruz.

\section{Origen}

Los depósitos hidrotermales deben su origen a la circulación de fluidos en la corteza terrestre y a la capacidad que tienen estas soluciones de remover, transportar y concentrar metales que revisten importancia económica (Robb, 2004). Los fluidos que generan este tipo de concentraciones pueden originarse a partir de diversas fuentes: magmáticas, marinas, metamórficas, meteóricas, de aguas formacionales (Fig. 9-1) o una mezcla de estas (Misra, 2000).

El agua que es alojada en poros de las rocas sedimentarias, sin implicancias genéticas, es denominada agua formacional. Se diferencia de las aguas connatas que son las que quedaron atrapadas en los espacios porales de los sedimentos en el momento de su formación.

Para el depósito polimetálico Purísima-Rumicruz ha sido establecido, sobre la base de los estudios isotópicos, detallados en el capítulo VIII, que la fuente de los metales fueron derivados de la corteza superior. Respecto a los fluidos hidrotermales, estos podrían asignarse a una fuente sedimentaria, aunque no puede descartarse el aporte de aguas magmáticas. Sin embargo, ha sido señalado oportunamente la ausencia de afloramientos de rocas ígneas intrusivas o extrusivas a los que pueda vincularse directamente la mineralización.

El análisis de los datos isotópicos de azufre permitió interpretar que ha sido derivado probablemente de las pelitas negras de la Formación Acoite. En este sentido, 
los valores isotópicos de oxígeno son coherentes con una fuente de agua sedimentaria o magmática.

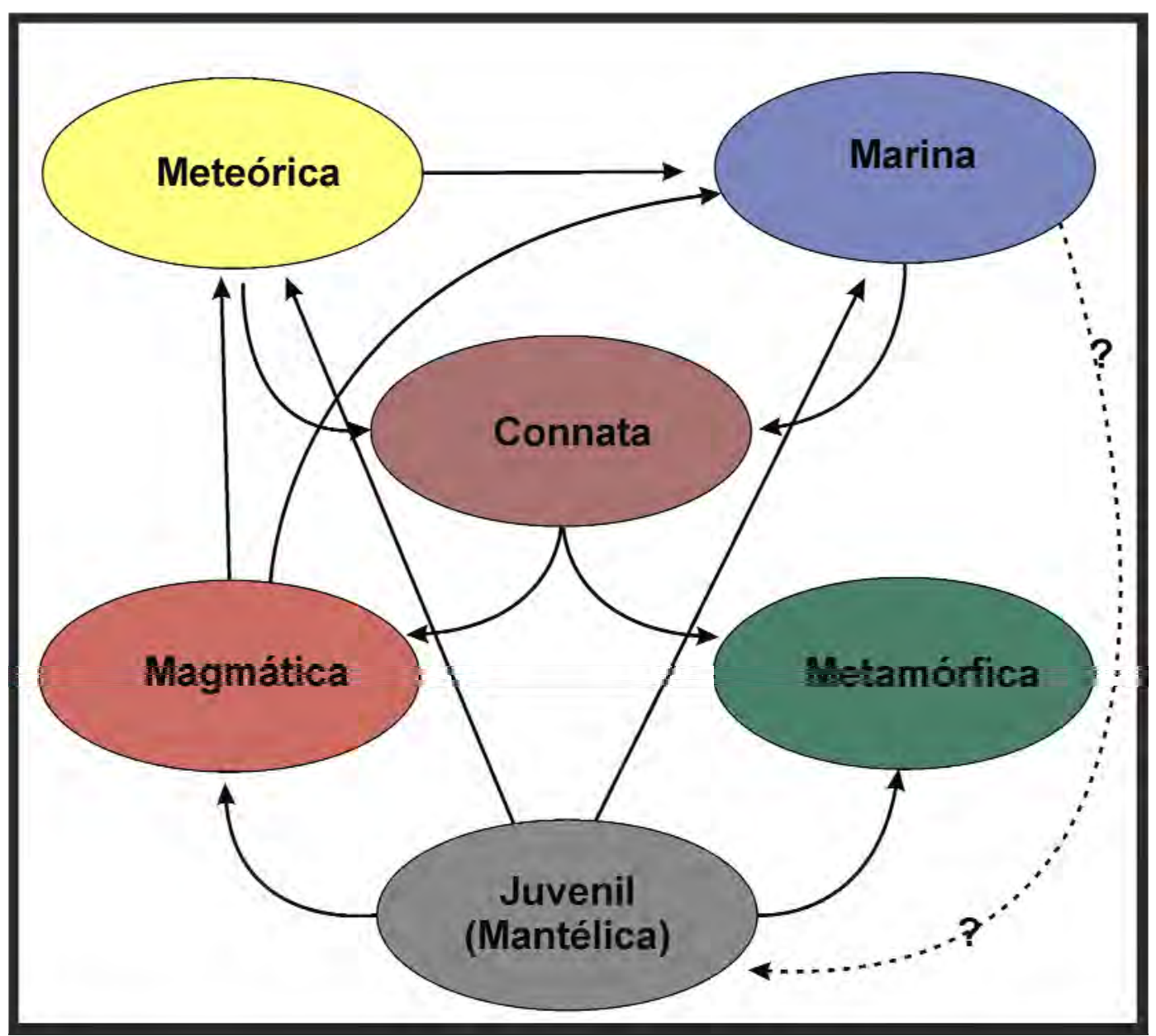

Fig. 9 - 1. Modelo simplificado de los reservorios que contribuyen agua a las soluciones hidrotermales, con flechas se señala las posibles mezclas y caminos evolutivos, modificado de Bodnar (1999).

La salinidad de los fluidos hidrotermales del distrito Purísima corresponde a valores elevados entre 5 y 12\% en peso $\mathrm{NaCl}$ eq para el cuarzo y $\sim 20 \%$ en peso $\mathrm{NaCl}$ eq. para la calcita. Valores como estos, e incluso mayores, han sido frecuentemente registrados en perforaciones profundas de cuencas sedimentarias actuales (Munz et al., 1995). El origen de la salinidad de las aguas connatas es controversial, algunas teorías proponen que es producto de la evaporación de agua marina alojada en los poros de las arcillas, debido a la disolución de evaporitas, al efecto "membrana" en pelitas (shale membrane filtration) o a procesos diagenéticos (Tornos y Heinrich, 2008).

Por otro lado, los resultados de los análisis geoquímicos sobre muestras de pelitas negras de la Formación Acoite, exhibieron elevados valores en $\mathrm{Ba}, \mathrm{Cu}, \mathrm{Pb}, \mathrm{Ag}, \mathrm{As}, \mathrm{Ni}$, 
Zn, U y S. Por lo tanto, estas rocas presentan la potencialidad química de haber constituido la fuente de los elementos constituyentes de la mineralización metalífera de las vetas del distrito Purísima-Rumicruz. Considerando los análisis geoquímicos efectuados en las pelitas de la Formación Acoite, las muestras exhibieron contenidos relativamente bajos en cobalto, respecto a los valores promedio de la corteza superior. Esta deficiencia en cobalto es también registrada en la paragenesis del distrito, donde los sulfoarseniuros identificados corresponden a minerales de níquel con contenidos menores de cobalto.

Como corolario, se propone que la fuente más probable de los fluidos y los metales hayan sido aguas formacionales, intracuencales, prevenientes de la Formación Acoite. Ha de contemplarse también que los fluidos no prevengan exclusivamente de esta unidad y que tengan participación reservorios connatos más profundos. Estas soluciones habrían interactuado geoquímica e isotópicamente con las pelitas de la Formación Acoite. Una alternativa que no puede descartarse con los datos expuestos es el aporte de aguas magmáticas a los fluidos hidrotermales.

El origen de estos fluidos, entonces, podría ser aguas connatas de origen meteórico o marino que han sufrido modificaciones sustanciales por procesos diagenéticos (compactación o litificación). Las pelitas, inicialmente muy porosas, pueden generar 3.500 I de fluido por $\mathrm{m}^{3}$ en los primeros estadios diagenéticos (Hanor, 1979), a medida que aumenta la presión y temperatura, se agrega el agua estructural de los argilominerales. (Robb, 2004) (Fig. 9-2).

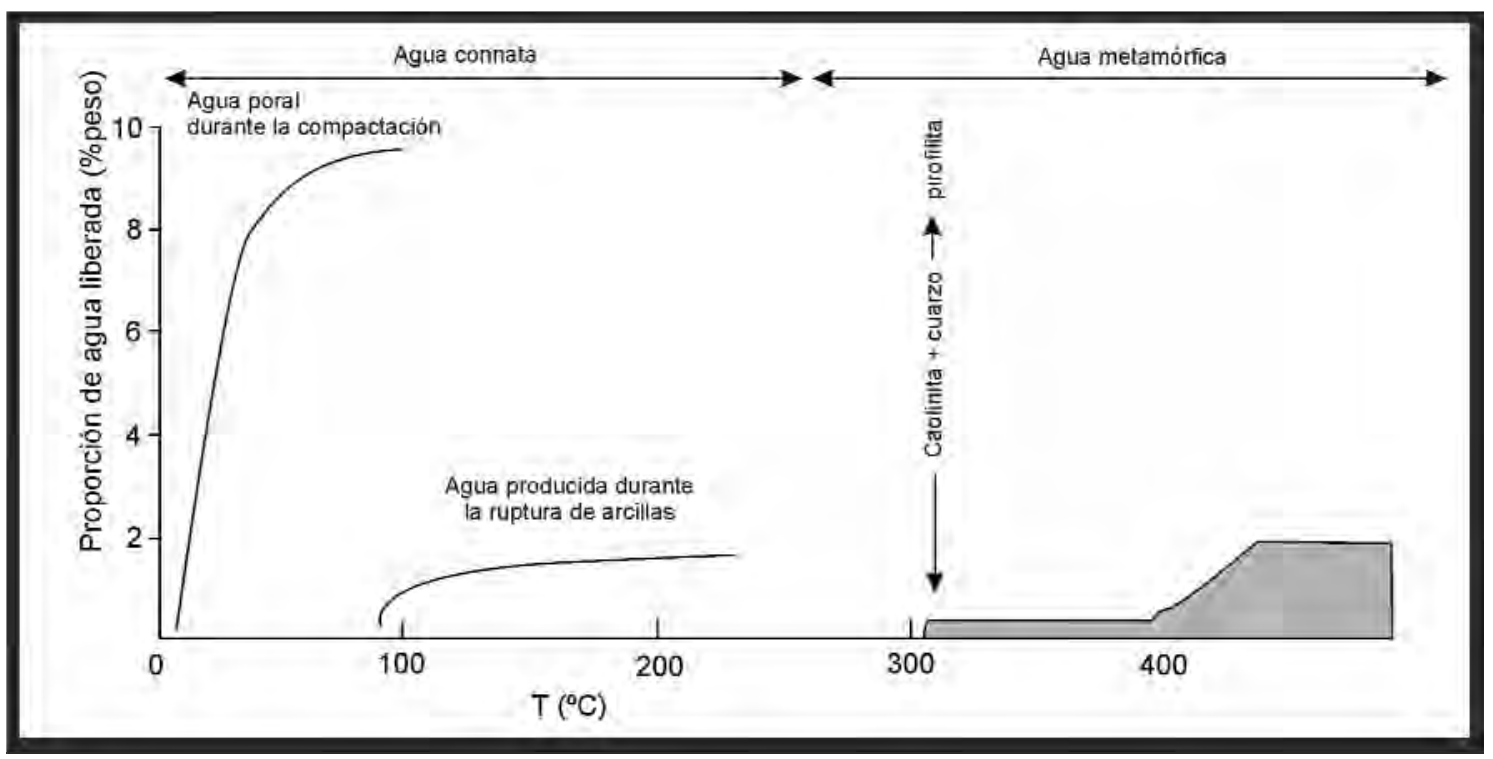

Fig. 9-2. Diagrama que vincula la proporción de agua liberada en función de la temperatura. En las etapas iniciales de la diagénesis se produce la mayor liberación de agua debido a la compactación. Modificado de Stevens et al. (1997) y Robb (2004) 
Durante los eventos de máxima inundación (maximum flood surface), ambiente de sedimentación interpretado para la Formación Acoite (Moya, 2008), son comunes en el interior de la cuenca las pelitas negras, que pueden estar enriquecidas en elementos metálicos (Sáez et al., 2011) y convertirse en roca fuente para la generación de fluidos metalíferos (Ruffell, 1998) (Fig. 9-3). En las secciones condensadas que se producen bajo esta configuración, pueden ser concentrados elementos radioactivos como el $\mathrm{U}$ y el Th, mientras que el $\mathrm{Cu}$ y el Co pueden ser fijados mediante acción bacteriana en la diagénesis temprana (Ruffell, 1998).

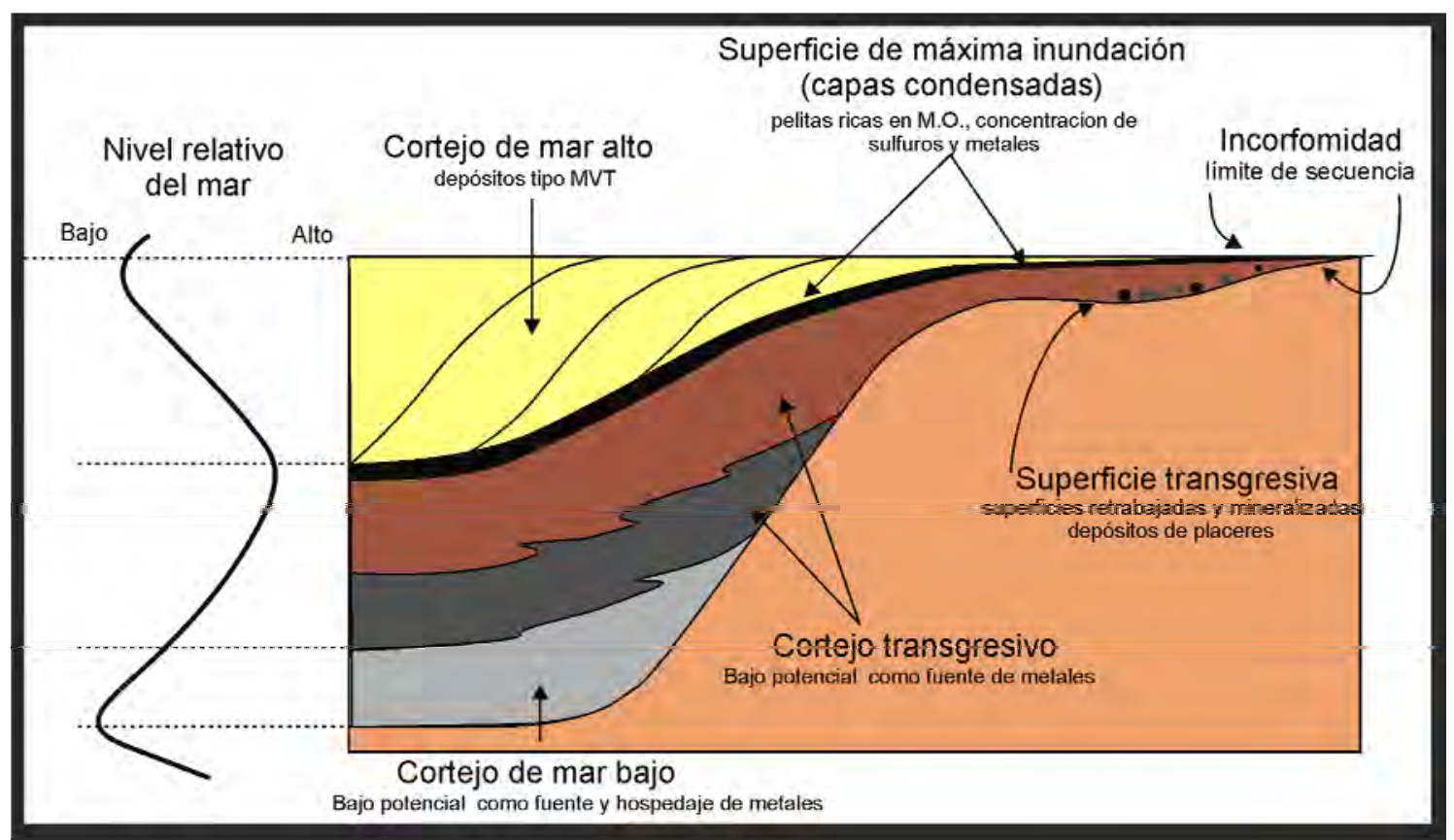

Fig. 9-3. Vinculación entre el potencial metalogenético y los diferentes cortejos sedimentarios, desde una perspectiva estratigráfico-secuencial. Los depósitos sedimentarios vinculados a las etapas finales del cortejo transgresivo y a la superficie de máxima inundación pueden ser portadores de concentraciones metalíferas. Modificado de Ruffel (1998).

\section{Transporte}

Para la circulación y el ascenso de fluidos hidrotermales en la corteza superior es preciso que una fuente energética produzca este movimiento. Esta energía puede provenir por una diferencia de densidad de los fluidos, generada por una fuente de calor (Smith, 1996, en Staude et al., 2009) o por la presencia de domos salinos (Wilkinson et al., 2005). También pueden ser factores relevantes los canales abiertos debido a extensión cortical acompañado de fallamiento normal; la sobrepresión producto de reacciones diagenéticas o a gradientes topográficos a escala cuencal (Garven y Raffensperger, 1997; Carmona, 2000) (Fig. 9-4). 
Asimismo, un posible mecanismo de transporte de soluciones hidrotermales es debido al "bombeo de fluido" (fluid pumping) (Sibson et al., 1975). Cuando se produce una ruptura, el esfuerzo de cizalla disminuye drásticamente pero la presión de fluido aumenta, resultando en una expulsión del fluido a lo largo de la falla (Robb, 2004; Olivares et al., 2010). Al reinstaurarse las fuerzas de fricción el esfuerzo de cizalla aumenta nuevamente y el ciclo puede volver a repetirse. Un proceso semejante ha sido registrado a escala granular (granular fluid pump) en condiciones de alta temperatura y presión (Fusseis et al., 2009).

Como se ha mencionado en los capítulos IV y VI, las vetas del distrito PurísimaRumicruz se alojan en zonas de cizalla, con evidencias de múltiples pulsos de brechamiento mecánico/hidráulico. Por lo tanto, se propone que la generación y/o reactivación de estas fallas proporcionó la permeabilidad secundaria y el mecanismo de ascenso de soluciones hidrotermales portadores de metales.

En igual sentido, los procesos de rifting continental son escenarios favorables para la circulación de fluidos corticales. En primer lugar, la instalación de un ambiente tectónico activo promueve la generación de zonas extensionales y de fracturas que favorecen el ascenso de los fluidos. En segundo lugar, se establecen anomalías en el gradiente geotérmico debido al adelgazamiento cortical, que pueden ser intensificadas por la instalación de cuerpos intrusivos. En tercer lugar, la exhumación de rocas puede producir una liberación de fluidos porales debido a la diferencia de compresión que existe entre estos fluidos y la roca que los contiene (Staude et al., 2009). El ascenso de los fluidos a partir de fallas normales mayores y de rumbo en sistemas de rifting puede ocurrir rápidamente, (i.e. semanas o meses) (Wagner et al., 2009).

Los fluidos hidrotermales son soluciones electrolíticas multicomponentes donde los metales están presentes en concentraciones trazas formando predominantemente iones complejos (Seward y Barnes, 1997). Esto es debido a la baja solubilidad que presentan los elementos como iones aislados, que se incrementa notoriamente con la formación de complejos. El anión más común en los fluidos hidrotermales es el $\mathrm{Cl}^{-}$por lo tanto los metales suelen formar complejos clorurados, sin embargo esto puede variar de acuerdo al comportamiento químico de los elementos. El transporte de los metales considerados como metales débiles $\left(\mathrm{Zn}^{+2}, \mathrm{~Pb}^{+2}, \mathrm{Fe}^{+2}\right)$ o los denominados metales límite (borderline) $\left(\mathrm{Ag}^{+}, \mathrm{Cu}^{+}\right)$, según su comportamiento como ácido o base, es probable que haya sido como complejos clorurados. Mientras que los considerados metales fuertes (As, $U$ ) probablemente hayan sido transportados asociados a bases fuertes como $\mathrm{O}_{2}{ }^{2}, \mathrm{OH}^{-} \mathrm{O} \mathrm{CO}_{3}{ }^{2}$ (Seward y Barnes, 1997; Robb, 2004). El distrito 
Purísima-Rumicruz presenta calcita como ganga predominante, por lo tanto es probable que el $\mathrm{U}^{+4}$ hayan sido transportados como complejos carbonatados. Este elemento junto con los elementos de tierras raras exhiben una alta afinidad para la formación de complejos carbonatados (Ondruš et al., 2003a; 2003b; Dolníček et al., 2008; Bagheri, 2009).

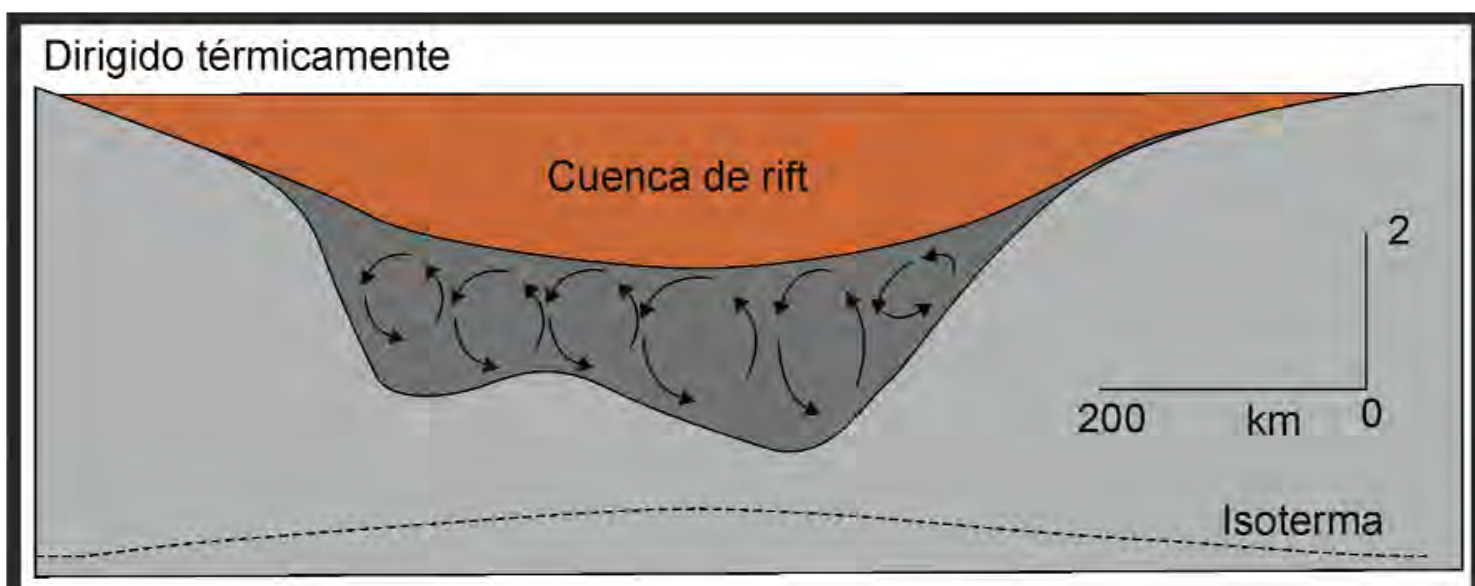

Dilatancia/dirigido por fallas

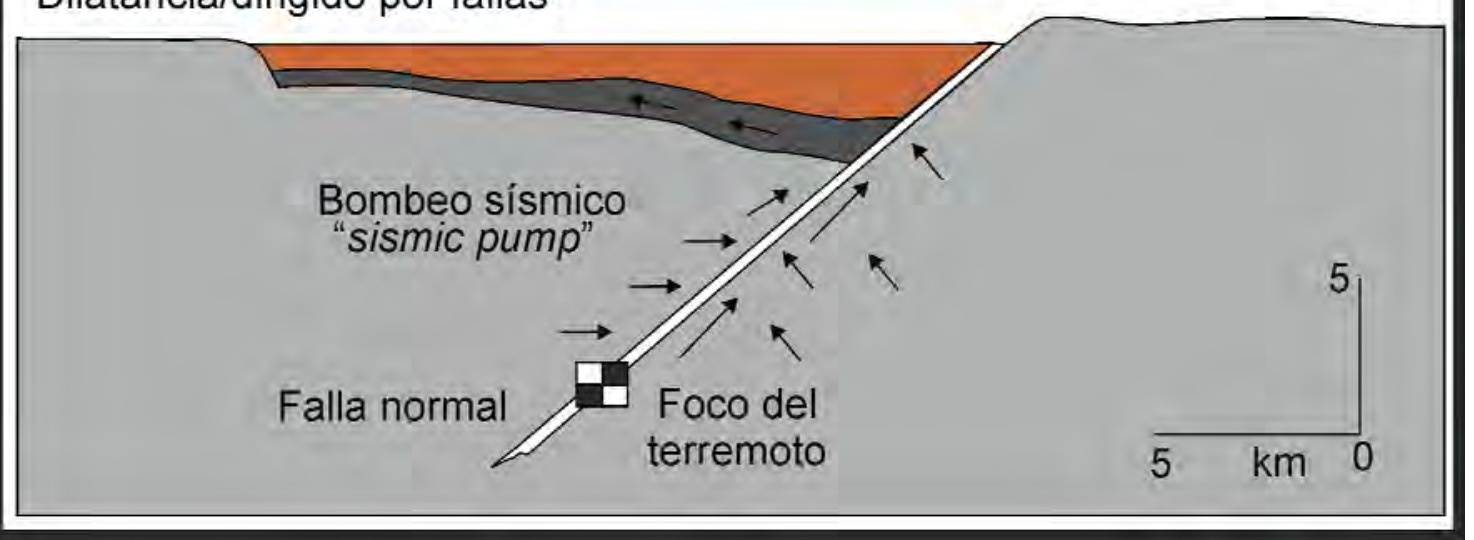

Fig. 9-4. Escenarios de circulación de fluidos en eventos de rift. Se muestra la dinámica de los fluidos "dirigidos térmicamente" por un ascenso astenosférico, afectando las isotermas, (superior). Los fluidos que circulan por bombeo de fluido pueden ser localmente importantes (inferior).

\section{Precipitación}

La precipitación de los metales se produce cuando, debido a cambios en el fluido hidrotermal, se provoca la disociación de los complejos metálicos. Estos cambios pueden desencadenarse por procesos físico-químicos (temperatura, presión, pH, Eh, adsorción) o por la acción de microorganismos (Robb, 2004).

Como ha sido mencionado en las consideraciones referentes al fluido hidrotermal (Capítulo VIII), en el distrito Purísima Rumicruz, se postula como principal mecanismo de precipitación el cambio en condiciones químicas del fluido. El Eh reductor de las 
capas de pelitas negras en la Formación Acoite podría haber funcionado como una trampa geoquímica y propiciado la precipitación de los metales.

$\mathrm{El} \mathrm{pH}$, también suele ser un fuerte control en la precipitación de minerales (Staude et al., 2007). Pequeñas variaciones en el pH generan fuertes caídas en la solubilidad de los metales en varias unidades logarítmicas (Seward y Barnes, 1997). Este es un mecanismo que funciona efectivamente para $\mathrm{Pb}, \mathrm{Zn}, \mathrm{Co}, \mathrm{Ni}, \mathrm{Ag}$ y $\mathrm{Cu}$ cuando son transportados como complejos clorurados, en soluciones hidrotermales de moderada temperatura (Seward y Barnes, 1997; Shock et al, 1997; Sverjensky et al., 1997; Wood y Samson, 1998).

La temperatura es otra variable importante que puede producir la precipitación de metales debido a que la solubilidad de los complejos clorurados depende en relación directa con la temperatura (Seward y Barnes, 1997), por lo tanto el enfriamiento produce la saturación y precipitación.

Como ha sido mencionado previamente, en la primera etapa de precipitación fueron definidas texturas de reemplazo de calcita tipo platy. Esta textura es generada al producirse una sobresaturación y consecuente rápida precipitación de calcita y en sistema epitermales es frecuentemente asociada a ebullición (Simmons y Christenson, 1994; Dong et al., 1995; Simmons, 2000). Si bien en las inclusiones fluidas estudiadas no han sido reconocidas evidencias de este proceso, no se descarta que pueda haber estado presente en algún estadio de la precipitación mineral.

\section{EDAD DE LA MINERALIZACIÓN}

Las vetas que conforman el depósito Purísima Rumicruz son claramente epigenéticas, por lo tanto la edad mínima de la mineralización es posterior al Ordovícico inferior que es la edad de las pelitas de la Formación Acoite, encanjante de la mineralización. Las vetas se alojan en dos sistemas de fallas, E-O y ESE-ONO; estas orientaciones son acordes a esfuerzos donde la mayor compresión $(\sigma 1)$, se ubica en posición ONO-ESE, y la extensión (ఠ3), ENE-OSO (Capítulo VI). Esta configuración de los esfuerzos es coherente con los correspondientes al evento de rifting del ciclo Patagonídico. La edad modelo $\mathrm{Pb}-\mathrm{Pb}$ obtenida a partir de los sulfuros de la mineralización corresponde a una edad de 235 Ma.

Al ser comparados los resultados $\mathrm{Pb}-\mathrm{Pb}$ de la mineralización Purísima Rumicruz con los obtenidos en los sulfuros de mina Aguilar y mina Pumahuasi (Fig. 9-5), se observa que existe un evento metalogenético correspondiente al Ordovícico para los 
minerales de mina Aguilar (Gemmel et al., 1992), mientras que existe otro evento más moderno para los minerales de las vetas de Pumahuasi (Sangster y Sangster, 2001) y Purísima-Rumicruz.

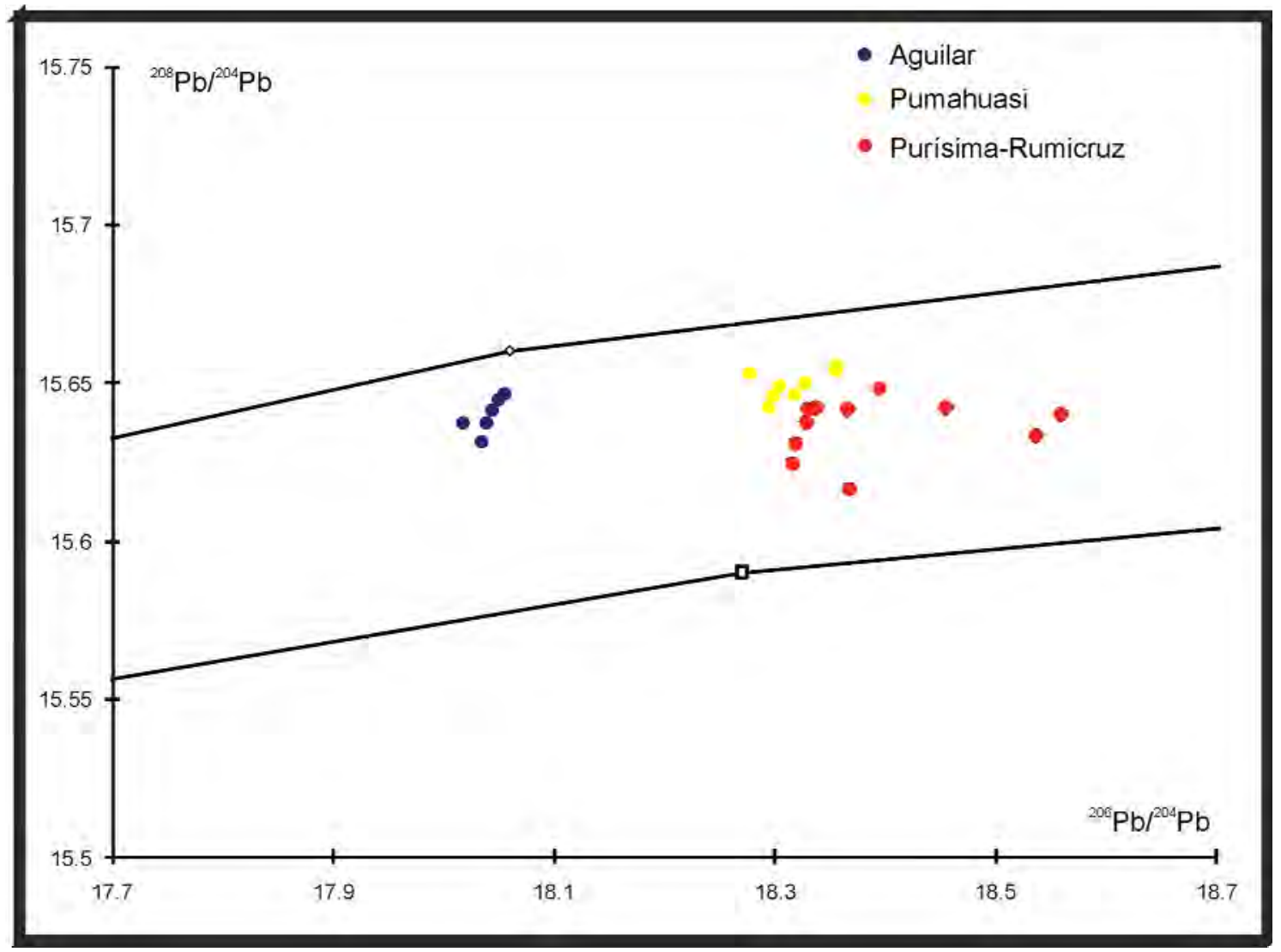

Fig. 9-5. Relaciones ${ }^{206} \mathrm{~Pb} /{ }^{207} \mathrm{~Pb}$ para las vetas correspondientes a los depósitos de Mina Aguilar (azul), Mina Pumahuasi (amarillo), y Purísima-Rumicruz (rojo). Los datos de Mina Aguilar determinaron que la edad de la mineralización primaria era sincrónica con la depositación de pelitas de edad Ordovícica inferior. Los datos de Pumahuasi y Purísima Rumicruz corresponden a un evento metalogenético posterior.

Sobre la base de lo expuesto y considerando, (1) que la edad obtenida es una edad modelo, (2) que existe una moderada dispersión de los datos $\mathrm{Pb}-\mathrm{Pb}$ y (3) que no se registran eventos tectónicos que se correspondan con esta edad, se propone tentativamente una edad Jurásico superior-Cretácica inferior para la mineralización, coincidentes con los eventos iniciales del rifting continental ocurridos en el NOA (Zappettini, 2008). Sin embargo, deberán profundizarse las investigaciones isotópicas para lograr interpretaciones más ajustadas referentes a la edad de la mineralización.

\section{MODELO METALOGENÉTICO}

Considerando los datos presentados, se propone un modelo de la evolución de los procesos metalogenéticos que generaron las vetas del distrito polimetálico PurísimaRumicruz. 
Durante el Ordovícico inferior se produjo la máxima transgresión registrada sobre la cuenca eopaleozoica (Moya, 2008). La Formación Acoite registra los depósitos finos desarrollados sobre esta plataforma interna, que son intercalados por delgados niveles de areniscas producto de depositación de tempestitas distales. Durante el periodo de máxima inundación se generaron condiciones favorables para la acumulación de metales ( $\mathrm{Cu}, \mathrm{Pb}, \mathrm{Ni}, \mathrm{Co}, \mathrm{Ag}, \mathrm{Zn}, \mathrm{U})$, depositados conjuntamente con las pelitas negras en un ambiente anóxico (Fig. 9-6). En el sector de mina Aguilar en Jujuy (Sureda, 1999), y de La Colorada (Lurgo Mayón et al., 1999), afloramientos sincrónicos contienen concentraciones de metales base interpretadas como depósitos sedex.

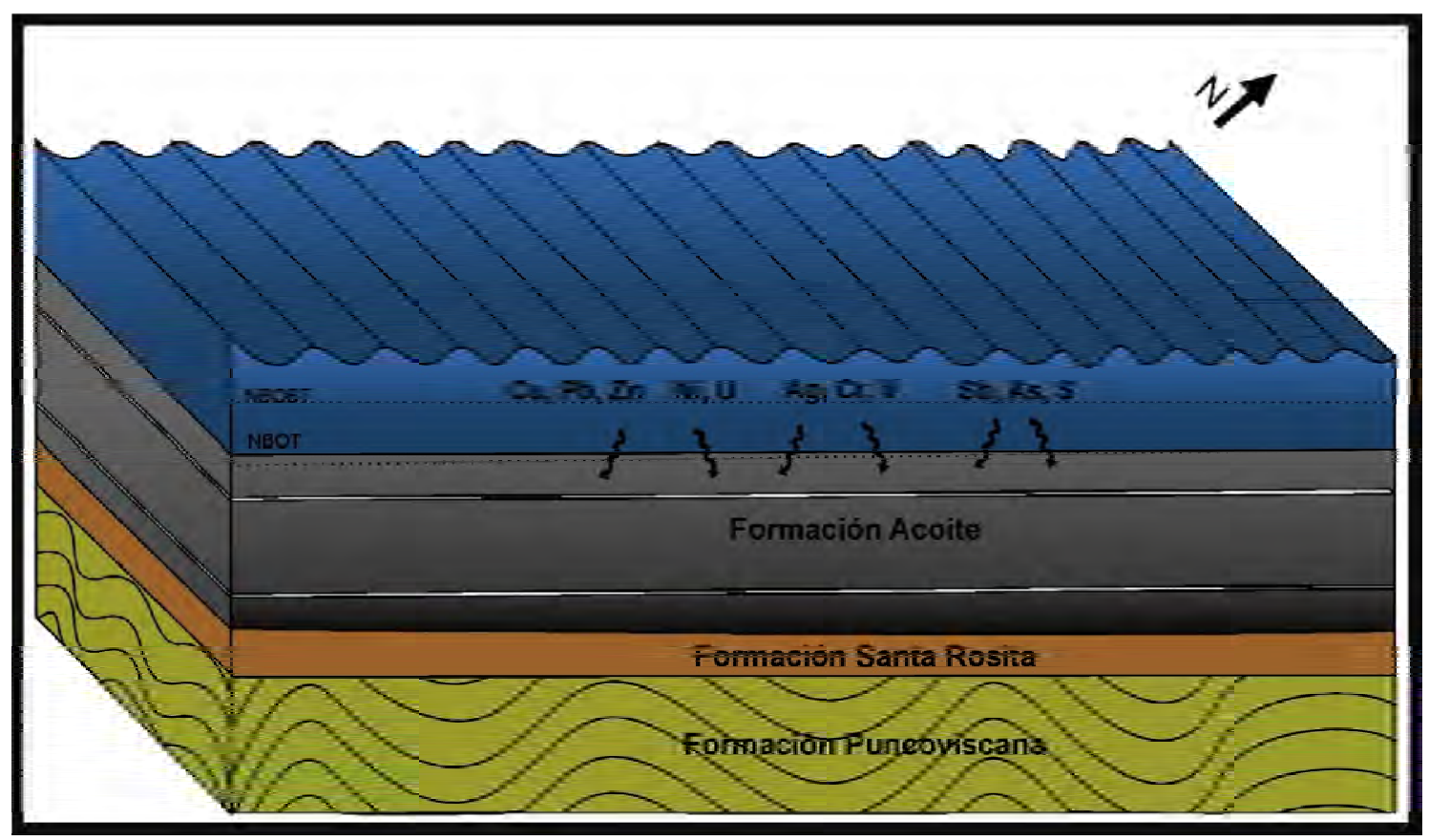

Fig. 9-6. Depositación de la Formación Acoite. El ambiente de depositación es una plataforma externa donde dominan eventos de decantación, con episódicos eventos de tormentas, desarrollado durante la máxima inundación de la cuenca eopaleozoica. En esta Formación se concentran algunos elementos como el cobre, plomo, zinc, níquel, uranio, plata, cromo, vanadio, antimonio, arsénico y azufre.

Hacia finales del Ordovícico, la fase Oclóyica produjo una deformación penetrativa registrada en la Formación Acoite con un fuerte plegamiento y con la generación de clivaje de plano axial.

El rifting continental desarrollado desde el Jurásico superior-Cretácico inferior (Zappettini et al., 2008), fue debido a extensión en el retroarco y también asociado a la apertura del Océano Atlántico (Viramonte et al., 1999). Durante las etapas iniciales se produjo una anomalía térmica en la corteza superior que generó la migración de aguas formacionales de la Formación Acoite (Fig. 9-7), con un posible aporte de aguas de unidades infrayacentes, como las Formaciones Santa Rosita o Puncoviscana. A pesar de la ausencia de registro de rocas ígneas post-ordovícicas en las inmediaciones del 


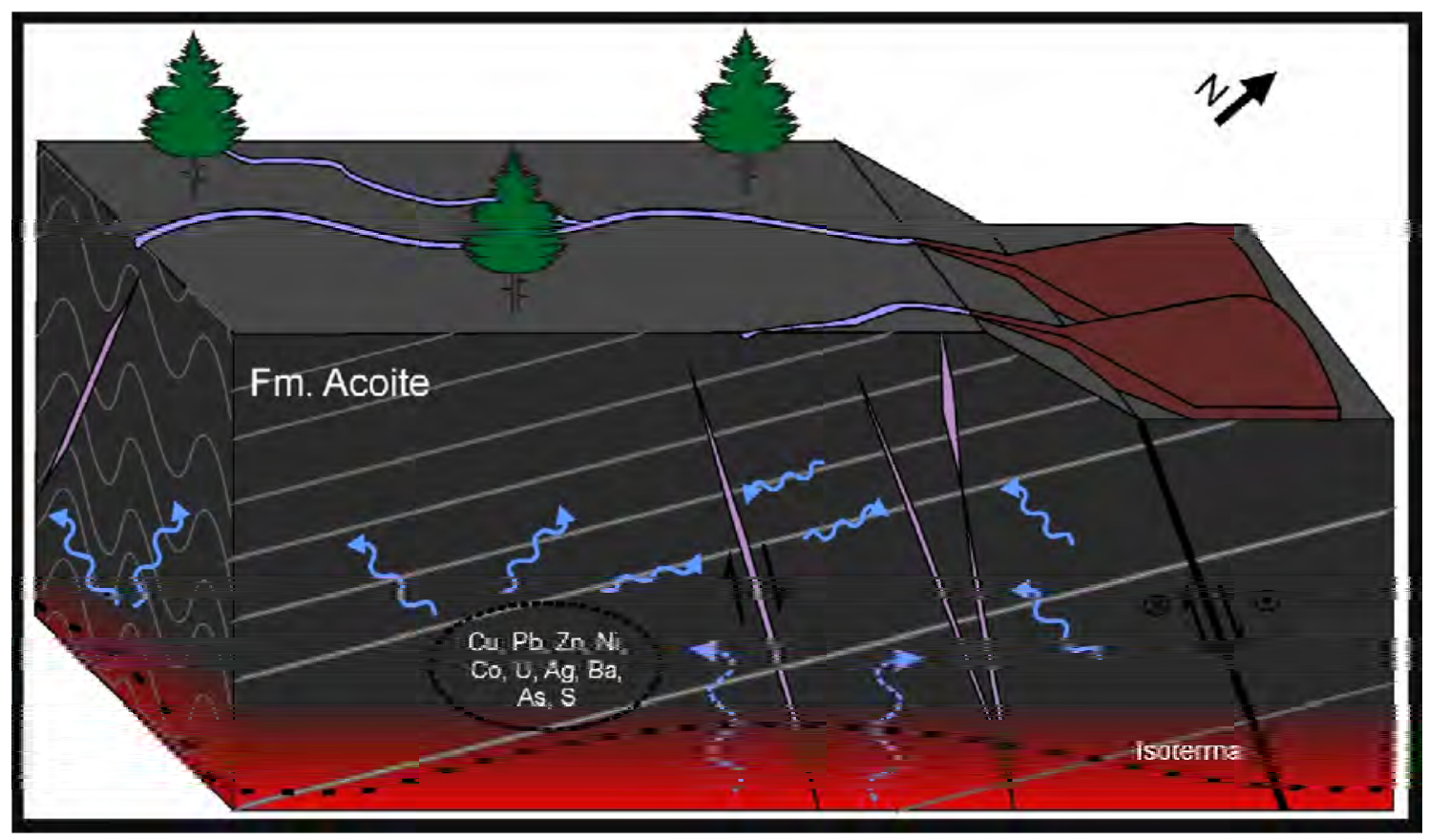

Fig. 9-7. Rifting continental iniciado durante el Jurásico superior-Cretácico inferior. Generación de espacios de dilatancia por el fallamiento directo, ascenso de fluidos por estos canales, posiblemente mediante bombeo de fluidos. Esta circulación puede ser favorecida por un ascenso de las líneas de isotermas. Los metales son lixiviados de las pelitas de la Formación Acoite mediante fluidos generados en esta formación y posiblemente de niveles infrayacentes

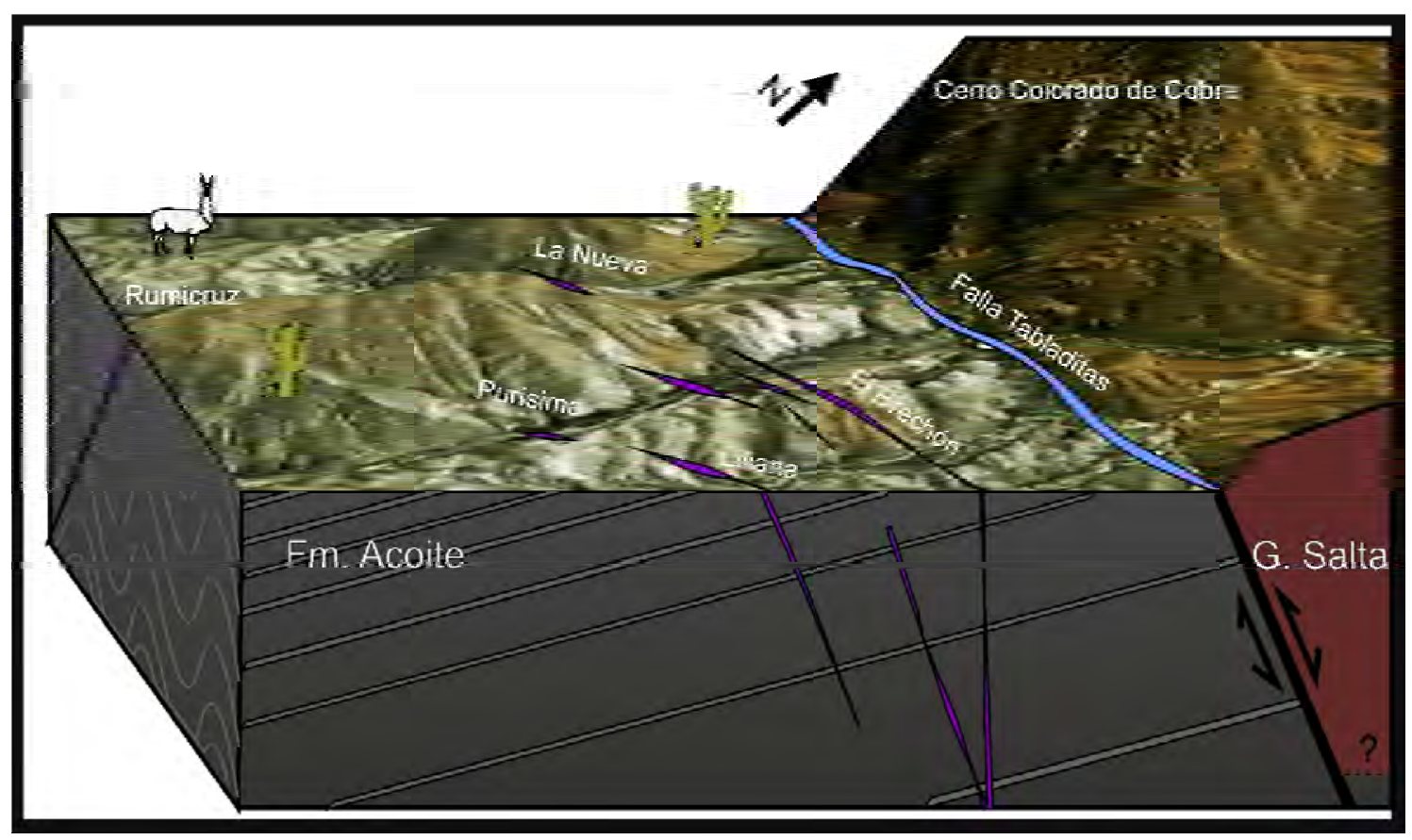

Fig. 9-8. Escenario actual del distrito polimetálico Purísima-Rumicruz. Las fallas generadas o reactivadas durante el Cretácico son reactivas durante el ciclo Ándico con una tectónica compresiva. 
depósito (i.e. $\sim 30 \mathrm{Km}$ ), no es posible descartar a los fluidos magmáticos como fuente de aporte de los fluidos hidrotermales.

Si bien es posible la generación de celdas convectivas en la circulación de los fluidos debido a la permeabilidad secundaria que ofrecieron las pelitas, estos fueron vehiculizados a través de canales subverticales, que configuran las actuales vetas. La circulación de los fluidos por la Formación Acoite habría posibilitado la lixiviación de los metales de la roca de caja. No es necesaria una circulación convectiva prolongada por la roca de caja para producir esta lixiviación; soluciones moderadamente salinas logran solubilizar los metales de roca migrando solo una vez a través de ella (Tornos y Henrich, 2008). Estos fluidos interactuaron geoquímica e isotópicamente con las pelitas negras de la Formación Acoite, fuente de los metales de los fluidos mineralizantes.

El ascenso de los fluidos fue canalizado a través de fallas que actuaron como canales para la circulación vertical. La migración de los fluidos alojados en la Formación Acoite hasta estos canales fue limitada debido a la reducida porosidad primaria de las pelitas. Podría haber favorecido a esta migración la generación de permeabilidad secundaria a través de microfracturación tectónica-hidráulica en los márgenes de las fallas. También los planos de clivaje de las pelitas o los niveles psamíticos-tempestíticos pueden haber incrementado la permeabilidad de la unidad. La precipitación pudo desencadenarse por cambios en el pH y Eh y en menor medida el descenso de la temperatura de los fluidos hidrotermales. Esta se produjo durante sucesivas etapas de fallamiento, acompañado por un accionar hidráulico, que le imprimió una textura de brecha multiepisódica a las vetas.

Durante el Neógeno se produce un cambio en el escenario tectónico de la región (Ramos, 1999). La tectónica extensional registrada en durante el Cretácico y Paleoceno se reconfigura en una tectónica compresiva, a partir del Mioceno superior (Salfity y Marquillas, 1999). Las fallas directas que limitaron el desarrollo de los hemigrabenes y que sirvieron como control para la sedimentación en las etapas de sinrift, son reactivadas como fallas inversas (Monaldi et al., 2008) (Fig. 9-8). 
En este apartado se discutirá la clasificación del depósito Purísima-Rumicruz como un FED. En una primera instancia, se abordarán las características generales y las dificultades para generar una definición inclusiva a los depósitos $F E D$, asimismo se expondrán ejemplos mundiales y locales de este tipo de yacimiento. Luego se analizarán detalladamente las características de yacencia, mineralogía, fluidos hidrotermales y modelos genéticos propuestos para estos depósitos. En cada uno de ellos se confrontará los modelos idealizados con los resultados producidos en este trabajo para el depósito Purísima-Rumicruz.

\section{Introducción}

Una serie de depósitos clasificados como five element deposits (FED) se distribuyen alrededor del mundo. La característica distintiva es su singular mineralogía y paragénesis. A pesar de esta similitud mineralógica, la proporción y la secuencia de precipitación en estos depósitos son altamente variables. La primera caracterización de los FED fue efectuada por Bastin (1939) que realiza un profundo análisis de los depósitos conocidos en la época y propone las primeras interpretaciones genéticas. En este sentido este autor enfatiza las posibles excepciones al modelo general. Los FED han recibido múltiples denominaciones y pueden ser conocidos como nickelcobalt- silver veins ore type, five element veins y Cobalt type silver-sulpharsenides (Lefebure, 1996). Aún para aquellos autores que utilizan los términos five element deposit, no existe aún un acuerdo acerca de cuáles son los cinco elementos que deben estar formando los minerales de la paragénesis de estos depósitos. Sin embargo una formula general podría resumirse como: Ag, As, Co y $\mathrm{Ni} \pm \mathrm{Bi}, \mathrm{U}$ (Kissin, 1993; Lefebure, 1996; Bagheri et al., 2007).

Los minerales formados a partir de estos elementos son arseniuros, sulfoarseniuros, antimoniuros y sulfoantimoniuros de cobalto y níquel. El cobre esta casi invariablemente presente en forma de calcopirita. La plata y el bismuto se encuentran como nativos o sulfosales. El plomo se presenta como galena y el zinc forma esfalerita, aunque es llamativamente escaso. Otra particularidad es la ausencia de oro. La ganga está compuesta por carbonatos, principalmente calcita o dolomita, aunque también suele presentarse ankerita y siderita (Jambor, 1971). El cuarzo está presente en gran número de depósitos, la baritina en aproximadamente la mitad y la fluorita se encuentra solo ocasionalmente. 
Kissin (1993) nota la dificultad de una definición que sea inclusiva a todos los depósitos denominados FED, debido a la enorme variedad que existe entre ellos, sin embargo establece que deben incluir, al menos, una mineralogía con arseniuros de NiCo asociado a plata nativa. Esta paragénesis suele estar separada de otra que contenga cobre, plomo y zinc, y en algunos casos existe un pulso tardío de baritina. Las minas de estos depósitos generalmente producen solo plata, sin embargo el cobalto e incluso el cobre, logran tener potencialidad económica en algunos distritos.

La explotación de los FED data de la edad media y en algunos lugares tuvieron implicancias históricas, como en Canadá y Noruega donde se generaron asentamientos humanos alrededor de estas minas, colonizando parajes desolados (Dolníček et al., 2008). Sin embargo la mecanización de la explotación, y las consecuentes ventajas de explotar yacimientos de baja ley, pero gran tonelaje, desplazaron del escenario minero a estos depósitos caracterizados por una yacencia de vetas delgadas, discontinuas y con estructura pinch and swell que dificultó la exploración y explotación. Sumado a esto el fluctuante valor de la plata y el descubrimiento de fuentes alternativas más económicas de níquel y cobalto, produjeron un desinterés en este tipo de yacimientos.

Hasta la década de los 90's solo existía registro de los FED en América del Norte y Europa (Fig. 9-9) (Kissin, 1993), sin embargo actualmente se ha ampliado la distribución de los mismos en otros continentes con los registros de Chañarcillo en Chile (Sillitoe, 2007), Anarak en Irán (Bagheri et al., 2007), Baiyangping en China (Liu et al., 2010), y Bou Azzer en Marruecos (Essarraj et al, 2005), entre otros.

En Argentina, algunos depósitos que pueden ser clasificados como FED son Carrizal en San Juan (Morello y Rubinstein, 1997; Rubinstein y Morello, 2006), San Santiago (Brodtkorb, 1969; 1999) y King Tut (Schalamuk y Brodtkorb, 1999), en La Rioja y La Niquelina y La Esperanza en Salta (Lurgo Mayón, 1999). Sin embargo, algunos de estos depósitos carecen de estudios detallados respecto a las características de los fluidos hidrotermales (temperatura, salinidad, isotopía, edad) para producir modelos genéticos robustos. 


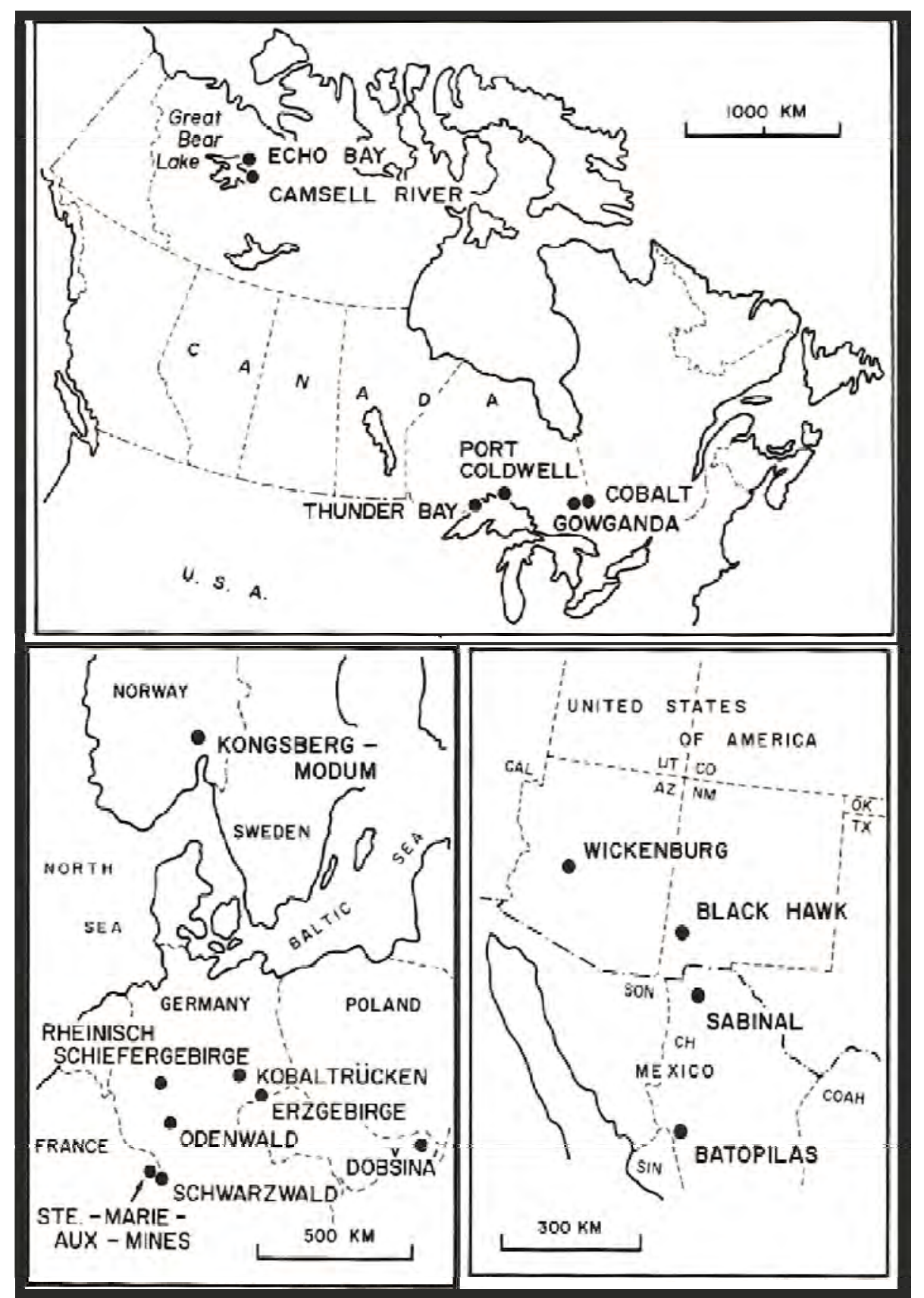

Fig. 9-9. Distribución mundial de los yacimientos más importantes clasificados como Five Element Deposits. Tomado de Kissin (1993).

\section{Yacencia}

La roca hospedante de las vetas del distrito minero Purísima Rumicruz, consistente en una alternancia de areniscas y pelitas negras depositadas en plataforma abierta, es similar a otras descriptas para los FED (e.g. Wenzel, Staude et al., 2007; Kupfershiefer, Wagner et al. 2009). Sin embargo la roca de caja es una característica altamente variable en los FED. Se presentan encajados en rocas sedimentarias, terrenos graníticos y metamórficos de grado variable. Es significativo que en 
numerosos depósitos las rocas volcánicas son escasas o no están presentes (Kissin, 1993), como ocurre en Purísima-Rumicruz. Sin embargo en otros depósitos estas rocas han sido reconocidas como las generadoras de anomalías térmicas y/o como fuente de metales de la mineralización, como en Cobalt, Canadá (Bastin, 1939; Marshall y Watkinson, 2000) o en Bou Azzer (Ahmed et al., 2009).

La alteración hidrotermal en el distrito Purísima-Rumicruz es muy débil y no supera los pocos milímetros hacia la roca de caja, este aspecto es similar a los registrados en los FED donde la alteración hidrotermal es prácticamente es irreconocible. En un balance de masas en el distrito Cobalt Gowganda Andrews et al. (1986), demostraron que los fluidos hidrotermales fueron la principal fuente de $\mathrm{Ca}, \mathrm{Na}, \mathrm{CO}_{2}, \mathrm{Ag}, \mathrm{As}, \mathrm{Nb}, \mathrm{y}$ $\mathrm{Sr}$, y los minerales de la veta se enriquecieron en REE, al igual que la roca de caja alterada. Esta última presentó perdidas de Fe, Mg, K, Al, Mn y P.

La yacencia del depósito Purísima-Rumicruz es similar a la de los depósitos tipo FED. Estos son de tipo vetiformes, rellenos por minerales hidrotermales, y suele ser frecuentes múltiples episodios de fracturación seguidos por mineralización. El estilo de las vetas es pinch and swell, de pocos centímetros a escala de metros (Kissin, 1993, Lefebure, 1996). En algunos distritos de los FED, la mineralización parece estar limitada por la profundidad y en los casos en que las vetas continúan a mayores profundidades son estériles. La zona mineralizada alcanza en ocasiones hasta los 500m en profundidad (e.g. depósito Wenzel, Staude et al, 2007). Ha sido registrado también la asociación mineralógica de los FED como relleno de poros de rocas sedimentarias con granulometrías psefíticas-psamíticas (Zimmer Lake Area, Canadá, Watkinson et al., 1975).

\section{Mineralogía}

La mineralogía es, como se ha mencionado, la característica distintiva de los FED. Existe una recurrencia en los pulsos paragenéticos encontrada en numerosos depósitos de este tipo. Kissin (1993), sistematizó una secuencia paragenética completa e idealizada, caracterizada por 5 etapas de precipitación de minerales.

- Etapa temprana estéril: cuarzo, con cantidades menores de sulfuros de metales base (pirita, calcopirita, galena).

- Etapa de uraninita: uraninita y cuarzo. Esta etapa está completamente ausente en algunos distritos, aunque en otros es de suma importancia económica. 
- Etapa arseniuros de Ni-Co-Ag: se asocian arseniuros de Ni-Co con plata y bismuto nativo. Los minerales de ganga que acompañan suelen ser carbonatos.

- Etapa de sulfuros: pirita, esfalerita, galena, calcopirita y otros sulfuros de cobre con plata nativa y argentita, en una ganga de calcita, cuarzo, fluorita y baritina. Esta etapa es transicional con la etapa anterior.

- Etapa tardía estéril: está compuesta por calcita que puede estar acompañada por cantidades significativas de fluorita o baritina.

En numerosos depósitos han sido registradas texturas de rápido crecimiento de los cristales como dendritas o esqueletales, (Misra y Feet, 1975; Canals et al., 1992.; Staude et al., 2007; Dolníček et al., 2008), interpretadas como rápida precipitación a partir de fluidos sobresaturados.

No obstante, en la mayoría de los depósitos considerados FED esta sucesión de etapas no es completa o incluso alguna de estas puede alterar su ubicación temporal (Barbanson et al., 2003; Ondruš et al., 2003a; Rubinstein y Morello 2006).

El depósito Purísima Rumicruz presenta una paragénesis que comprende cinco etapas de precipitación, tres primarias (sulfuros; sulfoarseniuros-arseniurospechblenda; sulfuros), una cuarta etapa de enriquecimiento secundario y una quinta que removiliza los elementos previamente depositados. Kissin (1993) establece necesaria la presencia de plata (nativa o formando sulfosales) en la asociación paragenética de los FED. A pesar de no hallarse minerales portadores de este elemento bajo estudios microscópicos y de química mineral, los tenores relativamente altos, de más de 500 ppm obtenidos en los análisis geoquímicos son consecuentes con la presencia de este elemento en la paragénesis. Considerando la asociación mineral y los pulsos identificados, la mineralogía y paragénesis establecida para el depósito Purísima-Rumicruz es acorde al modelo paragenético de los FED (López et al., 2011).

\section{Fluidos hidrotermales}

\section{Temperatura y salinidad.}

Los FED se caracterizan por presentar temperaturas de precipitación variables que pueden alcanzar hasta $500^{\circ} \mathrm{C}$ (Kissin, 1993), pero comúnmente oscilan entre 100 y $300^{\circ} \mathrm{C}$ (Wilkerson et al., 1988; Marshall y Watkinson, 2000; Bagheri et al., 2007; 
Staude et al., 2007). Las inclusiones son dominantemente acuosas, aunque se han registrado fases con dióxido de carbono, particularmente en las últimas etapas donde la ganga es carbonática. Las salinidades son generalmente altas, pueden alcanzan la saturación en $\mathrm{NaCl}$, sin embargo salinidades por debajo de $10 \%$ en peso $\mathrm{NaCl}$ eq. también han sido consignadas (Bagheri et al., 2007; Dolníček et al., 2008). La ebullición fue documentada en numerosos depósitos y se logró determinar la Po de atrapamiento, que en general no superan los 600 bares como en Cobalt Gowganda (Kerrich et al., 1986), aunque pueden ser considerablemente menores, alrededor de 200 bares como en Great Bear Lake (Changkakoti et al., 1986).

En el depósito Purísima-Rumicruz las temperaturas mínima obtenidas a partir de inclusiones fluidas en cuarzo y calcita se establecieron entre 110 y $350^{\circ} \mathrm{C}$, mientras que las salinidades en cuarzo variaron entre 5 y $12 \%$ peso $\mathrm{NaCl}$ eq., aunque en los carbonatos las salinidades son mayores, con un promedio de $19 \%$ peso $\mathrm{NaCl}$ eq. Estos valores estarían dentro del amplio campo de los FED (Fig. 9-10).

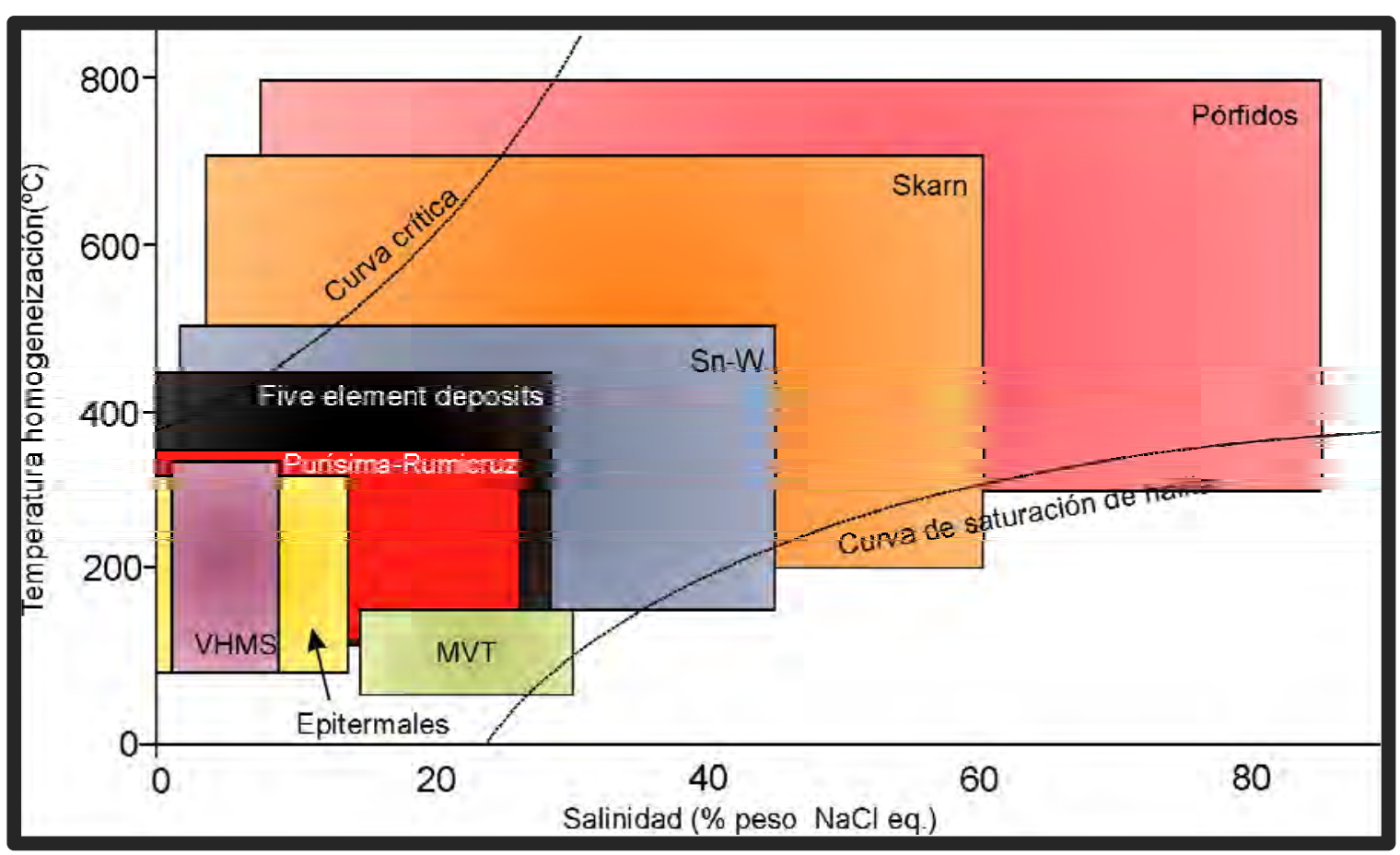

Fig. 9-10. Diagrama temperatura de homogeneización vs salinidad (\% en peso $\mathrm{NaCl}$ eq.), ilustrando la distribución esquemática de los principales tipos de yacimientos hidrotermales. Los límites de los cuadros para cada tipo de yacimiento son aproximados y no deben considerarse definitivos. Nótese la similitud en los campos de los FED y el correspondiente con el depósito Purísima-Rumicruz. Modificado de Wilkinson (2001).

\section{Isotopos estables}

Los estudios de isótopos estables han producido un gran número de interpretaciones sobre la fuente de los metales y de los fluidos hidrotermales. En este 
sentido, han sido propuestas fuentes juveniles (Kerrich et al., 1986), magmáticas (Changkakoti et al., 1986), formacionales (Goodz et al., 1987) y marinas (Robinson y Ohmoto, 1973).

\section{Modelo genético}

Las interpretaciones genéticas propuestas para los FED han sido motivo de un prolongado debate. No existe consenso sobre un modelo que sea factible de ser utilizado para todos los yacimiento tipo FED. Los depósitos más antiguos estudiados son los localizados en Europa Central, que suscitaron el enfrentamiento entre interpretaciones plutonistas y neptunistas a mediados del siglo XIX (Dolníček et al., 2008).

Asimismo, este debate se trasladó al siglo XX en los nuevos depósitos encontrados. Han sido propuestos modelos que vinculan estos depósitos vetiformes con intrusiones graníticas (Bastin, 1939), máficas (Tyrell, 1907), o vinculados a pórfidos de cobre (Wilkerson et al., 1988). Además hay modelos de mezcla de fluidos magmáticos con aguas meteóricas (Marshall et al., 1993; Marshall y Watkinson, 2000).

Las teorías no magmáticas proponen fluidos FED juveniles (Kerrich et al., 1986), circulación de aguas connatas (Kissin, 1988) y removilización de elementos de rocas de caja (Boyle y Dass, 1971) o aguas metamórficas (Dolníček et al., 2008).

Es destacable, no obstante, que en las últimas décadas las interpretaciones de yacimientos que se clasifican como $F E D$, han asignado una elevada relevancia a los procesos removilizadores de elementos de las rocas de caja por aguas formaciones (Kissin, 1988; Staude et al., 2007). La heterogeneidad de las rocas fuentes de donde son extraídos los metales podría explicar las variedades de los FED.

En cuanto al ambiente geotectónico, los depósitos tipo FED han sido vinculados frecuentemente a procesos de rifting continental (Canals et al., 1992; Kissin, 1993; Essarraj et al., 2005; Bagheri et al., 2007; Staude et al., 2007). En este sentido, existe un clímax metalogenético para los FED desde fines del Triásico hasta principio del Cretácico (Kissin, 1993) (e.g. Essarraj et al., 2005; Staude et al., 2007; Rubinstein y Morello, 2006). Este evento metalogénico se lo vincula con los procesos de rifting ocurridos debido a la apertura del Océano Atlántico con la consiguiente generación de depósitos tipo FED en ambas márgenes de éste (Essarraj et al., 2005; Staude et al., 2007). 
Debido a las características de la yacencia, mineralogía, química mineral e isotópica, temperatura, salinidad y al contexto geológico Purísima Rumicruz reúne características para ser considerado un FED. Si bien la edad $\mathrm{Pb}-\mathrm{Pb}$ de la mineralización obtenida es algo más antigua, debido a la dispersión de los datos (Capítulo XIII), el yacimiento Purísima Rumicruz podría vincularse genéticamente a los eventos de rifting continental Cretácico-Terciario del Grupo Salta. Este proceso de rifting ha sido vinculado a eventos geotectónicos relativos a la apertura del océano Atlántico (Viramonte 2009). 


\section{CAPÍTULO X}

CONCLUSIONES 


\section{CONCLUSIONES}

Este apartado se expone sucintamente las conclusiones más relevantes que se desprendieron de este trabajo:

- En el sector sur del Cerro Colorado de Cobre afloran depósitos de la Formación Acoite (Ordovícico inferior) y del Grupo Salta (Cretácico-Paleógeno). análisis de las facies en la Formación Acoite permitió reconocer cuatro asociaciones de facies. La interpretación ambiental propuesta para estas asociaciones es un ambiente de plataforma abierta clástica dominada por corrientes de turbidez afectadas por tormentas. La sucesión psamo-pelítica corresponde a la alternancia de procesos de decantación con eventos de corrientes unidireccionales diluidas modificadas por corrientes oscilatorias de tormentas.

- Las pelitas de la Formación Acoite concentran elementos metálicos como $\mathrm{Ag}, \mathrm{Ba}, \mathrm{Cu}, \mathrm{Ni}, \mathrm{Pb}, \mathrm{S}, \mathrm{Sb}, \mathrm{U}$ y $\mathrm{Zn}$. La firma geoquímica de las pelitas indica un ambiente de depositación anóxico. Estos depósitos constituyen uno de los registros más septentrionales y occidentales de la plataforma silicoclástica desarrollada durante el Ordovícico inferior.

- Las rocas de la Formación Acoite y del Grupo Salta registran evidencias de deformación frágil y dúctil. Las estructuras mayores se presentan en sentido meridiano desarrolladas o reactivadas posiblemente durante la orogenia Andina. Las diferencias estructurales registradas entre los sedimentos de la Formación Acoite y los depósitos del Grupo Salta posiblemente se deban a una estructuración previa de los primeros durante la orogenia Oclóyica.

- El distrito polimetálico Purísima-Rumicruz contiene un conjunto de vetas alojadas en la Formación Acoite, que han sido clasificadas de acuerdo a su composición en sulfuro dominante, baritina dominante y cuarzo. En las vetas de sulfuro dominante la textura más frecuente es el brechamiento de carácter multiepisódico, producto de cizalla y brechamiento mecánico/hidráulico.

- Las vetas presentan estructuras delgadas, corridas cortas y geometrías tipo pinch and swell. Contienen una rica y compleja mineralogía donde se identificaron cinco etapas de precipitación, tres primarias (primera de sulfuros; segunda de sulfoarseniuros-arseniuros-pechblenda; tercera de sulfuros), una cuarta etapa de enriquecimiento secundario y una quinta que removiliza los elementos previamente 
depositados. La ganga principal es carbonática y en algunas vetas puede ser importante el contenido de baritina. La geoquímica de las vetas de sulfuros exhibe un enriquecimiento en $\mathrm{Ag}, \mathrm{As}, \mathrm{Co}, \mathrm{Cu}, \mathrm{Ni}, \mathrm{Pb}, \mathrm{S}, \mathrm{Sb}$ y $\mathrm{Zn}$.

- Las vetas del distrito Purísima Rumicruz presentan un marcado control estructural. La disposición tanto de las vetas como de las fallas identificadas en la Formación Acoite es coherente con una orientación del $\sigma 1$ en dirección ONO-ESE, y el $\sigma 3$ en posición ENE-OSO.

- Los minerales precipitaron a partir de un fluido hidrotermal con temperaturas mínimas moderadas a bajas, aproximadamente entre 113 - y $350{ }^{\circ} \mathrm{C}$. Los sólidos disueltos en esta solución registraron una salinidad aproximada entre 5 a 12\% peso $\mathrm{NaCl}$ eq. para el cuarzo y salinidades mayores para los carbonatos alcanzando un promedio de 19 y una moda en $22 \%$ peso $\mathrm{NaCl}$ eq.

- La fuente del plomo que conforma la mineralización fue originados en la corteza superior. Esto es sustentado principalmente por los datos de $\mathrm{Pb}-\mathrm{Pb}$ y es acorde con los resultados de los isótopos estables.

- De acuerdo a los datos registrados en el estudio de los isótopos estables se propone que el origen de los metales provenga de la Formación Acoite. El origen de los fluidos pudo provenir de una fuente de aguas formacionales sin embargo no debe descartarse una proveniencia o un aporte de fluidos magmáticos.

- Los fluidos hidrotermales fueron probablemente movilizados debido a la anomalía térmica que precedió al proceso de rifting ocurrido durante el Jurásico superior-Cretácico. Las soluciones migraron por las fallas generadas o reactivadas durante este evento tectónico. La precipitación de los minerales se produjo por cambios en el Eh y pH de la solución, sin embargo no se descartan procesos de mezcla de fluidos o ebullición que hayan contribuido a la precipitación.

- La edad de la mineralización fue asignada a través de una edad modelo $\mathrm{Pb}-\mathrm{Pb}$ correspondiente a $235 \mathrm{Ma}$. Sin embargo, debido a que existe una moderada dispersión de los datos y que la información estructural es coherente los esfuerzos distensivos del rifting continental del NOA para el sector estudiado, se propone una edad Jurásico superior-Cretácica inferior para la mineralización.

- El depósito reúne características en cuanto a su firma geoquímica, su variada mineralogía, la temperatura y salinidad de los fluidos hidrotermales, así como 
valores isotópicos y estilo de la yacencia del depósito, que permite clasificarlo como un five element deposit.

- Los estudios geoeléctricos de potencial inducido y resistividad resultaron una herramienta adecuada para la exploración de este depósito. Existen anomalías positivas en cargabilidad que presentan una correlación negativa con valores de resistividad. Estas anomalías presentan continuidad lateral y vinculación espacial con las vetas registradas en superficie. Los valores de cargabilidad registrados en la roca de caja son moderadamente altos debido a la presencia de pirita diseminada de origen diagenético, sin vinculación con la actividad hidrotermal.

- El distrito polimetálico Purísimo-Rumicruz presenta potencialidades para continuar la exploración de minerales metalíferos y no metalíferos. Entre los primeros, considerando el modelo genético propuesto y comparado con otros ejemplos mundiales, la exploración debería centrarse en el reconocimiento de pequeños clavos, controlados estructuralmente, muy ricos en sulfuros y se debería evaluar el potencial argentífero del depósito. En cuanto a los minerales no metalíferos se destaca la baritina. El área de mayor relevancia para las tareas prospectivas de este mineral se encuentra en el sector San Agustín.

- La Formación Acoite en contacto mediante fallas de escala regional con los depósitos del Grupo Salta, originadas o reactivadas durante el rifting continental, constituye un metalotecto en el NOA que puede resultar una guía exploratoria para la identificación de nuevos depósitos. 


\section{REFERENCIAS BIBLIOGRÁFICAS}


Aceñolaza, F.G. y Toselli, A.J. 1973. Consideraciones estratigráficas y tectónicas sobre el Paleozoico Inferior del Noroeste Argentino. Actas $2^{\circ}$ Congreso Latinoamericano de Geología, 2: 755-783, Caracas.

Aceñolaza, F.G., Milana, J.P., Heredia, S. y Simoes, M. 2003. Stratigraphical and biostratigraphical framework of the Angosto de la Quesera conglomerate complex (Cordillera Oriental of Salta): an incised valley system in the Tremadocian of NW-Argentina. En: Albanesi, G, Beresi, M., Peralta, S. (Eds.), Ordovician from the Andes, Serie Correlación Geológica. 17: 365-370.

Aceñolaza, F.G. y Aceñolaza, G. 2005. La Formación Puncoviscana y unidades estratigráficas vinculadas en el Neoproterozoico-Cámbrico temprano. Latin American Journal of Sedimentology and basin analysis. 12 (2), 65-87

Aceñolaza, F.G. y Alonso, R. 2008. Los estudios geológicos en Jujuy. Geología y Recursos Naturales de la Provincia de Jujuy. En Coira B, E Zappettini, eds. Relatorio XVII Congreso Geológico Argentino. Jujuy: Asociación Geológica Argentina, 3-10. Buenos Aires.

Ahmed, H., Arai, S. y Ikenne, M. 2009. Mineralogy and Paragenesis of the Co-Ni Arsenide Ores of Bou Azzer, Anti-Atlas, Morocco. Economic Geology, 104(2):249-266.

Aigner T. y Reineck, H.E. 1982. Proximality trends in modern storm sands from the Helgoland Bight (North Sea) and their implications for basin analysis. Senckenbergiana Maritima, v. 14, p. 183-215.

Aitchison, J. 1986. The statistical analysis of compositional data: Monographs on Statistics and applied Probability. Chapman \& Hall Ltd., 416 p., London.

Andrews, A.J., Owsiacki, L., Kerrich, R. y Strong D.F. 1986. The silver deposits at Cobalt and Gowganda, Ontario. I: Geology, petrography, and whole-rock geochemistry: Canadian Journal of Earth Sciences (23):1480-1506.

Angelelli, V. 1950. Recursos minerales de la República Argentina I. Yacimientos metalíferos Rev. Inst. Inv. Mus. Arg. Cs. Nat. (Geol.) N9 2.

Astini, R.A. y Waisfeld, B.G. 1993. Análisis estratigráfico y paleoambiental del Ordovícico inferior (Formaciones Acoite y Sepulturas) al oeste de Purmamarca, Cordillera Oriental jujeña. $12^{\circ}$ Congreso Geológico Argentino, 1: 96-106. Mendoza.

Astini, R. A. 2003. The Ordovician Proto-Andean basins. En: Benedetto, J.L. (Ed.): Ordovician fossils of Argentina. Secretaría de Ciencias y Tecnología, Universidad Nacional de Córdoba: 1-74. Córdoba.

Astini, R.A., Waisfeld, B.G., Toro, B.A. y Benedetto, J.L., 2004. El Paleozoico Inferior y Medio de la región de Los Colorados, borde occidental de la Cordillera Oriental (Provincia de Jujuy), Argentina. Revista de la Asociación Geológica Argentina, 59: 243-260.

Astini, R. A. 2005. Las sedimentitas que apoyan en no concordancia sobre el "granito rojo" en el angosto de la Quesera (Cordillera Oriental, Salta): una revisión crítica a más 60 años de los trabajos pioneros de J. Keidel. Revista de la Asociación Geológica Argentina 60, 513-523.

Astini, R. A., Spagnuolo, C., Dávila, F.M. y Rapalini, A.E. 2005. El Grupo Mesón y la discordancia Irúyica en el noroeste argentino. $16^{\circ}$ Congreso Geológico Argentino, 4: 595- 597. La Plata.

Astini, R.A. 2008. Sedimentación, facies, discordancias y evolución paleoambiental durante el cambroordovícico. Geología y Recursos Naturales de la Provincia de Jujuy. En relatorio del XVII Congreso Geológico Argentino. Editores: Coira B. y Zappettini E.O. Ila 50-73. Buenos Aires.

Awad Sultan, S., Mansour, S.A., Monteiro Santos, F. y Sobhy Helaly, A. 2009. Geophysical exploration for gold and associated minerals, case study: Wadi El Beida area, South Eastern Desert, Egypt. Journal of geophysics and engineering, 6: 345-356.

Babinski, M., Van Schmus, W. y Chemale Jr., F., 1999. Pb-Pb dating and Pb isotope geochemistry of Neoproterozoic carbonate rocks from the São Francisco basin, Brazil: Implications for the mobility of $\mathrm{Pb}$ isotopes during tectonism and metamorphism. Chemical Geology, 160(3):175199.

Bachmann G., Grauert B., Kramm U., Lork A. y Miller H. 1987. El magmatismo Cámbrico medio-Cámbrico superior en el basamento del noroeste argentino: investigaciones isotópicas y geocronológicas sobre los granitoides de los complejos intrusitos Santa Rosa de Tastil y Cañaní. $10^{\circ}$ Congreso Geológico Argentino, 4: 125-127. Tucumán.

Bagheri, H. 2009. Rare earth and trace element mobility by $\mathrm{CO} 2$ bearing fluids in five-element deposits of the Anarak area, Central Iran. Journal of Geochemical Exploration, 101(1),3.

Bagheri, H., Moore, F. y Alderton D. 2007. Cu-Ni-Co-As (U) mineralization in the Anarak area of central Iran. Journal of Asian Earth Sciences, 29(5-6): 651-665. 
Bahlburg, H. 1990. The Ordovician basin in the Puna of NW Argentina and N Chile: Geodynamic evolution from back-arc to foreland basin. Geotektonische Forschungen, 75:1-107.

Bahlburg, H. 1991. The Ordovician back-arc to foreland successor basin in the Argentinian-Chilean Puna: tectono-sedimentary trends and sea-level changes. En: Macdonald, D. (Ed.): Sedimentation, Tectonics and Eustasy: Processes and Products. Special Publication International Association of Sedimentologists, Blackwell Scientific Publications, 1: 465-484.

Bahlburg, H. 1993. Hypothetical southeast Pacific continent revisited: new evidence from middle Paleozoic basins of northern Chile. Geology, 21: 909-912.

Bahlburg, H. y Furlong, K. 1996. Lithospheric modeling of the Ordovician foreland basin in the Puna of northwestern Argentina: on the influence of arc loading on foreland basin formation. Tectonophysics 259 1-3: 245-258.

Bahlburg, H. y Hervé, F., 1997. Geodynamic evolution and tectonostratigraphic terranes of nothwestern Argentina and northern Chile. Geological Society of America Bulletin, 109: 869-884.

Barbanson, L. Chauvet, A., Gaouzi A., Badra L., Mechiche M. 2003. The Cu (Ni-Bi-U-Au-Ag) mineralization of Ifri ("Haut Seksaoua" district, Morocco): contribution of a textural study to the discussion syngenetic versus epigenetic. Comptes Rendus Géoscience, 335(14):1021-1029.

Bastin, E.S., 1939. The nickel-cobalt-native silver ore-type: Economic Geology, v. 34, p. 1-40.

Becchio, R., Luccassen, F., Franz, G., Viramonte, J. y Wemmer, K. 1999. El Basamento Paleozoico Inferior del noroeste de Argentina $\left(23^{\circ}-27^{\circ}\right)$. Metamorfismo y geocronología. $14^{\circ}$ Congreso Geológico Argentino, Relatorio 1: 58-78.

Bentley, S.J. y Nittrouer, C.A. 2003. Emplacement, modification, and preservation of event strata on a flood-dominated continental shelf: Eel shelf, Northern California. Continental Shelf Research 23: 1465-1493.

Bodnar, R.J. 1993. Revised equation and table for determining the freezing point depression of H2O$\mathrm{NaCl}$ solutions. Geochim. Cosmochim. Acta 57, 683- 684.

Bodnar, R.J. y Vityk, M.O. 1994. Interpretation of microthermometric data for $\mathrm{H}_{2} \mathrm{O}-\mathrm{NaCl}$ fluid inclusions. In Fluid Inclusions in Minerals, Methods and Applications, B. De Vivo and M. L. Frezzotti, eds., Virginia Tech, Blacksburg, VA, p. 117-130.

Bodnar, R.J. 1999. Hydrothermal Solutions. En Encyclopedia of Geochemistry, C.P. Marshall y Fairbridge eds., Kluwer Academic Publishers, Lancaster, pp. 333-337.

Boll, A. y Hernández, R. 1985. Área Tres Cruces. Prov. de Jujuy. Análisis estratigráfico-estructural. Evaluación como objetivo exploratorio. Informe YPF. Inédito.

Boyle R. y Dass A. 1971. The origin of the native silver veins at Cobalt, Ontario. Canadian Mineralogist, 11(1):414.

Brett, R. 1964. Experimental data on the system Cu-Fe-S and their bearing on exsolution textures in ores. Economic Geology. 59:1241-1269.

Brodtkorb de, M.K. 1965. Estudio de la mineralización del yacimiento "La Esperanza", Provincia de Salta. $2^{\circ}$ Jornadas Geológicas Argentinas, 25-33. Tucumán.

Brodtkorb de, M. K. 1969. Estudio de la mineralización del yacimiento San Santiago. Asociación Geológica Argentina, Revista, 25: 307-310.

Brodtkorb de, M K. 1972. Hallazgo de pechblenda en La Mina Romicruz, Prov. de Jujuy. Actas del V Congreso Geológico Argentino, 63-68. Córdoba.

Brodtkorb de, M K. 1973. Estudio de la mineralización del yacimiento "La Niquelina", provincia de Salta y un análisis .comparativo de sus posibles relaciones con los depósitos "Rumicruz" y "Esperanza". Revista de la Asociación Geológica Argentina, 27 (4): 364-368.

Brodtkorb, M. K. de, 1999. El yacimiento de níquel y uranio San Santiago, La Rioja. En: Recursos Minerales de la República Argentina (Ed. E. O. Zappettini), Instituto de Geología y Recursos Minerales SEGEMAR, Anales 35: 631-632, Buenos Aires.

Brown, P.E. 1989. FLINCOR: A microcomputer program for the reduction and investigation of fluidinclusion data. American Mineralogist 74, 1390.

Buatois, L.A., Mángano, M.G. y Moya, M.C. 2000. Incisión de valles estuarinos en el Cámbrico tardío del noroeste argentino y la problemática del límite entre los grupos Mesón y Santa Victoria. Resúmenes $2^{\circ}$ Congreso Latinoamericano de Sedimentología y $8^{\circ}$ Reunión Argentina de Sedimentología: 55.

Buatois, L.A. y Mángano, M.G. 2003. Sedimentary facies, depositional evolution of the Upper CambrianLower Ordovician Santa Rosita formation in northwest Argentina. Journal of South American Earth Sciences, 16(5):343-363. 
Buatois, L.A., Zeballo, F.J., Albanesi, G.L., Ortega, G., Vaccari, E. y Mángano, M.G. 2006. Depositional Environments and Stratigraphy of the Upper Cambrian-Lower Ordovician Santa Rosita Formation at the Alfarcito area, Cordillera Oriental, Argentina: Integration of biostratigraphic data within a sequence stratigraphic framework. Latin American Journal of Sedimentology and Basin Analysis 13: 65-95.

Butler, I., Rickard, D. y Grimes, S. 2000. Framboidal Pyrite: Self Organization in the Fe-S System. Goldshmidt 2000, Journal of Conference abstracts. 5 (2): 276-277.

Caffe, P. y Coira, B.L. 2008. Depósitos epitermales polimetálicos asociados a complejos volcánicos dómicos: Casa Colorada, Pan de Azúcar, Chinchillas y Cerro Redondo. En relatorio del XVII Congreso Geológico Argentino. Editores: Coira B. y Zappettini E.O., Ilf: 350-357. Buenos Aires.

Canals, A., Cardellach, E., Rye, D. y M. Ayora, C. 1992. Origin of the Atrevida Vein (Catalonian coastal ranges, Spain); mineralogic, fluid inclusion, and stable isotope study. Economic Geology, 87(1):142-153.

Carmona, J.M., Bitzer, K., López, E. y Bouazza, M. 2000. Isotopic composition and origin of geothermal waters at Caldetes (Maresme-Barcelona). J. Geochem. Expl. 69-70, 441-447.

Changkakoti, A., Morton, R.D., Gray, J. y Yonge, C.J. 1986. Oxygen, hydrogen, and carbon isotopic studies of the Great Bear Lake silver deposits, Northwest Territories: Canadian Journal of Earth Sciences (23):1463-1469.

Chayle, W. 1999. Mina Pirquitas, Jujuy. En: Recursos Minerales de la República Argentina Ed. E. O. Zappettini, Instituto de Geología y Recursos Minerales SEGEMAR, Anales 35: 1593-1598, Buenos Aires.

Chomnales, R., Vázquez R., y Palou, R. 1960. Noticia preliminar sobre la existencia de minerales de Ni en la mina Purísima (Rumicruz), Dto. de Cochinoca, Jujuy. Instituto de geología y minería. 5 pp. Jujuy.

Clayton, R.N. y Mayeda, T.K. 1963. The use of bromine pentafluoride in the extraction of oxygen from oxides and silicates for isotopic analysis. Geochimica et Cosmochimica Acta, 27, 43-52.

Coira, B. L., 1979. Descripción geológica de la Hoja 3c, Abra Pampa, Provincia de Jujuy. Secretaría de Estado de Minería, Servicio Geológico Nacional, Carta Geológico-Económica de la República Argentina. Boletín170. 91p. Buenos Aires.

Coira, B.L., Mahlburg, Kay, S., Pérez, B., Woll, B. Hanning, M. y Flores, P. 1999. Magmatic sources and tectonic setting of Gondwana margin Ordovician magmas, northern Puna of Argentina and Chile. En: Ramos, V.A. and Keppie, J.D. (Eds.): Laurentia-Gondwana Connections before Pangea. Geological Society of America Special Paper, 336: 145-170.

Coira, B., Caffe, P.J., Ramírez, A., Chayle, W., Díaz, A., Rosas, S., Pérez, A., Pérez, E.M.B., Orosco, O. y Martínez, M., 2004. Hoja Geológica 2366-I/2166-III Mina Pirquitas, Provincia de Jujuy (escala 1:250.000). Servicio Geológico Minero Argentino. Instituto de Geología y Recursos Minerales. Boletín, 269: 1-123 pág.

Coira, B., Díaz, A.M., Ramírez, A y Guevara, S.R., 2005. Volcanismo silíceo en la Quebrada de Taique, sus implicancias en la evolución de la faja magmática oriental de la Puna, Argentina. Actas del 16 Congreso Geológico Argentino, (1):709-716. La Plata.

Coira B. L. 2008. Volcanismo del Paleozoico inferior en la Puna Jujeña. Geología y Recursos Naturales de la Provincia de Jujuy. En Relatorio XVII Congreso Geológico Argentino. Jujuy (Coira B, E Zappettini, eds.), Asociación Geológica Argentina, Buenos Aires, pp. 134-139.

Coira B., Koukharcky M., Ribeiro Guevara S. y Cisterna C.E. 2009a. Puna (Argentina) and northern Chile Ordovician basic magmatism: A contribution to the tectonic setting. Journal of South American Earth Sciences (27):24-35

Coira, B., Kirschbaum, A., Hongn, F., Pérez, B. y Menegatti, N. 2009b. Basic Ordovician magmatism in northeastern Puna, Argentina: chemical composition and tectonic setting in the Ordovician back-arc. Journal of South America Earth Sciences (28):374-382.

Colella, A., Lapenna, V., Rizzo, E. 2004. High-resolution imaging of the High Agri Valley Basin (Southern Italy) with electrical resistivity tomography. Tectonophysics 386, 29-40.

Cristiani, C., Del Moro, A., Matteini, M., Mazzuoli, M. y Omarini, R., 1999. The Tusaquillas plutonic complex, Central Andes. Age, petrology and geodynamic significance. $2^{\circ}$ Simposio Sudamericano de Geología Isotópica, 1: 34-35. Carlos Paz.

Demanet, D., Renardy, F., Vanneste, K., Jongmans, D., Camelbeeck, T y Meghraoui, M. 2001. The use of geophysical prospecting for imaging active faults in the Roer Graben, Belgium. Geophysics, 66 (1):78-89. 
Dolníček, Z., Bohuslav, F., Prochaska, W., Kučera, J. y Sulovský, P. 2008. Origin of the Zálesí U-Ni-CoAs-Ag/Bi deposit, Bohemian Massif, Czech Republic: fluid inclusion and stable isotope constraints. Mineralium Deposita, 44(1):81-97.

Dong, G., Morrison, G. y Jaireth, S., 1995. Quartz textures in epithermal veins, Queensland; classification, origin and implication. Economic Geology, 90(6):1841.

Duke, W.L., 1990. Geostrophic circulation or shallow marine turbidity currents? The dilemma of paleoflow patterns in storm-influenced prograding shoreline systems: Journal of Sedimentary Petrology, 60: 870-883.

Duke, W.L., Arnott, R.W.C., y Cheel, R.J., 1991. Shelf-sandstones and hummocky cross stratification: new evidence on a stormy debate: Geology, v. 19, p. 625-628.

Dumas, S., Arnott, R.W.C., y Southard, J.B., 2005. Experiments on oscillatory-flow and combined flow bed forms: Implications for interpreting parts of the shallow marine rock record. Journal of Sedimentary Research, 75, (3):501-513.

Dumas, S. y Arnott, R.W.C. 2006. Origin of hummocky and swaley cross-stratification-The controlling influence of unidirectional current strength and aggradation rate. Geology, 34:1073 - 1076.

Essarraj, S. Boiron, M.C., Cathelineau M., Banks D.A. y Benharref M. 2005. Penetration of surfaceevaporated brines into the Proterozoic basement and deposition of $\mathrm{Co}$ and $\mathrm{Ag}$ at Bou Azzer (Morocco): Evidence from fluid inclusions. Journal of African Earth Sciences, 41(1-2): 25-39.

Evans, R.B. y Burley, A.J., 1969. Variable frequency induced polarization surveys in Western Swaziland. Institute of Geological Sciences, Geophysical Division, Geophysical Report No. GP/0/41, 1-36, London. (inédito).

Fanlo, I. y Subías, I. 2006. Textures and compositional variability in gersdorffite from The Crescencia Ni(Co-U) Showing, Central Pyrenees,Sspain: primary deposition or re-equilibration?. The Canadian Mineralogist 40: 1513-1528.

Fanlo, I., Subías, I., Gervilla, F., Paniagua, A. y García, B. 2004. The composition of Co-Ni-Fe sulfarsenides, diarsenides and triarsenides from the San Juan de Plan deposit, central Pyrenees, Spain. Canadian Mineralogist 42: 1221- 1240.

Fazzito, S.Y., Rapalini, A.E., Cortés, J.M. y Terrizzano, C.M. 2009. Characterization of Quaternary faults by electric resistivity tomography in the Andean Precordillera of Western Argentina. Journal of South American Earth Sciences 28: 217-228.

Fernández, J., Bondesio P. y Pascual, R. 1973. Restos de Lepidosiren paradoxa (Osteichthyes, Dypnoi) de la Formación Lumbrera (Eoceno) de Jujuy. Consideraciones estratigráficas, paleoecológicas y paleozoogeográficas. Ameghiniana, 10(2):152-172.

Forsythe R. D., Davidson J., Mpodozis C. y Jesinkey C. 1993. Lower Paleozoic relative motion of the Arequipa block and Gondwana; paleomagnetic evidence from Sierra de Almeida of northern Chile. Tectonics 12: 219-236

Friedman, I. y Gleason, J. 1973. Notes on the bromine pentafluoride technique of oxygen extraccion. Journal of Research. U.S. Geological Survey 1, 6: 679-680.

Fusseis, F., Regenauer-Lieb, K., Liu, J, Hough, R.M. y De Carlo, F.2009. Creep cavitation can establish a dynamic granular fluid pump in ductile shear zones. Nature, 459(7249): 974-977.

Galliski, M.A. y Viramonte, J.G. 1988. The Cretaceous paleorift in northwestern Argentina: A petrologic approach. Journal of South American Earth Sciences, 1: 329- 342.

Garven, G. y Raffensberger M. 1997. Hydrogeology and geochemistry of ore genesis in sedimentary basins. En H.L. Barnes (ed.), Geochemistry of Hydrothermal Ore Deposits, 3rd edn. John Wiley, pp. 90-125.

Gemmell, J.B., Zantop, H. y Meinert, L.D. 1992. Genesis of the Aguilar zinc-lead-silver deposit, Argentina; contact metasomatic vs. sedimentary exhalative. Economic Geology, 87(8):2085-2112.

Giano, S. I., Lapenna, V., Piscitelli, S. y Schiattarella, M. 2000, Electrical imaging and self-potencial surveys to study the geological setting of the Quaternary slope deposits in the Agri high valley (Southern Italy): Annali di Geofisica, 43(2): 409-419.

Goodz, M. Jonasson, I., Watkinson, D. y Kingston, D. 1987. The beaver-temiskaming silver sulpharsenide vein deposits, cobalt: Vein and host rock geochemistry with applications to exploration. Journal of Geochemical Exploration, 29(1-3):.411-412.

Guido D.M., Jovic, S.M., Echeveste, H., Tessone M.O., Ramayo Cortes, L. y Schalamuk, I.B. 2009: Descubrimiento y modelización de clavos mineralizados en vetas polimetálicas a partir de exploración geoeléctrica, proyecto Pingüino, Macizo del Deseado. Revista de la Asociación Geológica Argentina 64 (3): 203 - 210. 
Hanor, J.S. 1979 The sedimentary genesis of hydrothermal fluids. En H.L. Barnes (ed.), Geochemistry of Hydrothermal Ore Deposits. Wiley-Interscience, pp. 137-172.

Harms, U. 2010. Mineralogical Chemestry of gersdorffite - A powerful tool in the differentiation of hydrothermal systems. Chemie der Erde 70, 175-184.

Harrington, H.J. y Leanza, A.F. 1957. Ordovician trilobites of Argentina. Special Publication, 1. Department of Geology, University of Kansas Press, 276 pp. Lawrence.

Hauser, N., Matteini, M., Pimentel, M. y Omarini, R. 2008. K-Ar and Sr-Nd geochronology of alcaline lamprophyre dykes, from the Rio Grande valley, Eastern Cordillea, NW Argentina: origin of parental magma from a metasomatized mantle. $6^{\circ}$ South American Symposium on Isotope Geology. Actas CD. Bariloche.

Hem S.R. y Makovicky E. 2001. Compositional trends in Fe, Co and Ni sulfarsenides and their crystalchemical implications: results from The Arroyo de la Cueva deposits, Ronda Peridotite, southern Spain. The Canadian Mineeralogist 39: 831-853.

Hem, S.R. y Makovicky, E. 2004. The system Fe-Co-Ni- As-S. II. Phase relations in the $(\mathrm{Fe}, \mathrm{Co}, \mathrm{Ni}) \mathrm{As}_{1.5} \mathrm{~S}_{0.5}$ section at $650^{\circ}$ and $500^{\circ} \mathrm{C}$. The Canadian Mineralogist $42,63-86$.

Hem, S.R. 2006. Solid solution in the Fe-Co-Ni-As-S system. Chemical Geology 225, 291-303.

Hoefs, J. 2009. Stable Isotope Geochemistry. Springer. University of Göttingen. Germany Goldschmidtstr. Sixth Edition, 293 p.

Hoffman, D.L., Algeo, T.J., Maynard J.B., Joachimski M.M., Hower J.C. y Jaminski J. 1998 Regional stratigraphic variation in bottom water anoxia in offshore core shales of Upper Pennsylvanian cyclothems from Eastern Midcontinent Shelf (Kansas), U.S.A. En: Schieber J, Zimmerle W, Sethi $P$ (eds) Shales and mudstones I. E Schweizerbart'sche Verlagsbuchhandlung, Stuttgart, pp 243-269.

Hongn, F.D. y Mon, R. 1999. La deformación ordovícica en el borde oriental de la Puna. En González Bonorino, G., Omarini, R., Viramonte, J. G. (eds.) Geología del Noroeste Argentino. Relatorio $14^{\circ}$ Congreso Geológico Argentino, Salta, 1: 212-216.

Hongn, F.D., Tubía, J.M., Aranguren, A., Mon, R. y Battaglia, R. 2001. Intrusión del granito rojo del batolito de Tastil en areniscas eopaleozoicas en el Angosto de la Quesera, Cordillera Oriental, Salta. Revista de la Asociación Geológica Argentina 56, 249-252.

Hongn, F.D., Mon R. y Seggiaro R. 2008. Evolución estructural en el lapso Neoproterozoico-paleozoico inferior. Geología y Recursos Naturales de la Provincia de Jujuy. En Coira B, E Zappettini, eds. Relatorio XVII Congreso Geológico Argentino. Jujuy: Asociación Geológica Argentina, 37-49. Buenos Aires.

Hongn, F.D., Tubía J.M, Aranguren, A., Vegas, N. y Mon, R., Dunning G.R. 2009. Magmatism coeval with lower Paleozoic shelf basins in NW-Argentina (Tastil batholith): Constraints on current stratigraphic and tectonic interpretations. Journal of South American Earth Sciences 29 (2): 289-305

Hongn, F.D., Mon R., Petrinovic I., Del Papa C. y Powell J. 2010. Inversión y reactivación tectónicas Cretácico-Cenozoicas en el noroeste Argentino: Influencia de las heterogeneidades del basamento Neoproterozoico-Paleozoico inferior, Revista de la Asociación Geológica Argentina, 66: 38-53.

Horton, R.J., Smith, B.D. y Washburne, J.C. 1985. Electrical geophysical investigations of massive sulfide deposits and their host rocks, West Shasta copper-zinc district. Economic Geology 80, 22132229.

Immenhauser A., 2009. Estimating paleo-water depth from the physical rock record. Earth-Science Reviews, 96 (1-2): 107-139.

Jambor, J.L. 1971. Gangue mineralogy. The Canadian Mineralogist, 11:402-413.

Jébrak, M. 1997. Hydrothermal breccias in vein-type ore deposits: a review of mechanisms, morphology and size distribution. Ore Geology Reviews 12, 111-134.

Johnson, N., Craig, J. y Rimstidt, D. 1986. Compositional trends in tetrahedrite. Canadian Mineralogist. 24: 385-397.

Keidel, J., 1943. El Ordovícico inferior en los Andes del Norte Argentino y sus depósitos marino glaciares. Boletín Academia Nacional de Ciencias 36 (2), 140-229.

Kerrich, R., Strong, D.F., Andrews, A.J. y Owsiacki, L. 1986. The silver deposits at Cobalt and Gowganda, Ontario. III: Hydrothermal regimes and source reservoirs - Evidence from $\mathrm{H}, \mathrm{O}, \mathrm{C}$ and $\mathrm{Sr}$ isotopes and fluid inclusions. Canadian Journal of Earth Sciences, 23, p. 1519-1550. 
Kilmurray, J., Igarzábal, A. 1971. Petrografía y rasgos geomórficos del batolito granítico de Santa Rosa de Tastil, Provincia de Salta, Rep. Argentina. Revista de la Asociación Geológica Argentina 26 (4), 417-438.

Kissin, S.A. 1988, Nickel-cobalt-native silver (five- element) veins: A rift-related ore type, in Kisvarsanyi, G. and Grant, S.K., eds. Proceedings Volume, North American Conference on Tectonic Control of Ore Deposits and the Vertical and Horizontal Extent of Ore Systems: University of MissouriRolla. Rolla, Mo., p. 268-279.

Kissin, S.A. 1993. Five-element (N i-Co-As-Ag-Bi) Veins. En: Ore Models v. II: 87-98. Geoscience Canada, Series 6.

Klemm, D.D. 1965. Synthesen und Analysen in den Dreiecksdiagrammen FeAsS-CoAsS-NiAsS und FeS2-CoS2-NiS2. Neues Jahrb. Mineral., Abh. 103: 205-255.

Leckie, D.A., y Krystinik, L.F. 1989. Is there evidence for geostrophic currents preserved in the sedimentary record of inner to middle-shelf deposits?. Journal of Sedimentary Petrology, 59:. 862-870.

Lefebure, D.V. 1996. Five-element veins Ag-Ni-Co-As+/-(Bi,U). En: Lefebure, D.V., Ho“ y, T. (Eds.), in selected British Columbia Mineral Deposit Profiles, vol. 2, Metallic Deposits. British Columbia Ministry of Employment and Investment, Open File report 1996-13: 89-92.

Lepeltier, C. 1969. A Simplified Statistical Treatment of Geochemical Data by Graphical Representation. Economic Geology, 64: 538-550.

Liu, J., Zhai, D., Li, Z., He, M., Liu, Y. y Li, C. 2010. Occurence of Ag, Co, Bi and Ni elements and its genetic significance in the Baiyangpin silver-copper polymetallic metallogenic concentration area, Lanping basin, southwestern China. Acta petrologica Sinica, 16(6): 1643-1660.

Loftus-Hills, G. y Solomon, M. 1967. Cobalt, nickel and selenium in sulphides as indicators of ore genesis. Mineralium Deposita 2 (3): 228-242.

Loke, M.H. y Dahlin, T. 2002. A comparison of the Gauss-Newton and quasi-Newton methods in resistivity imaging inversion. Journal of Applied Geophysics 49: 149-162.

López, L., Echeveste, H., Schalamuk, I.B. 2011. Caracterización paragenética del depósito tipo five element Purísima-Rumicruz, Jujuy, Argentina. XVIII Congreso Geológico Argentino. Actas DVD. Neuquén.

Lowrie, W. 2007. Fundamentals of Geophysics. 2nd ed. 381 pp. Cambridge, New York, Melbourne: Cambridge University Press

Lurgo Mayón, C. S. 1999. Depósitos polimetálicos ricos en níquel, cobalto y arsénico de la Cordillera Oriental, Jujuy y Salta. En: Recursos Minerales de la República Argentina (Ed. E. O. Zappettini), Instituto de Geología y Recursos Minerales SEGEMAR, Anales 35: 999-1004, Buenos Aires.

Lurgo Mayón, C. S., Segal S. J. y Zappettini E. O. 1999. El yacimiento de sulfuros masivos La Colorada, Salta. En: Recursos Minerales de la República Argentina (Ed. E. O. Zappettini), Instituto de Geología y Recursos Minerales SEGEMAR, Anales 35: 487-492, Buenos Aires.

Machado, A., Rocha, F., Araújo, M., Vitali, F., Gomes, C., Dias, J., Química, E., 2005. Geochemical characterization of surficial sediments from the southwestern Iberian continental shelf Caracterización geoquímica de los sedimentos superficiales del sudoeste de la plataforma continental ibérica. Ciencias Marinas 31: 161-177.

Mángano, M.G. y Buatois, L.A. 2000. Ichnology, sedimentary dynamics, and sequence stratigraphy of the Mesón Group: a Cambrian macrotidal shallow-marine depositional system in northwest Argentina. Instituto Superior de Correlación Geológica, Miscelánea, 6: 109-110.

Mángano, M.G. y Buatois., L.A., 2004. Integración de estratigrafía secuencial, sedimentología e icnología para un análisis cronoestratigráfico del Paleozoico inferior del noroeste argentino. Revista de la Asociación Geológica Argentina, 59: 273-280.

Marshall, D., Diamond, L.W. y Skippen, G.B. 1993. Silver transport and deposition at Cobalt, Ontario, Canada; fluid inclusion evidence. Economic Geology, 88(4): 837-854.

Marshall, D. y Watkinson, D., 2000. The Cobalt mining district: Silver sources, transport and deposition. Exploration and Mining Geology, 9(2), p.81-90.

Marshall, D. Anglin C.D. y Mumin H. 2004. Ore mineral atlas .Geol. Assoc. Canada - Mineral deposits division 112.

Matteini, M., Hauser, N., Pimentel, M., Omarini, R., Dantas, E.L. y Buhn, B.M. 2008. Combined in situ U$\mathrm{Pb}, \mathrm{Lu}-\mathrm{Hf}$ and Sm-Nd systematics applied to the Tastil batholith, Eastern Cordillera, NWArgentina: Implications for the evolution of western margin of Gondwana during the Early Paleozoic. VI South American. Symposium on Isotope Geology, p. 42. Bariloche. 
Méndez, V., Navarini, A., Plaza,D. Viera, V., 1973. Faja eruptive de la Puna Oriental. Actas $5^{\circ}$ Congreso geologico Argentino. 4: 89-100. Córdoba.

Menegatti, N., 2001. El Complejo Alcalino Sierra de Rangel. Provincia de Salta. Argentina. Facultad de Ciencias Naturales, Universidad Nacional de Salta. Tesis Doctoral. 153 pág. Inédito.

Misra K. C. y Fleet M.C. 1975. Textural and compositional variations in a Ni-Co-As assemblage. Canadian Mineralogist 13: 8-14.

Misra, K. C. 2000. Understanding mineral deposits. Dordrecht: Kluwer Academic Publishers, 845 pp.

Mon, R. y Hongn, F., 1987. Estructura del Ordovícico de la Puna. Revista de la Asociación Geológica Argentina, 42: 3138.

Mon, R. y Hongn, F., 1988. Caracterización estructural de la Formación Puncoviscana dentro del basamento del Norte Argentino. Revista de la Asociación Geológica Argentina, 43: 124127.

Mon, R. y Hongn, F. 1991. The structure of the Precambrian and Lower Paleozoic Basement of the Central Andes between $22^{\circ}$ and $32^{\circ} \mathrm{S}$. Lat. Geologische Rundschau 83: 745-758.

Monaldi, C.R., Salfity, J.A. y Kley, J. 2008 - Preserved extensional structures in an inverted Cretaceous rift basin, northwestern Argentina: Outcrop examples and implications for fault reactivation. Tectonics 27: TC1011, 21p.

Morello, O. y Rubinstein, N.1997. Mineralización de As-Ni-Co-U-Bi de la manifestación nuclear Carrizal, Provincia de San Juan, Argentina. Revista de la Asociación Geológica Argentina, 52 (1): 41-46.

Moya, M.C. 1997. La fase Tumbaya (Ordovícico Inferior) en los Andes del norte argentino. Actas $8^{\circ}$ Congreso Geológico Chileno, Actas 1: 185-189. Antofagasta.

Moya, M.C. 1998. El Paleozoico Inferior en la Sierra de Mojotoro, Salta-Jujuy. Revista de la Asociación Geológica Argentina, 53 (2): 219-238.

Moya, M.C. 1999. El Ordovícico de los Andes del Norte Argentino. En: González Bonorino, G, Omarini, R. y Viramonte, J. (Eds.): Geología del Noroeste Argentino.Relatorio, 1: 134-152.

Moya M.C. 2008. El paleozoico inferior en el Noroeste Argentino. Evidencias, incógnitas, propuestas para la discusión. Geología y Recursos Naturales de la Provincia de Jujuy. En Coira B, E Zappettini, eds. Relatorio XVII Congreso Geológico Argentino. 50-73. Buenos Aires.

Munz, I. 1995. Deep penetration of sedimentary fluids in basement rocks from southern Norway: Evidence from hydrocarbon and brine inclusions in quartz veins. Geochimica et Cosmochimica Acta, 59(2): 239-254.

Myrow P.M., Fischer, W. y Goodge, J.W., 2002. Wave-modified turbidites: combined-flow shoreline and shelf deposits, Cambrian, Antarctica. Journal of Sedimentary Research, 72, (5): 641-656.

Myrow, P.M. y Southard, J.B. 1996. Tempestite deposition. Journal of Sedimentary Research. 66: 875887.

Nittrouer, C.A. y Wright, L.D. 1994. Transport of particles across continental shelves: Reviews of Geophysics 32:85-113.

Ohmoto, H., 1972. Systematics of sulfur and carbon isotopes in hydrothermal ore deposits. Economic Geology, 67: 557-578.

Ohmoto, H. y Rye, R.O. 1979. Isotopes of sulfur and carbon. En: H.L. Barnes (Editor), Geochemistry of Hydrothermal Ore Deposits, 2rid ed. Wiley-Interscience, New York, pp. 509-561.

Ohmoto, H., 1986. Stable isotope geochemistry of ore deposits. En: J.W. Valley, H,P. Taylor Jr. and J.R. O'Neil (Editors), Stable Isotopes in High Temperature Geological Processes. Rev. Mineral. Soc. Am., 16: 491-560.

Ohmoto, H. y Goldhaber M.B. 1997.Sulfur and carbon isotopes. En: Geochemistry of Hydrothermal Ore Deposits, Tercera Edición, Hubert L. Barnes (ed.), John Wiley and Sons Inc. Publication, 517612.

Olivares, V., Cembrano, J., Arancibia, G., Reyes, N, Herrera, V. y Faulkner, D. 2010. Significado tectónico y migración de fluidos hidrotermales en una red de fallas y vetas de un Dúplex de rumbo: un ejemplo del Sistema de Falla de Atacama. Andean geology, 37(2): 473-497.

Omarini, R.H., Sureda, R.J., Toselli, A. y Rossi, J., 1999. Ciclo Pampeano-Proterozoico superiorEocámbrico: Magmatismo. En: González Bonorino, G., Omarini, R. y Viramonte, J. (Eds.): Geología del Noroeste Argentino.Relatorio $14^{\circ}$ Congreso Geológico Argentino, 1: 29-40.

Omarini, R.H., Sureda R., J. López de Azarevich V. y Hauser N. 2008. El basamento NeoproterozoicoCámbrico inferior en la provincia de Jujuy. Geología y Recursos Naturales de la Provincia de Jujuy. En Coira B, E Zappettini, eds. Relatorio XVII Congreso Geológico Argentino. Jujuy: Asociación Geológica Argentina, 17-28. Buenos Aires. 
Ondruš, P., Veselovský, F., Gabašová, A, Hloušek, J., Šrein, V. 2003a. Geology and hydrothermal vein system of the Jáchymov (Joachimsthal) ore district. Journal of the Czech Geological Society, 48(3-4): 3-18.

Ondruš, P., Veselovský, F., Gabašová, A., Drábek, M., Dobeš, P., Malý, K., Hloušek, J., Sejkora, J. $2003 b$. Ore-forming processes and mineral parageneses of the Jáchymov ore district. J Czech Geol Soc 48 (3-4):157-192

Pascual, R. y Odreman Rivas, O. 1973. Las unidades estratigráficas terciarias portadoras de mamíferos. Su distribución y sus relaciones con los acontecimientos diastróficos. Actas $5^{\circ}$ Congreso Geológico Argentino, 3:293-338. Buenos Aires.

Pascual, R., Vucetich M.G. y Fernández J. 1978. Los primeros mamíferos (Notoungulata, Henricorbornidae) de la Formación Mealla, sus importancias filogenéticas, taxonómicas y cronológicas. Ameghiniana, 15 (3-4):366-390. Buenos Aires.

Power, M.R., Pirrie, D., Jedwab, J. y Stanley, C.J. 2004. Platinum-group element mineralization in an Asrich magmatic sulphide system, Talnostry, southwest Scotland. Mineralogical Magazine 68: 395-411.

Preis, W. y Gamsjäger, H. 2002. Solid-solute phase equilibria in aqueous solution. XVI. Thermodynamic properties of malachite and azurite-predominance diagrams for the system $\mathrm{Cu}_{2}+-\mathrm{H}_{2} \mathrm{O}-\mathrm{CO}_{2}$. Journal of Chemical Thermodynamics, 34: 631-650.

Price, B.J. 1972. Minor Elements in Pyrites from the Smithers Map Area, British Columbia and Exploration Applications of Minor element studies. M.Sc. Thesis, Universidad British Columbia, Vancouver.

Putnis, A. 2002. Mineral replacement reactions: from macroscopic observations to microscopic mechanism. Mineralogical magazine 66: 689-708.

Raines, G.L., McGee, L.G., y Sutley, S.J. 1985, Near-infrared spectra of West Shasta gossans compared with true and false gossans from Australia and Saudi Arabia: Economic Geology 80: 2230-2239.

Ramallo, E., 1975. Informe Final Área de Reserva N 7, Rumicruz, Provincia de Jujuy. Dirección General de Fabricaciones Militares, Centro de Exploración Geológico-Minera II. Dirección Provincial de Minería, 20 p., inédito. San Salvador de Jujuy.

Ramdohr, P. 1980. The ore minerals and their intergrowths. Pergamon Press, 1205 p.

Ramírez A. y Díaz A. 2008. Manifestaciones minerales asociadas a calderas y volcanes compuestos del Neógeno de la Puna Norte. En Relatorio XVII Congreso Geológico Argentino. Jujuy (Coira B, E Zappettini, eds.), 358-367. Buenos Aires.

Ramos, V. A. 1986. Late Proterozoic-Early Paleozoic of South America: a collisional history. Episodes, 11: 168-173.

Ramos, V.A. 1999. Evolución tectónica de la Argentina. En: Caminos, R. (Ed.): Geología Argentina. Instituto de Geología y Recursos Minerales. Anales, 29 (24): 715- 784. Buenos Aires.

Ramos, V.A. 2007. The basement of the Central Andes: The Arequipa and related terranes. Annual Review of Earth and Planetary Sciences, 36.

Ramos, V.A., 2008. The basement of the Central Andes: the Arequipa and related terranes. Annual Review on Earth and Planetary Sciences, 36: 289-324.

Rapela, C., Pankurst, R,. Casquet, C., Fanning, C., Baldo, E.J., González-Casado y Galindo, C. 2007. The Rio de la Plata craton and the assembly of SW Gondwana. Earth Science Review, 83 (1-2): 4982.

Reyes, F.C. y Salfity, J.A. 1972. Consideraciones sobre la estratigrafía del Cretácico (Subgrupo Pirgua) del noroeste argentino. Actas $5^{\circ}$ Congreso Geológico Argentino, 3: 354-385.

Rimmer, S.M., 2004. Geochemical paleoredox indicators in Devonian-Mississippian black shales, Central Appalachian Basin (USA). Chemical Geology 206: 373-391.

Robb, L. 2004. Introduction to ore-forming process. Blackwell Science Ltd. 684 p. Oxford, U.K.

Robinson, B. y Ohmoto, H. 1973. Mineralogy, fluid inclusions, and stable isotopes of the Echo Bay U-NiAg-Cu deposits, Northwest Territories, Canada. Economic Geology, 68(5): 635.

Robinson, B.W. y Kusakabe, M. 1975. Quantitative preparation of sulfur dioxide for ${ }^{34} \mathrm{~S} /{ }^{32} \mathrm{~S}$ analyses from sulfides by combustion with cuprous oxide. Analytical Chemistry, 47, 7: 1179-1181.

Rodríguez, G.A., de Azevedo, F.I. (Jr), Coira, B. y Brodie, C. 2001. Mineralizaciones auríferas en sedimentitas ordovícicas de la sierra de Rinconada (Jujuy, Argentina): Implicancias para la exploración minera. Revista Geológica de Chile, 28 (1): 47-66.

Rodríguez G.A. 2008. Mineralizaciones auríferas en la Sierra de La Rinconada. Geología y Recursos Naturales de la Provincia de Jujuy. En Coira B, E Zappettini, eds. Relatorio XVII Congreso Geológico Argentino. 167-177. Buenos Aires. 
Roedder, E. y Bodnar, R. 1980. Geologic pressure determinations from fluid inclusion studies. Annual review of earth and planetary sciences, 8, 263.

Rossello E.A. 2001. Sistemas tectónicos transcurrentes: una síntesis de sus condiciones mecánicas y aplicaciones geoeconómicas. Asociación geológica Argentina, Serie D: Publicación Especial No5: $19-43$

Rubinstein, N. y Morello, O. 2006. Las mineralizaciones de la zona de Carrizal, Precordillera Occidental, Argentina. Boletín Geológico minero, 117 (3):379-388.

Rubiolo, D.G. 1998. El magmatismo alcalino de la Sierra de Santa Victoria, Cordillera Oriental Argentina. Actas $10^{\circ}$ Congreso Latinoamericano de Geología y $4^{\circ}$ Congreso Nacional de Geología Económica, 2:330.Buenos Aires.

Rubiolo, D.G. 1999. Esquema de evolución tectonosedimentaria para las cuencas cenozoicas de la Cordillera Oriental (22 a $23^{\circ}$ LS), Argentina. Acta Geologica Hispanica, 32(1-2):77-92.

Rubiolo, D.G. 2003. Hoja Geológica 2366-II/2166-IV. La Quiaca. Programa Nacional de Cartas Geológicas de la República Argentina 1:250.000: 113 p.

Ruffell, A. 1998. Characterisation and prediction of sediment-hosted ore deposits using sequence stratigraphy. Ore Geology Reviews, 12(4), 207-223

Russo, A. y Barcat, C., 1978. Relaciones entre los sedimentos cámbricos y ordovícicos en el norte de las provincias de Salta y Jujuy. Acta Geológica Lilloana, Suplemento, 14 (2): 117-119.

Rye, R.O. y Ohmoto, H., 1974. Sulfur and Carbon Isotopes and Ore Genesis: A Review. Economic Geology, 69(6): 826-842.

Sack R. O., Lynch, J.V.G. y Forr, F. Jr. 2003. Fahlore as a petrogenetic indicator: Keno Hill Ag-Pb-Zn District, Yukon, Canada. Mineralogical Magazine. 67 (5): 1023-1038.

Sáez R., Moreno, C., González F., Almodóvar, G.R., 2011. Black shales and massive sulfide Deposits: causal or casual relationships? Insights from Rammelsberg, Tharsis and Draa Sfar. Miner Deposita 46: 585-614

Salfity, J., Gorustovich, S.A. y Moya, M.C. 1984. Las fases diastróficas en los Andes del Norte Argentino. Simposio Internacional de Tectónica Centroandina y relación con los Recursos Naturales, 1-22. La Paz.

Salfity, J.A. y Marquillas, R.A. 1994. Tectonic and sedimentary evolution of Cretaceous-Eocene Salta Group basin, Argentina. En Salfity J.A. (ed.) Cretaceous Tectonics of the Andes. Earth Evolution Sciences, Friedr. Vieweg and Sohn, 266-315.

Salfity, J.A. y Marquillas, R.A. 1999. La cuenca Cretácico-Terciaria del norte Argentino. En: Caminos, R. (Ed.): Geología Argentina. Instituto de Geología y Recursos Minerales. Anales, 29 (19): 613626. Buenos Aires

Sánchez, M.C. y Salfity, J.A., 1990. Litofacies del Grupo Mesón (Cámbrico) en el oeste del Valle de Lerma, Cordillera Oriental Argentina. Actas $10^{\circ}$ Congreso Geológico Argentino, 2: 129-192. San Juan.

Sánchez, M.C. y Salfity, J.A. 1999. La cuenca cámbrica del Grupo Mesón en el noroeste argentino: Desarrollo estratigráfico y paleogeográfico. En: Colombo, F., Querault, I. y Petrinovic, I. (Eds): Geología de los Andes Centrales Meridionales: El Noroeste Argentino. Acta Geológica Hispánica, 34 (2-3): 123-139.

Sangster, A.L. y Sangster, D.F. 2002. Evaluation of the concept the Pumahuasi veins indicate a potential for the existence of underlying undiscovered sedex deposits, northern Argentina. Serie contribuciones tecnicas. Recursos Minerales 15. SEGEMAR.

Sato, K., Tassinari, C., Kawashita, K. y Petronilho, L., 1995. O método geocronológico Sm-Nd no IG/USP e suas aplicacoes. Anais da Academia Brasileira de Ciências, 67: 313-336.

Schalamuk, I.B. y Brodtkorb de, M.K.1999. El yacimiento cobaltoaurífero King Tut, La Rioja. En: Recursos Minerales de la República Argentina (Ed. E. Zappettini), Instituto de Geología y Recursos Minerales SEGEMAR, Anales 35: 633-635, Buenos Aires.

Seward, T.M. y Barnes, H.L. 1997. Metal transport by hydrothermal ore fluids. En: Geochemistry of Hydrothermal Ore Deposits, Tercera Edición, H.L. Barnes (ed.), John Wiley and Sons Inc. Publication, 435-487.

Sheppard, S.M.F. 1986. Characterization and isotopic variations in natural waters. En: Valley, J.W., Taylor, H.P., O Neil, J.R. (Eds.), Stable Isotopes in high temperature geological processes. Reviews Mineralogy. 16: 165-184.

Shock, E.L., Sassani, D.C., Willis, M. y Sverjensky D.A. 1997. Inorganic species in geologic fluids: Correlations among standard molal thermodynamic properties of aqueous cations, oxyanions, 
acid oxyanions, oxyacids and hydroxide complexes. Geochim. Cosmochim. Acta 61 (5): 907950.

Sibson, R.H., Moore, J.M.C.M. y Rankin, A.H. 1975. Seismic pumping - a hydrothermal fluid transport mechanism. J. Geol. Soc. London 131, 653-659.

Sillitoe, R.H. 2007. Hypogene Reinterpretation of Supergene Silver Enrichment at Chanarcillo, Northern Chile. Economic Geology, 102(5): 777-781.

Simmons, S.F. y Christenson B.W. 1994. Origins of calcite in a boiling geothermal system. American Journal of Science, 294, 361-400.

Simmons, S.F. 2000. Hydrothermal Minerals and Precious Metals in the Broadlands-Ohaaki Geothermal System: Implications for Understanding Low-Sulfidation Epithermal Environments. Economic Geology, 95(5):971-999.

Smith, B.D. Tippens, C.L., Flanigan, V.J. y Sadek H. 1983. Preliminary results of spectra in Induced polarization measurements, Wadi Bidah district, Kingdom of Saudi Arabia: U.S.G.S. Open-File Rept.03-70, 23 p.

Spagnuolo, C., Rapalini A. y Astini, R.A. 2005. Resultados paleomagnéticos preliminares del Grupo Mesón, Noroeste Argentino. $16^{\circ}$ Congreso Geológico Argentino, 5: 411-418. La Plata.

Stacey, J. y Krammers, J.D. 1975. Approximation of terrestrial lead isotope evolution by a two-stage model. Earth and Planetary Science Letters 26, 207-221.

Starck, D., Gallardo, E. y Schulz, A. 1992. La cuenca de Tarija. Estratigrafía de la porción argentina. Boletín de Informaciones Petroleras, Tercera Epoca, 9 (30): 2-14. Buenos Aires.

Staude, S., Wagner, T. y Markl, G. 2007. Mineralogy, Mineral Compositions and Fluid Evolution At the Wenzel Hydrothermal Deposit, Southern Germany: Implications for the Formation of Kongsberg-Type Silver Deposits. The Canadian Mineralogist, 45(5): 1147-1176.

Staude, S., Bons, P.D. y Gregor, M. 2009. Hydrothermal vein formation by extension-driven dewatering of the middle crust: An example from SW Germany. Earth and Planetary Science Letters, 286 (34): 387-395.

Staude, S., Mordhorst, T., Neumann, R., Prebeck, W., Markl, G. 2010. Compositional variation of the tennantita-tetrahedrite solid solution series in the Schwarzwald ore district (SW Germany): The role of mineralization processes and fluid source. Mineralogical Magazine 74 (2): 309-339.

Stevens, G., Boer, R., Gibson, R.L. 1997 Metamorphism, fluid flow and gold remobilization in the Witwatersrand Basin: towards a unifying model. South African Journal of Geology, 100, 363-75.

Suarez-Soruco, R., 2000. Compendio de Geología de Bolivia. Revista Técnica de YPFB, 16: 1-144.

Such, P., Buatois, L.A. y Mángano, M.G. 2007. Stratigraphy, depositional environments and ichnology of the lower paleozoic in the Azul Pampa área - Jujuy Province. Revista de la Asociación Geológica Argentina 62 (3): 331-344.

Sureda, J.R., 1999. Los yacimientos sedex de plomo y zinc en la Sierra de Aguilar, Jujuy. En: Recursos Minerales de la República Argentina (Ed. E. O. Zappettini), Instituto de Geología y Recursos Minerales SEGEMAR, Anales 35: 459-485, Buenos Aires.

Suter, J.R., 2006. Clastic shelves, En: Walker, R.G., y Posamentier, H., (eds.) Facies models revisited, SEPM Special Publication, 84: 339-397.

Suzuki, K., Toda, S., Kusunoki, K., Fujimitsu, Y., Mogi, T., Jomori, A. 2000. Case studies of electrical and electromagnetic methods applied to mapping active faults beneath the thick quaternary. Engineering Geology 56: 29-45.

Sverjensky, D.A., Shock, E.L. y Helgeson, H.C. 1997. Prediction of the thermodynamic properties of aqueous metal complexes to 1000 degrees $\mathrm{C}$ and $5 \mathrm{~kb}$. Geochimica Et Cosmochimica Acta, 61(7): 1359-1412. Tyrell, J.B., 1907. Vein formation at Cobalt, Ontario, Canadian Mining Journal, 28, p. 301-303.

Taylor, S.R., McLennan, S.M. 1985. The continental crust: its composition and evolution. Blackwell, Oxford, $312 \mathrm{pp}$.

Thio, S. 2004. CoDaPack software package. Universidad de Girona, España. http:// ima.udg.es 1 - thio/\#Compositional Data.

Tornos, F. y Heinrich, C. 2008. Shale basins, sulfur-deficient ore brines and the formation of exhalative base metal deposits. Chemical Geology, 247(1-2): 195-207.

Tubía, J.M., Hongn, F. y Aranguren, A. 2008. Inversión tectónica en la corteza dúctil: basamento neoproterozoicopaleozoico inferior de la sierra de Cachi (Salta). $17^{\circ}$ Congreso Geológico Argentino. Actas DVD. Jujuy.

Turekian, K., and K. H. Wedepohl. 1961. Distribution of the elements in some major units of the earth's crust. Geol. Soc. Amer. Bull. 72: 175-192. 
Turneaure, F. S. 1971. The Bolivian Tin-Silver Province. Economic Geology, 66: 215-225.

Turner, J. C.M. 1959. Estratigrafía del cordón de Escaya y de la sierra de la Rinconada, Jujuy. Revista de la Asociación Geológica Argentina, 13(1-2):15-40. Buenos Aires.

Turner, J.C.M. 1960. Estratigrafía de la Sierra de Santa Victoria y adyacentes. Boletín de la Academia Nacional de Ciencias de Córdoba, 41 (2): 163-196.

Turner J.C.M. 1964. Descripción de la Hoja Geológica 2c. Santa Victoria (Provincias de Salta y Jujuy), Instituto Nacional de Geología y Minería. Boletín 104. 99p. Buenos Aires.

Turner, J.C. y Méndez, V. 1975. Geología del sector oriental de los departamentos de Santa Victoria e Iruya, Provincia de Salta, República Argentina. Boletín de la Academia de Ciencias de Córdoba, 51: 11-24.

Tykajlo, R. y Donohue, J. 2007. Geophysics for Everyone, Workshop Notes. Editores y Organizadores, Canadian Exploration Geophisical Society (Kegs) y Prospectors and Developers Association of Canada.

Tyrell, J.B. 1907. Vein formation at Cobalt, Ontario, Canadian Mining Journal, 28, p. 301-303.

Vaughan, D.J. y Craig, J.R. 1997. Sulfide Ore Mineral Stabilities, Morphologies, and Intergrowth Textures. En: Geochemistry of Hydrothermal Ore Deposits, Tercera Edición, Hubert L. Barnes (ed.), John Wiley and Sons Inc. Publication, 367-435.

Velasco, F. 2004. Introducción al studio de las inclusiones fluidas. XXIII Curso Latinoamericano de Metalogenia. 98pp. Mendoza.

Viramonte, J.G. 1999. Cretaceous rift related magmatism in central-western South America. Journal of South American Earth Sciences, 12(2): 109-121.

Viramonte, J.G., Kay, S.M., Becchio, R., Escayola, M. y Novitski, I. 1999. Cretaceous rift related magmatism in central-western South America. Journal of South American Earth Science 12: 109-121.

Wagner T. y Lorenz J. 2002. Mineralogy of complex Co-Ni-Bi vein mineralization, Bieber deposit, Spessart, Germany. Mineralogical Magazine. 66(3): 385-407.

Wagner, T. Okrusch, M., Weyer, S., Lorenz, J., Lahaye, Y., Taubald, H. y Schmitt, R.T. 2009. The role of the Kupferschiefer in the formation of hydrothermal base metal mineralization in the Spessart ore district, Germany: insight from detailed sulfur isotope studies. Mineralium Deposita, 45 (3: 217-239.

Walker, R.G. 1984. General Introduction: facies, facies sequences and facies models. En: Walker, R. G. (ed.) Facies Models, Second Edition. Geoscience Canada, Reprint Series 1: 1-10.

Walker, R.G. 2006. Facies models revisited. En: Posamentier, H. W. y Walker, R. G. (eds.). Facies Models Revisited. SEPM Special Publication 84: 1-17.

Watkinson, D.H., Heslop, J.B. y Ewert, W.D. 1975. Nickel sulphide-arsenide assamblages associated with uranium mineralization, Zimmer Lake Area, Northern Saskatchewan. Canadian Mineralogist, 13: 198-204.

Welsink, H.J., Martínez, E., Araníbar, O. y Jarandilla, J. 1995. Structural inversion of a Cretaceous rift basin, southern Altiplano, Bolivia. En: Tankard, A.J., Suárez Soruco, R. and Welsink, H.J. (Eds.): Petroleum Basins of South America. Memoir American Association of Petroleum Geologists, 62: 305-324.

White, R.M.S., Collins, S., Denne, R., Hee, R. y Brown, P. 2001. A new survey design for 3D IP inversion modelling at Copper Hill. Exploration Geophysics 32: 152 - 155.

Wilkerson, G., Deng Q., Llavona R., Goodell P. C. 1988. Batopilas mining district, Chihuahua. Economic Geology, 83(8): 1721-1736.

Wilkinson, J.J, 2001. Fluid inclusions in hydrothermal ore deposits. Lithos 55, 229-272.

Wilkinson, J.J., Everett, C.E., Boyce, A.J., Gleeson, S.A., Rye, D.M. 2005. Intracratonic crustal seawater circulation and the genesis of subseafloor zinc-lead mineralization in the Irish orefield. Geol. 33: 805-808.

Wong, J. 1979. An electrochemical model of the induced-polarization phenomenon in disseminated sulfide ores: Geophysics 44: 1245-1265.

Wood, S.A., Samson I. M. 1998. Solubility of ore minerals and complexation of ore metals in hydrothermal solutions. Rev Econ Geol 10:33-76.

Zanettini, J. C. 1973. Observaciones sobre la fa- cies proximal del Subgrupo Santa Bárbara, en el sector noroeste de la Cordillera Oriental (provincias de Salta y Jujuy). Revista de la Asociación Geológica Argentina, 28:219-226. 
Zappettini, E.O. 2008. El plutonismo mesozoico en Jujuy. Geología y Recursos Naturales de la Provincia de Jujuy. En Coira B, E Zappettini, eds. Relatorio XVII Congreso Geológico Argentino. 244-253. Buenos Aires.

Zappettini, E.O., Coira, B. y Santos, J. 2008. Edad U/Pb de la Formación Chañi: Un granito del arco magmático Tilcárico. $17^{\circ}$ Congreso Geológico Argentino, 1: 248-249. San Salvador de Jujuy.

Zartman R. y Doe B. 1981. Plumbotectonics - the model. Tectonophysics 75:135-162.

Zheng Y.F. 1993. Calculation of oxygen isotope fractionation in hydroxyl-bearing silicates. Earth Planet Science Letter 120:247-263.

Zheng Y.-F. 1999. Oxygen isotope fractionation in carbonate and sulfate minerals. Geochemical Journal, 33, p. 109-126. 